\title{
"SHAKING HIS HAIRY CHAPS": THE ICONOGRAPHY OF BEARDED SNAKES
}

\author{
BY JAIMEE MURDOCH
}

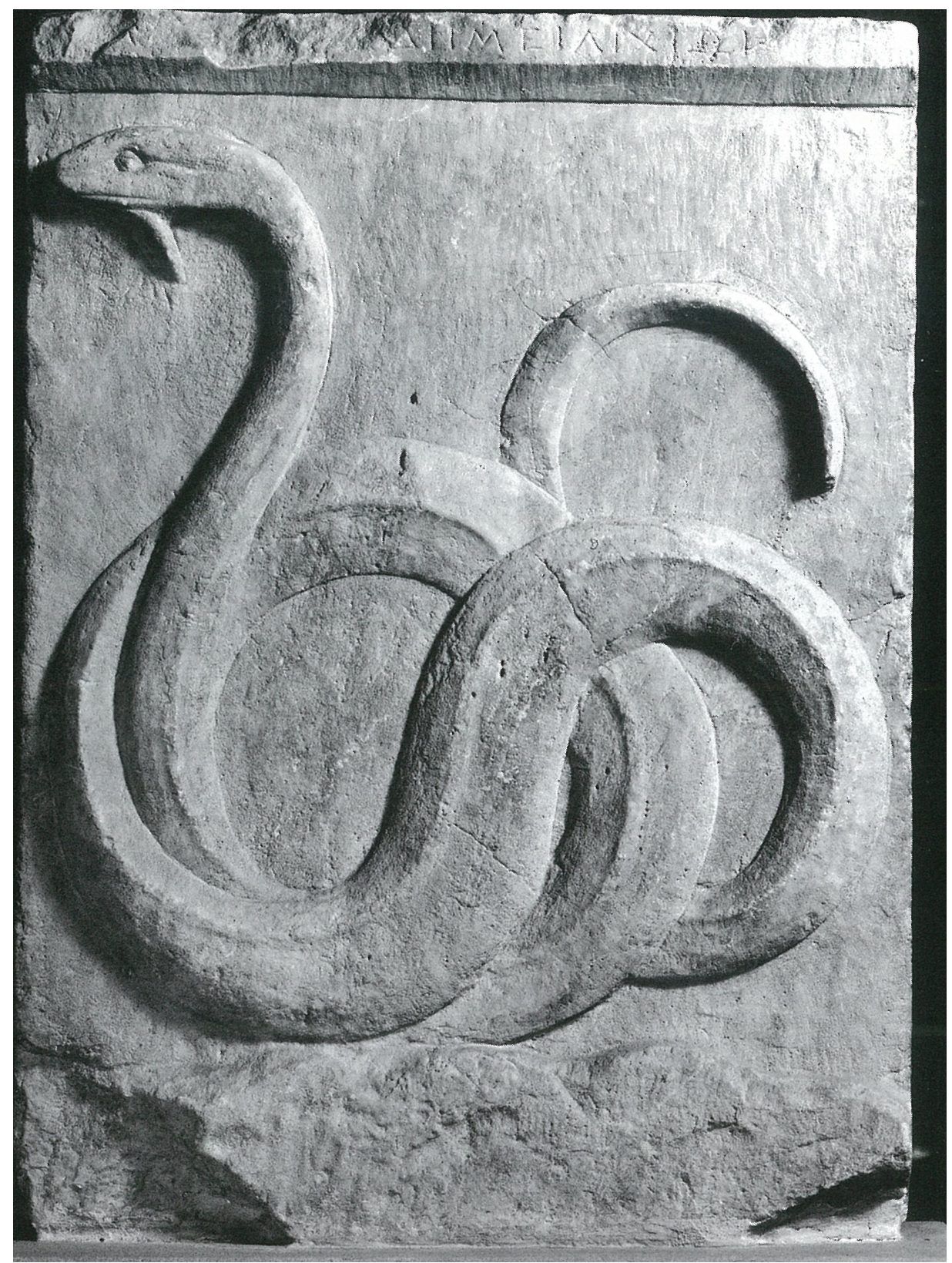

A thesis submitted to Victoria University of Wellington in fulfilment of the requirements for the degree of Master of Arts in Classical Studies 
The title of this thesis is a quote from Nonnus, Dion. 6.160 .

Cover Image: Votive relief of Zeus Meilichios. ca. 400 BC. Berlin, Staatliche Museum. Lalonde (2006) fig. 29. 
The bearded snake is an unusual motif that appears in a variety of contexts and media throughout the Classical world. It is used in Greek, Etruscan, Roman, and Egyptian art and literature. This thesis addresses the Greek use of the bearded snake. The beard of the snake, much like the beard of a human figure, varies in terms of its size, shape, and level of detailing. It may be a simple single line or a series of long, clearly defined hairs. The use of this human feature on serpents has received minimal attention. When the motif is discussed it is generally only considered in terms of its use in one context, such as on depictions of Zeus Meilichios or on the Lakonian hero reliefs. The aim of this thesis is to discuss the use of the bearded snake in the most common contexts in which it may occur in order to provide a better understanding of the meaning of this unusual motif. Such contexts include anguiform deities, pure serpents, hybrid creatures, and attributes of monsters and deities.

Two of the more influential explanations of the use of the beard are those by Aelian, from the third century AD, and Jane Harrison, from 1903. These interpretations consider the bearded snake in slightly different terms. Where Aelian believes the beard to indicate a male serpent, Harrison considers the feature to be a means through which the snake is implied to be an anthropomorphic deity. Chapter One provides the background interpretations of the snake and the beard as distinct motifs. The findings from this chapter will form the basis for the interpretations given in Chapters Two and Three. Chapter Two considers the flaws of Aelian's explanation of the beard as an indicator of gender, by looking at the use of the beard in the context of divine and monstrous women such as Medusa and Athena. Chapter Three addresses Harrison's anthropomorphic argument, by considering both anguiform and non-anguiform figures. This will provide a wider range of contexts than either Aelian or Harrison discuss. In doing so, I intend to consider the meaning of the bearded snake using a considerably larger range of sources, in order to give the best possible explanation for this unusual motif. 
There are many people who helped make this thesis possible and the time spent writing it enjoyable. I would first like to thank my incredible supervisor Diana Burton. Thank you for all of your advice and comments, which helped me to develop my ideas and complete this thesis. I would also like to thank Judy Deuling who first pointed out that some snakes are depicted with beards and thus gave me the idea to study bearded snakes. I am grateful to the support and encouragement from my family, in particular my mother Lexia Murdoch and my sister Donella Waddell, both of whom I am sure are sick of hearing about snakes and beards! Finally, thank you to all of my friends and colleagues in the Classics department who provided so much encouragement and stimulating conversation, particularly Nikki Carter, James McBurney, Julia Simons, Emily Simons, and Joel Gordon. I could not have done this without all the support.

Thank you all! 


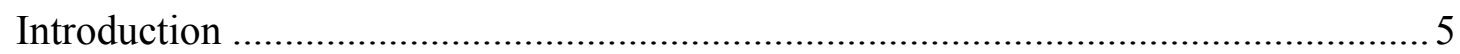

The History of the Motif in Greek Art ........................................................... 7

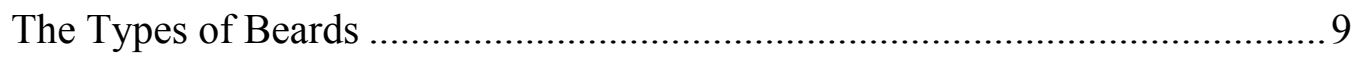

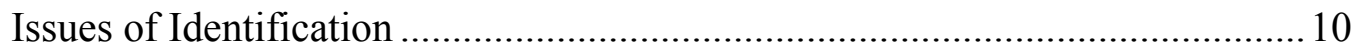

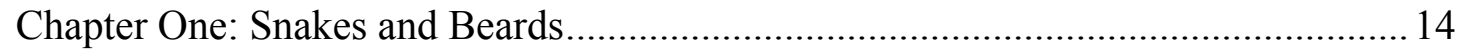

The Meaning Behind the Snake ................................................................... 14

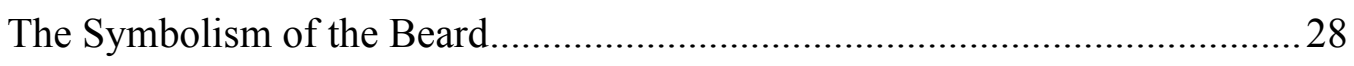

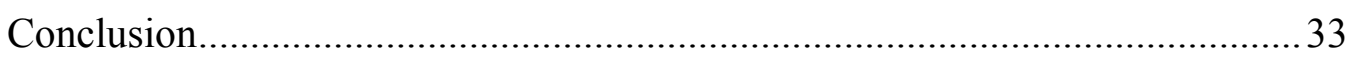

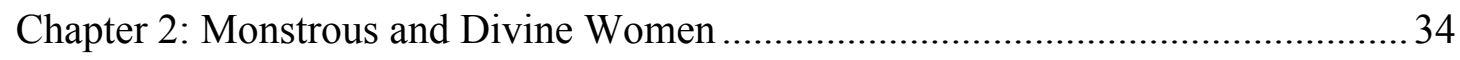

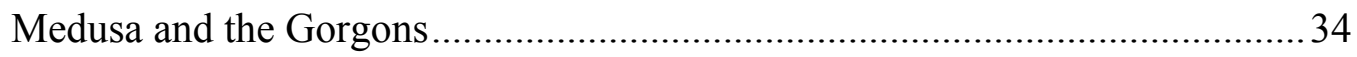

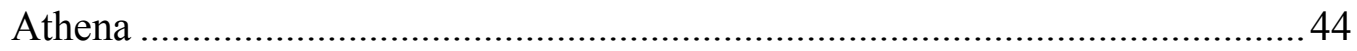

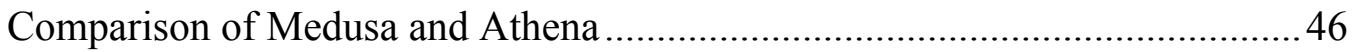

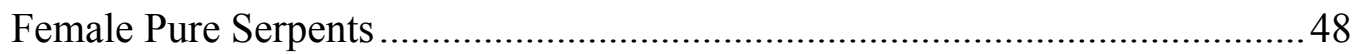

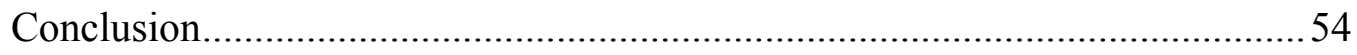

Chapter 3: Anthropomorphism and the Identifier of Divinity or Monstrosity ............ 56

Anguiform Deities and Heroes................................................................... 56

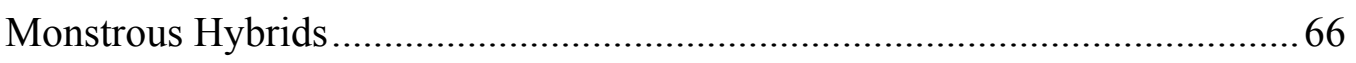

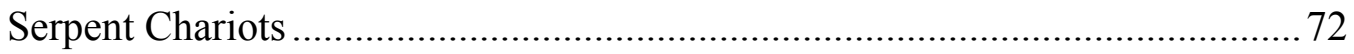

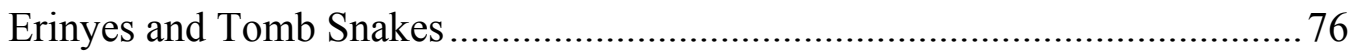

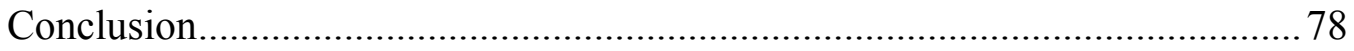

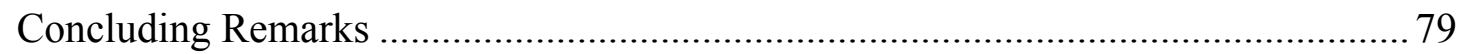

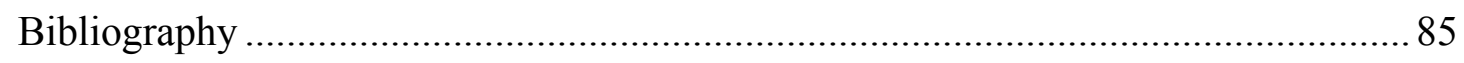

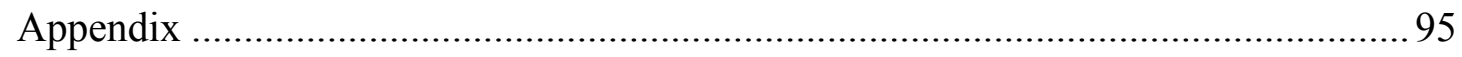


The motif of the bearded snake is used in a wide range of contexts and media throughout the Classical world. In a Greek context the beard is often added to snakes that appear as attributes or alternative forms of gods, such as Zeus Meilichios, and goddesses, such as Athena. The beard is also found on the mythological snakes that serve as the opponents of heroes in pursuit of the object of their quests. These mythological creatures may be either pure serpents, meaning they have a purely serpentine form like Python, or hybrid creatures with serpentine aspects, such as the Chimaira. This thesis provides an analysis of the function of the bearded snake in several of its most common contexts, in order to form a better understanding of the meaning of the motif.

Before discussing the bearded snake in its iconographic context it is important to consider the beard and the snake in the light of their own distinct meanings. While the beard is a relatively straightforward and masculine motif, the serpent is a complex creature with a multitude of connotations. To truly dissect the meaning of the snake in great detail is beyond the scope of this thesis. Discussion of its meaning without the beard will focus on the most common contexts in which a snake may be used. This discussion of the beard and the snake in their respective iconographic contexts is the focus of Chapter One, which forms the foundation for discussion of the bearded snake in its various differing contexts in Chapters Two and Three.

The only explanation of the bearded snake to come down to us from antiquity is that in Aelian's third century AD work, De Natura Animalium, in which Aelian explains the beard as an indicator of the masculinity of the snake. ${ }^{1}$ As this explanation comes from a primary source it has been influential on our understanding of the bearded snake today, with scholars such as Liliane Bodson briefly expanding on Aelian to suggest the beard indicates virile maturity. ${ }^{2}$ However, Aelian's discussion seeks to explain the beard as a naturally and realistically occurring feature of the snake, thus he only considers the meaning of the beard in its most obvious and basic form. Bodson does not follow Aelian in this regard; instead she considers the

\footnotetext{
${ }^{1}$ Ael. NA. 11.26.

2 Bodson (1975) 71-74.
} 
beard as a purely mythological addition to the snake that does not occur in reality. ${ }^{3}$ This interpretation of the beard as an indicator of masculinity overlooks a significant number of the contexts in which the beard is used. Chapter Two addresses this interpretation in detail and considers the beard's use in the context of monstrous and divine women, such as on Medusa and the aegis of Athena. Of particular concern is how such an overtly masculine motif functions in the context of such female figures. The women that are shown in association with bearded snakes can often be described as possessing at least some masculine qualities, as is the case with Athena. Aelian's explanation of the bearded snake serves as a starting point from which it is possible to view the bearded snake as a reflection of the masculine attributes and strengths of the women associated with it.

There has been relatively little modern attention devoted to the bearded snake. One of the more detailed discussions of the motif is that in Jane Harrison's 1903 Prolegomena to the Study of Greek Religion, in which Harrison focuses her discussion solely on representations of bearded snakes that function as alternative forms of gods, particularly those of Zeus Meilichios. As her analysis is largely limited to this one specific context she comes to the conclusion that the beard must function as a marker of the creature's anthropomorphic nature. ${ }^{4}$ Harrison also provides a specific origin for the beard, based on the type of snake she believes representations of Zeus Meilichios are styled on. This identification has been the foundation of more recent attempts to explain the beard, particularly that by Laurent Gourmelen in 2012. Gourmelen builds on Harrison's early and rather limited explanation of the beard by arguing that the beard should be considered as a symbolic adaption of reality, instead of a misrepresentation of reality. ${ }^{5}$ Where Harrison argues for the origin of the beard based on pictorial evidence from the fourth century BC, Gourmelen is able to consider the motif using a wider range of images that were not yet discovered when Harrison gave her interpretation of the beard. Chapter Three considers the use of the beard in the light of these claims that the beard is an anthropomorphic feature influenced by reality, while also countering such arguments by accounting for the beard's use on non-anthropomorphic creatures, such as the monstrous hybrids on which the bearded snake may appear.

\footnotetext{
${ }^{3}$ Bodson (1975) 73-74.

${ }^{4}$ Harrison (1903) 328.

${ }^{5}$ Gourmelen (2012) 339.
} 
A small number of more recent scholars have attempted to explain the bearded snake more broadly in its Greek context. These scholars include Eleanore Guralnick and Daniel Ogden. ${ }^{6}$ Guralnick provides an entirely different explanation for the origin of the motif than those of Harrison and Gourmelen. She claims that it was influenced by the depiction of bearded snakes in earlier Egyptian art, in particular those associated with the resurrection of Osiris. ${ }^{7}$ However, Guralnick follows in a similar vein to Harrison in that her discussion is focused on one specific use of the bearded snake, the one on the so-called Lakonian hero reliefs. Elpis Mitropoulou builds on Guralnick's explanation of the beard as a motif that originated in Egypt by arguing that the motif was first adapted by the Lakonians before it become a part of more widespread Greek art. ${ }^{8}$ In contrast to this limited view, Ogden provided a broader discussion of the beard in his 2013 monograph, Drakōn: Dragon Myth and Serpent Cult in the Greek and Roman Worlds. This monograph encompasses snakes in both artistic and literary depictions, as well as their function in cult and ritual. However, Ogden's discussion of the addition of the beard is largely limited to a brief outline of the history of the motif and outlines of older interpretations, such as Aelian's and Harrison's. ${ }^{9}$

The History of the Motif in Greek Art

The bearded snake motif first appears in Greek art during the Orientalizing Period (ca. 700-600 BC). However, during this period it is a rare motif. Arguably the earliest example of a bearded snake is found on the Eleusis amphora, dated to ca. 675$650 \mathrm{BC}$ (figs. 1-3). ${ }^{10}$ Its appearance on this piece is debatable due to the unusual appearance of the snakes protruding from the heads and shoulders of the two surviving Gorgons shown on the belly of the amphora. The serpents shown on these Gorgons are a blend of serpent and feline features. ${ }^{11}$ It is these felines that are shown with beards. Therefore, the extent to which they should be considered true bearded

\footnotetext{
${ }^{6}$ Guralnick (1974) passim; Ogden (2013) 155-161.

${ }^{7}$ Guralnick (1974) 183-185; an in-depth analysis of this explanation for the origins of the bearded snake is beyond the scope of this thesis.

${ }^{8}$ Mitropoulou (1977) 88-94.

${ }^{9}$ Ogden (2013) 155-161.

${ }^{10}$ Richter (1959) 299; for all figures please see appendix.

${ }^{11}$ Ogden (2013) 155; Boardman (1998) 90; Osborne (1998) 60.
} 
snakes is debatable. ${ }^{12}$ However, they serve as an example of the motif during a period in which the iconography of the Gorgon was not yet fixed. ${ }^{13}$ Another early and again debatable depiction of a bearded snake can be found on a late seventh century BC Corinthian alabastron (fig. 4). This alabastron depicts a male figure being swallowed or disgorged by a large serpent who is shown with something projecting from its lower jaw. However, the poorly preserved state of this piece makes it difficult to tell clearly if the projection is indeed a representation of a beard. ${ }^{14}$ For these early pieces the addition of the beard tends to be unclear. It is not until the sixth century BC that the beard becomes a more easily recognizable addition to depictions of serpents.

From the sixth century BC onwards the beard begins to be used in a wider range of contexts, including but not limited to divine or heroic attributes, monstrous hybrids, and guardian serpents. Bearded serpents continue to be used in such contexts throughout the sixth and fifth centuries. The motif is used to a lesser extent during the fourth century and ceases being used on such a wide scale by the third century BC. ${ }^{15}$ However, the image of the bearded snake persists in several later literary works. The works in which one or more bearded snakes appear range in date from the second century BC to the fifth century AD, and include Nonnus' Dionysiaca, Nicander's Theriaca, and Philostratus' Life of Apollonius of Tyana. In such literary works the serpents appear in similar contexts as in artistic pieces. They are described in association with divine or heroic figures, generally appearing in the form of a large, pure serpent. These literary works serve as an example of the continuation of the motif well beyond the third century BC. Although such descriptions are rare and significantly later than the Greek artistic tradition of the bearded snake, these texts can still be used to shed some light on the meaning of the motif as even those that do not seek to tell a mythological narrative, such as Nicander's Theriaca, still associate the bearded snake with divine figures. This implies a distinct connection between the bearded snake and the divine or heroic, which is evident throughout the history of this motif and its use in both artistic and literary works.

\footnotetext{
${ }^{12}$ Ogden (2013) 155.

${ }^{13}$ Further discussion of the cauldron influence on the shape of the Gorgons on the Eleusis amphora and the appearance of the bearded snakes is given in Chapter Two.

${ }^{14}$ Ogden (2013) 155.

${ }^{15}$ Ogden (2013) 156.
} 
There is little consistency in the way in which the beard is depicted. However, three general types of beards can be identified based on similarities in the beard's shape. These types are used interchangeably in all of the contexts in which a bearded snake may appear. Rather than being determined by context, the types may be distinguished through the size of the image and the medium in which the motif is depicted. The simplest and most common type consists of a simple straight-line, terminating in a point. This can be seen on the Serpent of the Hesperides on a hydria attributed to the Syracuse Painter, ca. 475-450 BC (fig. 5). Here the thin beard extends from the edge of the serpent's lower jaw. Due to its simplicity this beard may also be used for smaller scale attributes, as on the snakes positioned around Athena's aegis on a Little Master lip cup housed in the British Museum, attributed to Phrynos, ca. 575$525 \mathrm{BC}$ (fig. 6). On such small-scale representations the beard can be difficult to identify. The simplicity of the style also allows for this type of beard to be used on larger scale sculptural depictions, as on the three visible serpents of Athena's aegis on the east frieze of the Siphnian Treasury, ca. 525 BC (fig. 7).

The second type of beard is slightly more detailed and appears to be a stylistic preference of Lakonian vase painters. This type consists of a larger, more defined, and slightly globular beard. It has the appearance of a series of overlapping dots. Unlike the straight type, which may be positioned at either the edge or the center of the lower jaw, this globular type is consistently depicted as extending from the center of the lower jaw. This type is used on depictions of both pure serpents, as on the serpent who appears above the blinding of Polyphemos on a kylix attributed to the Rider Painter, ca. 550 BC (fig. 8), and on serpent hybrids, such as the debated representation of Typhon on the Typhon Painter's name kylix, ca. 550 BC (fig. 9). This type is significantly less common than the straight type and appears only in Lakonian examples. It also appears to be a stylistic favorite of the Rider Painter, whose depictions of the globular beard account for at least four of the surviving representations of bearded snakes from Lakonia.

The final type of beard is the most detailed and clearest representation of a beard. This type consists of several clearly defined hairs. These individually defined hairs cause the beard to appear as somewhat shaggy and unkempt. The best example of this type can be seen on the Serpent of Colchis on a kylix by Douris, ca. 500-450 
BC (fig. 10). The long, shaggy beard of this serpent is the most extreme example of this type of beard in terms of its size and length. This type is also used in smaller scale examples, such as on the snakes on the aegis of Athena also on the Douris kylix. While the beards of these snakes are not as defined as those on the Serpent of Colchis due to their smaller size, they retain the same defined detailing, shape, and positioning as the larger beard. A slight variation of this type is seen in Lucanian depictions of Medea's serpent-drawn chariot, like that on a hydria by the Policoro Painter, ca. 400 $\mathrm{BC}$ (fig. 11). The beards on these serpents have the same general features, namely the thickness and the individually defined hairs of the beard. However, they differ in regards to the length of the beard, being significantly shorter than those on the Douris kylix. This smaller version of the defined beard is also used in sculpted examples of the bearded snake, such as on a fragmentary votive relief depicting Zeus Meilichios (fig. 12). While this is indeed the clearest type of beard it is also the least common. The use of a specific style of beard appears to be purely a personal stylistic choice of the painter, as there is no single context in which one type is consistently used in preference over another. By defining these types I do not seek to claim that there is a distinct different meaning behind each individual style. Rather, by outlining the differences in the appearance of various beards it becomes possible to note some consistencies in regard to placement, size, and shape that make the identification particularly of smaller scale or uncertain beards easier.

\section{Issues of Identification}

Due to these inconsistencies in the representation of the beard, there have been brief attempts to explain the beard as an error on the part of the artist, or as the tongue of the serpent. ${ }^{16}$ These explanations have a tendency to focus solely on depictions of the simple, straight-line type outlined above. As this type of beard is often small and difficult to see, as on the Phrynos cup (fig. 6), it is not beyond reason to see the protrusion as something other than a beard. This is particularly the case when only one snake is shown with a beard of this type, as on a kylix attributed to the Hunt Painter, ca. 575-525 BC (fig. 13). Kerberos is shown covered with non-bearded snakes on this kylix, yet the larger snake that forms his tail seems to be bearded. This

\footnotetext{
${ }^{16}$ Ogden (2013) 155.
} 
snake is depicted in the same manner as the smaller snakes, with the minor difference of a faint line of slip, which extends from beneath the lower jaw. This may be an intentional way to differentiate the snakes, indicating that the snake forming the tail is of greater significance. Identification of this beard is complicated by a fracture in the kylix running directly through the tail snake and its potential beard. The modern restoration slightly obscures this section of the piece and may account for the difference between the two types of snakes. However, as the slip appears precisely where a beard might be expected to be placed, based on the consistencies discussed above, and has a globular shape similar to the second type of beard commonly found on Lakonian examples, I see this as an intentional representation of a beard. This piece shows the extent to which the preservation and restoration of any given piece can cause some difficulties in the interpretation of such a small aspect of the decoration. Any such restorations need to be taken into consideration when they partially obscure the area of a potential beard, as they may affect the shape or size of the motif.

The quality of the decoration can also cause problems with the identification of a beard. In instances where the application of the slip or incised decoration is rough, the beard of the serpent may indeed simply be an error. This sort of messy application can be seen on a Leagros Group column krater housed at Victoria University of Wellington (figs. 14a-b). The snake on the shield of the central hoplite of the farewell scene was once painted in a white slip, which has since flaked off, leaving only a faint silhouette (fig. 14b). The silhouette of the lower jaw seems to extend significantly beyond where we might expect the jaw to end; in fact it appears to be over twice the length of the upper jaw. It is possible that the jaw is positioned in this outward manner due to the positioning of the snake's body, which causes there to be limited space below the creature's jaw. This means the jaw is open to a lesser degree. However, the line of the lower jaw is also not a single continuous line. It has a slight break about one third of the way along. At this point the width of the line becomes slightly thinner. It is this break that leads me to suggest that this may be a depiction of a beard, in the style of the single line type. However, as none of the white slip of this section of the decoration has survived, this identification is uncertain. The silhouette of the potential beard of the snake is particularly faint and difficult to see in photographs. This identification is made even more uncertain when the quality of the slip application of the remaining decoration is considered. The added red and white 
slip is particularly rough. For example, the red detailing on the central hoplite's helmet extends well beyond the black, culminating in the appearance of an erroneous drip of red slip (fig. 14a). Such a rough application of added slip may account for the line extending beyond what should be the end of the serpent's lower jaw. Thus, this krater may be considered as an example of a bearded snake that is potentially a mistaken addition on the part of an artist, perhaps working in haste.

A further complicating factor in the identification of the beard may be seen in depictions in which it is not clear if the beard should truly be considered to be a beard, or simply the lower jaw of the serpent. Snakes with such unclear depictions are often described as having their mouths open wide, thus the potential beard is explained as a natural part of the serpent's anatomy. An example of an unclear depiction can be seen on a kylix by the Sotades Painter, ca. 500-450 BC (figs. 15a-b). At first glance this serpent appears to have its mouth open wide and is described as such by Hoffmann. ${ }^{17}$ This claim is partially due to the fact that the billowing cloud in front of the serpent causes it to appear to be breathing out fire, smoke, or some type of noxious fume (fig. 15b). ${ }^{18}$ However, the distinct lack of a tongue or a clear representation of fangs would seem to suggest that the mouth of the snake is in fact closed. This idea is supported by the rough appearance of the potential beard, which appears to consist of several rough lines similar to the third type of beard outlined above. ${ }^{19}$ This implies a shaggy or hairy addition to the anatomy of this particular serpent. There is also a distinct line above what Hoffmann considers to be the creature's upper jaw, which clearly divides the head of the snake into two horizontal sections, much like the line of a closed mouth. Emphasis is placed on the serpent's nostrils; they are approximately the same size as the snake's pupil, indicating that they are of importance to the action of the scene. ${ }^{20}$ Thus the snake appears to actually be breathing the smoke or noxious fume out of its nose, not its mouth which I suggest is closed. This serpent shows the extent to which the smallest of details must be considered when identifying a beard. Even the faintest of lines, such as the line I have suggested to be the serpent's closed mouth, needs to be taken into account.

As the context of the serpent is not always a determining factor in whether or not a beard is depicted, the details of the individual serpent become the deciding

\footnotetext{
${ }^{17}$ Hoffmann (1997) 34.

${ }^{18}$ Hoffmann (1997) 134; Griffiths (1986) 61.

${ }^{19}$ Griffiths (1986) 61.

${ }^{20}$ Griffiths (1986) 61.
} 
factor. Such details include the positioning of the potential beard. For example if it extends from the edge of the lower jaw, as on the Syracuse Painter hydria (fig. 5), it is more likely to be a beard than an unclear depiction of the lower jaw. The lack of a tongue or fangs, as on the Sotades Painter kylix, may imply that the mouth of the serpent is closed. However, this is by no means a certainty. There are depictions of bearded snakes that are shown with their mouths open but with no tongue, as on the Lernaean Hydra depicted on a hydria by the Geras Painter, ca. 500-450 BC (fig. 16). In such depictions it is the position of the beard that causes it to be identified as such, rather than as the tongue of the serpent. The size and shape of the potential beard is often the most definitive factor in identification. As the two more detailed types of beards are generally larger and have clearer indications of hair, they are more easily recognized as beards than the single-line type. In instances where the image is unclear, identification of the beard is based on a combination of the above factors. By pinpointing the problems of identifying such a small addition to the motif of the snake I am better able to recognize the beard when it does occur, expanding my examples beyond the limited contexts of Aelian and Harrison. Doing so has enabled me to consider their ideas in a wider context in order to provide a more comprehensive explanation of the motif of the bearded snake. 
Chapter One:

Snakes and Beards

To best consider how the unusual motif of the bearded snake should be interpreted, the beard and the snake need to be understood separately. As these two motifs function in a variety of different ways in order to imply a number of distinct ideas and features, there appears to be no obvious reason to combine the motifs. The serpent serves as an allusion to ideas prevalent in myth, such as guardianship and the underworld, while the beard functions as a means to distinguish individual characteristics of specific figures. By understanding how these two motifs function separately and the contexts in which they are used, it will be possible to see how they are connected and how, or even if, the meaning of these motifs change when they are combined.

The Meaning Behind the Snake

Putting aside the beard, the serpent has a variety of connotations and meanings. The association most prevalent in myth and depictions of mythological narratives is that between the serpent and the guardian. The mythological guardian serpent functions as the protector of an item or location of special or sacred importance, as is the case with the Serpent of Colchis and the Golden Fleece. Even outside the realm of myth the serpent is seen in this role. Snakes are considered to be guardians of houses, temples, sanctuaries, and tombs. ${ }^{21}$ Through this role serpents are connected with both heroic and divine figures. The locations or objects protected by such serpents are often associated with a specific god or goddess, as with the well of Ares protected by the Ismenian Dragon. ${ }^{22}$ The association with heroes is made through the role the snake takes as an obstacle that must be overcome by the hero. The quest or journey trope frequently features the hero attempting to gain access to a specific location, such as Kadmos' attempt to take water from the spring of Ares, ${ }^{23}$ or retrieve a specific object, such as Jason's quest to obtain the Golden Fleece. ${ }^{24}$ As the

\footnotetext{
${ }^{21}$ Burkert (1985) 130; Gilhus (2006) 108.

22 Apollod. Bibl. 3.4.1; The Ismenian Dragon is also referred to as the Serpent of Ares. For the purposes of this thesis I will refer to this serpent as the Ismenian Dragon.

${ }^{23}$ Apollod. Bibl. 3.4.1; Ap. Rhod. Argon. 3.1179 ff.; Paus. 9.10.5.

${ }^{24}$ Gantz (1993) 342-343, 358-361.
} 
serpent protects such places and objects, it is brought into direct conflict with the hero as a result of its role as a guardian. Beyond this role the snake is also seen as a symbol for ideas about renewal and healing, which can be seen in the snake's association with Asklepios. ${ }^{25}$ Due to the subterranean habitat of the snake and its ability to seemingly cheat death by shedding its skin, it is also connected with ideas concerning death and the underworld. ${ }^{26}$ This connection is emphasized by the portrayal of the serpent as an attribute of chthonic figures such as the Erinyes and Zeus Meilichios. ${ }^{27}$ For some mythological serpents such as Python, the snake is not directly associated with such chthonic figures. In this particular context it is the serpent's association with Gaea in her role as a pre-Olympian deity that is emphasized above such a chthonic association. ${ }^{28}$ These are the major ideas commonly associated with the snake, in terms of both its role in mythology and its function in daily religion. The following discussion on the symbolism of serpents without the beard will focus on how the serpent is presented in such roles.

Mythological snakes that function in this role of the guardian of a location or of a specific item include such serpents as the Ismenian Dragon and the Serpent of the Hesperides. ${ }^{29}$ The motif of guardianship is used in narratives involving the fighting and slaying of such serpents by a heroic figure such as Jason or Herakles. The serpents that act as guardians are defeated by a prominent hero, who is undertaking a quest or journey. The act of slaying is generally an act of necessity for the hero. For the hero to complete his quest he must either obtain the desired object or gain entrance into the area under the protection of the serpent. ${ }^{30}$ In order to do so the hero comes into direct conflict with the guardian serpent, ending with the defeat of said

\footnotetext{
${ }^{25}$ Gilhus (2006) 108; Ar. Plut. 727-738 contains the earliest surviving account of the ritual for healing at the Asklepieion, detailing how Asklepios called forth two large temple serpents who then licked Ploutos' eyes in order for his sight to be restored. Larson (2007) 194-195.

${ }^{26}$ Gilhus (2006) 108.

${ }^{27}$ Parker (2011) 81-83; as the snake burrows into the earth it is believed to be directly connected with the earth and the underworld. Through this physical connection to the underworld the snake is seen to be a chthonic creature in its own right.

${ }^{28}$ The role of Gaea is integral to several versions of the myth of Apollo's arrival at Delphi. It is Gaea who appointed Python to protect her oracle (or the oracle she had since passed to her daughter Themis); Apollod. Bibl. 1.4.1; Paus. 10.6.5; Ov. Met. 434 ff.; Eur. IT. 1244-1248; see further Gantz (1993) 88.

${ }^{29}$ This serpent guards the well of Ares, located outside of Thebes. Paus. 9.10.5; see further Gantz (1993) 467-473. The Serpent of the Hesperides is named Ladon in Ap. Rhod. Argon. 4.1367. This serpent is the guardian of both a location, the garden of the Hesperides, and a specific object, the golden apples sought by Herakles; Apollod. Bibl. 2.5.11; Ap. Rhod. Argon. 4.1396-1405; see further Gantz (1993) 410-413.

${ }^{30}$ Ogden (2013) 26.
} 
snake and the hero obtaining the objective of his quest. ${ }^{31}$ Depictions of myths involving this narrative motif will often present the objective of the hero's quest in a prominent location within the scene, particularly when the object is a physical item rather than a more generic location. In the case of the Serpent of Colchis, the Golden Fleece is an easily recognizable feature of many scenes. ${ }^{32}$ Two examples of this can be seen in a column-krater attributed to the Orchard Painter, ca. 470-460 BC, (fig. 17) and in the tondo of the Douris kylix discussed above (figs. 10a-b). Each of these scenes include depictions of Jason (the hero of the quest), Athena (his divine patron), the Serpent of Colchis (the guardian serpent), and the Golden Fleece (the object of the hero's quest). The inclusion of the object guarded by the serpent aids in the identification of the myth being depicted. Identification of the scene shown on the Orchard Painter krater is relatively straightforward. It presents the moment at which Jason is about to fulfill his quest by taking the fleece from the rocks on which it sits. The protective role of the Serpent of Colchis is shown in the way the serpent is coiled around the rock and about to strike Jason in order to prevent the fleece from being removed. The tondo of the Douris kylix, however, depicts a more unusual scene. In the scene Jason is being either swallowed or regurgitated by an impossibly large serpent, while Athena looks on (fig. 10). An inscription located between his hair and arms names the figure of Jason; Athena is identified by her attributes of the helmet, aegis, and spear. This scene depicts an episode of Jason's journey that is otherwise almost entirely unknown to us. ${ }^{33}$ As there are other similar images, albeit very few, this scene was likely a minor variant of Jason's retrieval of the Golden Fleece and not an invention of Douris himself. ${ }^{34}$ Other versions of the myth of Jason's retrieval of the Golden Fleece commonly detail Medea's involvement. For example Euripides' version includes Medea's claim that she killed the serpent herself, ${ }^{35}$ while in

\footnotetext{
${ }^{31}$ For example the Ismenian dragon is defeated by Kadmos so he can retrieve water from the well of Ares; the Serpent of the Hesperides is defeated by Herakles in order for him to obtain the golden apples; the Serpent of Colchis is defeated by Jason/Medea so they may take the Golden Fleece; Python is defeated by Apollo in order for him to take control of Delphi and establish his own oracle at the site. These are just four examples of this serpent-slaying narrative.

${ }^{32}$ LIMC Iason 32, 36, 37, 38, 42.

${ }^{33}$ Ogden (2013) 59, while there is no surviving written variant of the myth that includes Jason being swallowed by a large serpent at any point during his journey there are two similar Corinthian depictions of a man being disgorged by a large serpent, LIMC Iason 30 and 31, as well as three Etruscan examples which show a male figure, likely to be Jason, with only a leg in the mouth of the serpent, LIMC Iason 33-35.

${ }^{34}$ Sparkes (2013) 124; Ogden (2013) 58-59.

${ }^{35}$ Eur. Med. 475-485.
} 
Apollonius of Rhodes', she simply puts the serpent to sleep using a magical drug. ${ }^{36}$ Medea is not included on the Douris kylix. Instead emphasis is placed on the figure of Athena, perhaps implying her role in this particular version of events, and the role of Jason himself. ${ }^{37}$ Here he appears to have only divine help, rather than also having the aid of Medea as he does in the literary narratives mentioned above. This scene can safely be said to be a representation of the Serpent of Colchis due to the naming of Jason, inscribed in the space between his hair and arms, who is only associated with the one serpent during his travels. ${ }^{38}$ This identification of the serpent is further supported by the inclusion of the Golden Fleece hanging on a tree in the background of the scene. As the Golden Fleece is integral to this serpent's role as a guardian snake this clearly identifies the scene as a lesser known variant of the narrative of Jason's retrieval of the fleece and defeat of the serpent.

The serpent, in its role as a guardian, can be presented as a monstrous creature whose large size is one of the challenges the hero faces in defeating the creature. This is one of the distinguishing features of the Serpent of Colchis as it is presented on the Douris kylix. This snake is large enough to swallow a fully-grown man with ease. However, this is an extreme example of a monstrously large snake. Even when the narrative does not entail the swallowing of the hero the size of the serpent is often larger than life-size. ${ }^{39}$ When the size of the serpent is presented in this way it serves to show the guardian snakes as mythological creatures. ${ }^{40}$ It distinguishes them from the average garden-variety snake. As creatures of myth these monstrously large serpents stand between the hero and the object of his quest and must be defeated no matter what their size. By showing the snake as larger than life, the skills of the hero are emphasized. In slaying a creature of mythological proportions he is presented as even more heroic. As this trope of the hero slaying the monstrous guardian serpent out of necessity appears so frequently in mythological narratives involving such a snake, Daniel Ogden has defined the trope as a distinct narrative motif. ${ }^{41}$ The mythic

\footnotetext{
${ }^{36}$ Ap. Rhod. Argon. 4.156-161.

${ }^{37}$ Sparkes (2013) 124.

${ }^{38}$ Gantz (1993) 345-361; Ogden (2013) 58-59.

${ }^{39}$ For example on LIMC Hesperides 7, where the size of the serpent of the Hesperides is roughly the same as the human figures also in the scene.

${ }^{40}$ The size of the guardian serpent is not always so impossibly large, as can be seen on the Orchard Painter krater (fig. 17). Therefore, other features can also be used to distinguish the mythological snake from the every-day snake. The following chapters will consider the motif of the beard as one such feature that can be used to mark out a mythological figure.

${ }^{41}$ Ogden (2013) 26ff.
} 
accounts of these serpent-slaying narratives vary in the details involved in the defeat of the guardian serpent. Variations are apparent even in narratives detailing the same myth. Herakles' eleventh labour, his quest for the apples of the Hesperides, serves as just one example of the extent to which such variations can occur. The version of the eleventh labour told by Apollonius of Rhodes is one of the few surviving accounts that makes distinct use of the serpent-slaying narrative motif. In his version Apollonius claims that Herakles killed the guardian serpent of the Hesperides (here named as Ladon) with the use of his poisoned arrows. ${ }^{42}$ Other versions of the myth that do not explicitly use this narrative motif may instead focus on Herakles' manipulation of another figure into retrieving the apples in his place. This eliminates the necessity for him to slay the guardian serpent and thus removes the serpentslaying motif from the narrative. Apollodorus details one such version, in which Herakles, following the advice of Prometheus, chooses not to retrieve the apples himself. Rather, he convinces Atlas, the father of the Hesperides, to collect the apples for him while he takes Atlas' place holding up the heavens. ${ }^{43}$ This version also appears in artistic representations of the narrative, such as on a metope from the temple of Zeus at Olympia (fig. 18). Here Herakles is depicted holding up the heavens, emphasizing both his strength and his cunning as the myth entails his manipulation and deception of Atlas upon his return with the apples. Another variation appears in the artistic tradition. In this alternative Herakles enters the garden but does not encounter the serpent, as the Hesperides retrieve the apples for him. ${ }^{44}$ In such scenes the serpent may still be depicted coiled around the tree on which the golden apples grow, as on a hydria housed in the British Museum attributed to the Meidias Painter (fig. 19), serving as a reminder of the role it plays as the protector of the garden of the Hesperides. Even though in some of these variations of the eleventh labour Herakles does not come into direct conflict with the serpent, it still plays a

\footnotetext{
${ }^{42}$ Ap. Rhod. Argon. 4.1396-1405; Eur. $H F .394-399$ also makes clear use of the serpent-slaying motif; the chorus makes brief mention of the death of the serpent but does not give explicit details as to how Herakles killed it. Diod. Sic. 4.26.2-4 takes a euhemeristic approach to the serpent-slaying narrative, claiming that neither the guardian serpent or the apples of the Hesperides were in reality what the myths claimed. Diodorus interprets $\mu \tilde{\eta} \lambda \alpha$, which is commonly interpreted as apples, to actually mean sheep. He then claims that a shepherd named Drakon, not a monstrous serpent, guarded these sheep. This euhemeristic approach to the myth still encompasses the serpent-slaying motif as it seeks to provide a "real" version of the task that evolved into the mythical labour of Herakles, complete with the guardian serpent.

${ }^{43}$ Apollod. Bibl. 2.5.11; Gantz (1993) 410-413.

${ }^{44}$ LIMC Hesperides 7, 29, 30, 33, 36, 38, 62, 63.
} 
distinct role in the narrative. Herakles either fights and kills the serpent, ${ }^{45}$ or goes out of his way to avoid the serpent by convincing Atlas or the Hesperides to retrieve the apples in his place. ${ }^{46}$ In each of these scenarios the overall features and outcome of the narrative remain the same as any narrative featuring a guardian serpent; the hero must find a way to retrieve an object or gain entrance into a place being guarded by a monstrous serpent. The hero's quest frequently ends with the death of the serpent and the hero successfully achieving his aim. The eleventh labour stands out as an exception to this, as some variations do not include an encounter with the guardian serpent. However, it remains an example of the importance of the serpent in such narratives. These serpents are divinely appointed guardians. They protect the objects and areas that are sacred to those who appointed them and ward off unwelcome mortals. The Ismenian Dragon for example was placed as the guardian of a spring sacred to Ares by the god of war himself, with the instruction that no mortal was to take water from the spring. ${ }^{47}$ Even when the serpent of the Hesperides itself does not appear in direct conflict with Herakles, this divine appointment and the serpent's threatening nature are implied. This conveys the idea that the guardian serpent is a frighteningly powerful creature that even the greatest of heroes seeks to avoid.

This serpent-slaying motif is also used in a divine context. When a god is used in place of a hero the motif changes slightly to emphasize conflict with and challenges to the Olympian order. This change sees the serpent aligned with pre-Olympian deities, such as Gaea. Thus, myths that make use of this divine serpent-slaying narrative can be associated with the emergence of the Olympian order and the defeat and subsequent replacement of older divinities. Such narratives are typified by Apollo's defeat of Python at Delphi. In the earliest extant version of this narrative in the Homeric Hymn to Apollo, the role of the serpent as a guardian is downplayed, as it appears more as a curse upon the local people. ${ }^{48}$ These two roles are not mutually exclusive; instead, the two are often interconnected. This can be seen in the manner in which guardian serpents will violently protect their respective areas and objects. The Ismenian Dragon for example, kills anyone who enters the spring until Kadmos fights

\footnotetext{
${ }^{45}$ As is Eur. HF. 394-399 and Ap. Rhod. Argon. 4.1396-1405.

${ }^{46}$ As depicted on the Medias Painter hydria and the metope from the temple of Zeus at Olympia, and as described in Apollod. Bibl. 2.10.

${ }^{47}$ Apollod. Bibl. 3.4.1; Ap. Rhod. Argon. 180-181; Paus. 9.10.5; see further Gantz (1993) 469.

${ }^{48}$ Hom. Hymn Apol. 300-304; see Fontenrose (1974) 13-14.
} 
and slays the serpent. ${ }^{49}$ It is this act of violent protection that brings the serpent into conflict with the hero, and thus it can be seen as an integral part of the nature of the guardian serpent. However, the role of Python, as described in the Homeric Hymn to Apollo, differs from this aggressive protection, as it is purely the destructive nature of the serpent that is emphasized above any form of protective capabilities. In this early account of the myth of Apollo's defeat of Python, Apollo first lays the foundations of his temple before saving the local people from the affliction of the monstrous serpent. ${ }^{50}$ It is not until later sources, such as Euripides' Iphigenia in Tauris (ca. 414$410 \mathrm{BC})$, that the aspect of guardianship becomes explicitly apparent in the narrative. The serpent in Euripides' brief version is not the plague on mankind that it is in the Homeric Hymn. Instead the serpent is the guardian of an oracular shrine associated with Ge, located in a cave at the site of Delphi. ${ }^{51}$ It is on this site that Apollo wishes to construct his own temple and establish his oracle. In order to do so, and thus establish his dominance over the site, Apollo must first defeat the guardian of the old divine order. As these narratives focus on the defeat of the serpent, they are considered serpent-slaying narratives. Due to the divine context, their focus is more on the defeat of a representative of a pre-Olympian divinity by a representative of the emerging Olympian order, rather than simply the defeat of a guardian serpent by a hero seeking to fulfill the objective of his quest. ${ }^{52}$ It is this shift in focus that distinguishes divine serpent-slaying narratives from heroic narratives.

Serpents are also closely associated with ideas surrounding death, the underworld, and to a lesser extent, immortality. This is in part due to the unique appearance, behavior, and habitat of snakes. ${ }^{53}$ As snakes are set apart from other creatures by their limbless appearance, they are often viewed as unnerving or unsettling animals. ${ }^{54}$ This perception of serpents is further accentuated by their

\footnotetext{
${ }^{49}$ Apollod. Bibl. 3.4.1; Ogden (2013) 48.

${ }^{50}$ Hom. Hymn Apol. 300-304.

${ }^{51}$ Eur. IT. 1244-1247; Fontenrose (1974) 21 claims that the idea of guardianship first appears in the fragments of Simonides. The referenced fragment (Simon. frag. 573 Cambell, ap, ps.-Jul. Epist. 24)

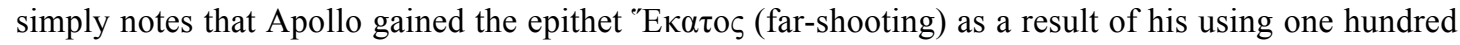
arrows to slay Python. While there is no explicit mention of the serpent as a guardian the role is implied through the myth.

${ }^{52}$ In this narrative Python is closely associated with Gaea, not only through the oracular shrine, but also through the figure of Typhoeus, the monstrous last child of Gaea who was raised by the serpent. In relation to Typhoeus, Python also acts in the role of a guardian as Apollodorus claims that it was Python who guarded the cave in which Typhoeus hid the tendons of Zeus, Apollod. Bibl. 1.6.3. Python was also considered to be a child of Gaea. Ogden (2013) 42-43.

${ }^{53}$ Burkert (1985) 195.

${ }^{54}$ Burkert (1985) 195.
} 
threatening nature as venomous creatures that have the potential to kill with a single bite. While its appearance and proximity to the ground show the serpent to be physically attached to the earth, it is its natural propensity to burrow into the ground and under rock piles, along with its ability to easily cause death that connect it with both death and the underworld. ${ }^{55}$ As the snake is able to cause death while also seemingly being able to transition between the worlds above and below the earth themselves, it is seen to have a unique or secret knowledge of the underworld and the dead that inhabit it. ${ }^{56}$ Essentially, the snake appears to be able to perform its own sort of katabasis and hence becomes a symbol associated with the heroic and divine figures that also accomplish this feat. ${ }^{57}$ Beyond such a perceived knowledge of death the serpent's ability to shed its skin and seemingly rejuvenate itself implies that the serpent has knowledge of how to cheat death and thus it is associated with the immortal. ${ }^{58}$ This image of immortality through resurrection is presented in the myth of Glaukos and Polyeidos, although the rejuvenation occurs in a slightly different manner. This myth details the events that occurred after Glaukos' death by drowning in honey, namely his restoration to life by the seer Polyeidos. ${ }^{59}$ After the death of his son, Minos entombed Polyeidos with Glaukos, ordering him to find a way to bring the boy back to life. ${ }^{60}$ While in the tomb Polyeidos observes a snake rise from the ground, this snake he kills out of fear as it approaches the body of Glaukos. He then witnesses a second snake appear and revive the first using a herb. Polyeidos then uses this same herb to bring Glaukos back to life. ${ }^{61}$ This mythical rejuvenation is depicted on the tondo of a Sotades Painter kylix currently housed in the British Museum, ca. 460-450 BC (figs. 20a-b). This kylix shows Polyeidos and Glaukos inside the tomb, with the two serpents depicted in the lower exergue (fig. 20b). As the ground line of the scene appears above the serpents, it is implied that they are underground. In contrast, Hoffmann has suggested that as the snakes are positioned near the rim of the kylix

\footnotetext{
${ }^{55}$ Morris and Morris (1965) 48; Salapata (2006) 551.

${ }^{56}$ Stutesman (2005) 35; Gilhus (2006) 108.

${ }^{57}$ This is a means through which the association between the snake and katabatic heroes such as Herakles and Orpheus, or gods such as Hermes and Dionysos, is further emphasized.

${ }^{58}$ Stutesman (2005) 34; Morris and Morris (1965) 26.

${ }^{59}$ Apollod. Bibl. 3.3.1-2; see further Gantz (1993) 270-271.

${ }^{60}$ Apollod. Bibl. 3.3.1; Hyginus later provides two alternatives for this tale. The first being that Glaukos was revived by Asklepios, Hyg. Fab. 49. The second follows that of Apollodorus, with Polyeidos being the one to revive Glaukos, Hyg. Fab. 136; Ogden (2013) 345-346; the inclusion of Asklepios in this later telling of the myth emphasizes the connection between the actions of the tomb serpents and the divine, implying that the healing of Glaukos is the action of a divinity. See further Gantz (1993) 270.

${ }^{61}$ Apollod. Bibl. 3.3.1; see further Gantz (1993) 345.
} 
they should be interpreted as being on the same ground line as Polyeidos and Glaukos due to the curve of the kylix. ${ }^{62}$ Both Glaukos and Polyeidos have their focus directed towards the snakes (fig. 20a), which in turn draws the viewer's attention to them, showing the importance of these small snakes to the scene depicted. ${ }^{63}$ This myth presents a variation on the snake's ability to rejuvenate, as here it does not do so by shedding its skin; rather the serpent is rejuvenated through the use of a special herb. This creates a distinct difference from the snake's natural ability as it implies that this renewal is available to others, as is exemplified by Polyeidos' use of the herb on Glaukos. The myth also emphasizes the connection between death and immortality. It is only through death that the snake and subsequently Glaukos can be rejuvenated. This is a slight variation on the serpent's natural ability, where only the skin of the snake dies. This combination of connections with death, rejuvenation, and immortality causes the serpent to be an ambivalent figure, or potentially a creature that functions as a mediator between various natural divisions, particularly that of life and death. ${ }^{64}$

This association between serpents, death, and the underworld is found in an artistic context through depictions of snakes in close proximity to tombs and burial mounds. Snakes are often presented either alongside or within such representations of burials. ${ }^{65}$ The snake will generally be depicted as if it is inside the burial mound, as on a Leagros Group hydria (fig. 21). In such instances it is unclear if the snake should be considered to be physically within the tomb or simply close to the exterior of the burial. Another alternative is that the snake may be a representation of a snake painted on the exterior of the tumulus. ${ }^{66}$ This interpretation is particularly likely for this hydria due to the small lion that appears below the snake, implying that both animals are depicted on the exterior of the mound. ${ }^{67}$ Unlike such an uncertain depiction, the Sotades Painter kylix discussed above clearly shows the snakes within the tomb (fig. 20a). The outline of the tholos encompasses all of the figures on the interior of the

\footnotetext{
${ }^{62}$ Hoffmann (1997) 126.

${ }^{63}$ Hoffmann (1997) 126.

${ }^{64}$ Gilhus (2006) 108; these ideas are concisely symbolized by the Ourobouros, the heavenly snake associated with later cults such as the Gnostics and Alchemists. This is not a widespread motif during the sixth and fifth centuries BC, but nevertheless, it becomes a symbol of the cyclical nature of life and death, implying that immortality or rejuvenation comes only through death and the two are intrinsically connected. Welling (2012) 19; Guiley (2006) 233.

${ }^{65}$ As in LIMC Achilleus 586, 588, 592, and LIMC Polyxene 22.

${ }^{66}$ Backe-Dahmen, Kästner, and Schwarzmaier (2010) 44.

${ }^{67}$ Backe-Dahmen, Kästner, and Schwarzmaier (2010) 44.
} 
kylix, snakes included. This connection between the serpent and a burial is, to some extent, an extension of the serpent's role as a guardian. ${ }^{68}$ Just as a mythological guardian snake protects places or objects of sacred importance, such as the oracular shrine at Delphi or the Golden Fleece, these tomb serpents can be seen to be protecting the area in which the burial is located, as well as the body of the deceased. This protection of the deceased can be seen in a fragmentary Tyrrhenian amphora, ca. 575-550 BC (fig. 22), which depicts a large bearded snake rising up in order to protect the recently deceased Eriphyle by striking out against her fleeing murderer and son, Alkmaion. ${ }^{69}$ Its wide-open mouth implies the protective role of this serpent; its pose also gives the impression that it is in the process of lunging forward to attack Alkmaion, emphasizing its role as a protector. ${ }^{70}$ This action places the serpent in the role of the guardian or protector of Eriphyle. Through its role as a protector, the serpent also takes on the task of avenging Eriphyle's murder. As a result the snake appears as an avenging spirit. The serpent acting in this role can also be seen on a kantharos attributed to the Amphitrite Painter in the British Museum, ca. 475-425 BC (fig. 23). This scene shows Ixion, entwined by a serpent, crouched on an altar, beside which Thanatos removes Ixion's victim. ${ }^{71}$ The serpent appears to be an avenging figure again due to its pose. Where the serpent on the Tyrrhenian amphora is striking out against Alkmaion, this serpent is already biting Ixion's shoulder. Such an avenging serpent may serve to evoke an association with the Erinyes. In the context of Eriphyle's murder, the aftermath consists of Alkmaion being pursued by the Erinyes for committing the act of matricide. ${ }^{72}$ In contrast, the scene of Ixion appears to be an unknown myth involving Ixion as it is not consistent with surviving narratives, which do not detail either his killing of a young man, as it is shown on the Amphitrite Painter kantharos, or his subsequently being pursued by the Erinyes. ${ }^{73}$ In this context it is the avenging serpent that is seen to imply the role of the Erinyes within the scene. ${ }^{74}$ The association between serpents and the Erinyes is attested by many depictions of the Erinyes either holding or alongside serpents, showing a precedent

\footnotetext{
${ }^{68}$ Salapata (2006) 550.

${ }^{69}$ Harrison (1903) 237.

${ }^{70}$ Harrison (1903) 237.

${ }^{71}$ Shapiro (1993) 159; Gantz (1993) 720; Burton (2005) 57.

${ }^{72}$ Apollod. Bibl. 3.7.5; see further Gantz (1993) 527-528.

${ }^{73}$ Shapiro (1993) 160; Gantz (1993) 720-721; the victim on this kantharos is sometimes interpreted as Eioneus, Ixion's father-in-law. However, this interpretation is complicated by the victim's lack of a beard, which implies he is younger than Ixion who is shown with a beard in this scene.

${ }^{74}$ Shapiro (1993) 159; Burton (2005) 57.
} 
for the association of these two chthonic figures. ${ }^{75}$ The association between the serpent and the Erinyes in these two scenes is complicated by the fact that there are no Erinyes depicted within the scenes. However, the extent to which the Erinyes are aligned with snakes is so comprehensive that it may be possible for the serpent to be separated from the Erinyes in an iconographic context, or even depicted in place of a Erinys, and still retain the implication of the vengeful figures. ${ }^{76}$ The serpent in these contexts also functions in its symbolic role as a mediator between life and death. The snake was seen to have a certain level of mobility between the worlds of the living and the dead due to its subterranean habitat. Therefore, it becomes emblematic of the change from living to dead, as well as the final transition to existence in the underworld. ${ }^{77}$ This makes the tomb a suitably appropriate place to find the snake. The association with the Erinyes can also imply this symbolic role of the serpent, as they too are chthonic figures who are able to travel between the underworld and the world of the living in order to enact vengeance on the living in certain contexts. ${ }^{78}$

Jane Harrison proposed another alternative to the meaning of such snakes shown in direct association with the body of the recently deceased. She suggests that the serpent should be seen as a physical representation of the deceased's soul. ${ }^{79}$ This interpretation relies heavily on the significantly later textual evidence that claims the snake is formed from the bodies of the dead, found in such texts as Aelian's De

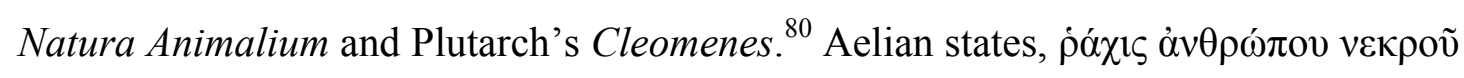

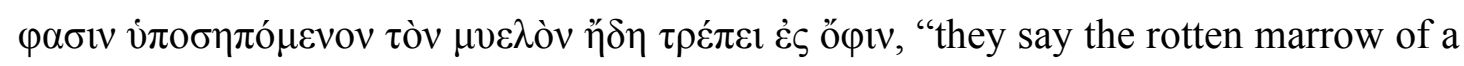
dead man's spine immediately turns into a serpent." ${ }^{\prime 81}$ Plutarch's description varies

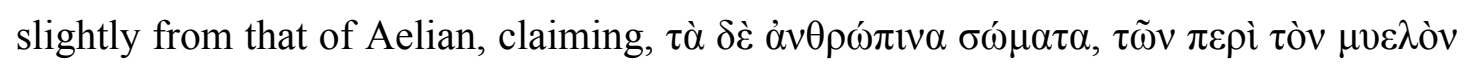

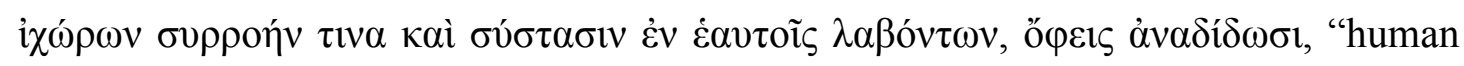
bodies, when the juices about the marrow collect together and coagulate, produce

\footnotetext{
${ }^{75}$ LIMC Erinys 1, 11, 21, 39, 41, 42, 58, 64, 68, 69, 70; these pieces show the Erinyes with serpents either in their hands, around their arms, in their hair, or placed alongside them.

${ }^{76}$ Ogden (2013) 256; Ogden cites LIMC Erinys 31 as evidence for such a disassociation. As this piece is a second-century Etruscan urn it is beyond the context of this thesis.

${ }^{77}$ Stutesman (2005) 35.

${ }^{78}$ Ogden (2013) 254.

${ }^{79}$ Harrison (1903) 327-328; Harrison claims that the addition of the beard to such serpents is indicative of this anthropomorphic representation. Her argument for this anthropomorphic association will be discussed in Chapter Three. Nilsson (1940) 71 greatly overstates the extent to which serpents were viewed as incarnations of the souls of the dead, as he claims that serpents were "always considered to represent the souls of the dead".

${ }^{80}$ Ael. NA. 1.51; Plut. Vit. Cleom. 39.3; also see Ov. Met. 15.389-390.

${ }^{81}$ Ael. NA. 1.51, all translations of Aelian's De Natura Animalium are my own unless otherwise stated.
} 
serpents". ${ }^{82}$ While both state that the serpent is formed from various decaying body parts or fluids, they differ in their explanation of the type of person in whom this transformation will occur. Aelian specifies that it is only from the wicked or evil that

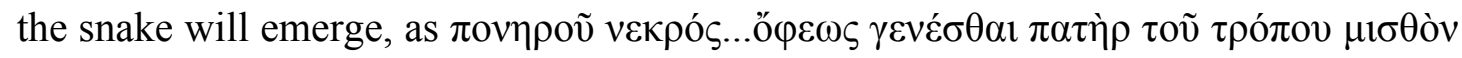

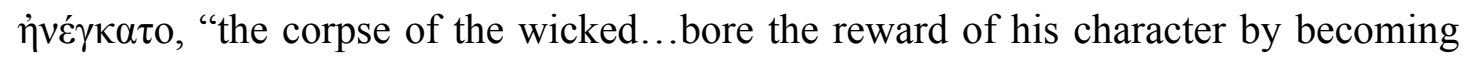
the father of a serpent." ${ }^{\prime 83}$ In contrast Plutarch states that it is because of this transformation that "the ancients associated the serpent more than any other animal with heroes", implying that it is only from the bodies of heroes that the snake will emerge. ${ }^{84}$ In the context of Cleomenes, this connection between serpents and heroes is particularly important as it is made as a result of a large snake appearing around the head of Cleomenes shortly after his death. ${ }^{85}$ This association causes some to venerate him as a hero and a child of the gods. ${ }^{86}$ In order to support this idea in an iconographic context Harrison draws largely on the so-called Lakonian hero reliefs. These reliefs, ranging in date from ca. $540 \mathrm{BC}$ to the Roman period, each consist of the same basic motif with minor variations, as exemplified by the Chrysapha relief housed in Berlin (fig. 24). ${ }^{87}$ The reliefs depict one or two seated figures, ${ }^{88}$ with the man holding a kantharos, with a snake partially coiled under the seat or positioned near the kantharos. This motif also appears on a number of Lakonian and Messenian terracotta plaques dating from the sixth to fourth centuries $\mathrm{BC}{ }^{89}$ As these terracotta plaques consist of the same iconographic motif as the larger stone reliefs, it is likely that they originated as a more affordable alternative version intended to be dedicated as votive offerings. ${ }^{90}$ As such, they can be viewed in a similar light to the hero reliefs. Harrison views the seated figures as representations of deceased figures who are worshipped as heroes in death, as evidenced by their large scale in the Chrysapha relief, which includes two significantly smaller figures approaching the seated couple. ${ }^{91}$ These seated figures are often interpreted as local heroes, who were

\footnotetext{
${ }^{82}$ Plut. Vit. Cleom. 39.3.

${ }^{83}$ Ael. NA. 1.51.

${ }^{84}$ Plut. Vit. Cleom. 39.3.

${ }^{85}$ Plut. Vit. Cleom. 39.1-2.

${ }^{86}$ Plut. Vit. Cleom. 39.2.

${ }^{87}$ Salapata (1993) 189; as of 1993 this series of reliefs consisted of more than forty reliefs featuring the same or similar motif.

${ }^{88}$ When only one seated figure is shown the figure is generally male, only one example of a solitary seated female has so far been found. Salapata (1993) 192.

${ }^{89}$ Salapata (2013) 187.

${ }^{90}$ Salapata (2013) 193.

${ }^{91}$ Harrison (1903) 327.
} 
worshipped in death. ${ }^{92}$ However, other interpretations identify the figures as either representations of specific mythical heroes or chthonic divinities. ${ }^{93}$ The identification of the seated couple in the Chrysapha relief as the heroized dead is largely due to the depictions of objects associated with funerary motifs. Such objects include the lotus flower and egg held by the two figures approaching the seated couple, and the pomegranate held by the seated female. ${ }^{94}$ Guralnick also adds what she terms the "veil of mourning" to this set of funerary motifs apparent in the relief. ${ }^{95}$ The veil to which Guralnick is referring is the himation the seated woman holds out in front of part of her face, in what is more likely to be an anakalypsis gesture, implying that she is the wife of the seated male, rather than in mourning. ${ }^{96}$ Neer suggests that in the context of a young woman of marriageable age who died unmarried, such wedding symbols and gestures can be used to show the woman to essentially be a "bride to Death", connecting the two transitional stages of a woman's life, namely marriage and death. ${ }^{97}$ The Chrysapha relief is the only one in this series of reliefs to be found in situ, placed on the peak of a tumulus-like mound, similar in shape and construction to a burial mound. ${ }^{98}$ In this context the inclusion of the snake would seem to emphasize the idea that these figures are either heroic, deceased, or both. However, beyond the addition of the beard to the serpent, which will be discussed in detail in Chapter Three, there is little to suggest that the serpent should be viewed as the physical incarnation of the deceased hero's soul, as Harrison argues. Rather, the inclusion of the serpent in the motif should be viewed as a means through which the nature of these heroes as local, autochthonous heroes is implied.

The connection between the serpent and the physical burial location and hero cult is more apparent in artistic evidence than a potential connection between the serpent and the body or soul of the deceased. This is due to representations of snakes within the burial mound or tomb of the deceased, as previously discussed. In the Leagros Group hydriai in figures 21 and 25 the snake is distinguished from the soul of the deceased by the inclusion of a small representation of the eidolon of the occupant

\footnotetext{
${ }^{92}$ Guralnick (1974) 175; Salapata (2013) 188; Ogden (2013) 251.

${ }^{93}$ Hibler (1993) 199, identifies the terracota figures as Agamemnon and Kassandra; Richer (2007) 251, builds on Andronikos' 1956 identification of the figures as Hades and Demeter.

${ }^{94}$ Guralnick (1974) 175; Richter (1949) 87.

95 Guralnick (1974) 175, refers to the "veil of mourning" once with no explanation as to why this veil should be associated with the act of mourning.

${ }^{96}$ Salapata (1993) 190; Neer (2012) 307.

${ }^{97}$ Neer (2012) 307.

${ }^{98}$ Salapata (1993) 189.
} 
of the tomb. ${ }^{99}$ Even the fragmentary amphora in figure 22, which at first glance has the appearance of the snake rising directly out of the body of Eriphyle, includes a representation of a tomb or burial mound, implying that the serpent is actually rising from the earth, not the body of Eriphyle. ${ }^{100}$ This association between the serpent and a physical burial location is less evident in the context of the Lakonian hero reliefs. The locality of the scene is instead implied through the identification of the seated figures as local, possibly autochthonous, heroes. This locality is suggested by the fact that these reliefs have largely been found within areas or sanctuaries associated with hero cults. ${ }^{101}$ The majority of the terracotta reliefs were found in a series of deposits scattered throughout Sparta and Amyklai, suggesting that they were dedicated at small local shrines to various heroes positioned throughout the towns. ${ }^{102}$ This function of the reliefs as votive offerings or indicators of hero cults is further supported by the context in which the Chrysapha relief was found (fig. 24), as discussed above. The tumulus-like mound on which the relief was positioned may imply that the site was considered to be the burial location of the figures depicted on the relief. The snake's close association with the earth serves to emphasize this connection to burial as, in the context of these reliefs, it reflects the image of the snake that is represented on the tombs of heroes such as Achilleus, as shown on the Leagros Group hydria discussed above (fig. 21).

What is apparent is that all of these many meanings that may be implied by the representation of a serpent are not independent from each other. When depicted in the context of a tomb or a deceased hero, the snake can convey ideas about the cyclical nature of life, death, and existence in the underworld, while also functioning in its common mythological role of a guardian or protector of the area of the hero's burial. When the snake is shown in association with a wrongfully murdered figure it becomes a symbol of the vengeful Erinyes; this does not exclude its function as a guardian, but rather can be seen as an extension of this role, as by attacking the killer, the snake can be seen to be protecting the dead. Essentially, the snake is a complex creature with a wide range of meanings that can vary depending on the context in which the creature is shown.

\footnotetext{
${ }^{99}$ Carpenter (1991) 30 n. 24.

${ }^{100}$ Ogden (2013) 249.

101 Salapata (1997) 252; Salapata (2013) 194, as of 2013 no relief featuring this motif has been found within a sanctuary dedicated to a pan-Hellenic deity, making it likely that the seated figures are not intended to be representations of major deities.

102 Salapata (2013) 194.
} 
The meaning behind the depiction of a beard is more straightforward than that of the serpent. Greek art is formulaic and systematic in the presentation of individual human characteristics such as age, gender, and ethnicity. ${ }^{103}$ Thus stylized motifs, including the beard, are used to infer broadly distinguishing characteristics. As beards are generally only depicted on male figures, a major implication of a depiction of a beard is that it denotes a male. ${ }^{104}$ For the purposes of this discussion I will address the motif of the beard only in its most common context, that of depictions on humans. In this context beards are exclusively depicted on males. ${ }^{105}$ Variations in the appearance of the beard are used to convey specific identifying details about the person with the beard.

Aside from indicating the gender of a particular figure the beard can be used to signify the various stages of male maturity. ${ }^{106}$ The lack of a beard can be used to distinguish a youth from an older bearded male. ${ }^{107}$ Through variations in the colour and styling of a beard, the middle-aged man can be distinguished from the old man. ${ }^{108}$ However, this is not always the case. A hydria attributed to the Kleophrades Painter, ca. 500-450 BC, serves as an example of the extent to which the identifiable feature of the beard can be subverted (figs. 26a-b). The elderly figures of Priam and Anchises are both shown as essentially bald and beardless, with only the indication of stubble. In contrast, the figures of Neoptolemos, a figure who is either Acamas or Demophon, and an unidentified Greek warrior, are all shown as beardless. However, in this instance the beardlessness of Neoptolemos and Acamas or Demophon may be explained as a way in which the Kleophrades Painter has indicated that these figures are of the younger generation of heroes involved in the sack of Troy, i.e. the sons of Achilleus and Theseus respectively. This would then suggest that the unidentified Greek warrior is also of this younger generation. The beard cannot be relied upon as an infallible indicator of age, as heroes such as Achilleus are often shown to be beardless, as on a volute krater attributed to the Berlin Painter (figs. 27a-b). Achilleus

\footnotetext{
${ }^{103}$ Jenkins (2009) 118.

${ }^{104}$ The obvious exception to this is the inclusion of beards on some monstrous women, such as Medusa. This will be addressed in Chapter Two.

${ }^{105}$ The sole exception, so far as I am aware, is Medusa, who will be discussed in Chapter Two.

${ }^{106}$ Jenkins (2009) 118.

${ }^{107}$ Carpenter (1994) 67.

${ }^{108}$ Carpenter (1994) 67.
} 
himself serves as an example of the extent to which the use of the beard may vary, as he is not consistently shown as beardless. ${ }^{109}$ Even in the instances where the beard is used to suggest age it indicates only a very generalized age of the men on which it is shown. The youth can be represented as an idealized young man, prior to the growth of his first beard, which is a symbol of his entering manhood. ${ }^{110}$ The age at which this occurs is unlikely to be much older than 18 or $19 .{ }^{111}$ A variation in this beardlessness can be used to indicate a slightly more specific age range, that of a young man who is growing his first beard. This is done by depicting a small amount of hair on the youth's cheek, as on an amphora housed in Wüzburg also attributed to the Kleophrades Painter, ca. 525-475 BC (figs. 28a-b). One of the scenes on this amphora depicts a youth arming for battle (fig. 28a). The youth is identified as a young man of around 18 or 19 due to his lack of a fully-grown beard and the small amount of hair depicted on his cheek, suggesting that he is on the cusp of manhood. ${ }^{112}$ When a man has reached maturity and is no longer considered to be a youth, he is commonly depicted with a short, neatly styled beard. This can be seen on the reverse of the Kleophrades Painter amphora (fig. 28b). Here the central reveler is depicted with this type of stylized beard, indicating that he is more mature than the effectively beardless youth on the opposing side. This is the most common type of beard and when it is used it presents the image of an idealized Athenian man, whose beard is neatly trimmed and styled.

The final stage of life a beard can be used to indicate is that of old age. A distinguishing feature of some depictions of old men is the white beard, which may be longer and scruffier than the immaculate black beards of younger men, as can be seen on an amphora by the Matsch Painter, ca. 500-450 BC (fig. 29). ${ }^{113}$ The figure to the left of this scene is presented as an older male through the added white slip used to

\footnotetext{
${ }^{109}$ Depictions of Achilleus with a beard include, but are not limited to, LIMC Achilleus 188, 200, 198, 216, 219, 234, 297, 303, 310, 322, 344, 345, 363, 392, 394, 404, 408, 410, 411, 421, 419, 423, 570, 645, 644. Depictions of Achilleus without a beard include, but are not limited to, LIMC Achilleus 189, 191, 204, 266, 269, 349a, 350, 354, 355, 367, 372, 420, 425, 426, 473, 508, 515, 566, 649, 657, 661, 729, 731, 734, 830. In particular note LIMC Achilleus 570, a kylix by Douris featuring a strikingly similar motif to the Berlin Painter volute krater discussed above, with Achilleus and Hektor flanked by Athena and a youth that is likely to be Apollo. Unlike on the Berlin Painter krater, Achilleus is shown on this kylix with a beard.

${ }^{110}$ As in Hom. Od.18.269-270, where the age at which Telemachus is able to take over his father's household is the age at which he grows his first beard.

${ }^{111}$ Moller (1987) 750; Osborne (2011) 111.

112 Osborne (2011) 59.

${ }^{113}$ Birchler Emery (1999) 17-20 identifies five common features used to depict elderly men, in order of prevalence: baldness, white beard and/or hair, wrinkles, posture (bent body/use of cane or stick), and other physical traits such as emaciation.
} 
colour his hair and long beard. The age of this man is further emphasized by the walking stick he holds in his hand, mirroring the spear of the warrior to the right of the composition. This motif of the bearded old man is also used in works of literature in order to effectively describe the appearance of old age. ${ }^{114}$ In instances where an elderly man is shown with a closely cropped beard or as bald, as on the figure of Priam on the Kleophrades hydria (fig. 26a), rather than with a long white beard, identification of his age relies on other formulaic features such as the context of the scene. $^{115}$

The use of a beard as a formulaic motif to distinguish men of various ages is simply one of the ways in which the motif is used to imply specific characteristics. The shape and style of the beard can also be used to create a distinction between 'civilized' and 'uncivilized' figures within the same scene. This is generally only seen in a mythological context, such as on a calyx krater by Euphronios, ca. 550-500 BC (fig. 30). This krater depicts Herakles wrestling the giant, Antaios. A stark contrast is created between the two figures through the styling of their beards and hair. ${ }^{116}$ The contrast between Herakles and Antaios is necessitated by mythological tradition, which presents the 'civilized' Greek hero prevailing over the 'uncivilized' barbarian. ${ }^{117}$ In order to create this distinction Herakles is shown with immaculately groomed and styled hair and beard, while Antaios is depicted with wild, unkempt hair and a long, scraggly beard. This contrast in appearance reflects their respective roles in society. As the well-groomed man, Herakles is presented as an idealized and, most importantly, civilized citizen. Antaios, with his wild, unkempt hair and long, straggly beard, is shown to be a more 'barbaric' or 'uncivilized' figure who stands apart from civilized society. ${ }^{118}$ This distinction of civilized vs. uncivilized also extends to the appearance of the female bystanders. Herakles' female supporter is depicted with her hair neatly arranged in a sakkos, reflecting the tidy styling of Herakles' relief ringlets. ${ }^{119}$ The two women standing behind Antaios do not have their hair so neatly styled. Neither wears a sakkos, instead the women are both pulling their hair in grief,

\footnotetext{
${ }^{114}$ Birchler Emery (1999) 20; cf. Hom. Il. 13.361-362, 22.74-76; Hom. Od. 24.498-499; Hom. Hymn Aph. 228-229; a clear difference between the literary and artistic use of this motif is the colour of the beard. While it is described as gray in the above passages, due to the limited spectrum of colours used in vase painting the beard is depicted as white.

${ }^{115}$ Birchler Emery (1999) 17.

${ }^{116}$ Schefold (1992) 142.

${ }^{117}$ Mertens (1972) 279.

${ }^{118}$ Mertens (1972) 279; Schefold (1992) 142; Stafford (2012) 56.

${ }^{119}$ Boardman (1975) 33.
} 
causing it to appear unkempt. This opposing characterization of the civilized Greek hero and his barbaric opponent presents an insight into Athenian attitudes towards their own standing. ${ }^{120}$ The figure of Herakles is effectively a representation of an idealized Athenian figure, as presented by an Athenian. ${ }^{121}$ The contrast is used to establish the hero's opponent as a barbarian who stands outside of, or in direct conflict with, the ideals and norms of Athenian society, as represented by the civilized appearance of the hero. As the embodiment of Athenian ideals, Herakles functions as a civilizing force that overcomes an embodiment of the uncivilized world.

Thus the hero's beard can be used to establish an 'us and them' image. Essentially, the hero's adversary is established as an outsider through variations from the norm of the stylized black beard. ${ }^{122}$ However, there are some instances where the Greek hero is distinguished by his lack of a beard. The Berlin Painter krater provides an example of this type of distinction (figs. 27a-b). On either side of this krater Achilleus is shown as beardless, in the manner of a youth. In contrast to this appearance, both Memnon and Hektor are shown with the neatly groomed beard we might expect of a mature Greek man. In this particular context neither of the beards are used to imply the men to be uncivilized or barbaric. Rather, they are part of the presentation of Memnon and Hektor as worthy opponents of the Greeks, as they are depicted essentially as Greeks. Achilleus' beardlessness distinguishes him from those he is fighting by causing him to be likened to the only other non-bearded male in the scene, Apollo. Apollo's appearance is effectively that of a 'divine ephebe', or a representation of the perfect idealized youth. ${ }^{123}$ By depicting Achilleus in a similar manner, specifically without a beard, he is likened to the epitome of youth and shown to be the idealized warrior. As Apollo is supporting Hektor in this scene, the worthiness of the Trojans is further emphasized, yet it is not the Trojan who is presented as similar in appearance to the god. This suggests that even the most civilized opponents, who possess divine support, are not equal to the Greek hero.

Ethnicity may also be implied through the shape and colour of the beard as it draws a distinction between a Greek man and a foreigner. ${ }^{124}$ The beard of a foreigner is often depicted as short and pointed, with a rougher or thinner appearance that the

\footnotetext{
${ }^{120}$ Schefold (1992) 142.

${ }^{121}$ Schefold (1992) 142; Miller (2000) 413.

122 The extent to which such variations can be used on monstrous hybrids, particularly hybrid women such as Medusa, in order to present them as outsiders will be considered in Chapter Two.

${ }^{123}$ Graff (2008) 12.

124 Tsiafakis (2000) 372.
} 
full, glossy beard of a mature Greek man. ${ }^{125}$ As these features differ from those of the Greek man, Tsiafakis has argued that they may be used to represent a Thracian, Scythian, or Persian man. ${ }^{126}$ This can be seen on each side of the Kleophrades Painter amphora (figs. 28a-b) and a bell-krater by the Painter of London E 497, ca. 475-425 BC (figs. 31a-b). On these pieces the beards of the Scythian (fig. 28a) and Thracian (fig. 31a) are contrasted with the beards of the Greeks on the reverse of the vases by being depicted as smaller and thinner. Even when a Greek male is shown with a closely cropped beard, as on the reveler to the left of the Kleophrades Painter amphora (fig 28b), the Scythian's beard is still distinguished by its small size. The Greek's stubble reaches high on his cheek, while the Scythian's is only along the edge of his jaw. The beard, when it is not shown in this manner, may be coloured red, as on an amphora attributed to the Antimenes Painter currently housed in Seattle, ca. 550500 BC (fig. 33). ${ }^{127}$ The clothes of figures depicted with such beards, including the Phrygian cap and patterned tunics and cloaks, further distinguishes these men from typical Greek men, commonly depicted nude, in hoplite armor, or in a chiton. ${ }^{128}$ In contrast to Tsiafakis' argument, MacKay has suggested that these features are not intended to create a distinction between the idealized Greek man and a foreigner, but to show a variation in the status of Greek warriors. ${ }^{129}$ As these non-Greek figures are commonly depicted in the company of Greek hoplites, as in figures 32 and 33, it appears as though such figures are directly associated with the typical Greek hoplite. ${ }^{130}$ In the scene on the Kleophrades Painter amphora (fig. 28a) the Scythian figure is involved in the farewell of the young hoplite and is raising his hand in farewell. Other such scenes show the supposed foreigner to be directly involved in the arming of the hoplite. Due to this association with hoplites, these figures can be seen as secondary heroes, whose presence serves to emphasize the heroic qualities of the young hoplite. ${ }^{131}$ These figures are essentially the hoplite's aides, who appear to have fought alongside the hoplites in pairs until their long-range bows were no longer effective in the battle. ${ }^{132}$ They are the light-armed infantry who are contrasted with the

\footnotetext{
${ }^{125}$ Cohen (2012) 473.

126 Tsiafakis (2000) 372.

127 Also see fig. 31 for a similar depiction of a Scythian archer on an unattributed amphora currently housed in San Simeon.

${ }^{128} \operatorname{Vos}(1963) 40$.

${ }^{129}$ MacKay (2010) 279.

${ }^{130}$ Ivantchik (2006) 215; Vos (1963) 1.

${ }^{131}$ Ivantchik (2006) 205-206; MacKay (2010) 279.

${ }^{132}$ Vos (1963) 62, 72-73.
} 
heavily armed hoplites who are the focus of these scenes. ${ }^{133}$ The variations of beard and dress mark their lower status. The hoplite is presented as the preeminent Greek warrior, while the other figure is seen as secondary or inferior as they are presented as distinctly different. ${ }^{134}$ Again, the beard functions as a means to distinguish the typical Greek and hero from the foreign or inferior 'other'.

\section{Conclusion}

As separate motifs the snake and the beard are used to convey a variety of different ideas. The serpent often functions in the role of a divinely appointed guardian of a specific location or object. Through this role it may be used to imply an association with the Erinyes or the heroes with whom it comes into conflict while protecting the object of the hero's quest. In contrast, the beard serves as a means to convey generalized characteristics such as gender, ethnicity, and rough age range. Variations in colour and styling affect the way in which the beard and, as a result, the characteristics of certain figures are interpreted. The styling of a hero's beard shows him to be an idealized Greek male who stands in direct contrast with the shaggy, unkempt, and thus uncivilized barbarians he comes into conflict with. This understanding of how these individual motifs can be interpreted in a variety of different contexts serves as a basis from which it is possible to see the extent to which such interpretations may change when the motifs are combined in the figure of the bearded snake.

\footnotetext{
${ }^{133} \operatorname{Vos}(1963) 70$.

${ }^{134}$ MacKay (2010) 279.
} 
Chapter 2:

Monstrous and Divine Women

The only explanation for the beard of the snake to survive from antiquity is found in the third century AD De Natura Animalium by Aelian. Aelian briefly explains the beard as a feature of naturally occurring male snakes, functioning in the same manner as the horns of the stag.

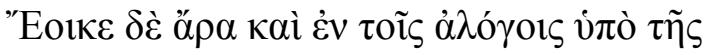

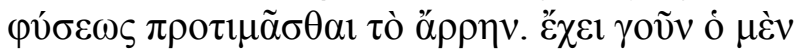

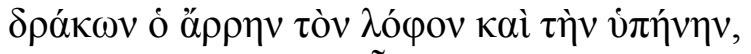

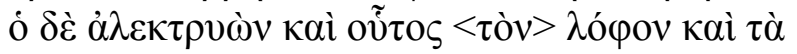

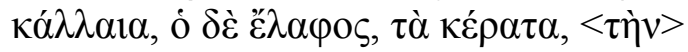

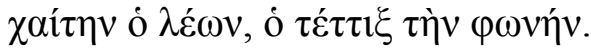

Among animals it seems that the male is naturally preferred. At least then the male serpent has the crest and the beard; and the cock has the wattles and the comb; and the stag has the horns; the lion the mane, the cicada the cry. ${ }^{135}$

This explanation of the beard has remained unchallenged by some modern scholars, including Liliane Bodson who considers the beard to be an indicator of masculine virile maturity. ${ }^{136}$ Interpreting the beard in this manner becomes problematic when attempting to understand its use on snakes associated with women such as Athena or Medusa, or on snakes generally regarded as female such as Python and the Lernaean Hydra. ${ }^{137}$ As the beard is an inherently masculine symbol it conveys ideas about a masculine nature in any context in which it is shown. However, when it is used in a female context it can change the way in which the female is viewed and imply that there are poorly understood layers to the women who appear with bearded snakes.

Medusa and the Gorgons

The Gorgons are closely associated with bearded snakes from the earliest depictions of such serpents. Arguably the earliest depiction of a bearded snake appears on the Eleusis amphora (ca. 650 BC), in a scene showing Perseus' slaying of

\footnotetext{
${ }^{135}$ Ael. NA. 11.26.

${ }^{136}$ Bodson (1975) 74.

137 The gender of Python varies depending on the author. Hom.Hymn. Apol. 300-304 contains the earliest mention of a female serpent at the site of Delphi. The changing gender of Python presents its own problems in interpreting the beard and will be taken into consideration when discussing the use of the beard on depictions of Python.
} 
Medusa (figs. 1-3). ${ }^{138}$ The two lower serpents protruding from the neck of the Gorgon to the viewer's right are shown with a faint line extending below their lower jaw (fig. 3). In part due to the thickness of these faint lines, they have been argued to be representative of beards. ${ }^{139}$ These particular Gorgons are unique in their appearance. They are presented as almost entirely monstrous creatures with few human features. Such a monstrous representation of the Gorgons, while common during the archaic and classical periods, becomes increasingly rare in later depictions, which downplay the monstrous aspect in favor of a more feminine portrayal. ${ }^{140}$ During the fifth century $\mathrm{BC}$ the frightening hybrid features of the Gorgons, such as the rictus-like grin, beard, and protruding tongue, begin to be replaced by the more elegant face of a beautiful woman, as on a bell-krater attributed to the Polydektes Painter (fig. 34). Rather than being modeled on human features, as later Gorgons are, those on the Eleusis amphora more closely resemble, in the shape of their heads and positioning of the snakes, contemporary bronze cauldrons. ${ }^{141}$ Osborne suggests that this cauldron shape is an intentional means through which the experience of entering a sanctuary or temple is implied through the myth of Medusa and the Gorgons. ${ }^{142}$ The cauldron heads of the Gorgons are reminiscent of dedicatory cauldrons, causing the Gorgons to have an apotropaic and protective function even in this early depiction as they remind the viewer of the potential dangers and benefits of coming face-to-face with the divine when making a dedication or sacrifice. ${ }^{143}$ The shape of the associated snakes emphasizes this cauldron appearance, as the ' $\mathrm{s}$ ' curve is common to cauldron protomes and, to a lesser extent, handles. Of the ten serpents shown on the two immortal Gorgons, only the two that are depicted fully frontal are certainly snakes (fig. 3). The remaining eight are shown with a combination of feline and serpentine features. ${ }^{144}$ These feline and serpentine protomes differ from contemporary cauldron protomes, which are often in the shape of griffins. While examples of serpentine protomes are not unheard of, they are few in number. Examples include a bronze

\footnotetext{
${ }^{138}$ Pedley (2007) 131; Ogden (2013) 155.

${ }^{139}$ Ogden (2013) 155.

${ }^{140}$ Wilk (2000) 35.

141 Carpenter (1991) 104; Marinatos (2000) 49; Osborne (1998) 60. The lower portion of the face appears rounded, like the belly and base of a cauldron, while the top of the head is flattened off, mimicking the lip of the vessel

142 Osborne (1998) 60.

${ }^{143}$ Osborne (1998) 60.

144 The poor preservation of these snakes obscures the features of five of these snakes. As the composition of the decoration is likely to be symmetrical it can be assumed that the features of the obscured snakes are the same as those shown on the other side of the Gorgon's head.
} 
bearded snake protome currently housed in the Delphi Archaeological Museum (fig. 35 ), which is roughly contemporary with the Eleusis amphora, and a depiction of a cauldron with a bearded snake handle on a kylix attributed to Onesimos (figs. 36a-b). While this is not a serpent protome, its positioning on the cauldron is similar to the positioning of the serpents on the necks of the Eleusis amphora Gorgons, suggesting that such handles may also have influenced the shape of these particular snakes.

The protomes on the Eleusis amphora that are shown with beards are two of the more feline, not the two that are clear representations of snakes. The extent to which these bearded protomes can be considered snakes is debatable. ${ }^{145}$ The feline features are most prominent in the creatures' appearance due to the depiction of muzzles. The stippling on the muzzles of these hybrids also appears on similar contemporary representations of lions, as on an olpe by the Ram Jug Painter (fig. 37). Due to the similarities in the appearance of the Ram Jug Painter feline with the felineserpent protomes, I consider the beards on the protomes to be an intentional development of such stippling. However, similarities between these feline-esque creatures and the snakes can be seen in the inclusion of the forked tongue and the similar colour patterning on the underbelly of the creatures. The overall appearance of these creatures is one of a hybrid of snake, feline, human, and cauldron protome. Much like the overall appearance of the Gorgons themselves, their attributes encompass aspects of animal, human, and object, emphasizing the hybrid nature of the Gorgon.

The faces of the Gorgons on the Eleusis amphora may show another connection to bearded snakes. Marinatos argues that the shape of the mouth, the positioning, and number of the teeth give the impression that the Gorgon's head incorporates features of the snake. ${ }^{146}$ The Gorgon's mouth extends the width of her face, implying the ability to open her mouth beyond the limitations of the human jaw. This ability reflects that of the snake which allows a wider gape in order to catch and swallow prey. This similarity is further emphasized by the positioning of the Gorgon's teeth around the edge of the mouth, with no visible fangs, which is similar to the structure of the teeth of an aglyphous snake, such as the Indian Python (Python molurus). ${ }^{147}$ An aglyphous snake has no distinct venom-conducting fangs, but instead

\footnotetext{
${ }^{145}$ Ogden (2013) 155; Osborne (1998) 60.

${ }^{146}$ Marinatos (2000) 49.

147 Also known as the Burmese Python.
} 
has a series of rows of teeth on the premaxilla, maxilla, palatine, and pterygoid bones (fig. 38). ${ }^{148}$ The Gorgon's teeth resemble this arrangement of rows around the edge of both the skull and mandible of the snake. ${ }^{149}$ If we are to view these heads as reflective of the python, I propose that the stippling patterning on the lower jaws of the Gorgons should be seen as representative of the beard of the Gorgon, much like the stippling on the muzzle of the lion on the Ram Jug Painter olpe discussed above (fig 37). In the context of the Gorgon the dots create the suggestion of hair, implying that she has a beard or stubble. The serpentine connection is also apparent on the torsos of these Gorgons, as there are the faint remains of a scale-like pattern on their torsos. This patterning is clearest on the decapitated Medusa on the reverse of the amphora (fig. 2). The patterning on the other two Gorgons is significantly more faded, causing it to be difficult to determine if this pattern is intended to be reminiscent of scales. The shape of their torsos further distinguishes the Gorgons from the only other female figure in this scene, Athena. Athena is shown with a fairly straight form (from what can be determined from her now largely lost form), the Gorgons are presented with a rounded torso that cinches in at the waist. This shape causes the scaled torsos to appear distinctly different from the female form of Athena. The overall appearance of the Gorgons is one that emphasizes their nature as monstrous hybrids. They are a fusion of animal, human, and object, effectively distancing them from the human figures they are shown alongside. ${ }^{150}$ They are something entirely different from the human form, thus emphasizing their power and monstrosity.

While the cauldron shape of the Gorgon's head is unique, the serpentine facial-features are early examples of features that become synonymous with the Gorgon in later archaic and classical art. These features include the frontal face, the wide mouth filled with exaggerated teeth, protruding tongue, and the indication of a beard. ${ }^{151}$ In the context of these hybrid Gorgons the addition of the beard to the felineserpent hybrid protomes serves as a means through which a clear human attribute is incorporated into the hybrid form. However, as only two of the associated serpents

\footnotetext{
${ }_{148}^{14}$ Menez (2003) 56; De Iuliis and Pulera (2011) 271-272.

${ }^{149}$ Osborne (1998) 60 argues that the teeth of the Gorgon are a geometric pattern that can be equated with the patterning on contemporary cauldrons and emphasize the interpretation of the Gorgon's head as representative of such a cauldron.

${ }^{150}$ Osborne (1998) 60.

${ }^{151}$ Wilk (2000) 31; Another feature that is commonly used on later Gorgons that does not appear on the Eleusis amphora is the depiction of protruding fangs, as in LIMC Gorgones 5, 36, 37, 38, 41, 42, 162, $167,293$.
} 
appear to have traces of a beard this must be viewed as a more tentative use of the bearded snake. This uncertainty is reflected in the overall form of the Gorgons, as their unique appearance implies that there was no set motif for the Gorgon during this period. ${ }^{152}$ The Gorgons on the Eleusis amphora serve as early examples of the features that become considerably more humanized. Here the monstrous nature of the creature is clearly displayed through their serpent-human-object hybrid appearance. These hybrid features become more standardized over time and become more human, especially in the form and details of the Gorgon's body. The face, however, retains the serpent-hybrid features, albeit in a less extreme form.

With this development of the overall form of the Gorgon significantly clearer depictions of associated bearded snakes also begin to appear. The bearded snakes shown on the representation of Medusa on the pediment of the temple of Artemis at Corcyra, ca. 600-580 BC, are the earliest known examples of such snakes in architectural sculpture and serve as an early example of clear representations of bearded snakes (figs. 39a-b). ${ }^{153}$ Medusa, shown with all of the features associated with an archaic Gorgon, is presented in the center of the pediment (fig. 39a). These features retain basic similarities with those of the Eleusis amphora Gorgons; she still has the wide rictus grin with a protruding tongue, frontal staring eyes, and snakes extending out from her head. ${ }^{154}$ However, her features are more human than those of the Eleusis amphora Gorgons. Her face is more rounded, her grin remains wide but does not extend the entire width of her face, and her body is essentially human in shape. There is no indication of the serpentine scales on her torso as there is on the amphora. Here less emphasis is placed on Medusa's hybridity. The way in which Medusa, and as a result her associated bearded snakes, can be viewed depends largely on how the smaller male figure to her left is interpreted. This figure is often explained as a representation of Medusa's son, Chrysaor, thus leading to the recreation of the pediment with Medusa's other son, Pegasos, to her right. ${ }^{155}$ In myth Chrysaor and Pegasos are traditionally born from Medusa's decapitated neck, ${ }^{156}$ however, on this pediment they are depicted alongside Medusa with her head still attached to her body. Such a depiction has caused scholars such as Marinatos to consider the figure of

\footnotetext{
152 Carpenter (1991) 104-105.

${ }^{153}$ Guralnick (1974) 183; Holloway (1973) 56.

${ }^{154}$ Spivey (1997) 98; Wilk (2000) 31-32.

155 Spivey (1997) 98; Neer (2012) 130; Richter (1949) 15; Pedley (2007) 156; Robertson (1981) 16-17.

${ }^{156}$ Hes. Theog. 278.
} 
Chrysaor to be a representative of a youth transitioning into manhood. ${ }^{157}$ This more generic symbolism also implies the youth's transitioning into the role of a warrior or hero, as he is shown complete with the attributes of a spear and a horse. ${ }^{158}$ Through this interpretation of Chrysaor, Medusa may be seen as a protector and patroness of heroes. ${ }^{159}$ It is in this role that Medusa can be seen to take on one of the aspects of her serpentine attributes. When viewed as both a protector and nemesis of the hero she essentially becomes a dual natured creature, much like the mythological guardian snake. ${ }^{160}$ However, this patroness role is problematic. As one of the defining tropes of the heroic narrative is the hero's defeat of monsters, such as Medusa, this perceived patroness role of Medusa seems somewhat counterintuitive. While tempting, this explanation is very speculative as Marinatos' argument largely relies on the fact that Chrysaor is depicted beside a still living Medusa. Yet, as Greek art has a tendency to condense narratives into a single snapshot, it is not surprising to find Medusa with her two children in the same image. ${ }^{161}$ That being said, the protective aspects of Marinatos' argument may be applicable to this use of Medusa, as she functions as an apotropaic figure. ${ }^{162}$ When displayed on a temple in this manner the Gorgon takes on an apotropaic function. Her power is transformed into one that wards off malevolence and evil. ${ }^{163}$ Medusa is able to instill terror through her monstrous appearance, becoming a figure who "turns away danger by her greater menace", while also serving as an example of the way in which mortals can be punished for hubris. ${ }^{164}$ In this context the bearded snakes imply this dual nature, they serve as a subtle emblem of a creature that is not entirely what it seems at first glance, who may be at once both threatening and protective.

The addition of a small beard to the snakes associated with Medusa or the Gorgons is not particularly unusual, as until the fourth century BC the Gorgon herself may be depicted with a more defined beard than the stippled beards on the Eleusis

\footnotetext{
${ }^{157}$ Marinatos (2001) 86.

${ }^{158}$ Marinatos (2001) 86.

${ }^{159}$ Marinatios (2001) 68.

${ }^{160}$ As discussed in Chapter One. Marinatos (2001) 86.

${ }^{161}$ Neer (2012) 130; this motif can also be seen in LIMC Gorgo, Gorgones 271-278.

162 This apotropaic use is also apparent in Osborne's interpretation of the Eleusis amphora Gorgons as their cauldron shape causes them to be reminders of the viewer's experiences when entering a temple. See Osborne (1998) 60.

${ }^{163}$ Howe (1954) 215; Holloway (1988) 177; the transformation of Medusa into the Gorgon also serves as a display of the powers of the Olympians and the actions that may be taken in response to an act of hubris.

${ }^{164}$ Warner (1985) 109.
} 
amphora, discussed above. ${ }^{165}$ The clarity of the beard varies, much like the shape and clarity of that shown on the snake. It may appear as a line around the mouth and tongue of the Gorgon, as on a painted terracotta metope from the temple of Apollo at Thermon, ca. $630 \mathrm{BC}$ (fig. 40). ${ }^{166}$ The beard can also be depicted as a series of distinct pointed tufts or lines of hair that may differ in texture from the Gorgon's hair, as on the François Vase, ca. 570 BC (fig. 41). ${ }^{167}$ Simpler beards are seen on a number of Gorgoneia, which present the basic and common attributes of the Gorgon in a highly stylized manner, as on a Gorgoneion on a Phrynos Painter amphora, ca. 575-525 BC (fig. 42). ${ }^{168}$ Of course, the Gorgon is also shown without a beard, as on an amphora by the Berlin Painter, ca. 525-475 BC (fig. 43). ${ }^{169}$ The Medusa from the temple of Artemis falls into this category of the beardless Gorgon. It is her associated snakes that are shown with the additional motif. The clearest examples of this are on the two serpents belted around her waist (fig. 39b). Unlike the uncertain beards on the Eleusis amphora, these sculpted beards are clear and intentional representations. The snakes positioned around Medusa's head and neck also possess similarly small and pointed beards. ${ }^{170}$

As the style of beard shown on Medusa herself can vary from those shown on the snakes, a distinction may be discerned. This distinction between the two forms of beards is clearest on an Amasis Painter oinochoe currently housed in the British Museum (figs. 44a-b). This oinochoe shows a distinction between the bearded snakes belted around Medusa's waist and the non-bearded snakes protruding from her head

\footnotetext{
${ }^{165}$ Cook (1940) 848-849; LIMC Gorgo, Gorgones 4, 5, 16, 35, 37, 41, 42, 162, 167, 234, 235, 243, 277, $283,293,313$.

${ }^{166}$ Also see LIMC Gorgo, Gorgones 4, 162, 234, 277.

${ }^{167}$ Also see LIMC Gorgo, Gorgones 37, 16, 35, 41, 42, 167, 235, 313.

${ }^{168}$ It is common for smaller scale depictions of a Gorgoneion, such as those on coins or shields, to economize space and depict either snakes or hair. Those that do not depict the serpent attributes often present the hair of the Gorgon in serpentine-curls in order to serve as a reminder of the missing attribute. Wilk (2000) 46; LIMC Gorgo, Gorgones 37, 38, 76, 77, 100, 102, 162.

${ }^{169}$ Also see LIMC Gorgo, Gorgones 27, 28, 31, 45, 46, 47, 52, 64, 65, 67, 68, 70, 73, 172, 173, 247 for other examples.

${ }^{170}$ While these beards are clear on the three surviving snakes protruding from her head and neck, the heads of those that form the serpentine curls along her brow are less clear. Of these curls, the head of only one snake appears to have survived. While this serpent seems to have a slightly extended lower jaw it is unlikely that this is intended as a representation of a beard as the beards on all other surviving snakes in this pediment are clearly positioned significantly further back from the edge of the lower jaw. Thus, in the case of the serpentine curls, it is likely that the snake was either depicted with a miniscule beard that has not survived or is too small to be seen, or the snake never possessed a beard in the first place.
} 
(fig. 44b). ${ }^{171}$ This is one of only a few pieces to include a depiction of both bearded and non-bearded snakes in the same scene. ${ }^{172}$ Due to the consistency with which the Amasis Painter styles his snakes, complete with a beard, this exclusion of beards on the snakes around Medusa's head should be viewed as an intentional effort to emphasize Medusa's own beard and those of the serpents around her waist. The Amasis Painter has seemingly positioned the lower jaws of the serpents around Medusa's head in such a way as to reference the positioning of the beards of other snakes, without actually depicting the physical attribute. By not depicting the tidy beard on these snakes the Amasis Painter has made a point of the shagginess of Medusa's own beard. The unkempt beard functions much in the same manner as the long, shaggy beards of uncivilized figures such as Antaios as he appears on the Euphronios krater (fig. 30). It marks the wearer as a barbaric, uncivilized, or wild creature. ${ }^{173}$ However, the neatly styled beards of the snakes around Medusa's waist contrast with this reading of her nature through the style of the beard, as their beards are reminiscent of the immaculately styled beards of both heroic and everyday Greek men. The beards of these snakes vary from the type shown on such men in terms of their exaggerated length, which more closely resembles the longer style of beard used to indicate an older male, as on the Matsch Painter amphora discussed in Chapter One (fig. 29). While the length is also similar to the beards shown on barbaric figures such as Antaios, the tidy, straight nature of the snakes' beards cause them to be more closely aligned with the beard of the old man as opposed to that of the barbarian. This

\footnotetext{
${ }^{171}$ These non-bearded snakes are an anomaly in the Amasis Painter's corpus of bearded snakes. The Amasis Painter is remarkably consistent with his depictions of snakes. They are generally shown in the same manner as those around Medusa's waist, with an open mouth, visible tongue, beard, and dot and line patterns on the body and head respectively. The exclusion of a beard on the snakes protruding from Medusa's head seems to be an intentional stylistic choice. As snakes appear in the Amasis Painter's usual manner on smaller scale examples, such as that on a Little Master band cup housed in the J. Paul Getty Museum, ca. 575-525 BC (fig. 45), it is apparent that the lack of beards on these snakes is not due to difficulties in reproducing the stylistic features on a smaller scale. Admittedly, the lower jaws of the non-bearded snakes do appear at somewhat odd angles that may be suggestive of a beard. However, the size and angle of the lower jaw of the serpent to the viewer's far right appears to be much the same size and at much the same angle as those on the Little Master band cup and on an Amasis Painter amphora housed in Boston, ca. 575-525 BC (fig. 46). It is due to such similarities that I have identified these features as lower jaws as opposed to beards, making them unique to the Amasis Painter's corpus of snakes.

${ }^{172}$ The others include the Hunter Painter Lakonian kylix (ca. 560-550), which depicts Kerberos covered in his associated snakes (fig. 13). Of these snakes only the larger serpent that forms Kerberos' tail is depicted with a beard. Also a number of depictions of the Lernaean Hydra shown with both bearded and non-bearded snakes, discussed below, due to the positioning of the Hydra's various heads, and LIMC Gorgo, Gorgones 247 which shows Medusa with a large bearded snake in her right hand and an un-bearded snake on either side of her head.

${ }^{173}$ As discussed in Chapter One; McNiven (2000) 87.
} 
long beard becomes a marker of the old man's age and the knowledge and wisdom gained over the course of their long life. Birchler-Emery suggests that archaic representations of old men, particularly those in epic literature, consist of two general types, the old king and the old paidagogos. ${ }^{174}$ These old men, characterized by their stereotypical features such as the long white beard, both function as teachers to the younger generation, albeit in different ways. The old king teaches through example. It is his life experiences that have paved the way for the new generation of heroes. ${ }^{175}$ The old paidagogos is a more traditional teacher who passes on the knowledge of his ancestors. ${ }^{176}$ This marker of an inherent knowledge is an appropriate symbol to add to the snake as they are creatures which were believed to possess a unique or secret knowledge of death and the afterlife. ${ }^{177}$ Like the wisdom of old age, the knowledge of the snake is gained only through life experience. The juxtaposition of bearded and non-bearded snakes on the Amasis Painter oinochoe causes the figure of Medusa to be further distanced from the civilized world. While some of her snakes possess a symbol of human knowledge, others do not. The combination thus causes the meaning to be tainted and morphed into something monstrous. The beards of the two larger snakes may appear to be similar to those shown on old men, yet because they are shown on snakes they no longer connect Medusa with civilized society. Instead they become a symbol of an inherent knowledge that no human possesses.

By exaggerating her hybrid appearance Medusa's bearded snakes aid in her portrayal as a threatening and wild creature. She exists so far outside of civilization and social norms that she is a seemingly insurmountable threat to anyone who comes into contact with her. In such moments Medusa becomes aligned with the 'bad' women of Greek myth, such as Klytaimestra and Medea. These women are dominant figures who transgress the traditional, more subservient role women were expected to play within society. Women such as Klytaimestra and Medea are able to control the men around them and will go to any length to achieve their aims. ${ }^{178}$ Medusa shows this control and dominance through her ability to turn the men who look at her to stone. She is a figure who, much like Klytaimestra and Medea, acts of her own volition. This self-dependence causes her to be increasingly seen as a masculinized

\footnotetext{
${ }^{174}$ Birchler-Emery (1999) 23.

175 Birchler-Emery (1999) 23-24.

${ }^{176}$ Birchler-Emery (1999) 24.

${ }_{177}$ As discussed in Chapter One; Stutesman (2005) 35; Gilhus (2006) 108.

${ }^{178}$ Haward (1990) 30.
} 
character. This is as a result of the predominance of the idea of sophrosyne or selfcontrol in the Greek, and particularly Athenian, construct of masculinity. Self-control is extolled as a masculine virtue to such an extent that van Nortwick states it to be the "fundamental requirement for manhood". ${ }^{179}$ The addition of the masculine feature of the beard to Medusa's associated snakes, be it those around her head or those held in her hands as on a Heidelberg Painter kylix (fig. 47), ${ }^{180}$ serve as a subtle indicator of this masculine virtue. By presenting the human feature on an animal the meaning of the beard is tainted. It is no longer simply the indicator of male maturity it is when depicted on human figures. ${ }^{181}$ Instead it becomes an indicator of a monstrous woman who exists outside of the norms and expectations of civilization. This shows Medusa to essentially subvert the masculine qualities the beard can imply. Due to this, Medusa's monstrous and hybrid nature is further emphasized. She is neither wholly female nor entirely male, but a unique amalgam of the attributes and natures of the two.

The inclusion of bearded snakes around Medusa's waist and head serve to show her as a monstrous hybrid of human and animal, as well as male and female. The addition of the beard aids in creating this image of a monstrously hybrid creature. As a traditionally male attribute on a female, it suggests that Medusa blurs the distinction between genders. She is at once both feminine, as evidenced through her role as the mother of Pegasos and Chrysaor, and masculine in the power and control expressed through her ability to turn men to stone. As she is presented as a monstrous amalgam of genders, even her most feminine role as a mother is distorted. She is only a mother in death, as her children are born from her decapitation. When the beard is considered as a human feature on an animal it causes Medusa to be presented as a wild creature who exists beyond the boundaries of the civilized world. She is presented in a similar manner to the guardian serpent through her dual nature. As a wild creature she is shown to be threatening and uncivilized, yet when used as an apotropaic device she is seen to also have a protective function. Essentially, the addition of the beard to Medusa's associated snakes reflects this dual nature of the

\footnotetext{
${ }^{179}$ van Nortwick (2008) 30; also see Fox (1998) 9.

180 Also see LIMC Gorgo, Gorgones: 235, 247, 250, 251, 255, 258, 260, 261, 280, 283 Marinatos (2000) 52 connects such images of the Gorgon holding snakes with depictions of the Mistress of Animals. LIMC Gorgo, Gorgones: 247 presents a running Gorgon with two non-bearded snakes in her hair and a larger bearded snake in her right hand. The inclusion of a beard on this particular serpent distinguishes it from those in her hair, implying that it may be of more importance.

${ }^{181}$ As discussed in Chapter One.
} 
monstrous hybrid. They show her to be a creature of dichotomies, a creature that is in both appearance and in nature, masculine and feminine, human and animal, as well as threatening and protective.

Athena

Athena's aegis and its Gorgoneion is often shown with bearded snakes. ${ }^{182}$ The Gorgoneion on the aegis is the decapitated head of Medusa herself, given to Athena by Perseus. ${ }^{183}$ This creates a direct connection between Medusa and Athena as Athena took on the iconographic motif of the Gorgon. Whether or not the bearded snakes on the aegis are the same snakes as those that appear in association with Medusa is a problematic question. The aegis is not consistently shown with either the Gorgoneion or snakes around its edge. When the Gorgoneion is shown it has many different views. The positioning of the snakes varies; they may be around Medusa's head, the edge of the aegis, or both. ${ }^{184}$ This level of inconsistency implies that any association between the snakes of the aegis and those of the Gorgoneion was made due to artistic preference, suggesting that the snakes associated with Medusa and those of the aegis may not be the same snakes. Distinguishing the serpents of the aegis from those of Medusa is supported by representations of the death of Medusa that include Athena complete with her snake-fringed aegis, such as that on a Pan Painter hydria, ca. 500$450 \mathrm{BC}$ (fig. 48). At the center of this composition is the headless Medusa, whose head is in the bag slung across Perseus' shoulders. The head has no visible serpents. Athena is wearing her aegis, which lacks the Gorgoneion as it has not yet been fixed to the aegis. However, around the edge of the aegis is a series of six small serpents, each of which have a very small indication of a beard at the edge of its lower jaw. The

\footnotetext{
${ }^{182}$ Shearer (1996) 46, Athena is also closely associated with serpents through both cult, i.e. the great serpent said to have lived on the Athenian Acropolis as the site's guardian, and mythology, particularly through her involvement in the myth of the anguipede Erichthonius. This discussion will focus on the serpents that appear in association with Athena's aegis due to the fact that the aegis is one of Athena's most common attributes. As Erichthonius is shown with serpentine legs and the torso and head of a mature male it is not unusual for him to be shown with a beard, therefore, his beard is beyond the limits of this thesis.

${ }^{183}$ Hom. Il. 5.738-742; Apollod. Bibl. 2.4.3; see further Gantz (1993) 84-85.

184 for example, LIMC Athena: (aegis with snakes but no Gorgoneion) 29, 31, 40, 42, 47, 49, 118, 119 , $120,140,175,186,187,194,349,351,368,387,388,429,452,465,472,475,477,485,493,494$, $504,506,512,518,521,523 \mathrm{~b}, 537,543,579,584,616$; (aegis with snakes and Gorgoneion) 98, 121, 127, 171, 173, 184, 195, 206, 220, 254, 267, 389, 393, 416, 437, 469, 500a, 591, 607; (aegis with snakes around both edge and Gorgoneion) 121, 127, 206.
} 
inclusion of serpents on the aegis in a scene prior to Athena's fixing the Gorgoneion to the aegis implies that the snakes are a distinct feature of the aegis that differ from those that are associated with Medusa and are shown around her head when it is attached, as on an amphora attributed to the Andokides Painter, ca. 550-500 BC (fig. 49).

Although the serpents of Medusa and the aegis can be considered to be distinctly different creatures, Athena remains connected to those of Medusa through the concept of transformation. Athena transformed the human Medusa into the monstrous Gorgon, complete with snakes in place of her hair as a punishment for her hubris. ${ }^{185}$ Therefore, Athena's placing of the Gorgoneion on the aegis may be seen as a reclaiming of the power inherent in the symbolism of the serpents that she conferred on Medusa. ${ }^{186}$ By reclaiming the serpents and the associated powers of Medusa, Athena is able to use them against her own enemies. In this context the symbol of the Gorgon retains its threatening nature, yet it is used in a more directed and purposeful way. The aegis, complete with its Gorgoneion, is used to protect the select few Olympians who wield it, as well as their favored mortals. ${ }^{187}$ The only figures to wield the aegis aside from Zeus himself are those deities who are most closely associated with the support and protection of Zeus and the patriarchal Olympian order, namely Athena and Apollo. ${ }^{188}$ When the aegis is used by Athena or Apollo on the battlefield it may be used as an aggressive and threatening defensive weapon. It can be used to instill fear in their enemies. For example Apollo is ordered by Zeus to return to the battlefield of Troy and shake the aegis over the Greek army, causing the men to panic and their horses to stampede. ${ }^{189}$ The combination of the aggressive and protective aspects of the aegis and its associated Gorgoneion cause it to have an apotropaic nature, similar to that of the use of the Gorgon on temples such as the temple of Artemis at Corcyra, as discussed above. In order to protect their favored heroes and cities, Athena and Apollo frighten off their enemies by presenting them with the terrifying image of the deity and the aegis. ${ }^{190}$ This particular aspect of the aegis is one that resonates with the protective aspects of Athena's role in myth, as she uses the

\footnotetext{
${ }^{185}$ Apollod. Bibl. 2.4.3; Ov. Met. 770ff.; see further Gantz (1993) 20-21.

${ }^{186}$ Warner (1985) 113.

${ }^{187}$ Vernant and Vidal-Naquet (1988) 195; Neils (2001) 221; Yasumura (2011) 91.

188 Apollo makes use of the aegis in order to frighten his enemies, Hom. Il. 15.229-233, 15.306-327, and protect his favored hero, Hektor, Hom. Il. 24.18-21.

${ }^{189}$ Hom. Il. 15.229-233; Buxton (2004) 79.

${ }^{190}$ Foster (2003) 182; Warner (1985) 190.
} 
aegis to protect heroes such as Achilleus during his return to the battlefield after the death of Patroklos. ${ }^{191}$ Apollo and Athena are able to wield the aegis in this manner as they stand as intermediaries between Zeus and mankind. ${ }^{192}$ They are the ardent supports of their father who make use of the protective and frightening emblem of the aegis and its associated Gorgoneion. In this context the threat apparent in the face of Medusa is no longer one of blurred gender lines, but the symbol becomes one tied to the victories of the Olympians through the figures of Athena and Apollo and their use of the aegis on the battlefield.

\section{Comparison of Medusa and Athena}

The bearded snakes on Athena's aegis and those associated with Medusa are both presented on powerful females with masculine qualities and attributes. Thus it is logical to consider them in a similar light. In both contexts the masculine attributes shown in association with Medusa and Athena, such as the beard of Medusa or Athena's helmet, are intrinsically connected with the nature of the two. Athena is predominantly depicted with the masculine attributes associated with her role as a warrior goddess. ${ }^{193}$ She is continually presented as a fervent supporter of male values. ${ }^{194}$ It is this blurring of gender, apparent in both the appearance and nature of Athena, that the addition of the beards to the snakes of the aegis can be seen to emphasize. Unlike Medusa, Athena is depicted as wholly human in form. Thus the hybrid qualities emphasized by the beard associated with Medusa are not as significant when the bearded snakes are used in association with Athena. Instead it is the juxtaposition of male and female that is important. This can be seen on a Little Master lip cup by Epitimos (figs. 50a-b), which shows Athena with her helmet, spear, and shield, but without the aegis (fig. 50a). Protruding from her shield is a large bearded snake protome that appears to be poised to strike her opponent. The positioning of Athena, with her spear raised as if she is in the process of throwing it, mirrors the positioning of Enkelados on the reverse (fig. 50b). This is Athena in her

\footnotetext{
${ }^{191}$ Warner (1985) 108; Hom. Il. 18.202-206.

192 As in Hom. Hymn Apol. 131-132, Apollo states he will act as intermediary for Zeus and mankind through prophesy.

193 Blundell (1995) 26; Cohen (2006) 164; Pomeroy (1975) 8-9; Downing (1988) 109-110; Neils (2011) 43.

${ }^{194}$ Deacy (1997) 153-157.
} 
element as a warrior goddess who involves herself in the fight. ${ }^{195}$ The masculine qualities of her armor and the beard of the large protome serpent contrast with the jewelry she is also shown to be wearing. ${ }^{196}$ Where the beard and armor highlight the masculinity inherent in warfare, the inclusion of earrings, a bracelet, and necklace underline Athena's own femininity. ${ }^{197}$ Athena is presented from birth as this warrior goddess, as on an Antimenes Painter neck-amphora which shows her bursting from Zeus' head dressed in full armour and a long chiton (fig. 51). ${ }^{198}$ This masculinized appearance causes a moment of terror among the Olympians, comparable to that during Apollo's arrival on Olympos. ${ }^{199}$ It is not until Athena removes these emblems of war and terror that the Olympians rejoice at her birth and Athena is first referred to as a maiden. ${ }^{200}$ The reactions of the Olympians to the attributes of the warrior establish her as a deity who has formidable martial prowess. This expertise is centered on the male activity of warfare and thus shows Athena to embody the seemingly contradictory aspects of the male and the female. ${ }^{201}$ The beards that appear on the snakes of the aegis serve to emphasize the masculine qualities of her appearance, even when she is shown with minimal masculine attributes, such as on the east frieze of the Siphnian Treasury (fig. 7). ${ }^{202}$ They emphasize her overall appearance as an amalgam of male attributes on a female form, which reflects her role as a goddess of both men's work on the battlefield and women's work within the home. ${ }^{203}$ Unlike the monstrous image presented by Medusa, this amalgam of genders does not cause Athena to be seen as monstrous. Rather it implies her to be a dual natured figure who embodies the best aspects of both genders. ${ }^{204}$

While both Athena and Medusa are presented as threatening women, who blur the line between male and female, when they appear as protective figures they do so in different ways. Athena's protective function stems directly from her role as a supporter and daughter of Zeus. It is this role that is also the basis for her blurring of

\footnotetext{
${ }^{195}$ Cohen (2006) 164; Blundell (1995) 26.

${ }^{196}$ Cohen (2006) 164-165.

${ }^{197}$ Cohen (2006) 164-165.

${ }^{198}$ Neils (2011) 43; in this scene Athena is shown complete with the snake fringed aegis.

199 Hom. Hymn Ath. 4-7; Hom. Hymn Apol. 1-4.

${ }^{200}$ Hom. Hymn Ath. 12-16.

${ }^{201}$ Deacy (2008) 28.

${ }^{202}$ Athena can be reconstructed here with a spear in her left hand, which has been lost. see Neer (2012) 188-189 for reconstruction.

${ }^{203}$ Buxton (2004) 80; Parker (1987) 190; Neils (2011) 43.

${ }^{204}$ Buxton (2004) 80; Blundell (1995) 26-27.
} 
genders. ${ }^{205}$ She is essentially the powerful son who would have overthrown Zeus, as was prophesied for the children of both Thetis and Metis. ${ }^{206}$ It is because she is a woman that this threat is neutralized and she becomes her father's strongest

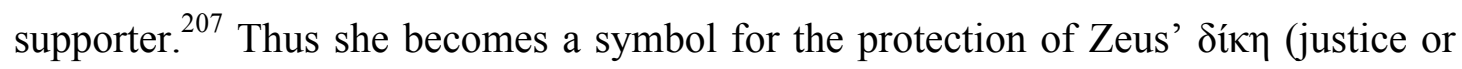
judgment). Much like the guardian snake, it is through her protective function that she may act in an aggressively defensive manner and is thus seen as threatening. Due to this association with the protection of Zeus' divine order, Athena's blurring of genders is never presented as grotesque. ${ }^{208}$ In contrast Medusa appears as a protective symbol due to her threatening nature and appearance as a monstrous hybrid. Medusa can be seen in the role of a guardian only when the image of the Gorgon is used as an apotropaic device. Athena's placing of Medusa's severed head, complete with her associated bearded snakes, onto the aegis emphasizes the protective function of Medusa. Yet even when used in this context, Medusa's role as a guardian is linked with her nature and appearance as a monstrous and threatening hybrid.

\section{Female Pure Serpents}

Aelian's assertion that the beard marks the serpent as male is further complicated by its use on female pure serpents, such as Python and the Lernaean Hydra. ${ }^{209}$ Where Athena and Medusa are either wholly or largely human in their respective appearance, these mythological monsters are purely serpentine. The beard, when it is depicted, is the only human feature these serpents are shown with. If Aelian is to be believed, the inclusion of the beard would imply that both Python and the Hydra are male serpents, which would differ from the literary tradition surrounding these serpents.

The gender of the monstrous guardian serpent at Delphi is not straightforward, nor is it consistent in surviving texts. The earliest account of the narrative of Apollo's defeat of the serpent at Delphi in the Homeric Hymn to Apollo refers to the creature as a $\delta \rho \alpha ́ \kappa \alpha \imath v \alpha$ (she-serpent). ${ }^{210}$ This female serpent is later given the name Delphyne in

\footnotetext{
${ }^{205}$ Otto (1954) 55.

${ }^{206}$ Yasumura (2011) 90.

${ }^{207}$ Yasumura (2011) 90.

${ }^{208}$ Buxton (2004) 80.

${ }^{209}$ Pure serpents are those creatures that are entirely serpentine in their form.

${ }^{210}$ Hom. Hymn Apol. 300.
} 
Apollonius. ${ }^{211}$ The next surviving account after the Homeric Hymn comes from a fragment of Simonides, transmitted in a letter by Julian, which details how Apollo

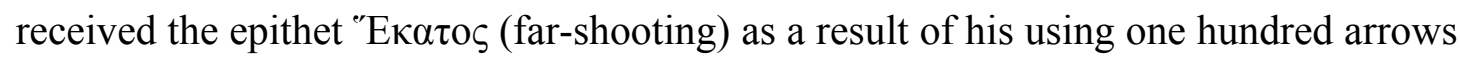
to slay the serpent. ${ }^{212}$ This fragment, which refers to the serpent using the masculine $\delta \rho \alpha ́ \kappa o v \tau \alpha$, may be the earliest occurrence of the name Python for the serpent at Delphi. ${ }^{213}$ However, it is possible that Julian has simply made use of a name that was in common usage during his lifetime for the serpent at Delphi. ${ }^{214}$ Several later authors, including Apollodorus, ${ }^{215}$ Euripides, ${ }^{216}$ and Pausanias, ${ }^{217}$ use this male version of Python in their narratives. Authors such as Apollonius of Rhodes and Nonnus use the female version, which appears in fewer texts. ${ }^{218}$ Harrison explains this irregularity in the textual tradition as a way in which Python was transformed into a worthy opponent of Apollo. ${ }^{219}$ This claim is founded on the idea that the female version of the serpent occurs only when the serpent is associated with Gaea and the male is used in narratives involving the defeat of the serpent at the hands of Apollo. ${ }^{220}$ However, this idea has largely been disproven due to the fact that there is no consistency in the gender of the serpent and its association with Gaea. ${ }^{221}$ Thus it can be said that the gender of Python is not indicative of the role the serpent plays in the narrative as either a guardian or pestilence, or of its association with Gaea as Harrison argued. $^{222}$ The physical defeat of Python by Apollo is integral to the narratives detailing the founding of Apollo's oracle and temple at Delphi. The serpent stands as an example of the monstrous guardian snake. Much like the Ismenian Dragon and the Serpent of the Hesperides, Python comes into conflict with Apollo through the snake's role as a guardian. ${ }^{223}$ This is apparent from the earliest account in the

\footnotetext{
${ }^{211}$ Ap. Rhod. Argon. 2.703; for the sake of consistency and clarity I will refer to this serpent as Python.

${ }^{212}$ Simon. frag. 573 Campbell, ap, ps.-Jul. Epist. 24.

${ }^{213}$ Simon. frag. 573 Campbell, ap, ps.-Jul. Epist. 24; Fontenrose (1974) 15.

${ }^{214}$ Fontenrose (1974) 15.

${ }^{215}$ Apollod. Bibl. 1.22.

${ }^{216}$ Eur. IT. 1244-1251.

${ }^{217}$ Paus. 10.6.5.

${ }^{218}$ Ap. Rhod. Argon. 2.703ff.; Nonnus, Dion. 13.22ff.

${ }^{219}$ Harrison (1927) 429.

${ }^{220}$ Harrison (1927) 429.

${ }^{221}$ For example, Paus. 10.6.5 describes a male drakon guarding the oracle of Ge; Ov. Met. 1.434 claims Telleus (Gaea) is the mother of the male serpent; and the female comes into conflict with Apollo in Hom. Hymn Apol. 355-369.

${ }^{222}$ A more recent explanation for the discrepancies in the serpent's gender is given by Joseph Fontenrose, who argues that the male and female versions of the serpent at Delphi should be considered as two distinct creatures and the inconsistencies are indicative of a combining of two different narratives of Apollo's battles with these serpents; Fontenrose (1974) 465.

${ }^{223}$ As discussed in Chapter One.
} 
Homeric Hymn to Apollo down to later narratives such as that in Nonnus' Dionysiaca. As the gender of Python is so inconsistent in these narratives it can be said that the gender of the serpent does not affect the narrative. No matter the serpent's gender the narrative ends with the defeat of Python and the establishment of Apollo's temple and oracle. Thus it is the defeat of the guardian snake that is the focus of these narratives.

Apollo's defeat of the serpent at Delphi is rarely seen in surviving works of art; of those that survive only three include a depiction of a beard. ${ }^{224}$ One such image of a bearded Python appears on a lost Apulian neck-amphora (fig. 52), another debated representation of a bearded Python can be seen on a Lakonian kylix attributed to the Rider Painter, ca. 550 BC (fig. 53). ${ }^{225}$ The lost amphora depicts Leto carrying her two small children while fleeing from the monstrously large Python. The beard of Python consists of a series of four lines of various lengths. This style of beard differs from many of those previously discussed, which generally consisted of a single solid grouping of hairs terminating in a point. This is due to the general differences in the artistic style of Apulian vases from those of Attic origins. In contrast, the beards on the snakes on the Rider Painter kylix are consistent with the common Lakonian style of serpent beard as it has a thick, globular appearance. Unlike the Python on the lost amphora, who is identified through the presence of Apollo, Artemis, and Leto, this serpent has no such clearly identifiable features. The kylix features two large bearded serpents, one coiled around a column at the front of what is likely to be a temple or shrine, the other is located on the back of this building. The snake coiled around the column is attacking or being attacked by a warrior armed with a hoplite shield and spear. It is this serpent that has been suggested to be a representation of Python due to its interaction with the human figure of the scene. ${ }^{226}$ A large part of the reasoning behind identifying this as a depiction of Apollo and Python is the inclusion of ravens, sacred birds of Apollo, on the roof of the temple. ${ }^{227}$ As these birds are considered to be the birds of prophecy it would seem appropriate to find them represented in a scene

\footnotetext{
${ }^{224}$ LIMC Apollon 995 and 1001c which features the scene on a coin and as such the identification of the beard is uncertain. The other being the Rider Painter kylix (fig. 53).

${ }^{225}$ For the purposes of this discussion I will refer to this potential Python as Python. Representations of a bearded Python also appear in two Etruscan and one Roman depiction of the narrative of Apollo/Aplu's defeat of Python at Delphi, LIMC Aplu 11, 14, and Apollon 1001c. However, this mirror, gem, and coin are beyond the limits of this thesis and as such, will not be discussed in detail.

${ }^{226}$ Pipili (1987) 50.

${ }^{227}$ Pipili (1987) 51, these birds sacred to Apollo are used in depictions of Achilleus' ambush of Troilos in order to set the scene within the sanctuary of Apollo Thymbraios.
} 
of the founding of Apollo's oracle. ${ }^{228}$ However, as these birds are commonly found on Lakonian kylikes they are by no means an indisputable identifying feature of the scene. Another complicating factor is the inclusion of multiple serpents and the male's armour, which are not consistent with either the literary or limited artistic tradition of Apollo's defeat of Python. ${ }^{229}$ It is the fact that this kylix was found in a sanctuary where Apollo was worshipped that provides the strongest suggestion that this is a representation of the god's defeat of Python, albeit a lesser known variant of the narrative. ${ }^{230}$

In both of the above examples, it is impossible to know for certain if the artist is depicting a male or female serpent. As the gender of Python is inconsistent across the literary narratives, it is possible that the beard is intended in the manner proposed by Aelian. It may identify the serpent in these particular depictions of Python as male, while those that are not bearded are implied to be either female or an unspecified gender. ${ }^{231}$ However, this interpretation would suggest that the artist has placed significant emphasis on the serpent's gender, even though it does not appear to be of primary importance to the majority of the written narratives, as indicated by its irregularity. As discussed above, it is Apollo's defeat of the serpent that is given the greatest significance in the mythological narratives. Thus there is no particular reason for a masculine serpent to be given preference over a female. The only instance when a gender is given preference is when the narrative includes Python's raising of Typhoeus, as in the Homeric Hymn to Apollo. The hymn claims that Python raised Typhoeus at the request of Hera, deliberately connecting the female serpent with the last great threat to Zeus and his reign. ${ }^{232}$ It is this detail in the hymn that suggests that, at least in this particular narrative, the gender of the serpent may be of importance. Python and Typhoeus are connected only through her raising of Typhoeus, an act that is reliant upon Python being a female serpent. ${ }^{233}$ Thus, the gender of the serpent at Delphi can only truly be said to be of narrative importance in sources that include such a connection with Typhoeus and the serpent in the role of a nurse. As scenes

\footnotetext{
${ }^{228}$ Pipili (1987) 51.

${ }^{229}$ An alternate interpretation of the scene is that it depicts the slaying of the Ismenian Dragon by Kadmos, however, the scene is also inconsistent with the tradition that commonly shows Kadmos as a traveller, not a warrior. Pipili (1987) 50-51.

${ }^{230}$ Pipili (1987) 51.

${ }^{231}$ Depictions of a non-bearded Python include LIMC Apollon 993, 998, and 1000.

${ }^{232}$ Hom. Hymn Apol. 353-354; Yasumura (2011) 121.

${ }^{233}$ Yasumura (2011) 121.
} 
such as those on the lost Apulian neck-amphora and the Rider Painter kylix include no suggestion of a connection with Typhoeus, an interpretation beyond Aelian's assertion must be considered. In this context the beard indicates that this serpent is not an ordinary snake. Essentially, as the beard is a human feature it implies that this is a creature of myth, not reality. It characterizes Python as a clearly mythological creature that stands outside of the conventions of society and reality. Because of this it can imply the wild or uncivilized nature of the serpent, much like the unkempt beard of the barbaric Antaios on the Euphronios calyx-krater discussed in Chapter One. The beard causes Python to be aligned, in iconographic terms, with those who stand against the Greeks and those who appear as threats to Greek society as well as with the guardian serpents that exist throughout Greek myth. This is perhaps portrayed nowhere better than in the myth of Apollo's defeat of Python. This myth, in its barest form, tells of the defeat of a powerful female representative of an older divine order that is closely associated with nature and the wild, who stands as a protector of this old order, in much the same way as Athena appears as a protector of the new Olympian order. ${ }^{234}$ Apollo serves as one of the clearest representations of the Greek ideal and the civilizing force that comes with the patriarchy of Zeus. He is the embodiment of the aristoi; he defeats the old and the wild to make way for his father. It is through the addition of the beard that the duality of this mythological serpent is explicated. Python is the wild and threatening guardian, no matter the gender of the snake. The beard serves as a marker of this mythological status as it is not a naturally occurring feature of snakes.

Unlike the inconsistent gender of Python, the Lernaean Hydra is consistently referred to as feminine from its earliest mention in Hesiod's Theogony. ${ }^{235}$ In contrast to many of the mythological pure serpents, such as the Serpent of Colchis and the Ismenian Dragon, the Hydra does not fulfill the common role of a protector or guardian. Instead, Hera raised the child of Echidna and Typhoeus for the sole purpose of being a dangerous opponent to Herakles. ${ }^{236}$ This causes the Hydra to fulfill a different function from both the pure guardian serpents and the female figures discussed above. This is reflected in the physical difference between the appearance of the Hydra and the pure guardian serpents such as Python. The Hydra generally

\footnotetext{
${ }^{234}$ Fontenrose (1974) 473.

${ }^{235}$ Hes. Theog. 313; see further Gantz (1993) 384.

${ }^{236}$ Hes. Theog. 314-315; see further Gantz (1993) 384.
} 
appears as a collection of individual serpents that are joined together in one body with one or two thick tails, as on a stamnos attributed to the Geras Painter (fig. 16). ${ }^{237}$ In this instance the Hydra is shown with a single thick tail that forms the majority of the creature's body and splits into two small points near its end. However, the Hydra cannot be considered to be a serpent hybrid to the same extent as creatures such as the Chimaira and Kerberos, as such hybrids feature more minimal serpentine aspects. ${ }^{238}$ The Hydra largely consists of serpentine features and is not a conglomeration of assorted animal features, therefore I consider the creature to be closer to pure serpents than to hybrids. The serpent forms the fundamental attribute of the Hydra, albeit as a collection of serpents rather than a single snake.

The Hydra is one of the mythological snakes that is most consistently shown bearded. ${ }^{239}$ In instances when the Hydra is shown with a beard, it will be added to each of the creature's various heads. The exception to this is when some of the heads are shown in a bird's-eye perspective, rather than in profile. ${ }^{240}$ This use of beards only on profile heads can be seen on the Geras Painter stamnos (fig. 16). Of the nine heads of the Hydra in this piece, five have visible beards while the remaining four are shown in bird's-eye perspective and thus have no visible beard. The use of beards on all of the Hydra's heads can be seen on an amphora attributed to the Swing Painter (ca. 550$500 \mathrm{BC}$ ), which also presents the Hydra with nine heads (fig. 54). The difference between this piece and that of the Geras Painter is that each of the nine heads on the Swing Painter amphora are shown in profile and have visible beards. This use of beards on all of the Hydra's heads suggests that artistically no distinction is being made between the creature's mortal heads and its immortal central head. This is not surprising considering that the literary version in which an immortal head is buried after Herakles discovers he is unable to kill it appears to be a variation on this myth that first appears in Apollodorus. ${ }^{241}$ As the Hydra does not function as a guardian the beard cannot be seen to imply duality to the same extent as with the other figures discussed throughout this chapter. In the context of the Hydra the beards of the creature's many heads serve to emphasize its nature as a wild and dangerous

\footnotetext{
${ }^{237}$ Also LIMC Herakles 1992, 1993, 1995, 1997, 1998, 2003, 2004, 2006, 2007, 2008, 2009, 2012 , 2013, 2015, 2016, 2030, 2033, 2037.

${ }^{238}$ Both pure and hybrid serpents will be discussed further in Chapter Three.

${ }^{239}$ As on LIMC Herakles: 2003, 2007, 2013, 2015, 2016, 2038, and 2033.

${ }^{240}$ As such heads are shown essentially from above it is impossible to depict a beard under the creature's chin.

${ }^{241}$ Apollod. Bibl. 2.5.2; Gantz (1993) 384-385; Fontenrose (1974) 356; Stafford (2012) 34.
} 
mythological creature. The Hydra was a creature who, much like Medusa, was deadly to any who came into contact with her. ${ }^{242}$ The Hydra exists in the wild swamplands surrounding Lerna. Thus the creature appears to live on the boundaries of society, once again in a similar manner to Medusa. The beards mark out an unusual creature which can exist only in the realm of mythology. As a wild and untamed creature, the Hydra is defeated by the civilizing force that is Herakles. ${ }^{243}$ His labours can be seen as the defeat of monsters emblematic of the dangers of the wild by a figure who is the epitome of the Greek hero and is seen as representative of Greek civilization. The Hydra stands as a threatening creature not because it blurs the boundaries of gender, as Medusa does, nor because it possesses the duality of a guardian serpent like Python, but because it transgresses the limits of humanity and civilization as it presents the viewer with a wild animalistic creature, which possesses one small human attribute.

\section{Conclusion}

Aelian's explanation of the bearded serpent focuses solely on the generalized idea that the beard, as a masculine attribute, identifies male snakes. While the beard is indeed traditionally a masculine emblem, this explanation does not take into consideration the various contexts in which the beard is used. This chapter has addressed just four examples of the use of the bearded snake in a female context, be it in association with powerful females such as Medusa and Athena, or bearded snakes that are themselves female such as Python and the Lernaean Hydra. In this context the addition of the beard distinguishes these serpents from the ordinary snake, showing them to be creatures that exist purely in the realm of myth. When used in association with a female goddess, such as Athena, or humanoid monster, like Medusa, the beard implies that the associated figure is a woman who transgresses the boundaries of her gender. For Athena this reflects her masculine strength in battle, for Medusa, her subversion of the masculine virtue of control. Athena and Medusa can also be seen as protective figures, albeit in different ways. Where Athena defends and protects the

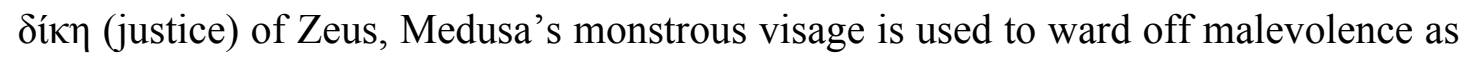
an apotropaic device. For these women their protective roles are dependent upon their

\footnotetext{
${ }^{242}$ Fontenrose (1974) 365

${ }^{243}$ Slater (2014) 388.
} 
blurring of gender indicated by the inclusion of bearded snakes. Python can also be seen to take on a similarly protective role as the guardian of an oracular shrine at Delphi. For this pure serpent the addition of the beard is less about an indicator of an amalgam of genders. Instead it suggests the dual nature of the guardian snake who can be at once both threatening and protective. The Lernaean Hydra is the anomaly among this selection of female serpents and hybrid serpents. This is due to the fact that this creature does not function in the role of a guardian as the others do. Instead the Hydra stands as a threating and wild creature. When used in this context the beard is seen more to imply her nature as a wild and dangerous creature. This is also apparent in depictions of Medusa, where the hybridity of her appearance serves to emphasize her threatening nature as a creature of dichotomies. While Aelian is not incorrect in believing there to be a correlation between masculinity and the beard of the snake, he has over-simplified his interpretation. In order to best understand the meaning of the bearded snake various contexts need to be considered. In the context of female snakes and associated figures the beard is used in order to imply the threatening and hybrid nature of these powerful mythological women. 
Chapter 3:

Anthropomorphism and the Identifier of Divinity or Monstrosity

Jane Harrison provided an explanation for the serpent's beard in her 1903 book, Prolegomena to the Study of Greek Religion. Harrison claimed that the beard was "mainly due to frank anthropomorphism". ${ }^{244}$ Where ideas based on Aelian's interpretation focus on the beard as an attribute of gender, this explanation considers the beard more generally to be a human attribute. The flaw in such an interpretation is that discussion is often limited in its scope. This is particularly evident in Harrison's supporting evidence, which is significantly limited due to the period in which she conducted her research. Harrison only considers the bearded snake in the context of anguiform deities, or those snakes directly associated with cult figures. While the anthropomorphic nature of the beard cannot, and should not, be disregarded, the varied contexts of the bearded snake should be considered in greater detail.

\section{Anguiform Deities and Heroes}

The anguiform Zeus Meilichios is central to Harrison's discussion on the meaning of the bearded snake. ${ }^{245}$ This particular form of Zeus is commonly presented in one of two ways. On several votive reliefs he is presented as a mature bearded man, seated on a throne, with a coiled serpent positioned nearby. ${ }^{246}$ The more common means of depicting Zeus Meilichios is as a monstrously large, coiled serpent, as on a votive relief currently housed in the Staatliche Museum, Berlin (fig. 55). ${ }^{247}$ This relief is one of a series of ten votive reliefs found near the Piraeus that show Zeus Meilichios in both human and serpentine forms. ${ }^{248}$ When shown as an anguiform the large size of the serpent form is implied through the composition of the relief, in which the serpentine Zeus Meilichios fills the entire height of the relief as in figure $55 .^{249}$ The scale of the serpent remains the same when worshippers are included in the scene, as can be seen on a relief housed in Athens (fig. 56). In such reliefs the snake

\footnotetext{
${ }^{244}$ Harrison (1903) 328.

${ }^{245}$ Harrison (1903) 328-329.

${ }^{246}$ Lalonde (2006) 46.

${ }^{247}$ Lalonde (2006) 46; this relief will be referred to as the Berlin relief for the remainder of this discussion.

${ }^{248}$ Ogden (2013) 273.

${ }^{249}$ Lalonde (2006) 46.
} 
towers over the approaching figures who fill less than half the height of the relief. The scale of Zeus Meilichios compared to that of the human figures, shows him to be the focus of their worship. The addition of a small beard to these anguiform depictions appears to be a relatively consistent feature of this series of votives. ${ }^{250}$ Eight of these ten reliefs show Zeus Meilichios in the form of a serpent, either alone or with worshippers, complete with a beard. ${ }^{251}$ The remaining two reliefs depict Zeus Meilichios in his human form, enthroned with a serpent nearby. ${ }^{252}$

The beard on the anguiform Zeus Meilichios, particularly as it appears on the Berlin relief (fig. 55), has received attention from the likes of Jane Harrison and Laurent Gourmelen. ${ }^{253}$ Harrison rationalizes the addition of the beard by claiming it has a foundation in reality. The crux of her argument is the identification of the type of serpent she believes these depictions of an anguiform Zeus Meilichios are based on. ${ }^{254}$ With the help of Dr. Hans Gadow, Harrison identifies the serpent as the coelopeltis lacertina, more commonly known as the Montpellier snake (Malpolon monspessulanus monspessulanus) (fig. 58). ${ }^{255}$ Harrison gives only a very brief explanation for the connection between the appearance of the anguiform Zeus Meilichios and the Montpellier snake. ${ }^{256}$ She appears to draw largely on the similarities in the shape of the head, claiming that the head of Zeus Meilichios has a depression at the top similar to the Montpellier snake. ${ }^{257}$ This causes the head to appear flatter and more lizard-like. ${ }^{258}$ As the head of the snake on the Berlin relief is shown in profile, it is impossible to tell if such a depression is indeed a part of this snake's skull shape. No further reasoning for the identification is given, therefore I find it difficult to believe that the basic image of a serpent portrayed on the Berlin relief can be seen as an accurate representation of the Montpellier snake. ${ }^{259}$ However, this identification forms the basis for Harrison's interpretation of the origin of the

\footnotetext{
${ }^{250}$ Cook (1940) 1107.

251 Ogden (2013) 273.

252 Harrison (1903) 328.

${ }^{253}$ Gourmelen (2012) builds on Harrison's 1903 discussion on the interpretation of the addition of the beard.

${ }^{254}$ Harrison (1903) 328.

${ }^{255}$ Harrison (1903) 328.

${ }^{256}$ Harrison (1903) 328; this identification appears to have been made through private correspondence with Dr. Gadow, as such, Harrison provides only minimal details. Dr. Gadow makes no mention of this connection in his own ornithological works.

${ }^{257}$ Harrison (1903) 328.

${ }^{258}$ Harrison (1903) 328.

${ }^{259}$ Lalonde (2006) 46 n. 31 discredits Harrison's explanation for the natural origins of the bearded snake, stating that the argument is unconvincing.
} 
serpent's beard. This interpretation is based on the observation that the fangs of the Montpellier snake are positioned far back in the snake's mouth, as opposed to the more common position towards the front of the mouth (fig. 59). Due to this positioning of the fangs, the Montpellier snake has to drop its lower jaw significantly further in order for its fangs to be of use. It is this dropped jaw that Harrison sees reflected in the beard of Zeus Meilichios, claiming that the angle created by the dropped jaw is the same as that created by the addition of the beard. ${ }^{260}$ Harrison expands on this idea and claims that the beard was originally developed from a misinterpretation of a representation of a snake with this dropped jaw, or an artist had seen the jaw from a distance, which Harrison claims would have seemed suggestive of a beard. ${ }^{261}$ It is from such an ancient misinterpretation of reality, Harrison believes, that the representations of bearded snakes developed and eventually became an anthropomorphic symbol in their own right.

Such an interpretation of the origin of the beard is difficult to accept as it presupposes the positioning of the beard to be consistent across all the depictions of Zeus Meilichios. In fact the size, angle, and even shape of the beard vary slightly across the depictions. The beard shown on representations of Zeus Meilichios can be the simple small point that is common on sculpted examples of the beard, as can be seen on the Berlin relief (fig. 55). Alternatively, it may be a significantly more defined, larger beard, as on NM 3329, in the National Archaeological Museum in Athens (fig. 56). Mitropoulou describes this particular type of beard as "goat-like", implying its bushy appearance. ${ }^{262}$ Yet another type stands between these two in terms of size and definition. This third type can be seen on NM 1434, also in the National Archaeological Museum (fig. 57). On this snake the beard is neither as clearly defined as hair as that on NM 3329, nor as thin as that on the Berlin relief. This shows that much like other depictions of bearded snakes, there is no consistency in the way in which the beard is portrayed on these reliefs of Zeus Meilichios. Another flaw in Harrison's argument of the origin of the motif is her use of relatively late examples of depictions of bearded snakes. This was due to the limited sources available to her during the early twentieth century. The majority of the reliefs depicting Zeus

\footnotetext{
${ }^{260}$ Harrison (1903) 328-9.

${ }^{261}$ Harrison (1903) 329.

${ }^{262}$ Mitropoulou (1977) 113.
} 
Meilichios in the form of a snake date to the first half of the fourth century. ${ }^{263}$ This is significantly later than the earliest surviving images of the bearded snake, which date from the middle of the seventh century. ${ }^{264}$ The earliest example of a bearded snake known to us today, the Eleusis amphora, was unknown to Harrison as it was discovered during the 1954 excavation at Eleusis, some 26 years after Harrison's death. $^{265}$ These earlier bearded snakes differ from the bearded Zeus Meilichios both in terms of context and appearance. There is little reason to suggest that the depictions of Zeus Meilichios cited by Harrison serve as the connection between the reality of the Montpellier snake and the origins of the iconographic scheme of the bearded snake. The unique ways in which artists present these snakes suggests that there is no single 'original' real snake that is the basis of the iconographic scheme of the snake, with or without the beard.

Gourmelen builds on Harrison's interpretation of the beard as an indicator of a specific species of serpent and a reflection of a real feature of the Montpellier snake. In order to do so, the motif is considered in a slightly broader context. Where Harrison attempts to explain the use of the beard on specific representations of Zeus Meilichios, Gourmelen uses such images as supporting evidence for his explanation of the beard in the context of divine or mythical figures as a whole. Gourmelen claims that the dropped jaw or the positioning of the fangs of the Montpellier snake or a similar snake may have inspired the beard, but it should not be seen as a misinterpretation of reality, as Harrison claims. ${ }^{266}$ Instead, the beard should be seen as an adaption of reality that serves a symbolic rather than functional purpose. ${ }^{267}$ The beard can therefore be seen as an intentional addition to the motif of the snake, used to denote certain deities or mythological figures. In this interpretation the beard serves to emphasize the character of such figures by indicating their ambivalent or dual nature. ${ }^{268}$ This is particularly appropriate for Zeus Meilichios who is characterized by his nature as a chthonic deity who upholds social norms and has the ability to bring prosperity to his worshippers. ${ }^{269}$ Even his name has been suggested to be reflective of this dual nature. As a chthonic deity his epithet $\mu \varepsilon \imath \lambda i ́ \chi 10 \varsigma$ seems to be a euphemistic

\footnotetext{
${ }^{263}$ Mitropoulou (1977) 149.

${ }^{264}$ Such as those on the Eleusis amphora, as discussed in Chapter Two.

${ }^{265}$ Mylonas (1955) 62-63.

${ }^{266}$ Gourmelen (2012) 339.

${ }^{267}$ Gourmelen (2012) 339.

${ }^{268}$ Gourmelen (2012) 339.

${ }^{269}$ Larson (2007) 22; Ogden (2013) 278; Lalonde (2006) 46-47.
} 
name, through which his worshippers are able to express their desire for him to be propitious. ${ }^{270}$ The snake itself, through its connections with the underworld and the dead, presents Zeus Meilichios as a potentially frightening or threatening creature. Through this idea of the beard marking a dual natured divinity Gourmelen builds some support for Harrison's choice of the Montpellier snake. If the beard is viewed as a stylized representation of this particular snake's fangs, as Harrison suggested, it may be seen as an allusion to the extent to which the snake would have to open its mouth in order for its bite to have any effect. ${ }^{271}$ This reference to the small fangs and the open mouth of the Montpellier snake implies that the snake is positioned in such a way that it is poised to bite. ${ }^{272}$ Such a threatening pose is countered by the implication of such small fangs positioned near the back of the snake's mouth, which suggests the snake's inability to easily harm humans. ${ }^{273}$ This combination of the threatening pose and the ineffectual fangs implies the ambivalent nature of such anguiform deities, who can be at once both protective and dangerous. Essentially, the beard can be used to denote creatures of a dual character. ${ }^{274}$

However, even this idea seeks to explain the motif in a way that fails to account for the dissimilarities in the shape and size of the beard of the artistic depictions of the snake and the fangs of the Montpellier snake. When the two are compared side-by-side (figs. 59-60) these differences are compounded. The size of the beard is the most obvious difference. The beard is generally slightly longer than the width of the snake's head. This contrasts with the relatively small fangs of the Montpellier snake. Of course, such a size difference may be due to an emphasis being placed on the beard, which would cause the feature to vary from its natural inspiration. The shape of the serpent's beard is by no means consistent in each and every representation. The size and shagginess varies depending on the artist and the medium. Sculpted examples such as those on Zeus Meilichios tend to be simpler, creating the pointed shape Harrison argues to be symbolic of fangs. However, as discussed throughout this thesis, there are many examples of beards that are significantly larger and more detailed, such as the goat-like beard of Zeus Meilichios on NM 3329 (fig. 56), or the globular Lakonian beards from the mid to late sixth

\footnotetext{
${ }^{270}$ Larson (2007) 21; $\mu \varepsilon \imath \lambda i ́ \chi 10 \varsigma$ meaning "gentle", "mild”, "gracious", etc. suggests that worshippers hoped for such characteristics in Zeus Meilichios.

${ }^{271}$ Gourmelen (2012) 339.

${ }^{272}$ Gourmelen (2012) 339.

${ }^{273}$ Gourmelen (2012) 339.

${ }^{274}$ Gourmelen (2012) 337.
} 
century, as on the Rider Painter kylix showing the blinding of Polyphemos (fig. 8). These differences, apparent in both the examples cited by Harrison and in the earlier pieces unknown to her, lead me to believe the beard should not be considered an adapted representation of the fangs of the Montpellier snake. Rather, it should be perceived as an intentional depiction of a beard. This idea is further supported by depictions of beards on snakes that are not shown as simple pointed beards in the manner of that on Zeus Meilichios. ${ }^{275}$ An intentional depiction of a beard does not detract from the idea that it reflects the dual nature of the figure on which it appears. Instead, it causes the creature or deity to have aspects of both human and bestial anatomy, showing it to be a combination of the two. ${ }^{276}$ By viewing the beard in this manner it is possible to see its meaning in a wider context. When the beard is viewed as a reflection of a specific snake the explanation becomes intrinsically linked with one particular context due to the stylistic inconsistencies.

The use of a beard on representations of a serpentine Zeus reappears in significantly later works of literature. ${ }^{277}$ The bearded snakes in Nonnus' Dionysiaca provide the only surviving literary description of bearded anguiform deities that possess the ability to transform from human form into that of a serpent. In the epic there are two instances in which a bearded serpent appears, each at a crucial point of the narrative. Nonnus' epic focuses on a wholly mythological narrative, telling of the life of Dionysos, from his birth to his achievements when he reaches maturity. ${ }^{278}$ From the earliest point of the poem there is a clear association between Dionysos and animals. $^{279}$ This association is made apparent through the inclusion of two

\footnotetext{
${ }^{275}$ The several varieties of types of beards shown on snakes are discussed in the Introduction.

${ }^{276}$ Harrison (1903) 328 draws on this apparent transgression to claim that the beard is indicative of a divinity as, in her argument, the beard is a marker of a human and "human for the artist means divine". Such a connection is suitable for Zeus Meilichios as he is depicted in both human and serpentine forms, implying such a transgression from human to beast. However, such an interpretation relies on the idea that divinity must be equated with humanity, which is not always the case; Lalonde (2006) 46-47.

${ }^{277}$ These later works do not necessarily draw on the same influences as the sixth-fourth century BC depictions of bearded snakes in Greece. As bearded snakes also appear in both Etruscan and Roman art, as in the Tomb of the Blue Demons at Tarquinia (late fifth century BC) and the House of the Centenary at Pompeii (first century AD), it is likely that these later sources are drawing on such uses of the bearded snake which continue well after the motif ceases to be used in Greek art. These Etruscan and Roman examples of the bearded snake differ from the Greek in terms of the appearance of the beard. However, they continue to be used in the context of depictions of divinities, monsters, and cult practices.

${ }^{278}$ Shorrock (2001) 7; as expected in an epic this intention is outlined in the invocation of the muse in the opening lines of the poem Nonnus, Dion. 1.1-45.

279 The connection between Dionysos and snakes is attested through depictions of maenads bearing snakes. While the snake is not one of the common attributes of Dionysos himself, the connection with his female followers can be used to imply an association with Dionysiac revelry or other such themes,
} 
monstrously large, bearded snakes. ${ }^{280}$ Of the two snakes, that described in 6.155-168 appears as an alternate form of Zeus, who sneaks into Persephone's bedchamber and rapes her.

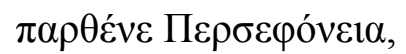

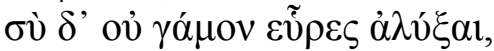

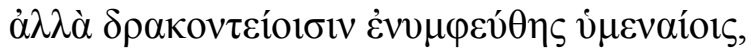

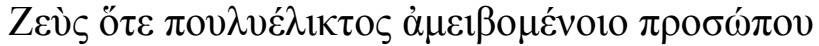

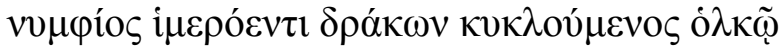

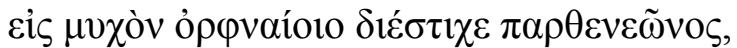

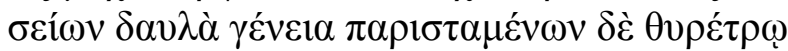

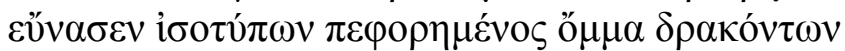

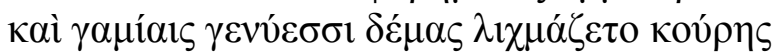

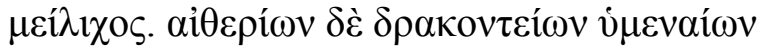

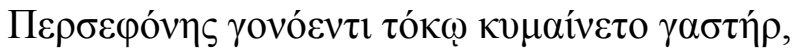

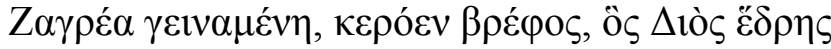

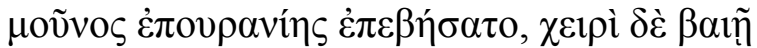

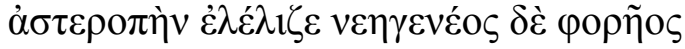

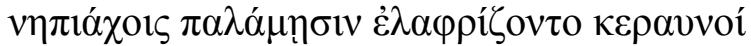

Ah, maiden Persephoneia! You could not find how to escape your mating! No, a dragon was your mate, when Zeus changed his face and came, rolling in many a loving coil through the dark to the corner of the maiden's chamber, and shaking his hairy chaps: he lulled to sleep as he crept the eyes of those creatures of his own shape who guarded the door. He licked the girl's form gently with wooing lips. By this marriage with the heavenly dragon, the womb of Persephone swelled with living fruit, and she bore Zagreus the horned baby, who by himself climbed upon the heavenly throne of Zeus and brandished lightning in his little hand, and newly born, lifted and carried thunderbolts in his tender fingers. ${ }^{281}$

This child of Zeus is considered to be the "chthonian Dionysos". ${ }^{282}$ By including Zagreus in this narrative Nonnus is retelling the Orphic myth of the birth of Dionysos. In the Orphic tradition Zagreus was believed to have been reborn as Dionysos after he was killed by the Titans. ${ }^{283}$ This chthonic association reflects both the nature of his mother, Persephone, as well as the form taken by Zeus at the time of his conception. This particular version of the conception of Zagreus also features serpents in their expected role as guardians. In order to protect Persephone from a prophecy that stated

thus connecting snakes with the powers of the god. Austin (2010) 93; Carpenter (2007) 415; LIMC Mainades 7, 27, 35, 36, 38, 116; LIMC Dionysos 311, 314, 325, 451 869; Dionysos himself is associated with snakes in LIMC Dionysos 470 (holding a snake), 614 and 620 (associated snake attacks a Giant), and 830 (possible theatrical parody of Jason's retrieval of the Golden Fleece).

${ }^{280}$ Nonnus, Dion. 6.155-168, 12.319-323.

${ }^{281}$ Nonnus, Dion. 6.155-168.

${ }^{282}$ Cook (1914) 398.

${ }^{283}$ Cook (1914) 398. 
she would be seduced by a half-monster (a prophecy that is fulfilled by the anguiform Zeus), Demeter hid her away in a cave and placed two snakes outside to guard the cave from any intruders. ${ }^{284}$ By taking the form of a monstrous snake Zeus is able to usurp this role of the guardian snakes and slip past them in order to fulfill the prophecy. The one difference between Zeus, as he appears in the form of a snake, and the guardian serpents is the beard. Zeus is the only serpent in this passage to be described with this human feature, clearly differentiating him from those that are fulfilling their traditional role by guarding the cave in which Persephone is hidden.

The second bearded snake described in the Dionysiaca does not strictly appear as an alternate form of a divinity and thus cannot be considered to be a true anguiform. This snake is instead closely associated with the etiology of wine and the resurrection of Ampelus in book 12. ${ }^{285}$ The bearded snake makes its appearance in the second of two narratives explaining Dionysos' discovery of wine. ${ }^{286}$ This second narrative is said to be the older of the two, popularized by poets in their attempts to describe the origin of wine. ${ }^{287}$ The grape vine in this narrative originates as a drop of ichor that fell from Olympos; Dionysos then discovers this divine vine after witnessing a large bearded snake drinking the juice from the grapes on the vine. ${ }^{288}$ As this passage serves as an etiology for wine the liquid is heavily emphasized as it trickles out of the creature's mouth and stains its beard with purple. ${ }^{289}$ The inclusion of the beard on this particular snake functions as a way to further emphasize the unusual and otherworldly nature of wine and the vineyard. It also provides a connection between the two narratives of Dionysos' discovery of wine. The anthropomorphic nature of the beard connects this serpent with the transformation of Ampelus from the previous narrative. Ampelus' transformed shape is initially likened to the form of a snake as he becomes the creeping vine, ${ }^{290}$ thus the beard of the second snake alludes to this initial tale of the transformation of Ampelus. By connecting the narratives in this way Nonnus effectively draws the character of Ampelus into the

\footnotetext{
${ }^{284}$ Nonnus, Dion. 6.90-144.

${ }^{285}$ Nonnus, Dion. 12.138-336.

286 The first of these two narratives claims the vine to be the resurrected form of Dionysos' lover Ampelus, Nonnus, Dion. 138-291. This narrative connects the close association between Dionysos and wine with the love he felt for Ampelus as it effectively replaces his lost love in the fact that it will always be with him. Shorrock (2005) 375.

${ }^{287}$ Nonnus, Dion. 12.292-293.

${ }^{288}$ Nonnus, Dion. 12.293-323.

${ }^{289}$ Nonnus, Dion. 12.322-323.

${ }^{290}$ Nonnus, Dion. 12.174-176.
} 
second, older narrative. Throughout the remainder of the epic the transformative nature of wine is emphasized, it is something that gives comfort and pleasure as well as being an instigator of wild abandon. ${ }^{291}$ It is a transformative liquid, as is made apparent from its very creation.

The addition of the beard to these select snakes in the Dionysiaca serves to emphasize the themes of chaos and disorder apparent throughout the epic. ${ }^{292}$ These themes are expressed through both the structure and the content. The seeming lack of structure in the narrative and the "stream-of-consciousness" style employed by Nonnus serves to emphasize the disorder of the world described by the poet. ${ }^{293}$ The frequent metamorphoses and the ever-changing gender roles that occur in the Dionysiaca are the narrative devices that strengthen this theme of disorder as they show that not even the norms of gender and humanity can be relied upon in the world crafted by Nonnus. This fluidity of expected gender roles is often seen in the form of the male taking on the roles of a woman, particularly in regards to childbirth or childrearing. ${ }^{294}$ This disrupted sense of reality is again expressed through the combining of animal and human features on the bearded snakes. It emphasizes the confusion of expectations, particularly as it is used in association with an alternate form of Zeus. ${ }^{295}$ Within the narrative of the Dionysiaca Zeus is seen to cross the traditional boundaries of both gender and humanity. Zeus appears in both the roles of man and woman, as well as being presented in anthropomorphic and animal forms at various points of the epic. ${ }^{296}$ It is through the addition of the beard that Nonnus aligns the snakes in books six and twelve with such transformative gods. These two snakes appear at crucial points of the narrative of Dionysos' life, the conception of Zagreus and his discovery of wine. The appearance of such an unusual creature marks these as moments of importance, while also referencing the transformative powers of gods such as Zeus, who are able to pass beyond the construct of a human appearance due to their divinity.

\footnotetext{
${ }^{291}$ Shorrock (2005) 375.

${ }^{292}$ Newbold (1984) 91.

${ }^{293}$ Newbold (1999)37-38.

${ }^{294}$ Newbold (1984) 91.

${ }^{295}$ Also, to a lesser extent with the bearded snake that appears in association with Dionysos in Nonnus, Dion. 12.292-323.

${ }^{296}$ Zeus takes on a more feminine role in Nonnus, Dion. $1.5-10$ by birthing both Dionysos and Athena; 1.46-50: Zeus takes the form of a bull to abduct Europa; 25.429-441: abducting of Ganymede with Zeus taking the form of an eagle; 5.568-569 and 6.155-161: seducing Persephone in the form of a snake. These are just several of the forms Zeus takes throughout the Dionysiaca; Cavero (2009) 573.
} 
This use of the beard as a means to show a connection between the serpent and the divine may also be seen in the so-called Lakonian hero reliefs, exemplified by the Chrysapha relief (fig. 24). If the seated figures depicted on these reliefs are interpreted as figures of local importance, worshipped as local cult heroes, ${ }^{297}$ the addition of the beard to the associated snake may be seen as a marker of their status as heroes or divinities. In contrast to Harrison's assertion that the bearded snake should be seen as a representation of the physical incarnation of the deceased hero, ${ }^{298}$ more recent scholarship has considered the serpent to more broadly evoke an association with guardianship and death. ${ }^{299}$ This sees the serpent functioning once again in its common mythological role as a guardian or protector, a role which extends outside of mythology to the serpent's protection of the deceased and their tombs. ${ }^{300}$ Eleanor Guralnick considers the addition of the beard to the snake to be an indicator of the divinity of the two seated figures of the Chrysapha relief and other such reliefs. ${ }^{301}$ In order to make this connection and suggest a precedence for this motif, Guralnick draws on similarities in the composition and style of this series of reliefs to Egyptian stelae, which feature a similar motif of a seated figure flanked by a large, sometimes bearded, serpent. ${ }^{302}$ Using this perceived precedence, Guralnick connects the bearded snake of the Lakonian compositions with that associated with Osiris, suggesting that it becomes a symbol of the divinity of the seated figures, as the bearded snake of Osiris evokes such a connection. ${ }^{303}$ While such a precedence is intriguing, it is not strictly necessary to make in order to show a connection between the bearded snake and divinity in a Greek context. The snake in Greece is a well-attested attribute of deities and their favored heroes. What this means is that the mere presence of the large snake may highlight the heroic or divine nature of the seated figures, as it would serve as a reminder of the role the snake plays in mythology, as an alternate form of certain gods and an attribute of others, as well as the snake's role as the protector of sacred objects and places, and their position as an opponent to heroes. ${ }^{304}$ In such an interpretation of the snake the addition of the beard further emphasizes its nature as a creature of myth,

\footnotetext{
${ }^{297}$ As discussed in Chapter One.

${ }^{298}$ Harrison (1903) 328; the connection between serpents and reincarnated heroes is discussed in Chapter One.

${ }^{299}$ Guralnick (1974) 183; Salapata (2006) 550-551.

${ }^{300}$ As discussed in Chapter One.

${ }^{301}$ Guralnick (1974) 184.

${ }^{302}$ Guralnick (1974) passim .

${ }^{303}$ Guralnick (1974) 184.

${ }^{304}$ Salapata (2006) 552.
} 
associated with heroes and gods. The beard causes it to be seen as a creature that cannot exist in reality, thus it must belong to the realm of myth, implying that the figures with which it is depicted must also exist beyond the normal mortal world. Thus the snake in the Lakonian hero reliefs aids in identifying the seated figures, albeit rather broadly, as heroic or divine figures. This is not done, as Harrison suggests, by viewing the serpent as an incarnation of the deceased. Rather, by considering the bearded snake in its traditional role as a mythological guardian and opponent of heroes, the heroic nature of the seated figures is implied. Essentially, this means that the bearded snake that appears in the Lakonian hero reliefs can be seen in similar terms to the monstrous mythological bearded snakes, such as the Serpent of Colchis on the Douris kylix (fig. 10a), and the snakes that often appear on the shields of heroes, as on the Victoria University of Wellington Leagros Group krater (fig. 14a). In such contexts the beard does not connect the snake with a specific divinity. Rather it marks the snake as something beyond the ordinary, a creature based in myth and legend that stands as either protector or opponent of heroes and gods.

\section{Monstrous Hybrids}

While the beards of anguiforms such as Zeus Meilichios can be seen as representative of their ability to transform, as Harrison suggests, the same cannot be said for the numerous monstrous serpents which are also shown with beards. These monstrous serpents can be pure serpents, meaning those creatures that are shown as entirely serpentine, or serpent hybrid creatures. The hybrids are often shown with a serpent as a small part of their anatomy, as on the Chimaira, who has a snake as its tail as seen on a Siana cup by the Heidelberg Painter (fig. 61), and Kerberos, who is shown with serpents attached to various points of his body, as on the Hunt Painter kylix (fig. 13). ${ }^{305}$ These monstrous serpents frequently come into conflict with both heroes and gods. ${ }^{306}$ As these monstrous serpents do not have an alternate human form, the beard cannot be considered to be an anthropomorphic attribute to the same extent as it is in the context of anguiform deities. A significant difference between pure

\footnotetext{
${ }^{305}$ Unlike this Lakonian example which shows Kerberos with serpents encompassing his body, Attic examples often show a snake only in place of his tail. As on LIMC Herakles 2554, 2556, 2571, 2588. This tail snake is shown on Attic examples with a beard in LIMC Herakles 2595, 2603, 2614, and LIMC Kerberos 15.

${ }^{306}$ As I have discussed the roles of such monstrous snakes in Chapter One, this discussion will focus on the general interpretation of the beard on such creatures.
} 
serpents and serpent hybrids, aside from their appearance, is the way in which they are brought into conflict with the hero. The pure serpents serve as divinely appointed guardians and protectors of the sacred. This can be seen in the likes of the Serpent of the Hesperides (fig. 5), the Serpent of Colchis (fig. 62), and the Ismenian Dragon (fig. 63). These serpents guard the object of the hero's quest and thus must be defeated in order for him to achieve the aim of his journey. In contrast to these pure serpents, the serpent hybrids function more as the object of the hero's quest, as is the case with Kerberos, who is taken from the underworld for Herakles' twelfth labour. ${ }^{307}$ It is in this way that the serpent hybrid is most often brought into conflict with the hero.

As the pure serpents appear as the threatening opponents to heroes as a direct result of their roles as guardians, these serpents function in a role that is defined by its duality. For example, Herakles comes into conflict with the Serpent of the Hesperides only because he is attempting to remove the apples from the garden Ladon protects. ${ }^{308}$ The Ismenian Dragon protects the spring of Ares, from which Kadmos attempts to remove water, bringing him into conflict with the monstrous guardian of the spring. ${ }^{309}$ A specific deity appoints these guardian serpents to protect either an object or location of special or sacred importance, i.e. Ares appoints the Ismenian Dragon to guard the spring from which no one was permitted to draw water. ${ }^{310}$ In this context the inclusion of a beard serves as a means through which the ambivalent or dual nature of such serpents is represented. It shows the serpent to be monstrous and threatening as it is something beyond the ordinary, while also implying the creature's connection to the divine. Essentially, the beard shows the serpent to be of two natures. They can be threatening and dangerous, as well as protective. These natures are not distinct from each other. Rather they are two sides of the same coin. These monstrous serpents are only dangerous because of their role as guardians. Through protecting their appointed object or location they become a threat to those who chose to cross them.

This dual or ambivalent nature is also true of the serpent hybrids, although it is expressed differently. These monstrous hybrids generally do not function in the role of a guardian or protector, which causes the pure serpents to be both protective and threatening. Instead the hybrids more commonly serve solely as rampaging beasts that

\footnotetext{
${ }^{307}$ Apollod. Bibl. 2.5.12; Hom. Od. 11.623-626; see further Gantz (1993) 413-416.

${ }^{308}$ Apollod. Bibl. 2.5.11; Ap. Rhod. Argon. 4.1396-1405; see further Gantz (1993) 410-413.

${ }^{309}$ Apollod. Bibl. 3.4.1; Paus. 9.10.5; see further Gantz (1993) 467-473.

${ }^{310}$ Ogden (2013) 166-167.
} 
must be defeated by heroes such as Bellerophon and Herakles. ${ }^{311}$ The Chimaira for example is consistently described as a frightening composite creature who serves no purpose beyond its role as a monster and its death at the hands of Bellerophon. ${ }^{312}$ Kerberos stands as an exception to this due to his role as the guardian of the entrance to the underworld. For Kerberos it is this protective role that brings him into conflict with Herakles. ${ }^{313}$ Kerberos is further distinguished from both pure serpents and serpent hybrids by the fact that he is not killed by Herakles. Instead he is returned to his position as the guardian of the underworld after Herakles has shown him to Eurystheus. ${ }^{314}$ In the context of these monstrous hybrids the addition of the beard to the creature's serpentine attribute serves to emphasize the creature's ambivalent nature as a hybrid. When the beard is depicted, as on the Heidelberg Painter cup (fig. 61 ), it is not a central feature of the creature, who in this case is the Chimaira. ${ }^{315}$ This is due to the fact that the serpent itself is not the main attribute of the Chimaira. Rather, the serpent is just one aspect of the hybrid's monstrous appearance. The addition of the beard in such instances emphasizes the composite appearance of the hybrid. It further implies that such creatures are an amalgam of various different 'everyday' animals that, when compiled into one creature, become a dangerous and rampaging mythical beast. The ambivalence of their appearance lies in the fact that they are not one single creature, but a collection of various different animals. The beard is simply one more attribute that aids in creating the image of a monstrous hybrid. For both the pure serpents and the serpent hybrids the addition of the beard serves to distinguish them from snakes that occur in nature. It distinguishes such creatures as something that is beyond the ordinary, something that stands as an opponent of heroes, be it as a protector of the sacred or as a rampaging beast.

An alternate expression of this duality can be found in the bearded snakes described in Nicander's Theriaca (second century BC) and in the later Vita Apollonii by Philostratus (third century AD). ${ }^{316}$ Nicander's Theriaca details many types of real venomous creatures such as snakes and scorpions, along with the remedies for the

\footnotetext{
311 The Hyrda, as discussed in Chapter Two, can be seen to have a similar narrative function to these serpent hybrids.

${ }^{312}$ Hom. Il. 6.178-183; Hes. Theog. 319-324; Apollod. Bibl. 2.3.1; see further Gantz (1993) 23.

${ }^{313}$ Ogden (2013) 104.

${ }^{314}$ Apollod. Bibl. 2.5.12; see further Gantz (1993) 416.

${ }^{315}$ Also see LIMC Chimaira 3, 22, 25, 77a, 87, 108; Chimaira (in Etruria) 34, 35, 36, 39.

${ }^{316}$ Due to the late date of the Vita Apollonii it is likely that Philostratus, as with Nonnus, was more heavily influenced by the Roman use of the bearded snake motif than the Greek.
} 
poisons of such creatures. ${ }^{317}$ The inclusion of a bearded snake in this particular work may at first seem to imply that the bearded snake was a naturally occurring creature due to the Theriaca's apparent attempt to convey factual scientific observations and information. However, as a Hellenistic author, Nicander blends the scientific with the poetic. ${ }^{318}$ This is particularly evident in his descriptions of several remedies where the specific ingredients and measurements seem not to matter as much as would be expected of an accurate scientific work. ${ }^{319}$ Thus a certain degree of ambivalence is favoured over accuracy. It is possible to see Nicander's attempts as a poet to present his readers with a mixture of naturally occurring creatures and plants, and the fantastical and exotic items and creatures that appear throughout the Theriaca. ${ }^{320}$ The bearded snake stands out among the other various deadly snakes described by Nicander, not only due to its beard, but also because of its ineffectual bite.

$$
\begin{aligned}
& \text { ov̉ } \mu \dot{\varepsilon} v \text { ö } \gamma^{\prime} \alpha u ̛ \tau \omega \varsigma
\end{aligned}
$$

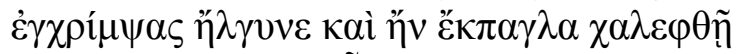

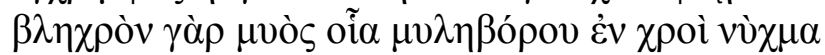

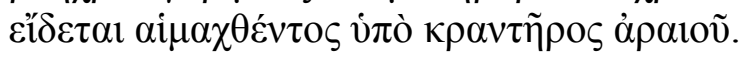

Yet when he fastens on a man he does not hurt as other snakes, even though his rage be violent, for the wound upon the skin of one whose blood is drawn by his slender fangs seems slight as that of a meal-nibbling mouse. ${ }^{321}$

This snake is unique among Nicander's serpents in terms of its abilities, nature, and appearance. It is described as possessing a "beard of yellow stain", ${ }^{322}$ and is directly connected to Пaióv (Paion), a cultic epithet of Apollo. ${ }^{323}$ This association with Apollo Paion emphasizes the dual nature of the snake. Much like the guardian snake, this serpent can be both threatening and protective. It threatens violence in its attempts to cause pain by biting, yet its connection to the god of healing implies the overcoming

\footnotetext{
${ }^{317}$ Gutzwiller (2007) 140 .

${ }^{318}$ Overduin (2009) 92.

${ }^{319}$ Overduin (2009) 83-84. Throughout the Theriaca Nicander claims that exotic or difficult to obtain

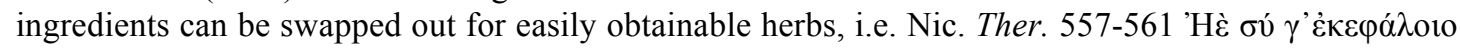

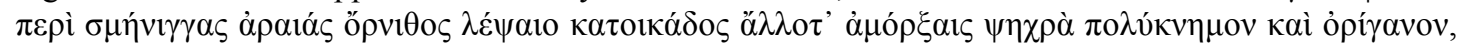

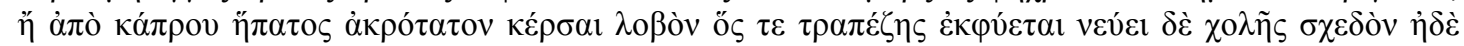
$\pi v \lambda \alpha \omega v$. "Or else you should peel off the thin membranes of the brain of a domestic fowl, or pare fine some field basil and marjoram, or cut from a boar's liver the tip of the lobe which grows from the table and inclines towards the gall-bladder and the portal fissure."

${ }^{320}$ Overduin (2009) 86.

${ }^{321}$ Nic. Ther. 444-447.

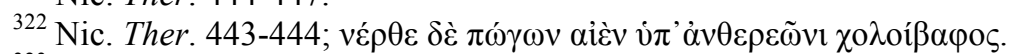

${ }^{323}$ Graf (2008) 67; this epithet is generally associated with Apollo in his role as a god of healing.
} 
of such pain. ${ }^{324}$ This reflects the nature of Apollo himself, as a god that can inflict and heal sickness. It is through this seemingly contradictory idea that this particular serpent is shown to possess a dual nature. It is a symbol of both the danger of a snake as well as of the healing of the bite from such a creature. This duality is further implied by the snake's inclusion alongside the more deadly snakes through which Nicander vividly describes the pains and death that can be caused by snakes in general. The bearded snake stands out in its association to Paion and its inability to cause such harm. By presenting this particular snake as bearded Nicander effectively distinguishes it physically from the ordinary snakes in the Theriaca. The beard shows this snake to be something different and more mythical, a role that is supported by the snake's association with a specific divinity. In this aspect the snake begins to more closely resemble the mythological pure serpents than the everyday snakes it is described alongside.

A less clear distinction between mythological and real snakes can be seen in Philostratus' Vita Apollonii, in which Philostratus describes two types of large bearded snakes that live in India. ${ }^{325}$ As these snakes have almost no clear connection with the divine or sacred it is implied that these are intended to be descriptions of real snakes. Philostratus claims that while in India Apollonius and his companions came across a snake hunt, during which they saw two types of snakes, both bearded and large enough to hunt elephants. ${ }^{326}$ These snakes are described as being able to grow to lengths of upwards of 30 cubits (approximately 18.5 meters). ${ }^{327}$ There is no credible evidence to suggest that a snake of this size ever existed in India. The largest modern snake in the region is the Indian python (Python molurus), which reaches lengths of approximately six meters. ${ }^{328}$ It is this exaggerated size that causes these snakes to be seen as almost mythological. They surpass the realm of reality in their size, appearance, and their actions. Both the plain and mountain varieties are said to attempt to kill elephants. ${ }^{329}$ For the smaller of the two, the plain variety, the size of the

\footnotetext{
${ }^{324}$ Ogden (2013) 345, rather than presenting a healing narrative, Nicander implies this aspect of the snake through its association with Apollo Paion.

${ }^{325}$ Philostr. VA. 3.7-8.

${ }^{326}$ Philostr. $V A .3 .6-8$.

${ }^{327}$ Philostr. VA. 3.6; this length is given by way of comparison with a third type of snake, the marsh variety, which is not described with a beard. Rather than providing lengths for the bearded plain and mountain varieties Philostratus simply states, "they grow to greater length" (3.7.1) and "they are of greater length than the plains variety" (3.8.2), respectively.

${ }_{328}$ Also known as the Burmese python; Stothers (2004) 229.

${ }^{329}$ Philostr. VA. 3.7-8.
} 
elephant causes the snake to die in its attempt to swallow the large creature. ${ }^{330}$ In contrast, the larger mountain variety snake is not killed by the elephant, but instead is caught and killed by the local Indians. ${ }^{331}$ This description of impossibly large snakes hunting elephants is reminiscent of two passages from Diodorus Siculus' Bibliotheca Historica (first century BC). Diodorus describes similarly large snakes found in Libya and Ethiopia in two separate accounts, the first of which is a part of his description of the people and animals of the region. ${ }^{332}$ Unlike the snakes described by Philostratus, this snake is easily able to take down elephants due to its size and the sluggish nature of the elephant's movements. ${ }^{333}$ The second snake appears in a narrative detailing its capture and transport to Alexandria as a curiosity of Ethiopia. ${ }^{334}$ This snake, we are told, is 30 cubits in length, making it a similar size to those in the Vita Apollonii. ${ }^{335}$ Diodorus Siculus' snakes differ from those of Philostratus in one major way: they do not possess beards. However, the description of these snakes and others like them shows that there is precedence for the exaggerated size of ordinary snakes. ${ }^{336}$ Diodorus even goes so far as to dispute the sizes given by others, claiming that they are a falsehood as there is no snake of one hundred cubits in length as some had claimed to see. ${ }^{337}$

This precedence suggests that some snakes, particularly those in exotic lands, could take on a mythic size. The inclusion of beards on the monstrous snakes in the Vita Apollonii adds another unrealistic feature to the impossibly large creatures. This causes the serpents to be aligned with the mythological pure serpents in terms of their appearance. The mythological aspects of these creatures are not so out of place in the Vita Apollonii as they may first appear. While the text is intended to resemble a true account of the travels of Apollonius of Tyana, several mythological animals are described throughout the text, including a unicorn in 3.2, griffins in 3.48 , and a phoenix in 3.49. The use of mythological creatures aids in Philostratus' characterization of Apollonius of Tyana as someone who may be likened to a

\footnotetext{
${ }^{330}$ Philostr. VA. 3.7.2.

${ }^{331}$ Philostr. $V A \cdot 3 \cdot 8 \cdot 1-3$.

${ }^{332}$ Diod. Sic. $B H \cdot 3 \cdot 10.5-6$.

${ }^{333}$ Diod. Sic. BH. 3.10.6.

${ }^{334}$ Diod. Sic. BH. 3.36-37.

${ }^{335}$ Diod. Sic. $B H .3 .36 .5$.

${ }^{336}$ Stothers (2004) 226-230 cites examples of monstrously large snakes from Africa, India, the Middle East, and Europe described by Aristotle (Hist. An. 606b9-14), Aelian (NA. 16.41), Strabo (Geog. 15.1.45), and others. I have chosen to only discuss those in Diodorus Siculus due to the similarities in size and actions of hunting elephants.

${ }^{337}$ Diod. Sic. BH. 3.36.1.
} 
mythical teacher and prophet. He is presented as someone who essentially becomes the object of sacred pilgrimage towards the end of his life, with people coming from all over Greece to hear his teachings. ${ }^{338}$ It is this presentation of Apollonius as a knowledgeable holy man that is the focus of Philostratus' work. ${ }^{339}$ In order to present Apollonius in such a way, Philostratus blends together historical information and mythological or sacred allegory, essentially creating the idea that Apollonius exists in the same world as the creatures of myth. ${ }^{340} \mathrm{He}$ has journeyed to mysterious lands beyond the civilized world and has seen creatures that exist only in the mythical world of gods and heroes. ${ }^{341}$ In this context of a blurring of the mythical and the real, the addition of the beard to these snakes serves as a means by which Philostratus is able to imply the mythical status of these seemingly ordinary snakes and by extension, the world that they inhabit.

\section{Serpent Chariots}

When the bearded snake is used as an attribute of a god or hero, rather than as an alternate form of such figures, it is possible to view it in the light of Gourmelen's argument, that the bearded snake marks a dual natured deity or hero. ${ }^{342}$ This can be seen in the bearded serpents that draw the chariots of Triptolemos and Medea. ${ }^{343}$ The serpent chariot is associated with Triptolemos through the myth of his bringing the knowledge of agriculture and thus civilization to the known world at the behest of Demeter. ${ }^{344}$ Depictions of this myth generally follow the same iconographic scheme; Triptolemos seated in a winged chariot often holding a phiale or a staff, with one or

\footnotetext{
${ }^{338}$ Elsner (1997) 32; Philostr. VA.8.15.2.

${ }^{339}$ Elsner (1997) 22.

${ }^{340}$ Elsner (1997) 32.

${ }^{341}$ Elsner (1997) 32.

${ }^{342}$ Gourmelen (2012) 336.

${ }^{343}$ Athena is also depicted in a chariot pulled by two large, bearded serpents, LIMC Athena 41. However, this is only seen in the one unique image on this pyxis lid (ca. 425-375). There is little to suggest that the serpent chariot is a regular attribute of Athena. Instead this image can be viewed as a unique means of depicting the goddess, in which the snakes of her chariot stand in place of her commonly associated snakes which are lacking in this particular image. The snakes may also serve to provide a visual allusion to the ideas presented through other, more common depictions of the serpent chariots of Medea and Triptolemos.

344 Apollod. Bibl. 1.5.2; Hom. Hymn Dem. 470-482 details Demeter's teaching of her rites and mysteries to Triptolemos, Polyxeinos, and Diokles, and her instruction to initiate others. There is no mention of the serpent chariot. See further Gantz (1993) 69-70.
} 
two snakes located near the hub of the wheels. ${ }^{345}$ Demeter and Persephone are also commonly shown alongside the seated Triptolemos. The wings of the chariot protrude from either the top or center of the wheel, while the snake (or snakes) is shown close to the wing. This can be seen on a skyphos attributed to Makron, ca. 500-450 BC (fig. 64). Here the wings of the chariot are attached to the hub of the wheel and the bearded snake is positioned slightly above the hub. The tail of a second serpent can be seen parallel with that of the visible snake. These snakes provide a visual distinction between Triptolemos and Ploutos, the embodiment of the bringing of agricultural wealth. ${ }^{346}$ These two figures associated with Eleusis and agriculture may be similar in terms of their mythologies, as both are youths who travel in order to bring a form of agriculture and the wealth associated with crops, but are very different in terms of their respective iconographies. ${ }^{347}$ Triptolemos is frequently shown in his serpentdrawn, winged chariot, ${ }^{348}$ while Ploutos is commonly presented as a young boy holding a cornucopia. ${ }^{349}$ It is the combination of knowledge and agriculture that the bearded snakes associated with the chariot of Triptolemos emphasize. As creatures closely associated to the earth, they are appropriate symbols of the cultivation of the ground for farming and agriculture. Due to the belief that snakes possessed a secret knowledge of the earth and the worlds beyond the earth, ${ }^{350}$ they also effectively function as markers of the transmission of a previously unknown comprehension of how to properly work and maintain the soil. ${ }^{351}$ The addition of the beards to the snakes of Triptolemos indicates that this knowledge is divinely bestowed. They show the creatures to be something beyond the ordinary and, when combined with the wings of the chariot, present an otherworldly vehicle for the imparting of Demeter's gift through Triptolemos. The beards of these snakes are a fairly consistent feature in depictions of Triptolemos seated in this chariot.

The inclusion of a serpent drawn chariot in depictions of Medea, particularly those on several Lucanian vases, has been suggested to be a reflection of the final

\footnotetext{
${ }^{345}$ LIMC Triptolemos 7, 36, 39, 41, 44, 48, 75, 76, 78, 91, 111, 127, 136, 138, 145, 151 and LIMC Persephone 101, 127.

${ }^{346}$ Smith (2011) 113-114.

${ }^{347}$ Smith (2011) 114.

${ }^{348}$ Clinton (1992) 47.

${ }^{349}$ Clinton (1992) 50.

${ }^{350}$ Stutesman (2005) 35; Gilhus (2006) 108.

${ }^{351}$ As discussed in Chapter Two, the beard of the snake can be used to imply an inherent or divinely bestowed knowledge.
} 
scene of Euripides' Medea. ${ }^{352}$ It appears likely that Euripides invented the final scene of his play, in which Medea escapes Corinth in the chariot of Helios. ${ }^{353}$ The Policoro Painter hydria (fig. 11) provides an example of this serpent drawn chariot. As this piece is dated to ca. $400 \mathrm{BC}$ it was likely made during the last few years of Euripides' life and roughly 30 years after the first performance of his Medea in $431 \mathrm{BC}^{354} \mathrm{An}$ unattributed Lucanian calyx-krater housed in the Cleveland Museum of Art (fig. 65), depicting a similar serpent chariot of Medea, is also dated to this period, suggesting that such pieces may have been influenced by Euripides' new tale of Medea's escape. ${ }^{355}$ However, a major difference between the images presented on the Lucanian vases and the description of the scene in Euripides' tragedy is the snakes themselves. There is no mention of a chariot drawn specifically by snakes. Medea simply states:

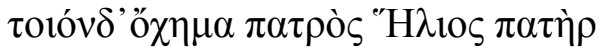

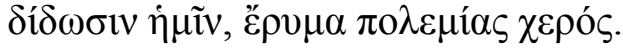

Such a chariot has Helius, my father's father, given me to defend me from my enemies. ${ }^{356}$

It is possible that the snakes were featured in the staging of the play and are not mentioned in the narrative, although this is purely speculation. ${ }^{357}$ The later literary tradition includes winged dragons in the description of Helios' chariot; however, the earliest of these sources is Ovid's Metamorphoses, ca. first century BC, significantly later than these Lucanian depictions. ${ }^{358}$ So the question must be asked, why depict the chariot of Helios with two large serpents? Horses would be more appropriate and Helios is indeed shown with a more traditional horse drawn chariot on multiple occasions. These horses may also be shown with wings, a feature which the Lucanian depictions of Medea's serpent chariot do not include, as on an unattributed Apulian calyx-krater housed in the British Museum (fig. 66). It is through the replacing of Helios' horses with serpents that the chariot becomes clearly distinguished as the chariot of Medea. The use of serpents, while not strictly appropriate for Helios, is suitable for Medea as they reflect her ambivalent or dual nature, as well as her mystical and potentially dangerous powers. Much like the guardian snake, Medea

\footnotetext{
${ }^{352}$ Taplin (2007) 117.

${ }^{353}$ Eur. Med. 1317-1419; Taplin (2007) 117.

${ }^{354}$ Taplin (2007) 117; Ogden (2013) 200.

${ }^{355}$ Taplin (2007) 117.

${ }^{356}$ Eur. Med. 1321-1322.

${ }^{357}$ Taplin (2007) 120-121.

${ }^{358}$ Ov. Met. 7.350, 7.391.
} 
may act in a violently protective manner. This can be seen in her murder of Apsyrtos. This act of violence was orchestrated in order to prevent Aietes from catching Jason on his escape from Colchis, essentially protecting him from her father. ${ }^{359}$ The inclusion of serpents on her chariot provides a visual connection between the Medea and the snake as similarly natured beings.

This connection between Medea and the snakes of her chariot is also exemplified by their shared capacity to rejuvenate. For the snake this ability is intrinsically linked with its appearance and nature, and is a part of the belief that connects the serpent with the immortal gods as it causes the creature to appear itself immortal. For Medea, this ability is one that she is only able to practice on others, as seen in her plot to murder Pelias, which involved her showing his daughters this power by rejuvenating a ram. ${ }^{360}$ She is seemingly able to subvert mortality, however, she uses this power to bring about the death of those who stand in her way. ${ }^{361}$ These powers emphasize Medea's nature as a threatening and protective figure, as her actions are intended to protect her own status. The combination of the snake with the chariot of the sun god himself combines the means through which Medea can be associated with the divine. It represents both her genealogical connection, through her grandfather Helios, and her more subtle personal connection, through the dangerous magic she is able to wield. By aligning Medea with such figures the morality of her actions becomes ambiguous, as she appears to have divine support, or at least the support of Helios. ${ }^{362}$ Therefore, the serpent is an appropriate attribute due to both its dangerous powers and its ambivalent nature.

The serpents of Medea's chariot are remarkably consistent in their inclusion of a beard. The beards appear as clear and intentional representations of beards, generally consisting of a series of medium to long clearly defined hairs. This consistent means of depicting the snakes associated with Medea extends to depictions that are lacking a representation of the chariot. A series of four black figure lekythoi, attributed to the Cock-Group, depict the head of a woman flanked by large bearded serpents, exemplified by the lekythos currently housed in the British Museum (fig.

\footnotetext{
${ }^{359}$ Ap. Rhod. Argon. 4.410-420; Apollod. Bibl. 1.9.24; see further Gantz (1993) 362.

${ }^{360}$ Apollod. Bibl. 1.9.27; Ov. Met. 7.297-349, also her rejuvenation of Aeson, Ov. Met. 7.251-296.

${ }^{361}$ Griffiths (2006) 45-46; Sourvinou-Inwood (1997) 266.

${ }^{362}$ Griffiths (2006) 76.
} 
67). ${ }^{363}$ The female figure on this lekythos is identified as Medea through an inscription. It is due to this inscription that the women on the remaining three lekythoi have been tentatively identified as Medea. ${ }^{364}$ As these lekythoi predate accounts of Medea's serpent-drawn chariot it is evident that this association between Medea and bearded snakes exists beyond depictions of her escape from Corinth. In this context the bearded snakes emphasize Medea's nature as a powerful woman who may be both protective and dangerous. She essentially embodies the qualities of the mythological guardian snake. ${ }^{365}$ These bearded snakes unquestionably belong to the realm of myth and the divine. They add a supernatural element to her iconography and, particularly in images including the chariot of the sun, distance her from mortality. ${ }^{366}$ As a woman who pushes the boundaries of what it means to be both mortal and a woman, Medea becomes a representation of a liminal character that exists beyond the boundaries of societal norms and expectations, much like Medusa. ${ }^{367}$ The beards on the snakes of the chariot of Medea serve to further emphasize this distancing from humanity.

\section{Erinyes and Tomb Snakes ${ }^{368}$}

This concept of the beard of the serpent serving as a marker of a dual-orambivalent natured mythological figure also extends to depictions of snakes in association with the Erinyes and tombs. These creatures can be seen in similar terms as both have the potential to be truly threatening and frightening, yet can also be protective and beneficial. As the snake can be used as a symbol with a significant range of meaning, particularly in association with death and the underworld, it is not surprising to find the snakes incorporated into the imagery of both tombs and the Erinyes.

The Erinyes are often shown with snakes in their hair, around their heads, wrists, and arms, or simply located nearby. ${ }^{369}$ Harrison, continuing her

\footnotetext{
${ }^{363}$ Lekythos with inscription identifying Medea: $A B V$ 471.117, LIMC Medeia 3; lekythos with similar depiction of Medea without inscription: $A B V$ 471.118, LIMC Medeia 4.

${ }^{364}$ The authenticity of the inscription of the London lekythos was called into question by Beazley, who claimed that it might have been a modern addition to the vase. However, this idea has been disproven through chemical testing of the features of the vase, which showed the inscription to be authentic, and had simply been touched up in recent years. Beazley (1934) 91; Haspels (1936) 68.

${ }^{365}$ As discussed in Chapter One.

${ }^{366}$ This is particularly the case in Euripides' Medea, where she appears in the chariot of the Sun in the

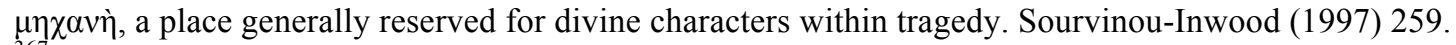
${ }_{367}$ Griffiths (2006) 54; as discussed in Chapter Two.

${ }^{368}$ Tomb snakes refer to those snakes that appear in association with tombs or the recently deceased.
} 
anthropomorphic argument, even suggests that the snake may be the original form of the Erinyes, hence the reason that they are often shown with snakes. ${ }^{370}$ This argument is based on the connection between snakes and the dead, or the afterlife. Harrison's argument for this connection claims that the serpents shown in association with tombs and the recently deceased can be viewed as an incarnation of the deceased, as well as being representative of the avenging Erinyes. ${ }^{371}$ However, there is little iconographic evidence to suggest that these snakes should be considered to be a physical incarnation of the deceased. ${ }^{372}$ Rather, the serpents associated with tombs and the deceased should be considered as similar to the guardian snakes. The serpent can be seen to also share similarities with the Erinyes, particularly in regards to its role as an avenger, in which it appears to essentially take on the role of an Erinys. ${ }^{373}$ This avenging nature is implied in scenes such as that on the fragmentary Tyrrhenian amphora discussed in Chapter One (fig. 22). In this scene the snake protects Eriphyle by avenging her murder. This is conveyed through the pose of the snake as it is positioned over Eriphyle's body while being poised to attack Alkmaion. ${ }^{374}$ Other scenes depicting a tomb serpent also convey this idea of a dual natured, protective serpent, as on two Leagros Group hydriai, one housed in Boston (fig. 25), the other in Berlin (fig. 21). These hydriai both include a depiction of a snake painted onto the exterior of a tumulus mound. ${ }^{375}$ These burial mounds also include a depiction of a lion (fig. 21), and a painted inscription naming the occupant of the tumulus (fig. 25), respectively. ${ }^{376}$ These snakes serve as a visual marker of the violently protective role that the tomb serpent plays. When a beard is included on the snake, as in figures 22 and 25 , the duality of this role is emphasized and the tomb snake becomes visually connected to the mythological guardian snakes.

As the tomb snake has the potential to be either a beneficent protector or a violent avenger its role can be seen as an extension of that of the guardian snake. ${ }^{377} \mathrm{~A}$ mythological snake that exemplifies this potential to be beneficent is the snake that

\footnotetext{
${ }^{369}$ LIMC Erinys 1, 6, 9, 11, 21, 27, 39, 41, 42, 45, 55, 58, 64, 68, 69, 70, 86, 107.

${ }^{370}$ Harrison (1899) 213; Ogden (2013) 257.

${ }^{371}$ Harrison (1899) 214.

${ }^{372}$ As discussed in Chapter One.

${ }^{373}$ Ogden (2013) 249; Morris and Morris (1965) 48 continues Harrison's argument that the snake was the physical embodiment of a dead hero's soul.

${ }^{374}$ Harrison (1903) 237.

${ }^{375}$ Backe-Dahmen, Kästner, and Schwarzmaier (2010) 44.

${ }^{376}$ The inscription located above the serpent on the tumulus in figure 25 reads ПАТРОК $\Lambda \Omega[\Sigma]$ (Patroklo[s]).

${ }^{377}$ As discussed in Chapter One.
} 
appears in the myth of the resurrection of Glaukos, depicted on a Sotades Painter kylix (figs. 20a-b). ${ }^{378}$ In this myth the beneficent serpent shows an ambivalent nature. This is due to the fact that the serpent is not directly responsible for the rejuvenation of Glaukos. Instead the snake incidentally shows Polyeidos how to rejuvenate Glaukos by doing so to the serpent killed by Polyeidos. Polyeidos is then left to act on what he has observed. When the beard is presented on a tomb serpent it implies the potential of the serpent to be a beneficent protector of the dead. The snake has the capabilities to be either a figure seeking to avenge a death, as on the Tyrrhenian amphora, or a beneficent figure, able to restore the dead to life, as on the Sotades Painter kylix. The beard aids in implying such a dual nature by providing a visual allusion to the guardian snakes who are similarly characterized by this duality. It shows the snake to be distinctly different from real world snakes and thus a protector of the deceased.

\section{Conclusion}

Due to the complex nature of the snake it can be viewed in many different lights and contexts. This makes it near impossible to give a single blanket explanation for the addition of the beard. Harrison's interpretation of the beard as a marker of a transforming creature is applicable for the motif's use solely in the context of depictions of Zeus Meilichios. However, when the wider use of the bearded snake is considered this interpretation becomes less convincing. The bearded snake is commonly used alongside deities, heroes, and chthonic figures with no indication that the forms of the two are interchangeable. Rather, the serpent serves to emphasize various aspects of the figure with which it is associated, particularly ideas concerning power, divinity, and dichotomy. Many of the figures that are shown either as or with a bearded snake are characterized by dichotomy and power. They are figures who have the potential to be dangerous and threatening, such as Athena, or they are a fully realized threat such as Medusa or Kerberos. By adding a beard onto the image of the snake the artist is adding another complex layer to the iconography of the snake. In doing so it becomes a creature that is neither entirely animal nor entirely human.

\footnotetext{
${ }^{378}$ Discussed in Chapter One.
} 


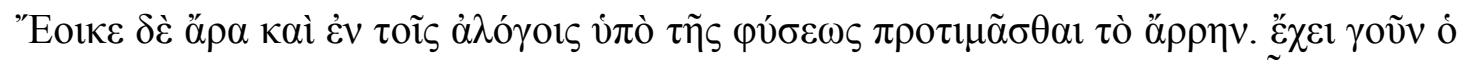

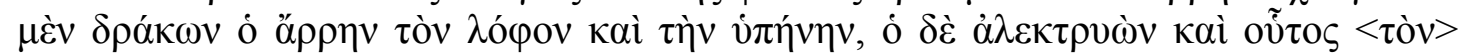

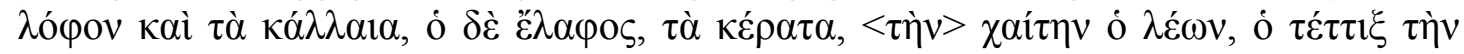
$\varphi \omega v \eta \dot{v}$.

Among animals it seems that the male is naturally preferred. At least then the male serpent has the crest and the beard; and the cock has the wattles and the comb; and the stag has the horns; the lion the mane; the cicada the cry. ${ }^{379}$

Aelian's comment on the bearded snake proposes that the addition of the beard serves only to emphasize the masculinity of the serpent. Such a basic interpretation of this unusual motif does not fully account for the many and varied contexts in which the bearded snake is used. These contexts include pure serpents such as the Serpent of Colchis, monstrous hybrid creatures with serpentine aspects such as the Chimaira, serpentine attributes or alternate forms of deities such as Zeus Meilichios, and attributes of monstrous women such as Medea. In each of these contexts the beard can imply a number of different meanings. What is particularly apparent across each of these contexts is that the beard distinguishes these creatures from ordinary serpents. It is a clear representation of a creature that cannot exist beyond the realms of mythology.

Attempts to explain the bearded snake as a reflection of reality, such as Harrison's equating of the anguiform Zeus Meilichios with the Montpellier snake, tend to be based on speculation about the artist or his intentions. The idea that the beard originated as a misrepresentation of the snake's fang or lower jaw is impossible to prove, as the intentions of an artist can never be known. Rather than looking for a naturalistic explanation for the addition of the beard I have considered the use of the bearded snake in its most common contexts, in order to see just how the motif functions in a variety of different contexts. Through this survey of uses I have not sought to explain the origins of the addition of the beard, nor why it ceases to be widely used by the third century BC. Instead, through such a survey it is possible to consider just what this unusual motif adds to the meaning of the snake in the contexts in which it may appear.

${ }^{379}$ Ael. NA. 11.26 
When the beard is applied to serpents that function as attributes of divine or monstrous women it is not possible to view the beard as solely a marker of masculinity, as Aelian claimed. Rather it should be viewed as an indicator of the associated figure's own power and nature. As the beard is an inherently masculine emblem, its use in the scene also suggests that the associated female figure may have some masculine traits. For women such as Athena and Medusa these traits are often closely associated with their power and authority. Medusa takes on a more traditionally male role as her power to turn men into stone causes her to be viewed as the dominant and controlling figure. Like Medusa, Athena is a powerful female who has the ability to subjugate any person she comes into conflict with. However, unlike Medusa, her power and authority ultimately stems from her support of Zeus and the Olympian patriarchy he establishes. Here the beard serves as a subtle reminder of Athena's connection to her father; the bearded snakes are after all shown on one of Zeus' ultimate defensive weapons. Even when used in the context of female divinities and monsters there is no one single explanation for the meaning of the bearded snake. In this context the simplest interpretation would see the addition of the beard as a way to show the female's nature as a woman who transgresses traditional gender constructs. This transgression can be viewed as threatening. This threat is fully realized in the monstrous Medusa, who steps well outside of the expected role of a woman and assumes a position of dominance over both men and women. As Athena's own power and authority, and the emblems of these, are closely connected with Zeus, she too stands as a potential threat. She embraces both male and female qualities as a patron goddess of household work and warfare. Although she has both male and female traits, it is her femininity that is one of her most defining traits, and what differentiates her from Medusa. Because she is a woman she stands in support of her father and bears his arms, rather than existing as an opposing force. Essentially, while Medusa and Athena share the iconography of the bearded snake, its meaning changes slightly due to their unique natures. Medusa's snakes show her dangerous and threatening nature, emphasizing her distance from the civilized world, showing her to be a monstrous hybrid of animal and human, as well as of male and female. In contrast, Athena's snakes emphasize her role as a supporter of Zeus by being associated with both the defeat of Medusa and the aegis. They also highlight her dual nature as a goddess who can be both threatening and protective. It is this dual nature that also provides a connection between Athena and the guardian serpents of myth, as 
both become threatening when they act as a protector. Athena is seen as a protector of the Olympian order and the dike of Zeus, showing her threatening nature to be one that is in defense of civilization and order, rather than to its detriment as Medusa's own dangerous nature is. The bearded snakes mark her dual nature as a patron goddess of both male and female pursuits, as well as the duality of the aegis itself. It appears as both a threatening and protective device, depending on the context in which it is used, reflecting the dangerous and defensive roles of Athena herself.

When the beard is added to monstrous pure and hybrid serpents it again functions differently. The beard, as a human attribute depicted on an animal or partially animal hybrid, emphasizes the creature's nature as a bestial hybrid. The pure and hybrid serpents function as monstrous and threatening creatures, albeit in slightly different ways. The threatening nature of the pure serpents is an extension of their role as divinely appointed guardians. They become threatening when the object or location they protect is itself threatened. In contrast, the hybrids do not function as guardians. Instead they are presented as menacing and wild creatures who serve as rampaging beasts. For these hybrid creatures, when the beard is shown to be particularly long and shaggy, it also highlights their barbarity. This use of the beard aligns the wild hybrids, in iconographic terms, with the barbarians such as Antaios who are shown in opposition to the Greek hero. It is often their long, unkempt beard that may be used to distinguish them from the civilized Greek hero who appears with a neatly trimmed and styled beard. As these creatures similarly serve as an opposing force to the Greek hero in his quest or journey, the unkempt beard again functions as a way to show that such creatures stand outside of civilization and exist in wild and barbaric places. While the shape and length of the beard differentiates the creatures from their heroic counterparts, the very inclusion of a human feature distinctly removes them from the civilized world. It shows them to be neither wholly human, nor entirely bestial. Medusa is an extreme example of the extent to which this liminality can be explored through the iconography of hybrid creatures. As an amalgam of both human and animal, and male and female, she exists beyond the constraints of humanity and gender. This is reflected in her iconographic form. She essentially has a basic human form that is corrupted by bestial features, including wings, tusks, and serpent attributes. Her form is a fusion of these features, to the extent that even some of her most bestial attributes have human aspects. This amalgamation is apparent to a 
significantly lesser extent in the other monstrous hybrids, as the inclusion of a beard on their associated serpents is often the only human attribute. The corruption of this human attribute by being placed on an animal is what causes it to be seen as an emblem of monstrosity and what clearly marks such creatures as mythological beings that exist beyond the boundaries of civilization and order.

Harrison suggested that such an amalgamation, when presented on pure serpents, shows the creature to be a theriomorphic deity, rather than a corruption of humanity used to represent monstrosity. This connection is very tenuous as it assumes a persistent correlation between the human form in art and the divine. It is only truly applicable to deities such as Zeus Meilichios, who are depicted in both human and serpentine forms. In the case of other pure serpents shown with a beard, such as the Serpent of Colchis, the beard implies the dual or ambivalent nature of the deity associated with the snake, rather than explicitly serving as a marker of an alternate form of the god. Gourmelen first presented this idea as a development of Harrison's claim that the beard emerged as a misrepresentation of the Montpellier snake's small fangs. While the connection between the beard and the Montpellier snake is overstated, Gourmelen's connection between the beard and dual-or-ambivalent natured deities is applicable to bearded snakes in many of the contexts in which they appear. This idea builds on the common role of the serpent, with or without the beard, as a guardian or protector. In this role the serpent becomes the embodiment of a dualor-ambivalently natured creature. When the serpent acts as a guardian or protector of a specific location or object, for example Python's protection of an oracular shrine associated with Gaea, it only comes into direct conflict with a hero as a result of this role. Thus they are only dangerous threats when the object or location they protect is threatened. The beard emphasizes this duality by being a liminal marker and showing the snake to have both human and serpentine features. When this symbol of duality and liminality is depicted alongside or as alternate forms of divine figures, it can suggest that these figures also embody some duality.

These ideas presented by Aelian and Harrison have served as the starting point for much of my own research, the aim of which has been to expand upon their interpretations of the addition of the beard to the motif of the snake. Their arguments are flawed by their narrow focus and limited sources. However, their ideas cannot be completely written off, nor should they be. Aelian and Harrison consider the addition 
of the beard in its most basic forms, as either an attribute of masculinity or humanity/divinity. In the most stripped back interpretation it can indeed be said that in each of the contexts in which the beard is included on a serpent, it has some connotations of masculinity or humanity/divinity. However, such an explanation fails to take into account just how such connotations affect the way in which the serpent or the serpent's associated figures can be viewed and just how complex the serpents themselves are. It is such effects I have addressed throughout this thesis, be it in the context of female monsters and divinities, pure or hybrid serpents, or divine and heroic attributes. What has become apparent is that there is no single reason behind the inclusion of the beard. The serpent itself appears in such a wide range of contexts that the beard can be seen to emphasize or imply a number of connected qualities. Had there been evidence for a real-world precedent for the motif of the bearded snake the explanation may have been simpler and easier to define, but with the snake nothing is simple. It is a complex creature that can be benign and threatening, protective and aggressive, and immortal and associated with the underworld. The addition of the beard is yet another aspect of the snake that shows its complexity as an emblem of duality and liminality. It marks out specifically mythological beasts that stand as potentially threatening and wild creatures that may also be closely associated with a deity. The beard can be further defined by the specific context in which it appears. Whether or not the snake itself or the associated human or divine figure is female will affect the extent to which the beard implies a concept of power and monstrosity through a subtle masculine emblem. Whether or not the snake is a hybrid creature will affect the extent to which the beard may imply the monstrous and wild image of the creature. The one thing these many depictions have in common is that they clearly depict a mythological creature. The addition of a beard, across all contexts, emphasizes this fact. Beyond this, the best answer to the question "what does the serpent's beard mean?", is simply that like the snake itself it has various meanings and serves to highlight certain qualities and features of its associated figures. 
Aelian. De Natura Animalium. (ed. and trans. A. Scholfield) Cambridge, MA: Harvard University Press. 1960.

Apollonius of Rhodes. Argonautica. (trans. R. Hunter) Oxford: Oxford University Press. 1993.

Apollodorus. Bibliotheca. (ed. and trans. J. G. Frazer) Cambridge, MA: Harvard University Press. 1921.

Aristophanes. Plutus. (ed. and trans. J. Henderson) Cambridge, MA: Harvard University Press. 2002.

Aristotle. History of Animals. (ed. and trans. A. L. Peck) Cambridge, MA: Harvard University Press. 1965.

Artus, P. (2011) Greek Vase Painting. Bellona Books.

Austin, N. (2010) Meaning and Being in Myth. Pennsylvania: Pennsylvania State University.

Backe-Dahmen, A., Kästner, U., and Schwarzmaier, A. (2010) Greek Vases: Gods, Heroes and Mortals. London: Scala Publisher Ltd.

Beazley, J.D. (1934) "Review of Martin von Wagner-Museum der Universität Würzburg: Griechische Vasen by Ernst Langlotz" Journal of Hellenic Studies 54:90-92.

Beazley, J.D. (1956) Attic Black-Figure Vase-Painters. Oxford: Oxford University Press.

Beazley, J.D. (1963) Attic Red-Figure Vase-Painters, Second Edition. Oxford: Oxford University Press.

Beazley, J.D. (1971) Paralipomena: Additions to Attic Black-Figure Vase Painters and to Attic Red-Figure Vase-Painters (Second Edition). Oxford: Oxford University Press.

Birchler Emery, P. (1999) "Old-Age Iconography in Archaic Greek Art", Mediterranean Archaeology, 12:17-28.

Blundell, S. (1995) Women in Ancient Greece. Cambridge, MA: Harvard University Press.

Boardman, J. (1975) Athenian Red Figure Vases: The Archaic Period. New York: Oxford University Press.

Boardman, J. (1998) Early Greek Vase Painting. London: Thames and Hudson Ltd. 
Boardman, J. (2001) The History of Greek Vases: Potters, Painters, and Pictures. London: Thames and Hudson Ltd.

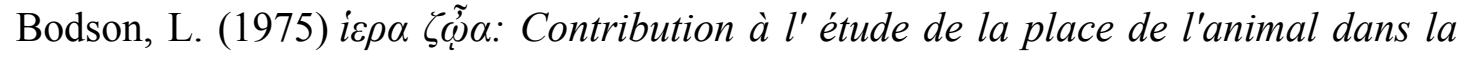
religion grecque ancienne. Bruxelles: Palais des Academies.

Brann, E. (1962) The Athenian Agora: Volume 3, Late Geometric and Protoattic Pottery. Princeton: The American School of Classical Studies at Athens.

Burkert, W. (1985) Greek Religion: Archaic and Classical. Oxford: Basil Blackwell Ltd.

Burton, D. (2005) "The Gender of Death", in E. Stafford and J. Herrin eds. Personification in the Greek World: From Antiquity to Byzantium. Hampshire: Ashgate Publishing Ltd.

Buxton, R. (2004) The Complete World of Greek Mythology. London: Thames and Hudson Ltd.

Carpenter, T.H. (1991) Art and Myth in Ancient Greece. London: Thames and Hudson Ltd.

Carpenter, T.H. (1994) "The Terrible Twins in Sixth-Century Attic Art", in J. Solomon ed. Apollo: Origins and Influences. Tuscon: The University of Arizona Press.

Carpenter, T.H. (2007) “Greek Religion and Art”, in D. Ogden ed. A Companion to Greek Religion. Malden: Blackwell Publishers Ltd. 398-420.

Cavero, L. (2009) "The Appearance of the Gods in the Dionysiaca of Nonnus", Greek, Roman, and Byzantine Studies, 49:557-583.

Clinton, K. (1992) Myth and Cult: The Iconography of the Eleusinian Mysteries. Stockholm: Paul Åströms förlag.

Cohen, B. (2006) "Outline in Black- and Red-Figure Vase-Painting”, in B. Cohen ed. The Colors of Clay: Special Techniques in Athenian Vases. Los Angeles: Getty Publications. 150-160.

Cohen, B. (2012) "The Non-Greek in Greek Art", in T. Smith and D. Plantzos eds. $A$ Companion to Greek Art. Malden: Blackwell Publishers Ltd. 456-479.

Cook, A. (1914-1940) Zeus: A Study in Ancient Greek Religion (3 Vols.). Cambridge: Cambridge University Press.

De Iuliis, G. and Pulera, D. (2011) The Dissection of Vertebrates. Burlington (MA): Academic Press Publications. 
Deacy, S. (1997) "Athena and the Amazons: Mortal and Immortal Femininity in Greek Myth", in A.B. Lloyd ed. What is a God? Studies in the Nature of Greek Divinity. London: Gerald Duckworth and Company Ltd. 153-168.

Deacy, S. (2008) Athena. London: Routledge.

Diodorus Siculus. Bibliotheca Historica. (ed. and trans. C.H. Oldfather) Cambridge, MA: Harvard University Press. 1935.

Downing, C. (1988) The Goddess: Mythological Images of the Feminine. New York: The Crossroad Publishing Company.

Elsner, J. (1997) "Hagiographic Geography: Travel and Allegory in the Life of Apollonius of Tyana", The Journal of Hellenic Studies, 117:22-37.

Euripides. Hercules Furens. (ed. and trans. D. Kovacs) Cambridge, MA: Harvard University Press. 1998.

Euripides. Iphigenia in Tauris. (trans. W. Bynner) Chicago: University of Chicago Press. 1956.

Euripides. Medea. (trans. R. Warner) Chicago: University of Chicago Press. 1944.

Fontenrose, M. (1974) Python: A Study of Delphic Myth and its Origins. New York: Bilbo \& Tannen Publishers.

Foster, H. (2003) "Medusa and the Real", Anthropology and Aesthetics, 44:181-190.

Fox, M. (1998) “The Constrained Man”, in L. Foxhall and J. Salmon eds. Thinking Men: Masculinity and its Self-Representation in the Classical Tradition. London: Routledge. 6-22.

Gantz (1993) Early Greek Myth: A Guide to Literary and Artistic Sources. Baltimore: The Johns Hopkins University Press.

Griffiths, A. (1986) “'What Leaf-Fringed Legend...?’ A Cup by the Sotades Painter in London", The Journal of Helenic Studies. 106:58-70.

Griffiths, E. (2006) Medea. London: Routledge.

Gilhus, I. (2006) Animals, Gods and Humans: Changing Attitudes to Animals in Greek, Roman and Early Christian Ideas. London: Routledge.

Gourmelen, L. (2012) "Le Serpent Barbu: Réalités, Croyances et representations. L'exemple de Zeus Meilichios à Athènes", Anthropozoologica, 47:323-343.

Graf, F. (2008) Apollo. London: Routledge.

Guiley, R. (2006) "Ouroboros”, in R. Guiley ed. The Encyclopedia of Magic and Alchemy. New York: Facts on File Inc. 233-234. 
Guralnick, E. (1974) “The Chrysapha Relief and Its Connections with Egyptian Art”. The Journal of Egyptain Archaeology, 60:175-188.

Gutzwiller, K. (2007) A Guide to Hellenistic Literature. Malden: Blackwell Publishing.

Hampe, R. and Simon, E. (1981) The Birth of Greek Art: From the Mycenaean to the Archaic Period. London: Thames and Hudson Ltd.

Harrison, J. (1899) "Delphika - (A) The Erinyes. (B) The Omphalos", The Journal of Hellenic Studies, 19:205-251.

Harrison, J. (1903) Prolegomena to the Study of Greek Religion. New York: Meridian Books, Inc.

Harrison, J. (1927) Themis: A Study of the Social Origins of Greek Religion. London: Merlin Press Ltd.

Haspels, C.H.E. (1936) Attic Black-Figured Lekythoi. Paris: De Boccard.

Haward, A. (1990) From Penelope to Poppaea: Women in Greek and Roman Society. Surrey: Thomas Nelson and Sons Ltd.

Hesiod. Theogony. (trans. M.L. West) Oxford: Oxford University Press. 1988.

Hibler, D. (1993) "The Hero-Reliefs of Lakonia: Changes in Form and Function”, in O. Palagia and W. Coulson eds. Sculpture from Arcadia and Laconia. Oxford: Oxbow Books. 199-204.

Hoffmann, H. (1997) Sotades: Symbols of Immortality on Greek Vases. Oxford: Oxford University Press.

Holloway, R. (1973) A View of Greek Art. Providence: Brown University Press.

Holloway, R. (1988) "Early Greek Architectural Decoration as Functional Art". American Journal of Archaeology, 92:177-183.

Homer. Iliad. (ed. and trans. W.F. Wyatt) Cambridge, MA: Harvard University Press. 1999.

Homer. Odyssey. (ed. and trans. A.T. Murray; revised by G.E. Dimock) Cambridge, MA: Harvard University Press. 1995.

Homeric Hymns. (ed. and trans. M. L. West) Cambridge, MA: Harvard University Press. 2003.

Howe, T. (1954) “The Origin and Function of the Gorgon-Head". American Journal of Archaeology, 58:209-221.

Hyginus. Fabulae. (trans. R.S. Smith and S.M. Trzaskoma) Indianapolis: Hackett Publishing Company, Inc. 2007. 
Ivantchik, A. (2006) “'Scythian' Archers on Archaic Attic Vases: Problems of Interpretation". Ancient Civilizations from Scythia to Siberia, 12:197-271.

Jenkins, I. (2009) The Greek Body. London: The British Museum Press.

Johnston, A. (1993) "Pre-Classical Greece", in J. Boardman ed., The Oxford History of Classical Art. Oxford: Oxford University Press. 11-82.

Kaltsas, N. (2000) Olympia. Athens: Archaeological Receipts Fund.

Lalonde, G. (2006) Horos Dios: An Athenian Shrine and Cult of Zeus. Leiden: Brill.

Larson, J. (2007) Ancient Greek Cults: A Guide. New York: Routledge.

Mackay, E.A. (2010) Tradition and Originality: A Study of Exekias. Oxford: Archaeopress.

Marinatos, N. (2000) The Goddess and the Warrior: The Naked Goddess and Mistress of Animals in Early Greek Religion. London: Routledge.

Marinatos, N. (2001) "Medusa on the Temple of Artemis at Corfu", in M. Bietak ed. Archaische Griechische Tempel und Altägypten. Wien: Verlag der Österreichischen Akademie der Wissenschaften. 83-88.

McNiven, T. (2000) "Behaving Like an Other: Telltale Gestures in Athenian Vase Painting", in B. Cohen ed. Not the Classical Ideal: Athens and the Construction of the Other in Greek Art. Leiden: Koninkijke Brill NV. 71-97.

Mertens, J. (1972) “A White-Ground Cup by Euphronios", Harvard Studies in Classical Philology, 76:271-281.

Menez, A. (2003) The Subtle Beast: Snakes, form Myth to Medicine. London: Taylor and Francis Group.

Miller, M. (2000) "The Myth of Bousiris: Ethnicity and Art", in B. Cohen ed. Not the Classical Ideal: Athens and the Construction of the Other in Greek Art. Leiden: Koninkijke Brill NV. 413-442.

Mitropoulou, E. (1977) Deities and Heroes in the Form of Snakes. Athens: PYLI Editions.

Moller, H. (1987) "The Accelerated Development of Youth: Beard Growth as a Biological Marker", Comparative Studies in Society and History, 29:748-762.

Morris, R. and Morris, D. (1965) Men and Snakes. New York: Hutchinson \& Co. (Publishers) Ltd.

Mylonas, G. (1955) "The Cemeteries of Eleusis and Mycenae", Proceedings of the American Philosophical Society 99:57-67. 
Neer, R. (2012) Art and Archaeology in the Greek World. London: Thames and Hudson.

Neils, J. (2001) “Athena, Alter Ego of Zeus”, in S. Deacy and A. Villing eds. Athena in the Classical World. Leiden: Brill. 219-232.

Neils, J. (2011) Women in the Ancient World. London: The British Museum Press.

Newbold, R. F. (1984) 'Discipline, Bondage, and the Serpent in Nonnus' Dionysiaca", The Classical World, 78:89-98.

Newbold, R. F. (1999) “Chaos Theory in Nonnus' Dionysiaca”, Scholia: Studies in Classical Antiquity, 8:37-51.

Nicander. Theriaca. (ed. and trans. A.S.F. Gow and A.F. Scholfield) Cambridge: Cambridge University Press. 1953.

Nilsson, M. P. (1940) Greek Folk Religion. Philadelphia: University of Pennsylvania Press.

Nonnus. Dionysiaca. (ed. and trans. W.H.D. Rouse) Cambridge, MA: Harvard University Press. 1940.

Ogden, D. (2013) Drakōn: Dragon Myth and Serpent Cult in the Greek and Roman Worlds. Oxford: Oxford University Press.

Osborne, R. (1998) Archaic and Classical Greek Art. Oxford: Oxford University Press.

Osborne, R. (2011) The History Written on the Classical Greek Body. Cambridge: Cambridge University Press.

Otto, W. (1954) The Homeric Gods: The Spiritual Significance of Greek Religion. New York: Pantheon Books Ltd.

Overduin, F. (2009) “The Fearsome Shrewmouse: Pseudo-Science in Nicander's Theriaca?", in M.A. Harder, R.F. Regtuit, and G.C. Wakker eds. Nature and Science in Hellenistic Poetry. Leuven: Peeters. 79-94.

Ovid. Metamorphoses. (trans. M. Innes) London: Penguin Books Ltd. 1955.

Parker, R. (1987) "Myths of Early Athens", in J. Bremmer ed. Interpretations of Greek Mythology. Kent: Croom Helm Ltd. 187-214.

Parker, R. (2011) On Greek Religion. Ithaca: Cornell University Press.

Pausanias. Description of Greece. (ed. and trans. W.H.S. Jones) Cambridge, MA: Harvard University Press. 1935.

Pedley, J. (2007) Greek Art and Archaeology. New Jersey: Pearson Education, Inc. 
Philostratus. Vita Apollonii. (ed. and trans. C. P. Jones) Cambridge, MA: Harvard University Press. 2005.

Pipili, M. (1987) Laconian Iconography of the Sixth Century BC. Oxford: Oxford University Committee for Archaeology.

Plutarch. Vita Cleomenes. (ed. and trans. B. Perrin) Cambridge, MA: Harvard University Press. 1921.

Pomeroy, S. (1975) Goddesses, Whores, Wives, and Slaves: Women in Classical Antiquity. New York: Schocken Books Ltd.

Richer, N. (2007) “The Religious System at Sparta”, in D. Ogden ed. A Companion to Greek Religion. Oxford: Blackwell Publishing Ltd. 236-252.

Richter, G. (1949) Archaic Greek Art. New York: Oxford University Press.

Richter, G. (1959) A Handbook of Greek Art. London: Phaidon Press Ltd.

Robertson, M. (1981) A Shorter History of Greek Art. Cambridge: Cambridge University Press.

Salapata, G. (1993) "The Lakonian Hero Reliefs in the Light of the Terracotta Plaques", in O. Palagia and W. Coulson eds. Sculpture from Arcadia and Laconia. Oxford: Oxbow Books. 189-198.

Salapata, G. (1997) "Hero Warriors from Corinth and Lakonia”, Hesperia, 66:245260.

Salapata, G. (2006) "The Tippling Serpent in the Art of Lakonia and Beyond", Hesperia, 75:541-560.

Salapata, G. (2013) "Laconian and Messenian Plaques with Seated Figures: the SocioPolitical Dimension", The Annual of the British School at Athens, 108:187200.

Schefold, F. (1992) Gods and Heroes in Late Archaic Greek Art (A. Griffiths trans.). Cambridge: University of Cambridge Press. (Original work published 1978).

Shapiro, H.A. (1993) Personifications in Greek Art: The Representation of Abstract Concepts 600-400 BC. Zürich: Akanthus, Verlagfür Archäologie.

Shearer, A. (1996) Athene: Image and Energy. London: Penguin Books Ltd.

Shorrock, R. (2001) The Challenge of Epic: Allusive Engagement in the Dionysiaca of Nonnus, Mnemosyne Supplementum 210.

Shorrock, R. (2005) "Nonnus”, in J. Foley ed. A Companion to Ancient Epic. Oxford: Blackwell Publishers Ltd. 374-385. 
Simonides. Fragments. (ed. and trans. D. Campbell) Cambridge, MA: Harvard University. 1991.

Slater, P. (2014) The Glory of Hera: Greek Mythology and the Greek Family. Princeton: Princeton University Press.

Smith, A. (2011) Polis and Personification in Classical Athenian Art. Leiden: Koninklijke Brill NV.

Sourvinou-Inwood, C. (1997) "Medea at a Shifting Distance: Images and Euripidean Tragedy", in J. Clauss and S. Johnston eds. Medea: Essays on Medea in Myth, Literature, Philosophy, and Art. Princeton: Princeton University Press. 253296.

Sparkes, B. (2013) The Red and Black: Studies in Greek Pottery. New York: Routledge.

Spivey, N. (1997) Greek Art. London: Phaidon.

Stafford, E. (2012) Herakles. Oxon: Routledge.

Stothers, R. (2004)"Ancient Scientific Basis of the 'Great Serpent' from Historical Evidence", Isis, 95:220-238.

Strabo. Geography. (ed. and trans. H.L. Jones) Cambridge, MA: Harvard University Press. 1930.

Stutesman, D. (2005) Snake. London: Reaktion Books Ltd.

Taplin, O. (2007) Pots and Plays: Interactions Between Tragedy and Greek Vase Painting of the Fourth Century BC. Los Angeles: The J. Paul Getty Museum

Tsaknis, N. (2004) Trophies of the Argonauts" Volos: Volos Publications.

Tsiafakis, D. (2000) "The Allure and Repulsion of Thracians in the Art of Classical Athens", in B. Cohen ed. Not the Classical Ideal: Athens and the Construction of the Other in Greek Art. Leiden: Koninkijke Brill NV. 364-412.

van Nortwick (2008) Imagining Men: Ideals of Masculinity in Ancient Greek Culture. Westport: Praeger Publishers.

Vernant, J. and Vidal-Naquet, P. (1988) Myth and Tragedy in Anicent Greece, trans. J. Lloyd. New York: Zone Books.

von Bothmer, D. (1985) The Amasis Painter and his World: Vase-Painting in SixthCentury BC Athens. New York: Thames and Hudson Ltd.

Vos, M.F. (1963) Scythian Archers in Archaic Attic Vase-Painting. Groningen: J.B. Wolters. 
Warner, M. (1985) Monuments and Maidens: The Allegory of the Female Form. London: Weidenfeld and Nicolson Ltd.

Welling, W. (2012) "The Secret of the Serpent" in W. Welling ed. Dangerous and Divine: The Secret of the Serpent. Amsterdam: KIT Publishers. 12-87.

Wilk, S. (2000) Medusa: Solving the Mystery of the Gorgon. Oxford: Oxford University Press.

Yasumura, N. (2011) Challenges to the Power of Zeus in Early Greek Poetry. London: Bristol Classical Press 
Appendix 

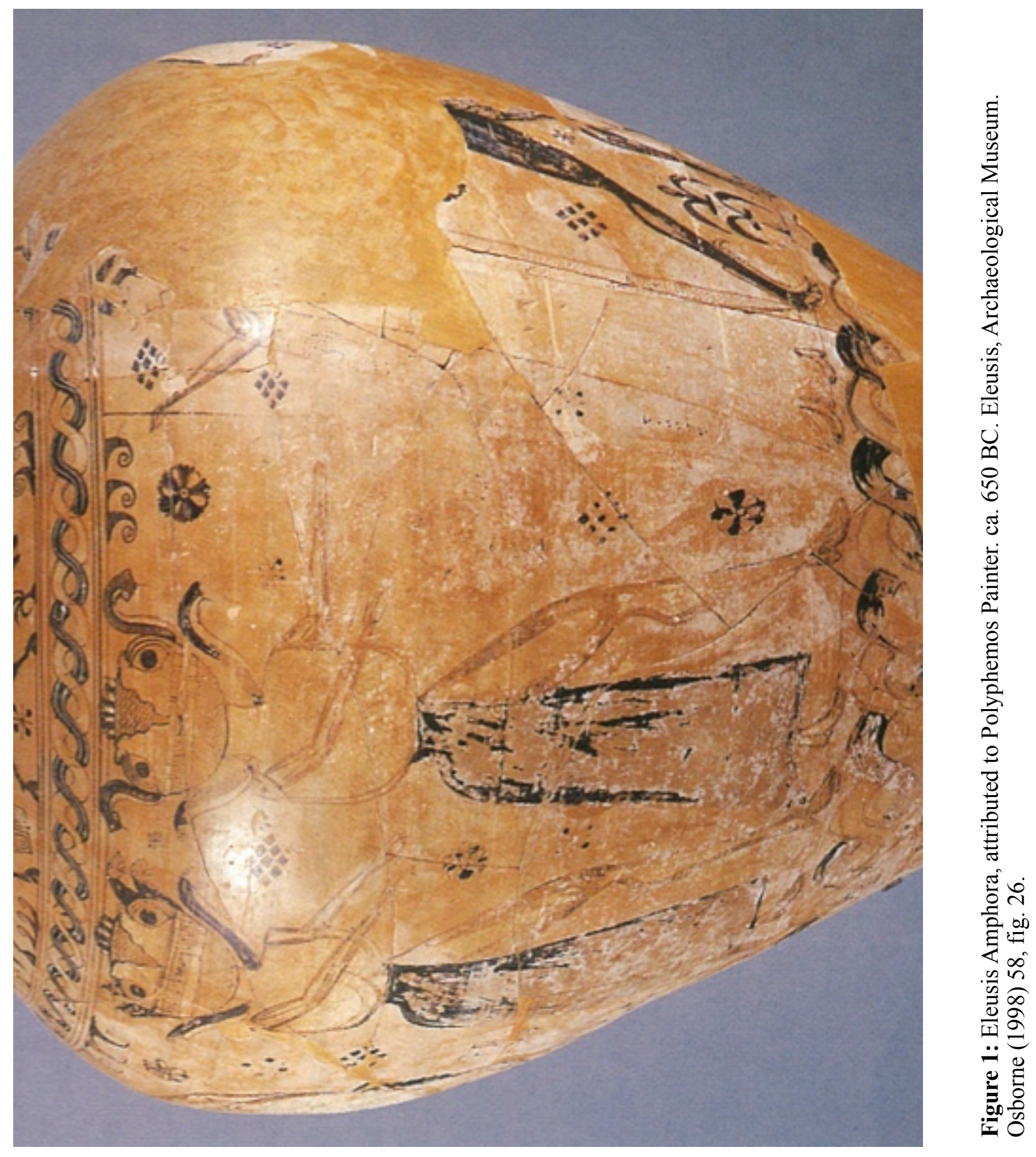


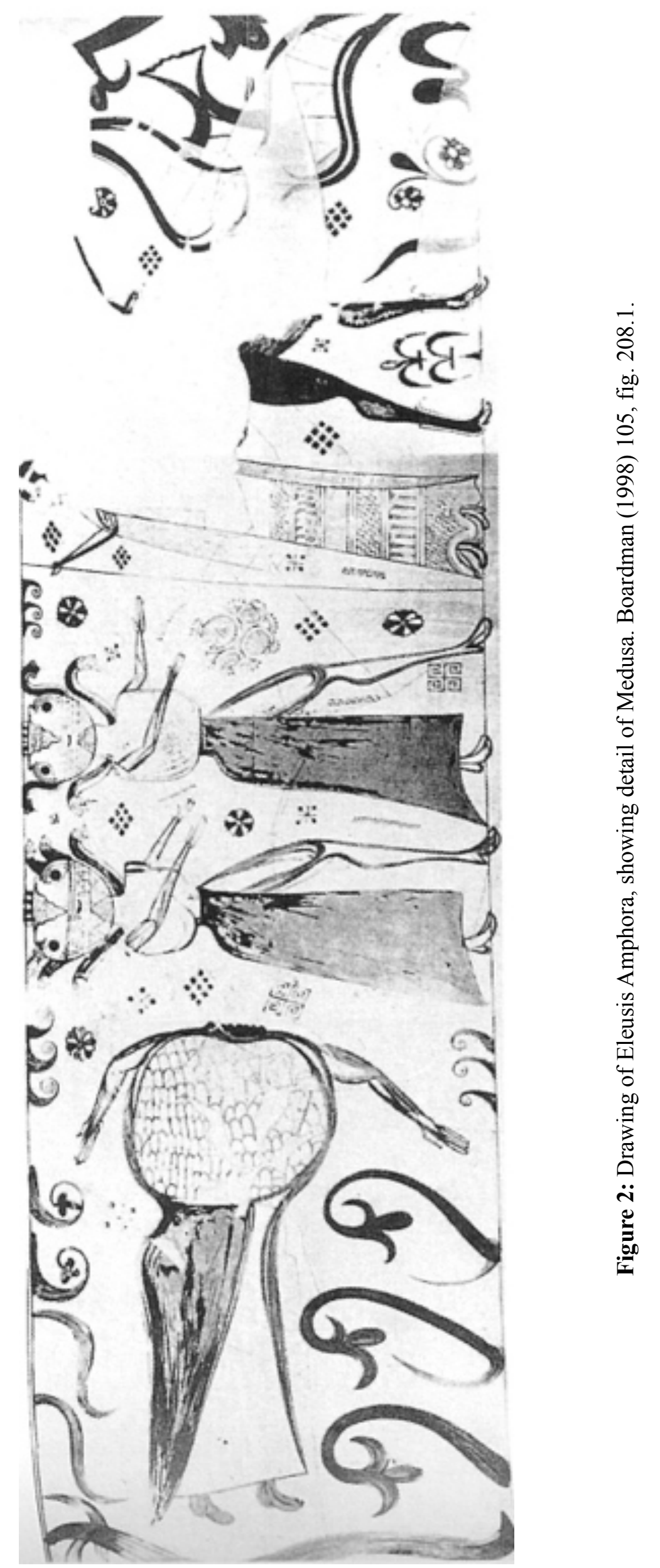




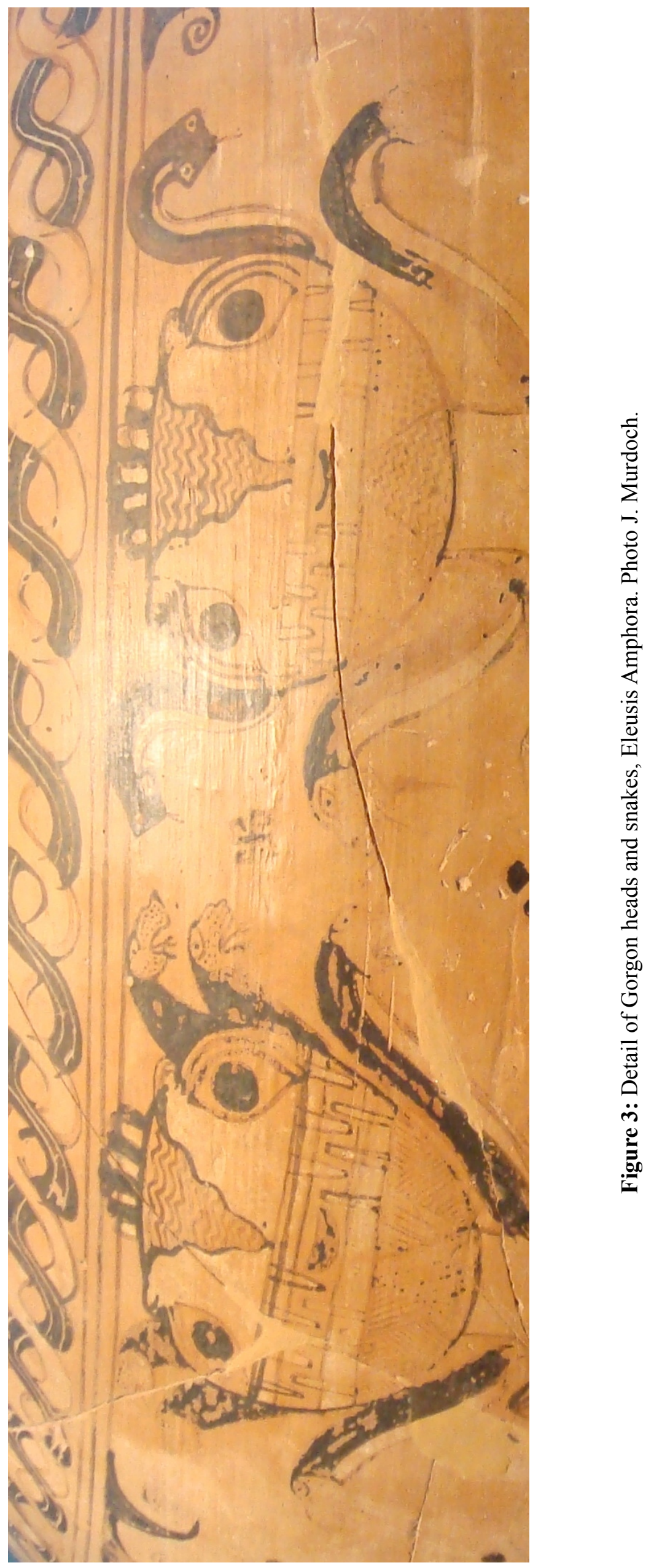




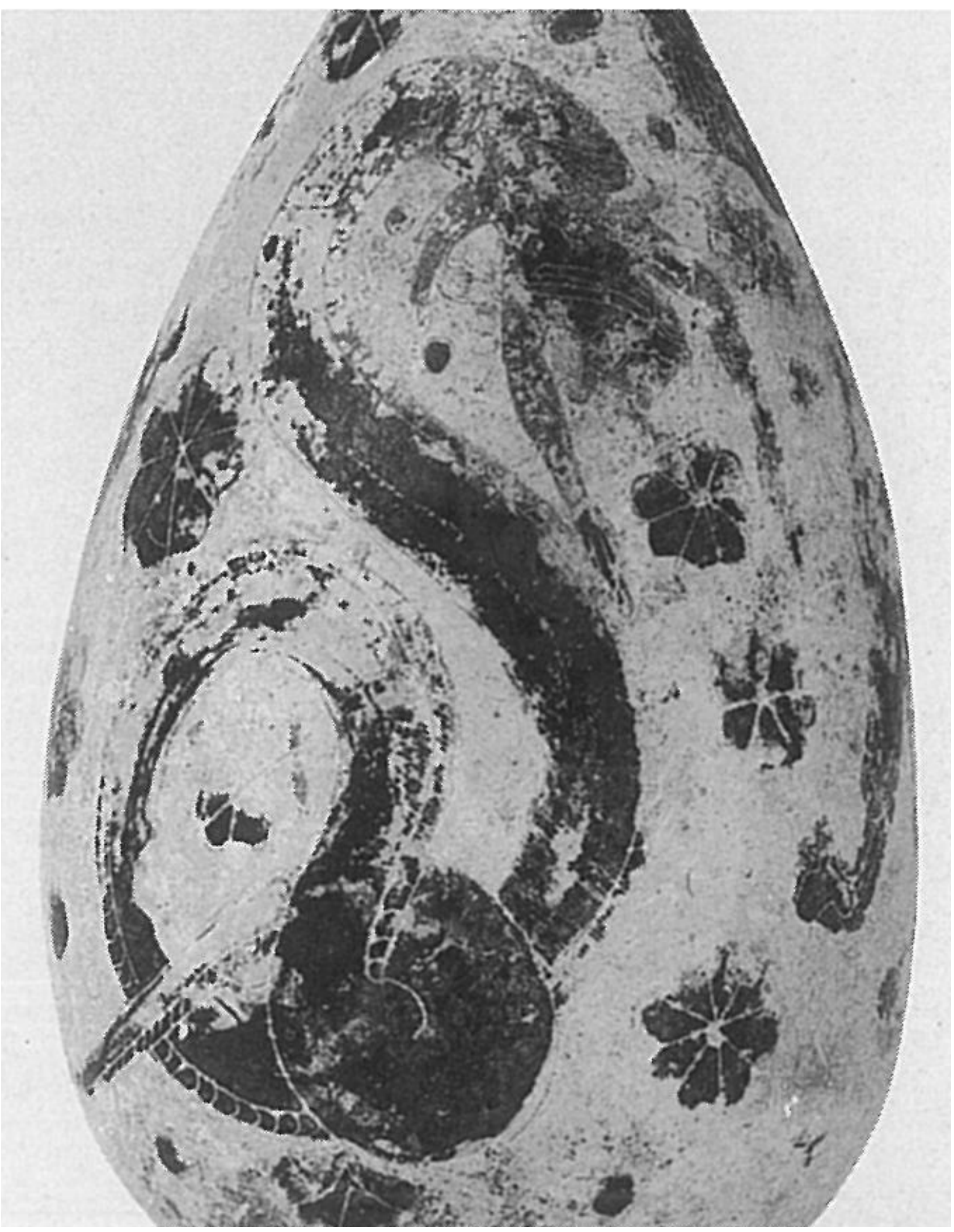

Figure 4: Corinthian alabastron. Last quarter of the 7th century BC. Bonn, Akademisches Kunstmuseum 860. LIMC Iason 30 


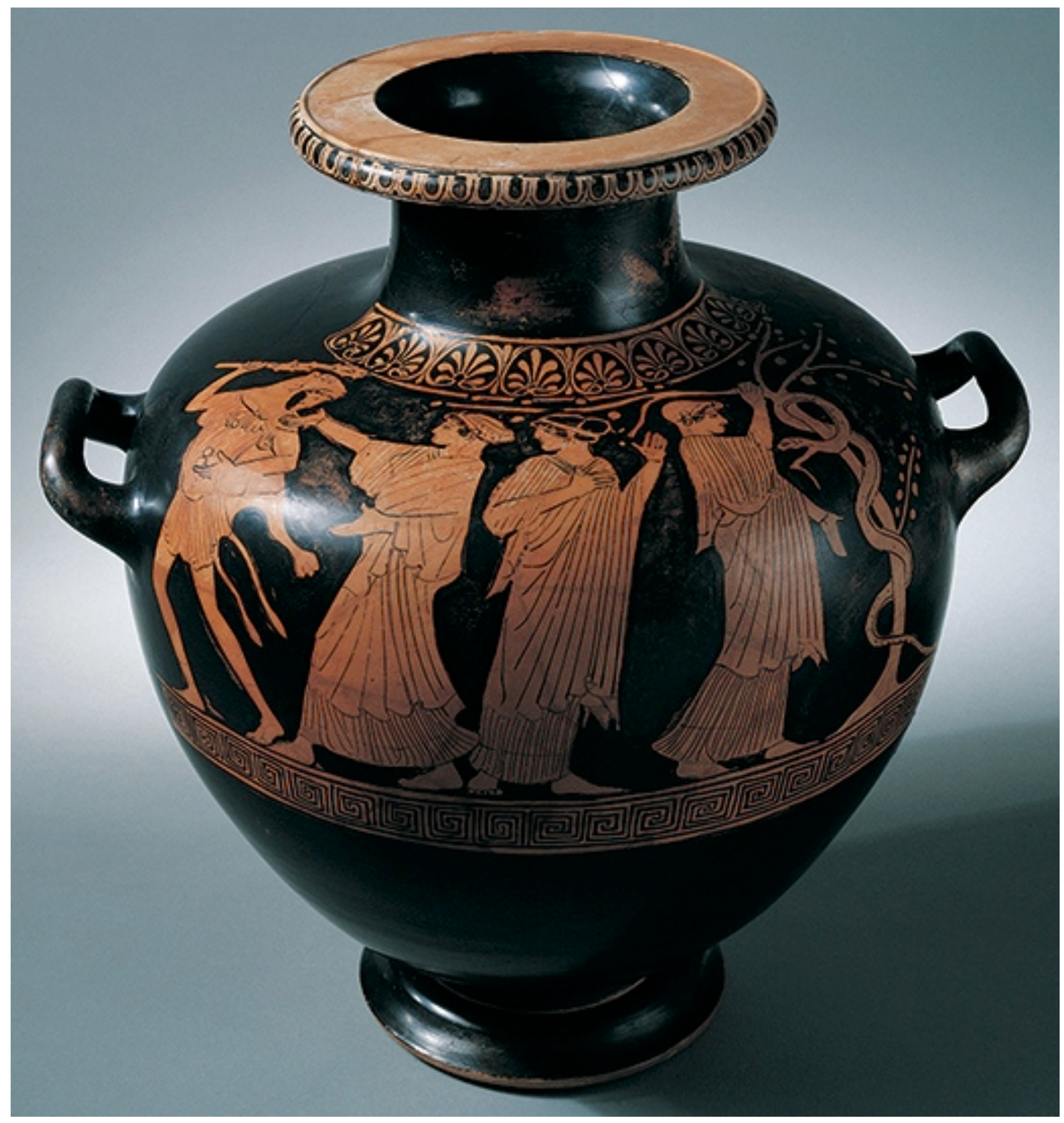

Figure 5: Syracuse Painter, red-figure hydria. ca. 475-450 BC. Champaign (IL), University of Illinois, Krannert Art Museum 70.8.4. BAPD 5159. Photo courtesy of Krannert Art Museum and Kinkead Pavilion, University of Illinois. 


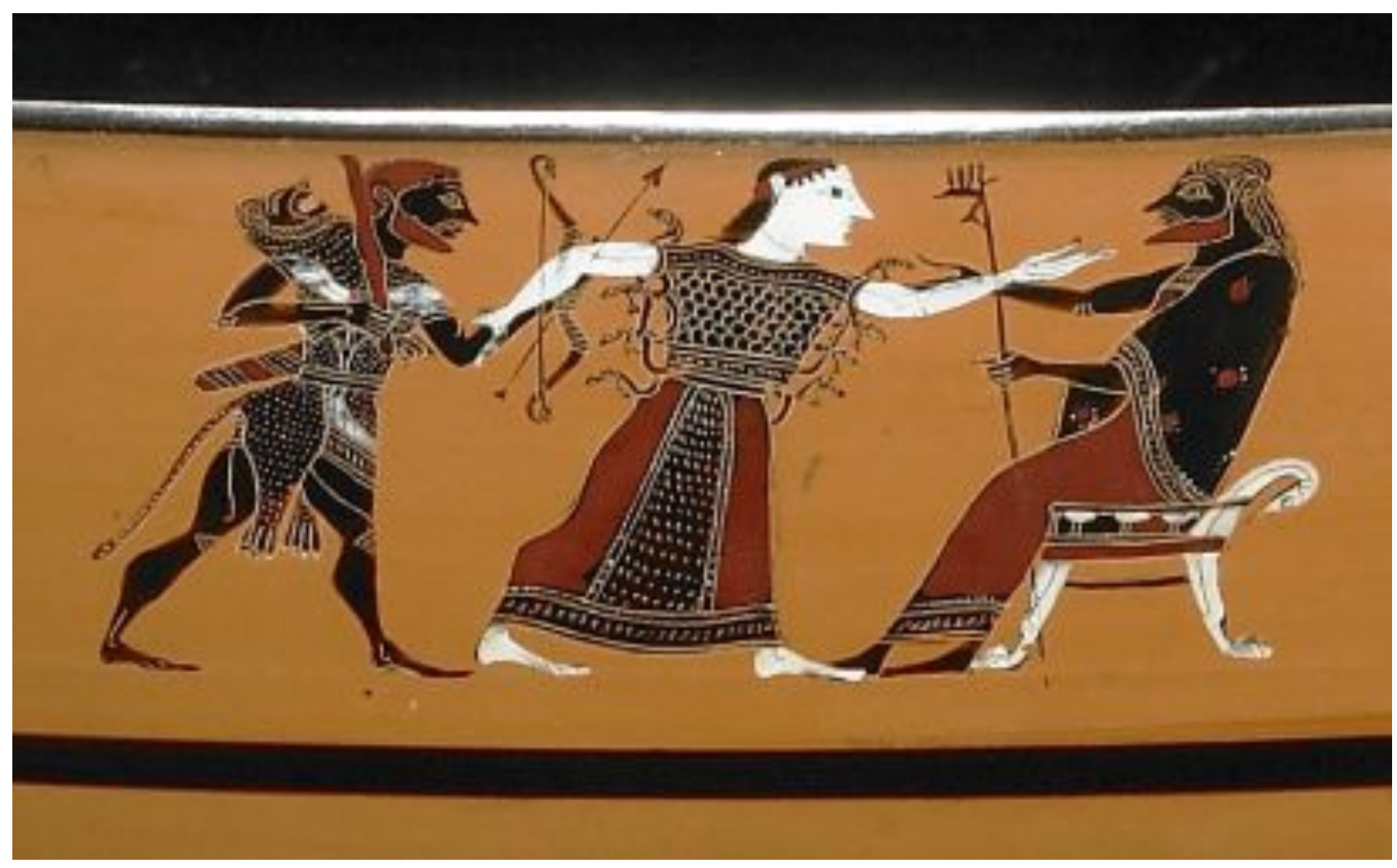

Figure 6: Phrynos Painter, black-figure Little Master lip cup. ca. 575-525 BC. London, British Museum B424. $A B V$ 168, 169.3. Para 70. BAPD 301068. Photo (C) Trustees of the British Museum. 


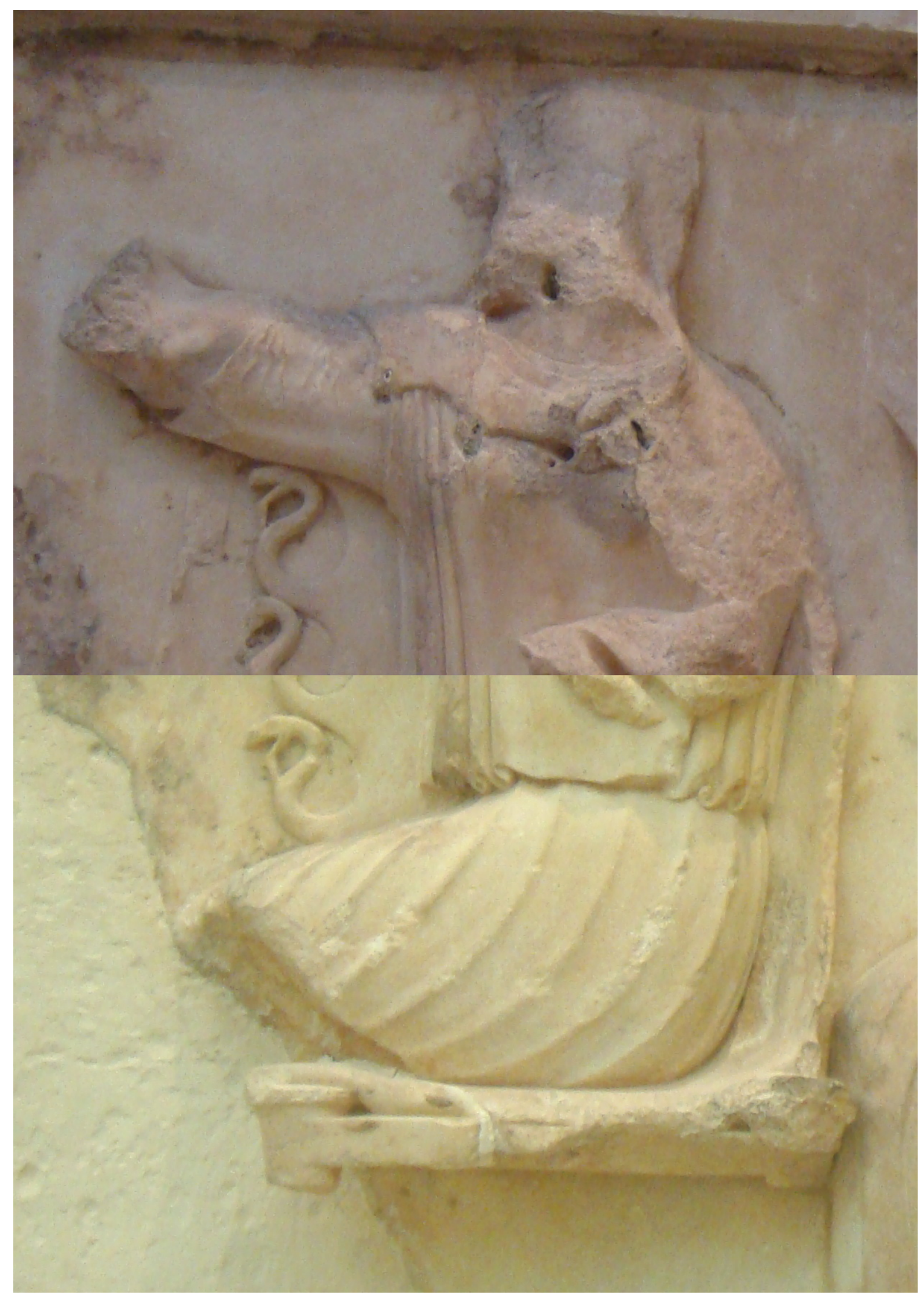

Figure 7: Delphi, Siphnian Treasury, detail of Athena from east frieze. ca. 525 BC. Delphi, Archaeological Museum. Photo J. Murdoch. 


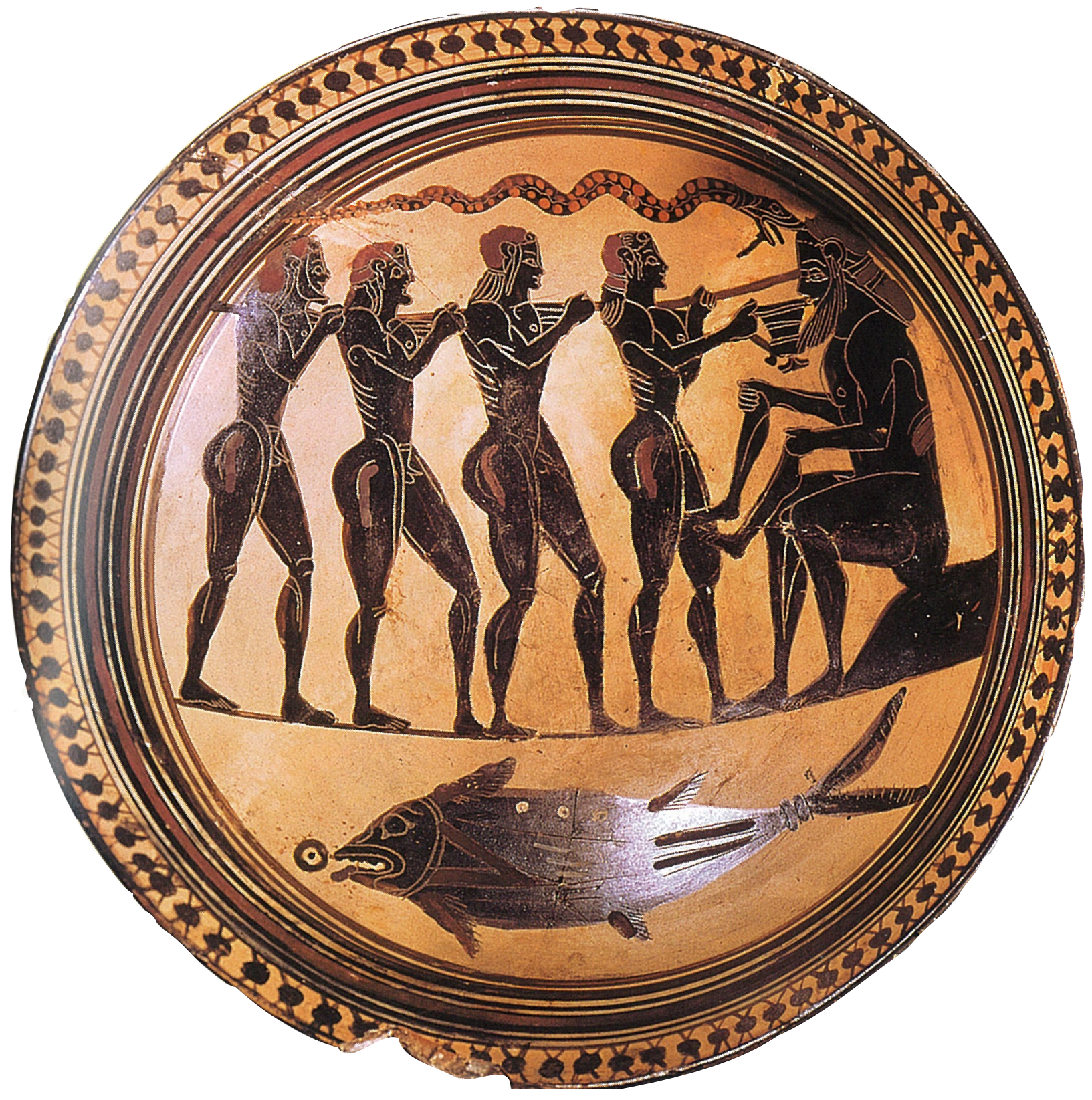

Figure 8: Rider Painter, black-figure Lakonian kylix. ca. 550 BC. Paris, Bibliothèque Nationale, Cabinet des Médailles, 190. Spivey (1997) 91, fig. 51. 


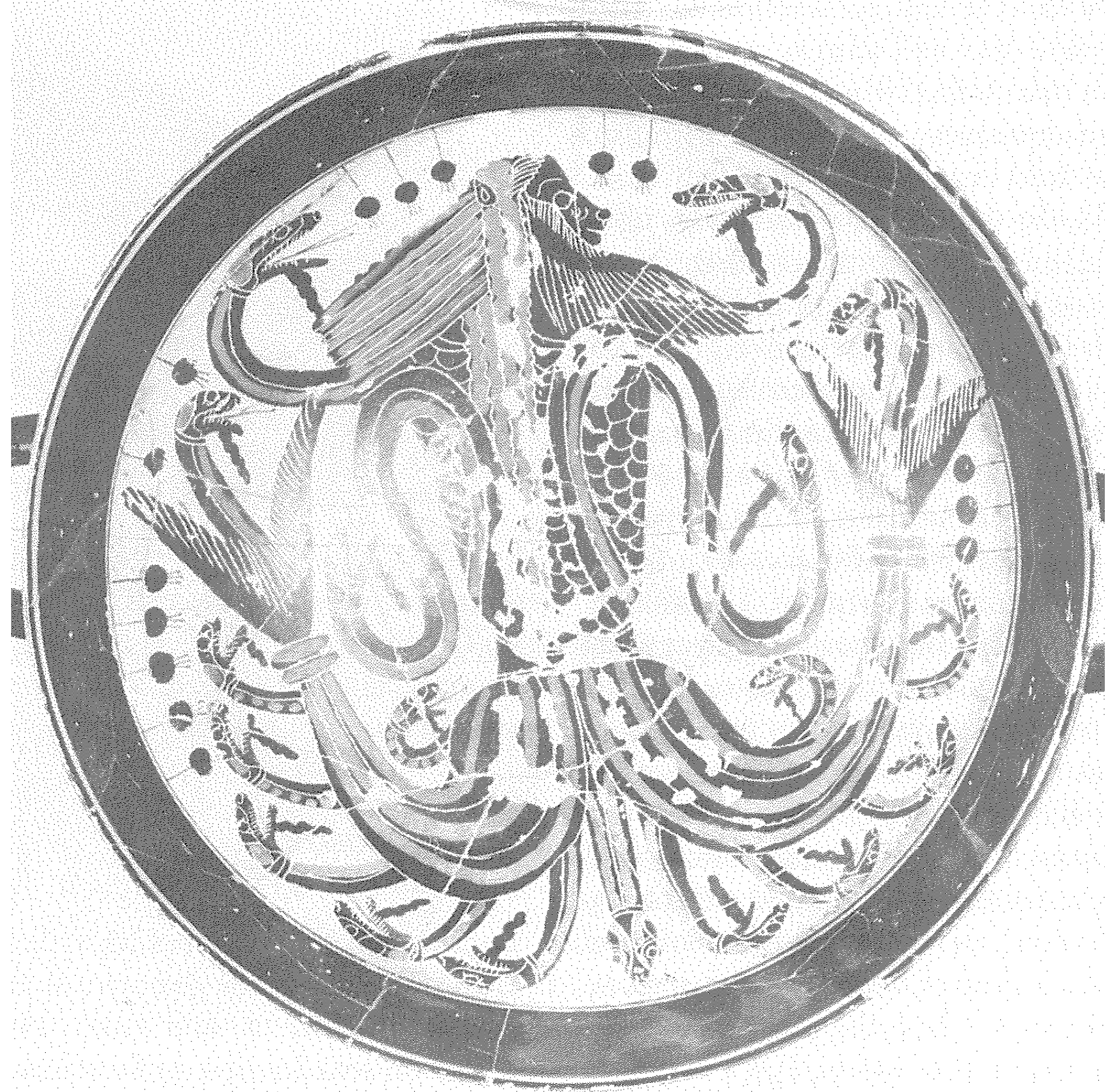

Figure 9: Typhon Painter, black-figure Lakonian kylix. ca. 550 BC. Cerveteri, National Archaeological Museum 67658. Pipili (1987) 70, fig. 102. 


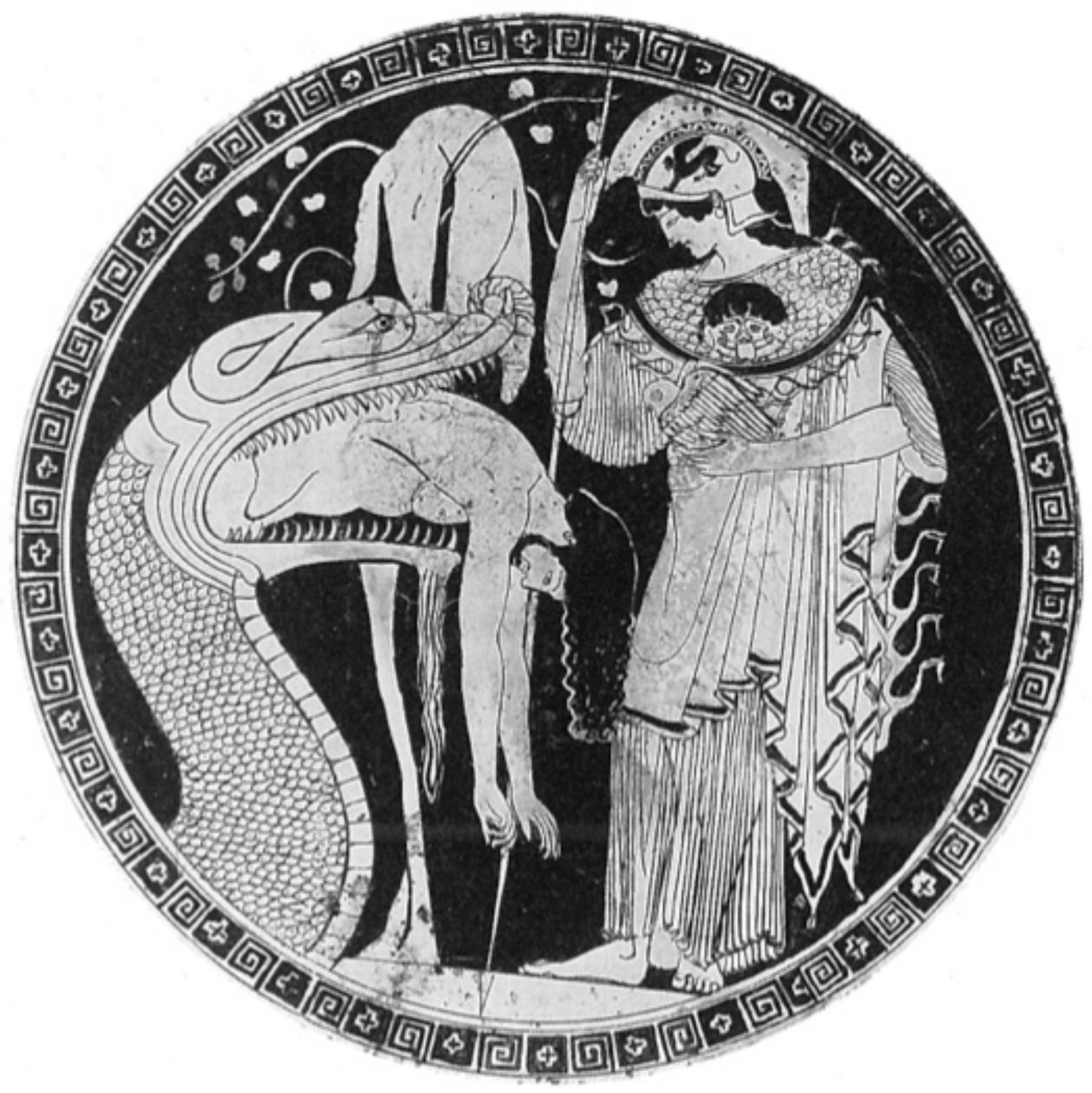

Figure 10: Douris, red-figure kylix. ca. 500-450 BC. Vatican City, Museo Gregoriano Etrusco Vaticano 16545. $A R V^{2}$ 437.116, 1653. BAPD 205162. Boardman (2001) 91, fig. 124. 


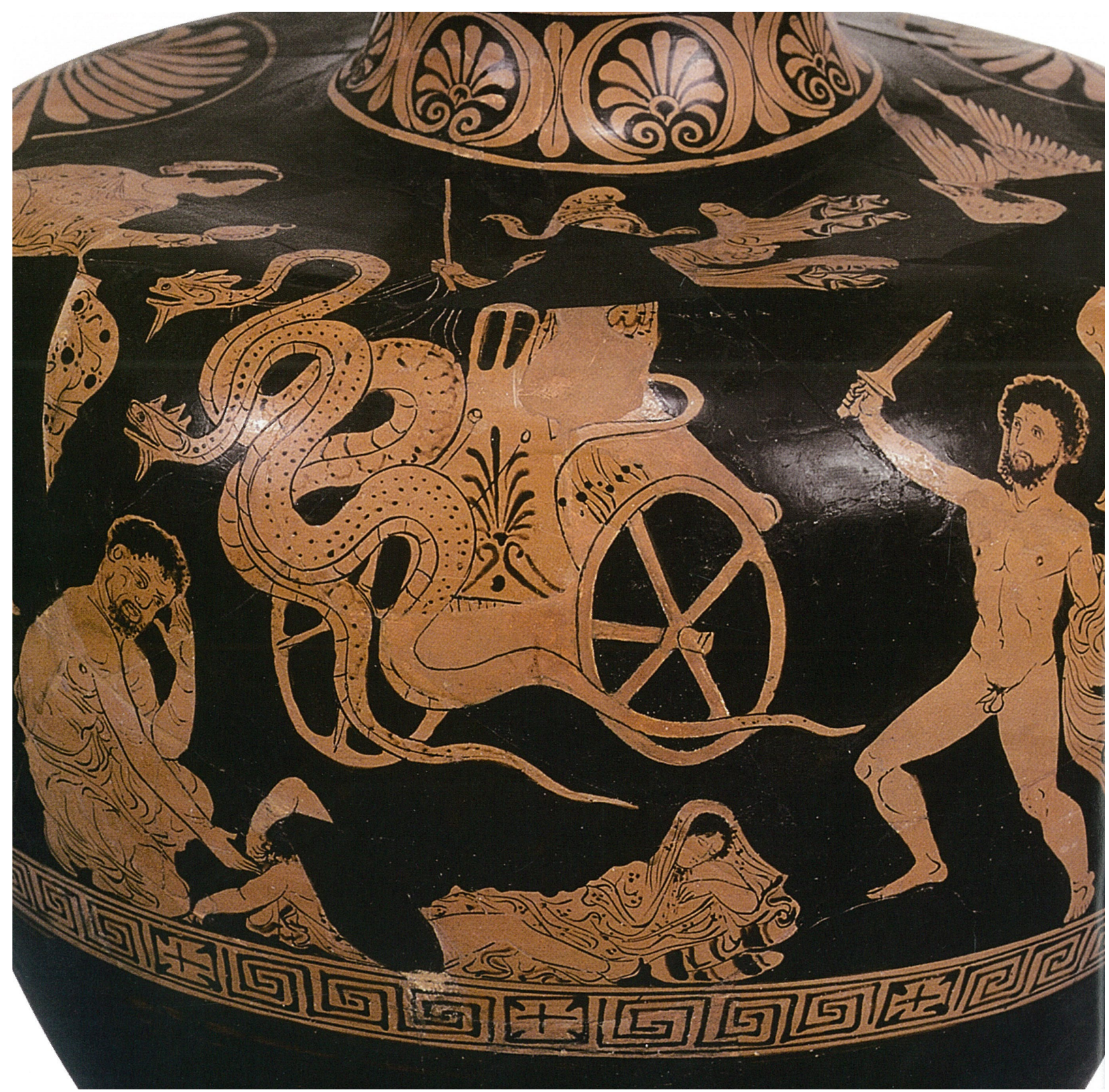

Figure 11: Policoro Painter, red-figure Lucanian hydria. ca. 400 BC. Policoro, Museo Nazionale della Siritide 35296. Taplin (2007) 118, fig. 34. 


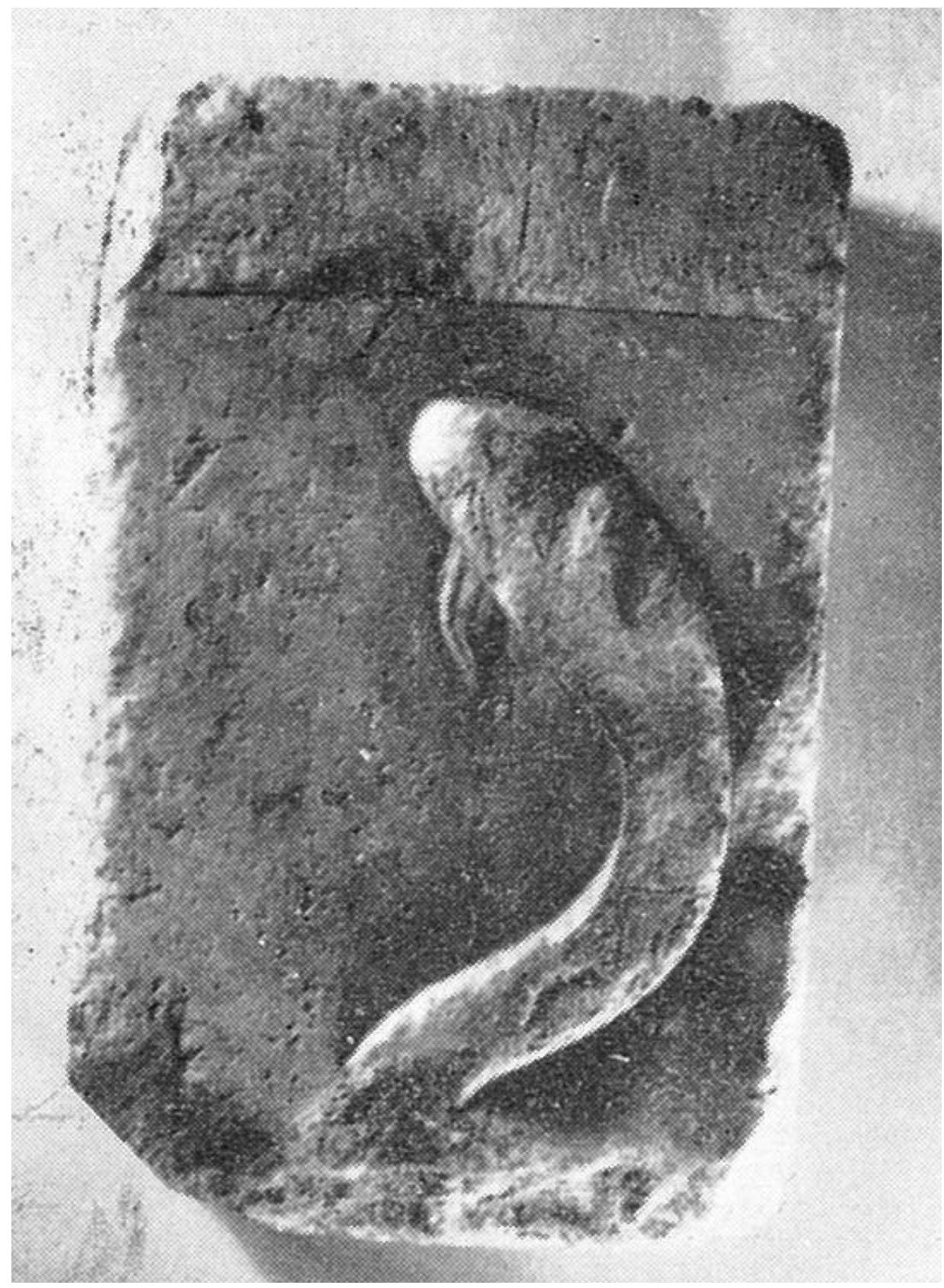

Figure 12: Fragmentary votive relief of Zeus Meilichios. 4th century BC. Athens, Agora Museum S 1238. Mitropoulou (1977) 120, fig. 52. 


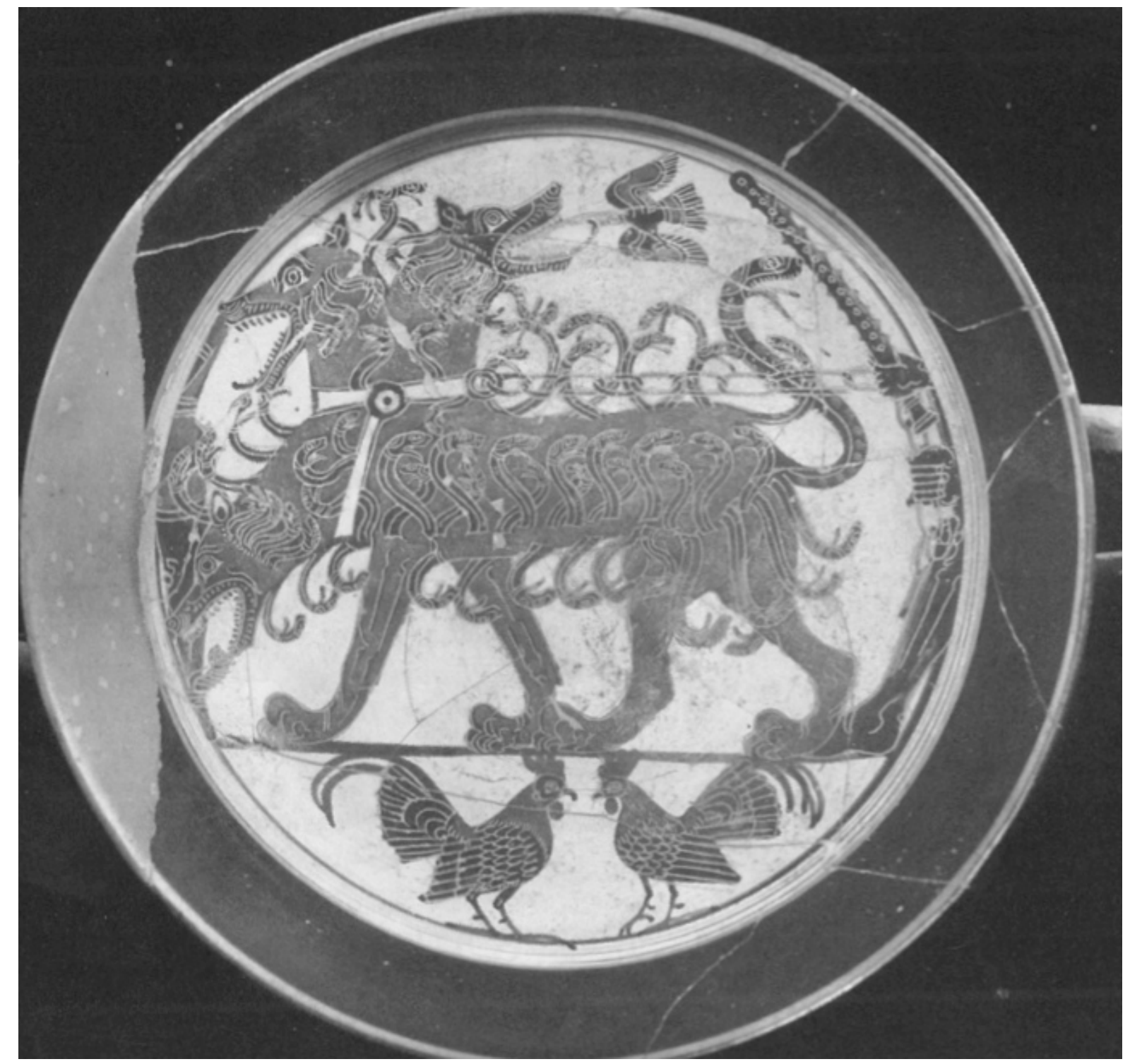

Figure 13: Hunt Painter, black-figure Lakonian kylix. ca. 575-525 BC. London, Erskine Collection. $B A P D$ 800006. Pipili (1987) 6, fig. 8, cat. 12. 


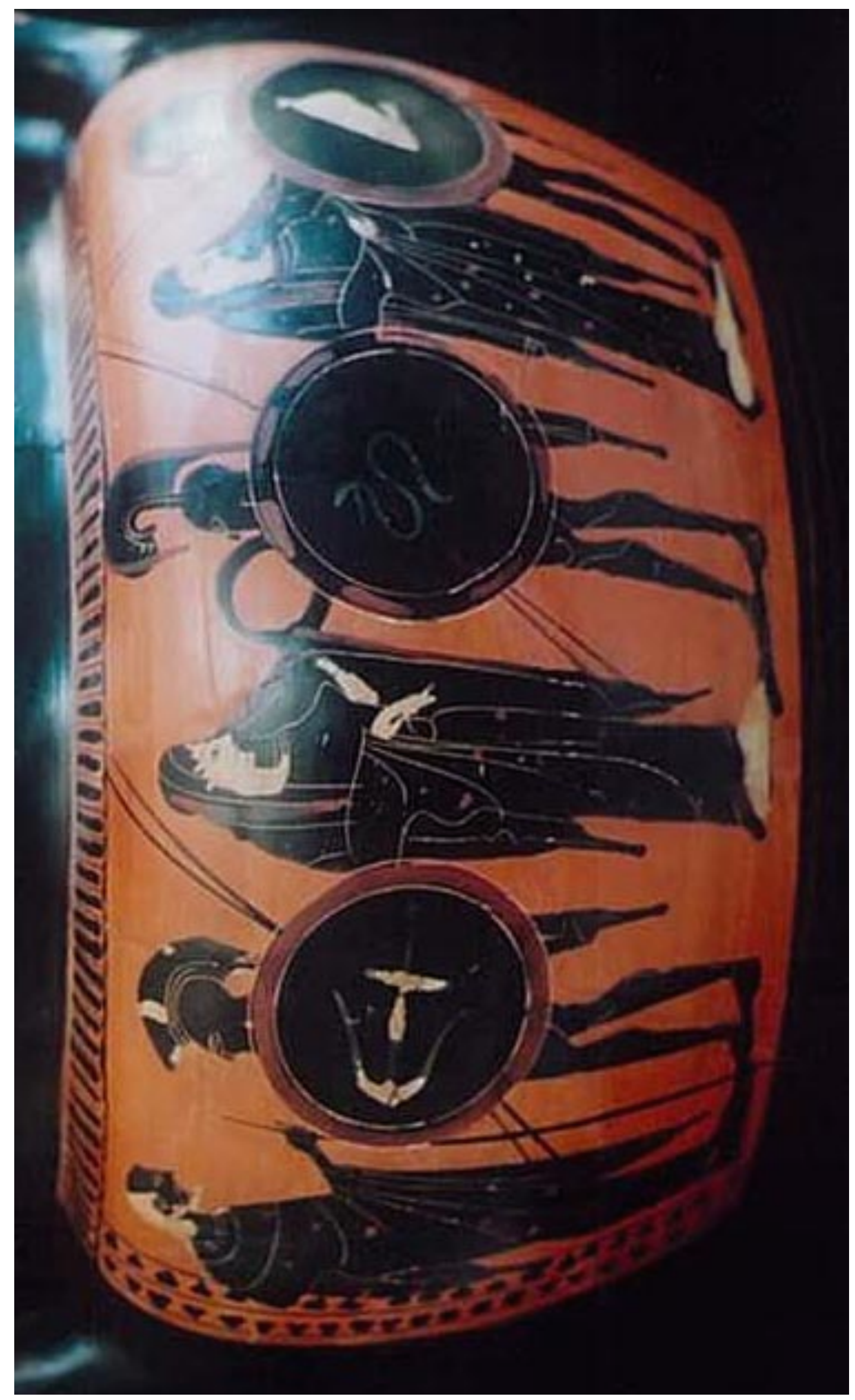

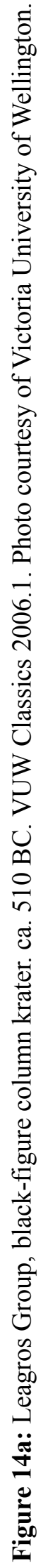




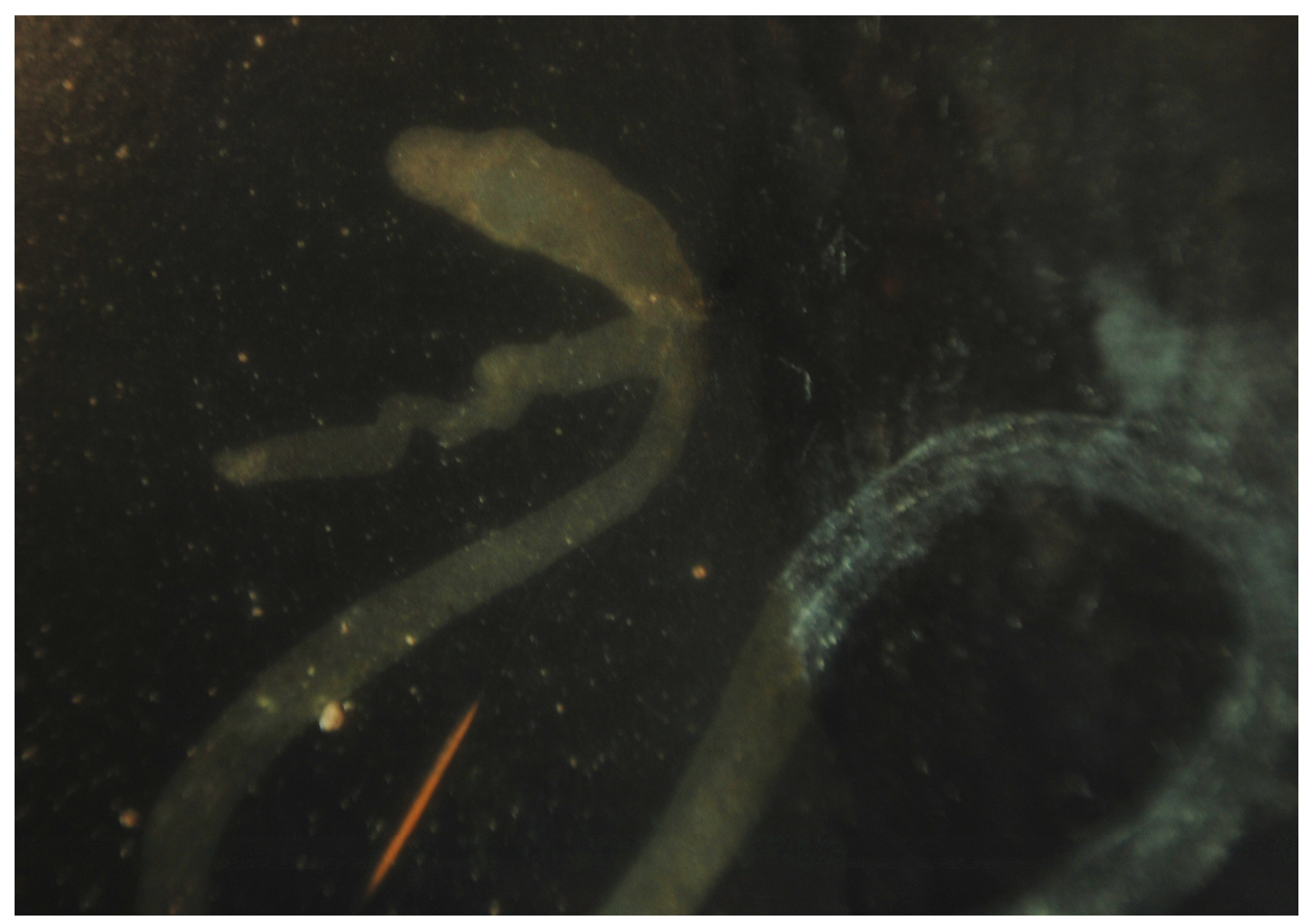

Figure 14b: Leagros Group, black-figure column krater, detail of snake from central shield. Photo courtesy of N. Carter. 


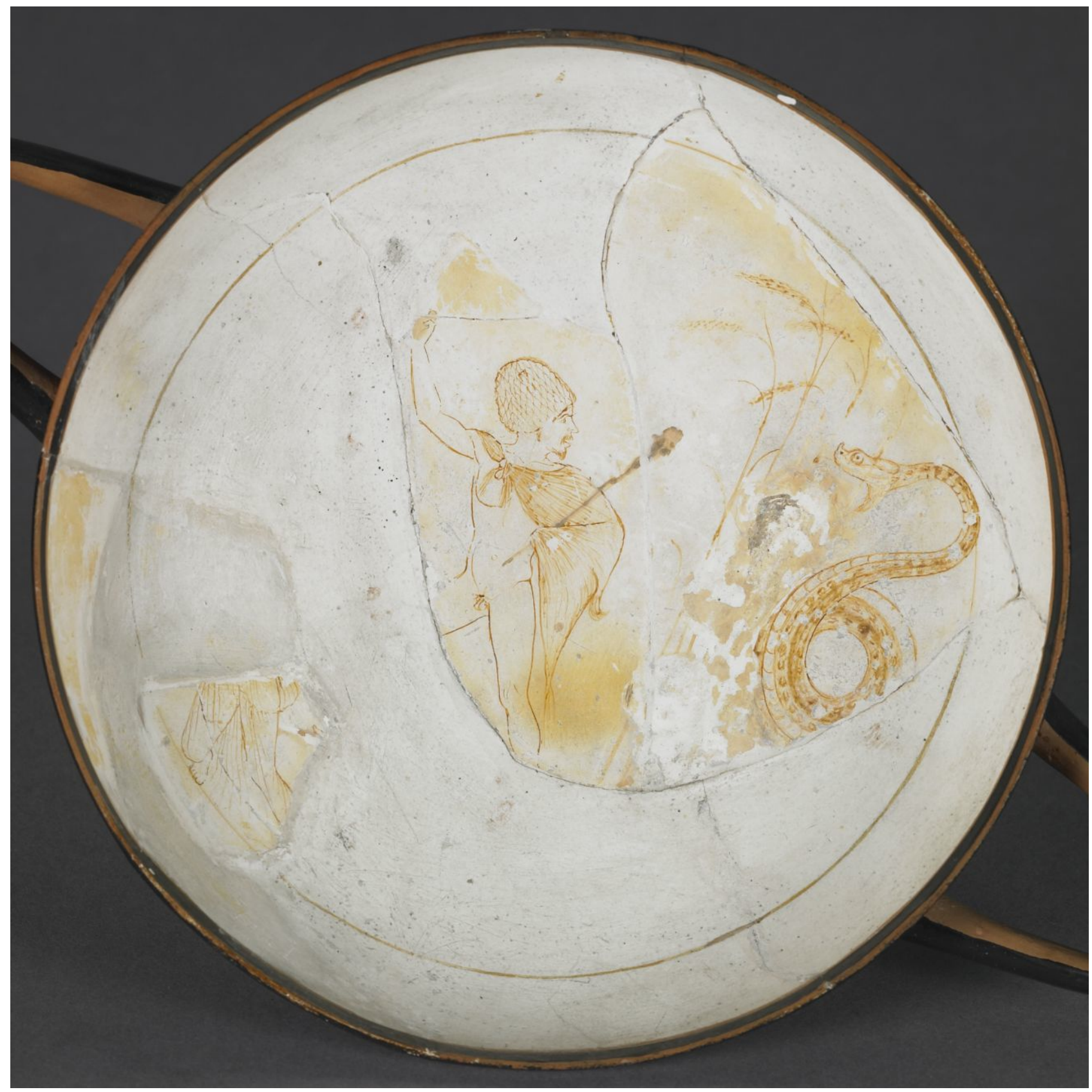

Figure 15a: Sotades Painter, white ground kylix. ca. 500-450 BC. London, British Museum D7. $A R V^{2}$ 763.3. BAPD 209460. Photo (C) Trustees of the British Museum. 


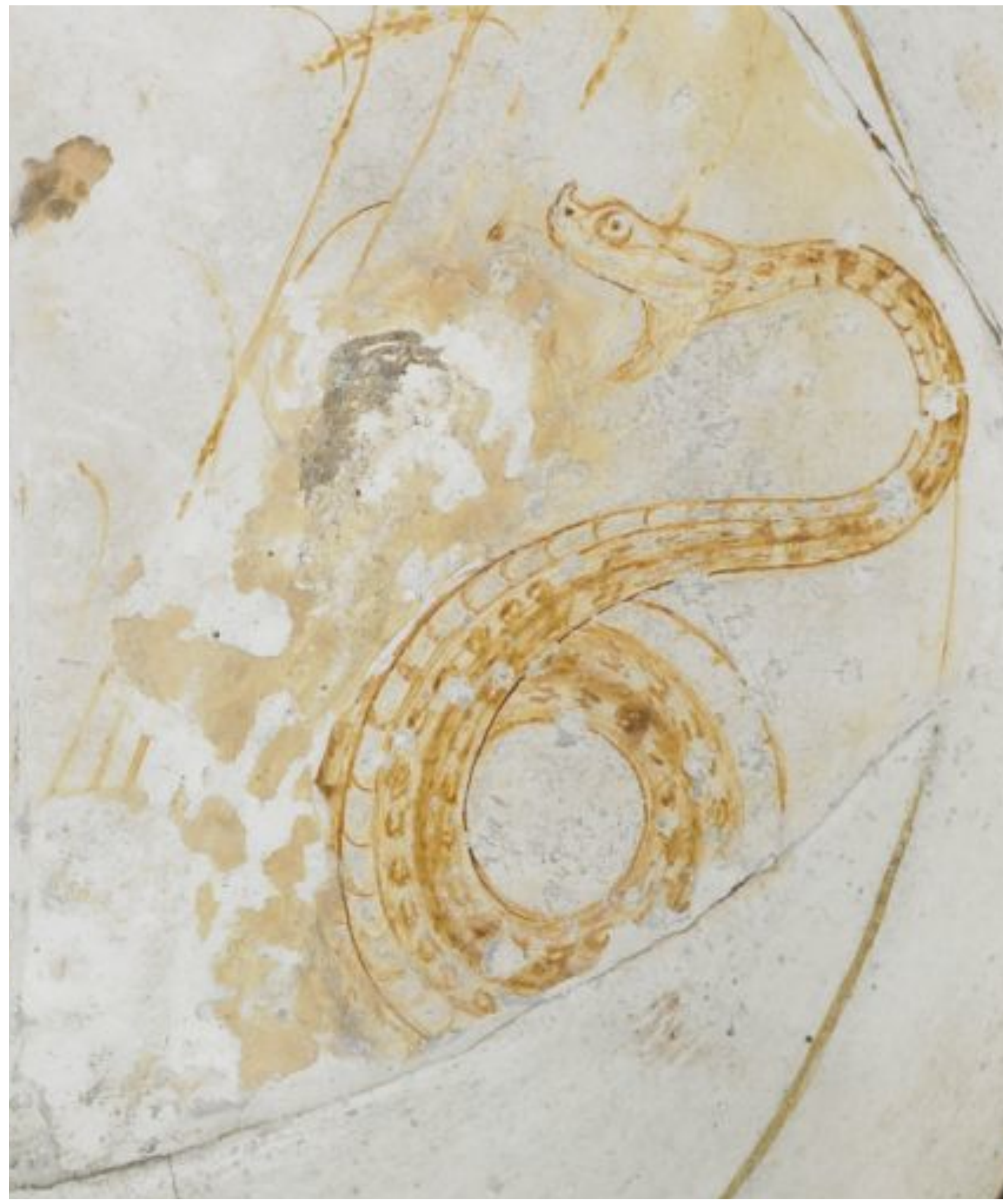

Figure 15b: Sotades Painter, white ground kylix, detail of serpent. Photo ${ }^{C}$ Trustees of the British Museum. 


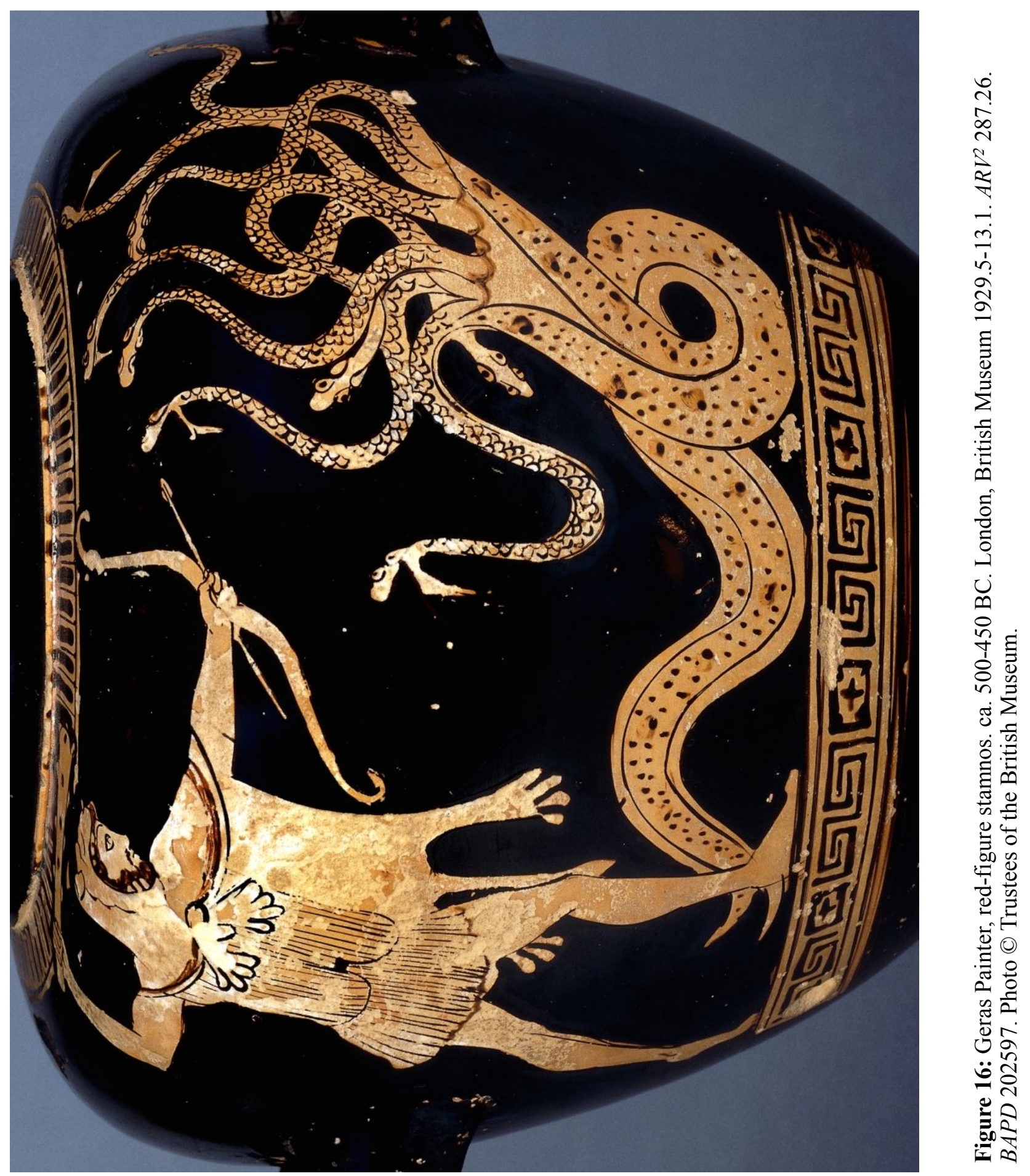




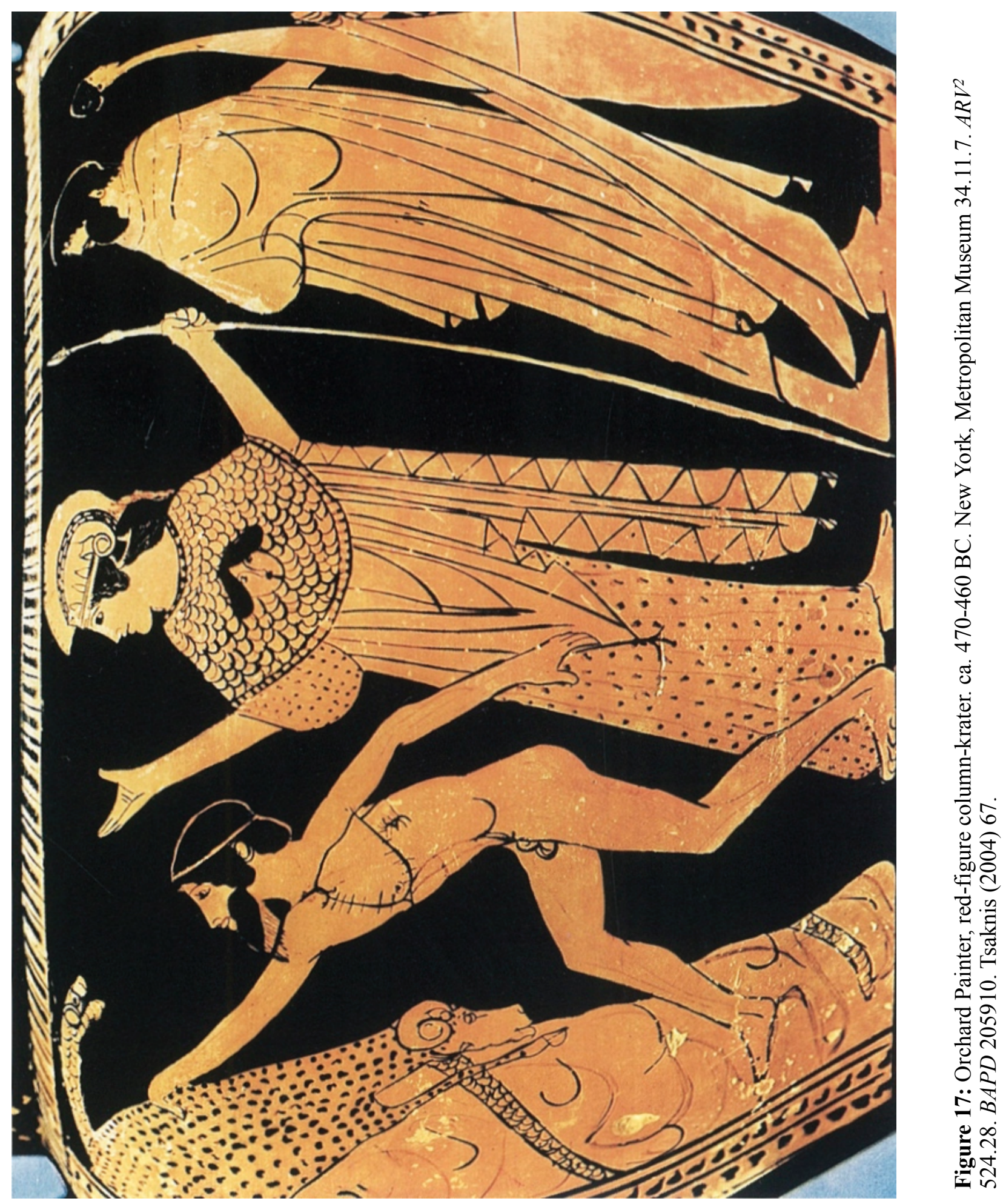




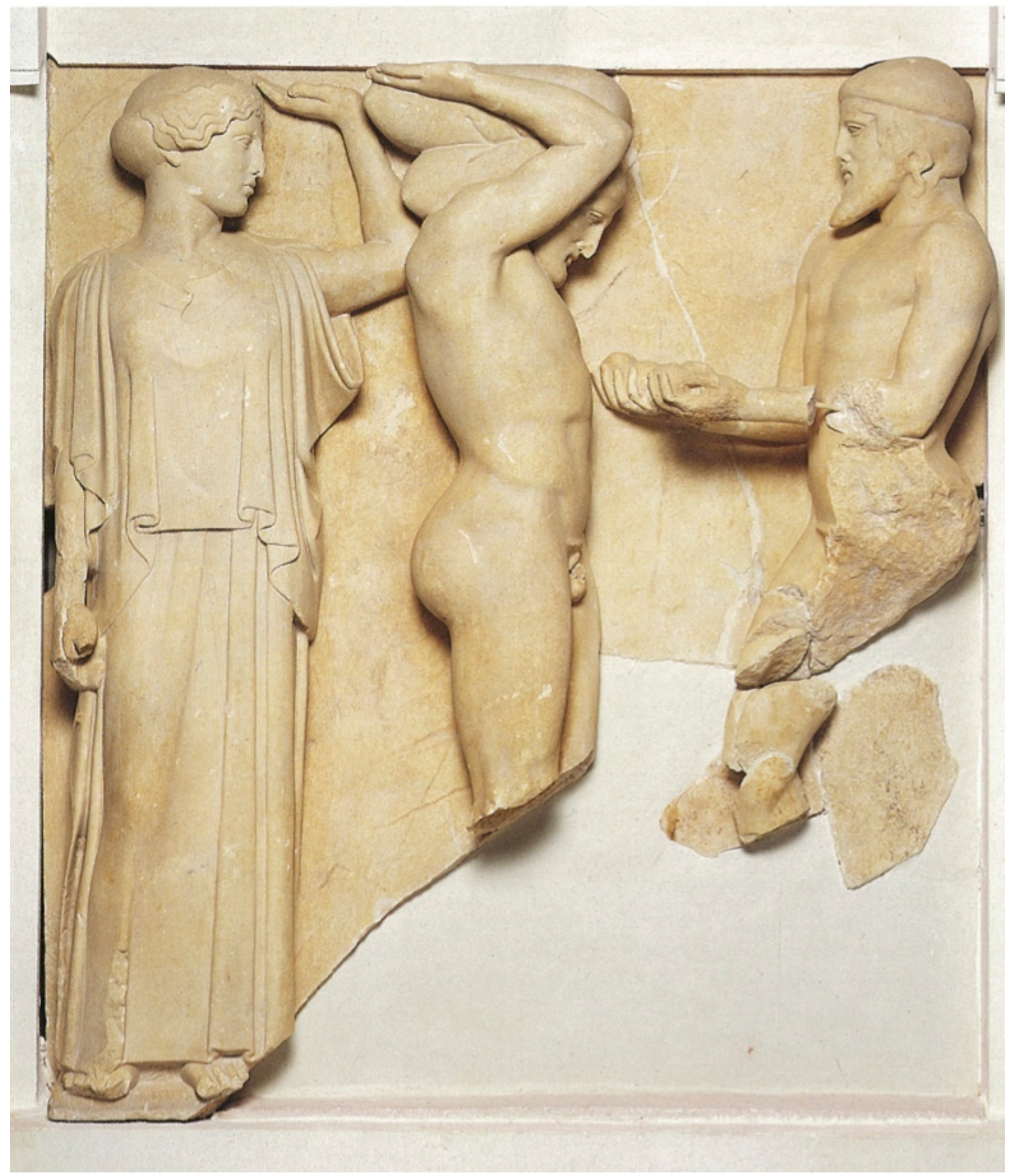

Figure 18: Olympia, Temple of Zeus east porch metope, eleventh labour of Herakles. ca. 460 BC. Olympia, Archaeological Museum. Kaltsas (2000) 80, fig. 100. 


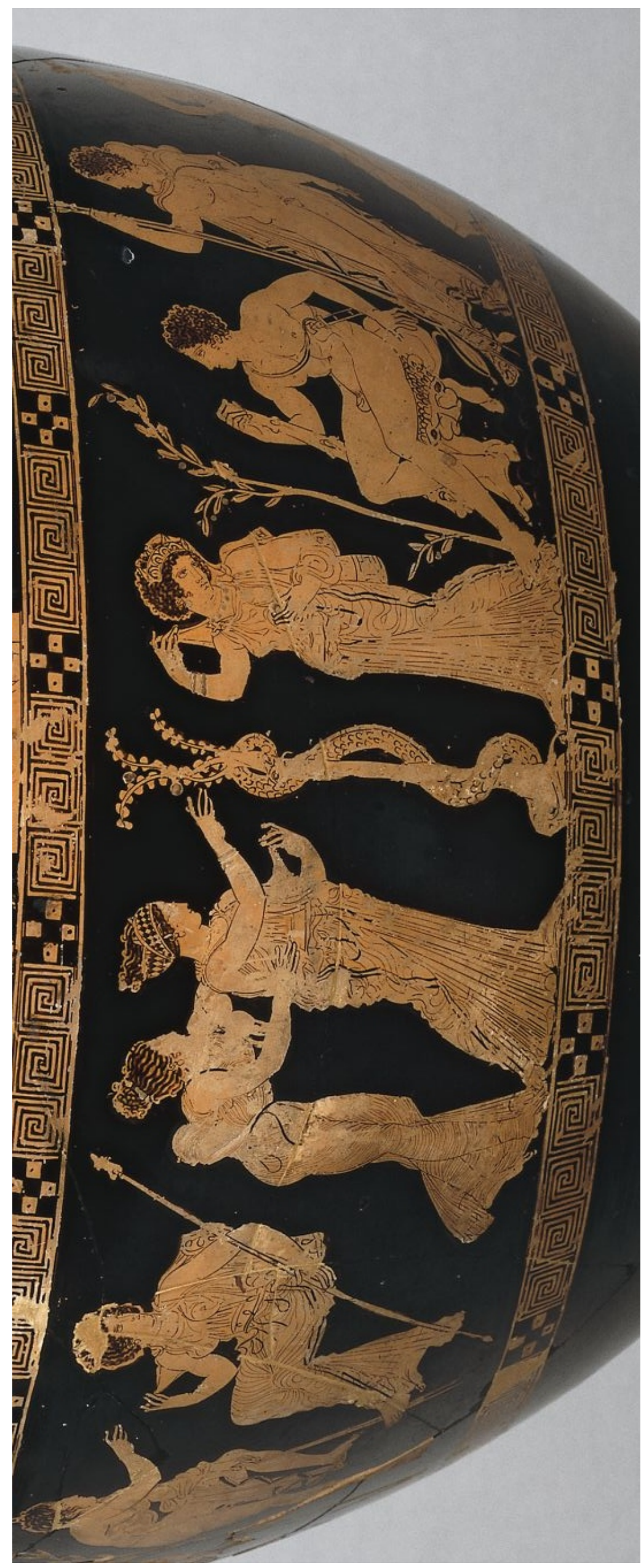

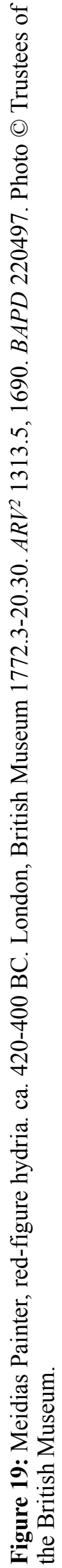




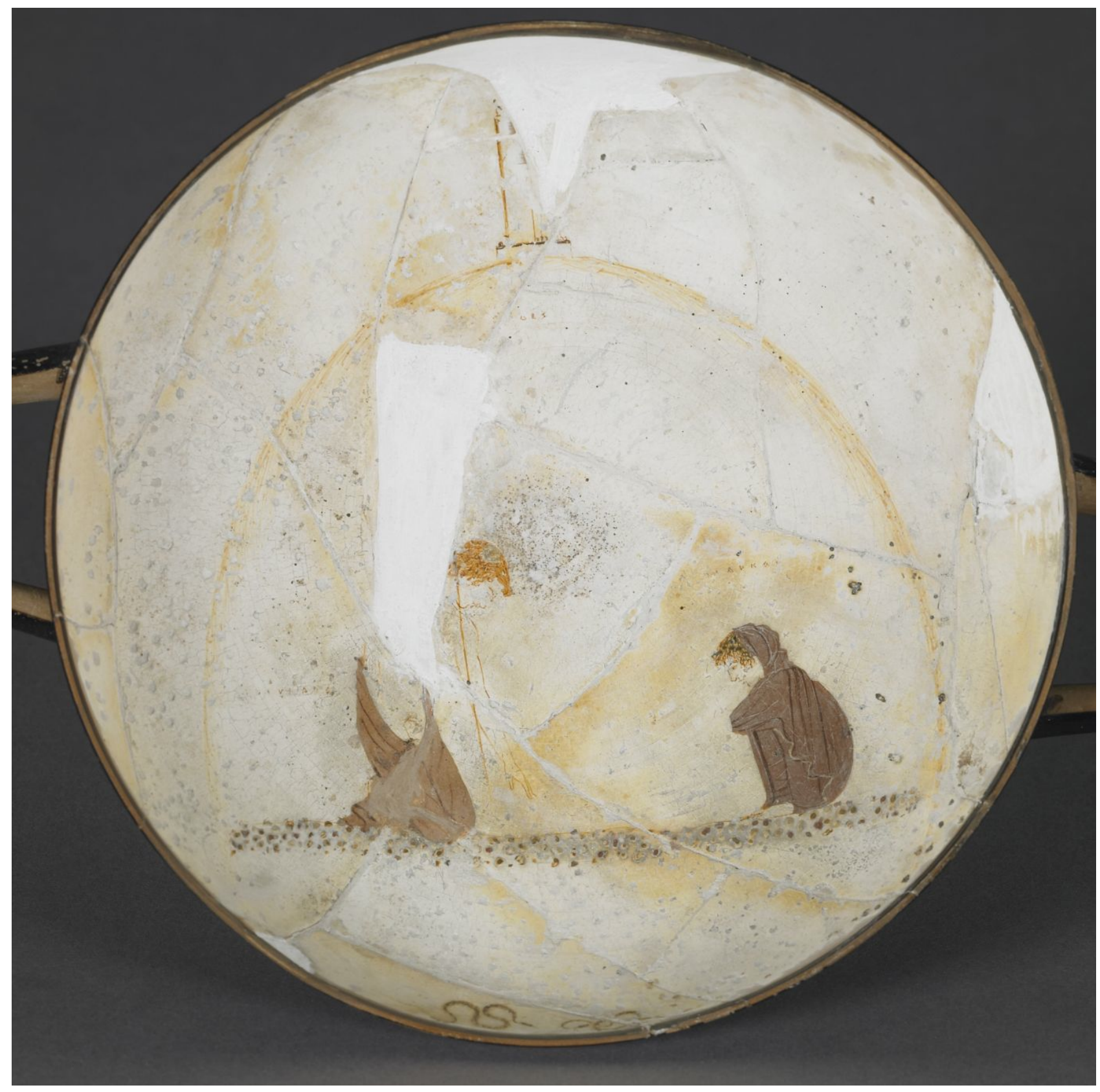

Figure 20a: Sotades Painter, white ground kylix. ca. 500-450 BC. London, British Museum D5. $A R V^{2}$ 763.2. BAPD 209459. Photo (C) Trustees of the British Museum. 


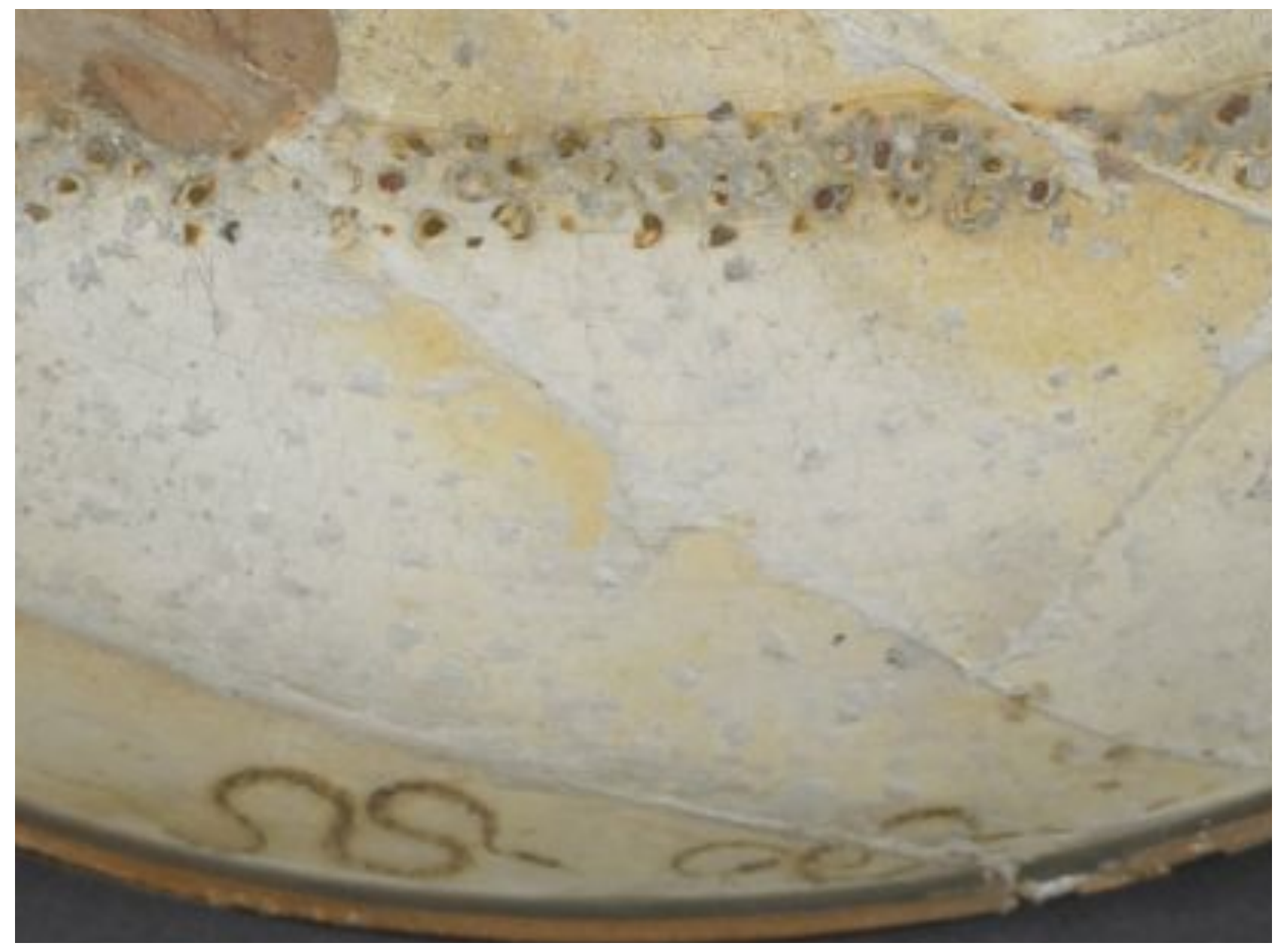

Figure 20b: Sotades Painter, white ground kylix, detail of snakes underground. Photo $($ C Trustees of the British Museum. 


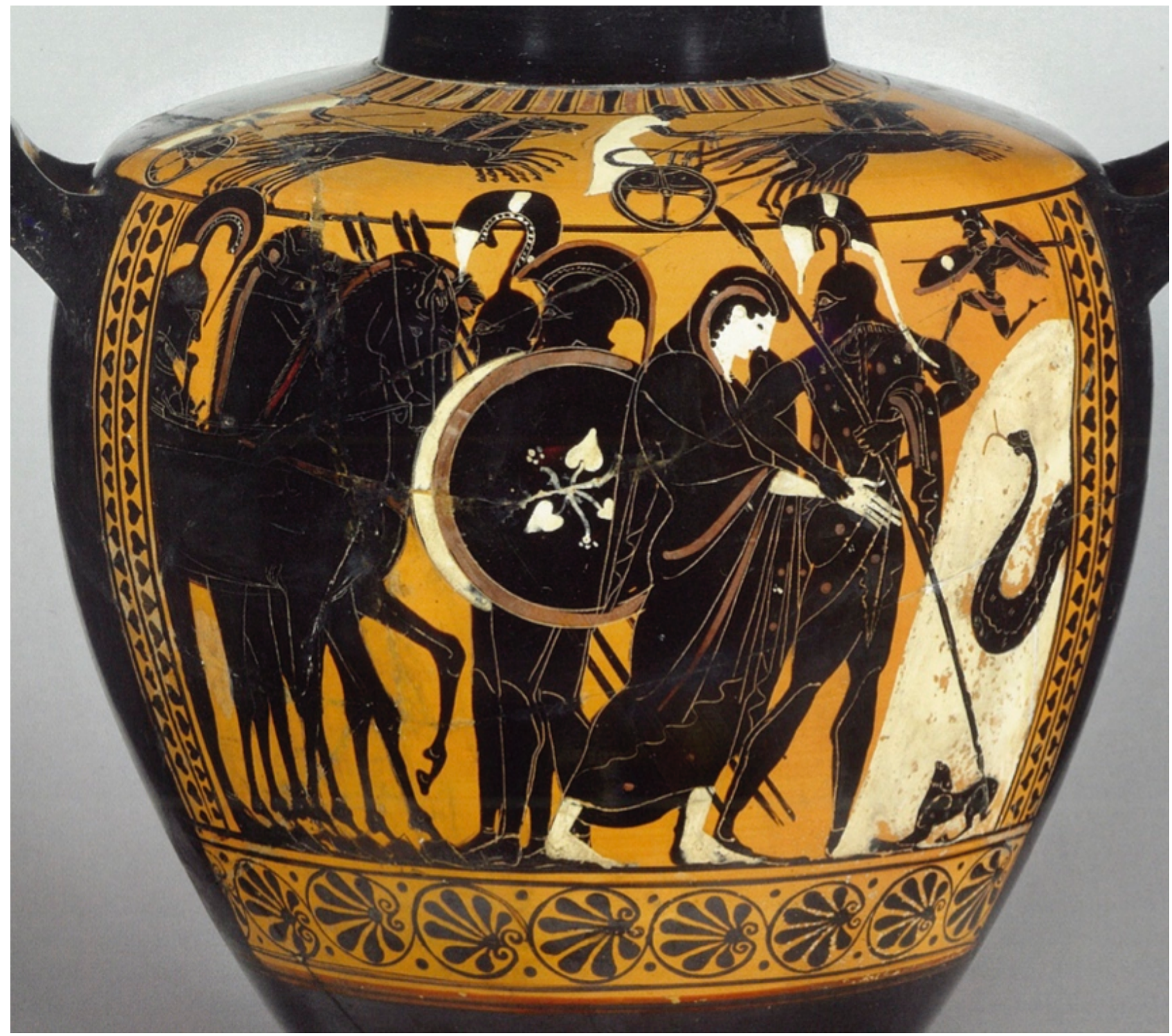

Figure 21: Leagros Group, black-figure hydria.ca. 550-500 BC. Berlin, Antikensammlung F1902. $A B V$ 363.37. Para 161 BAPD 302032. Backe-Dahmen, Kästner, and Schwarzmaier (2010) 45. 


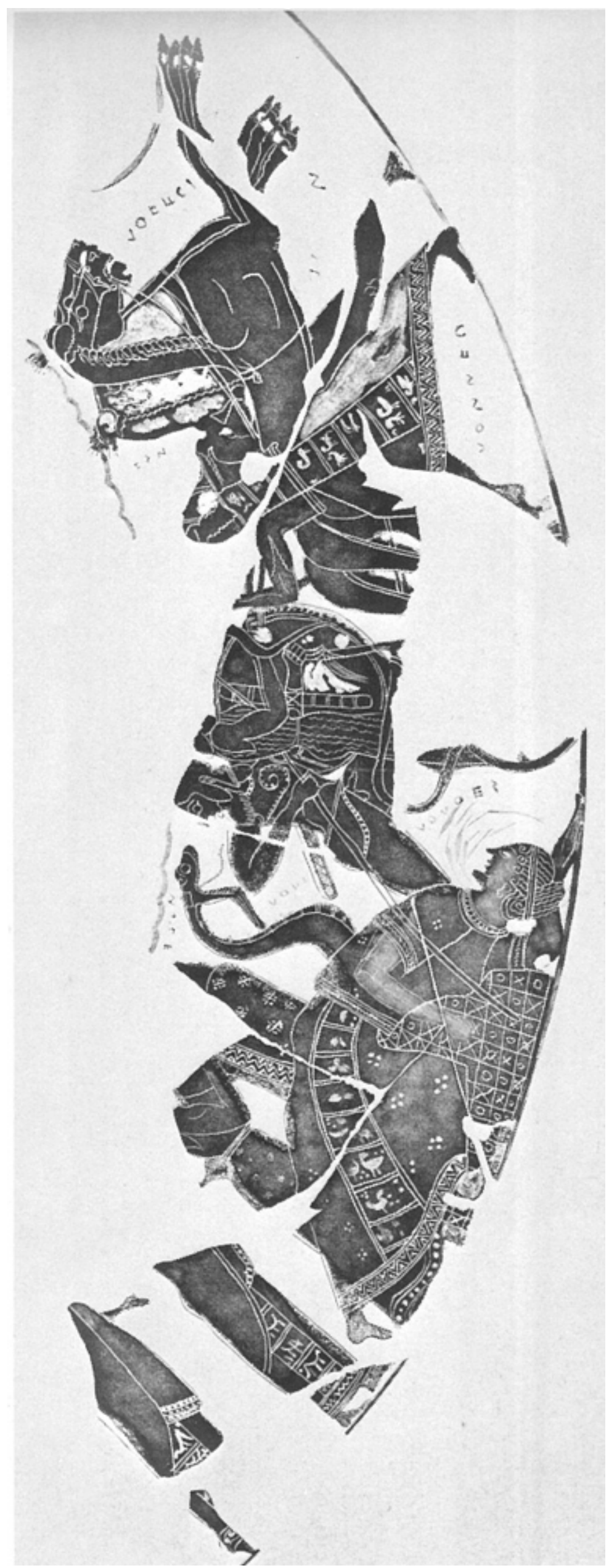

نี 


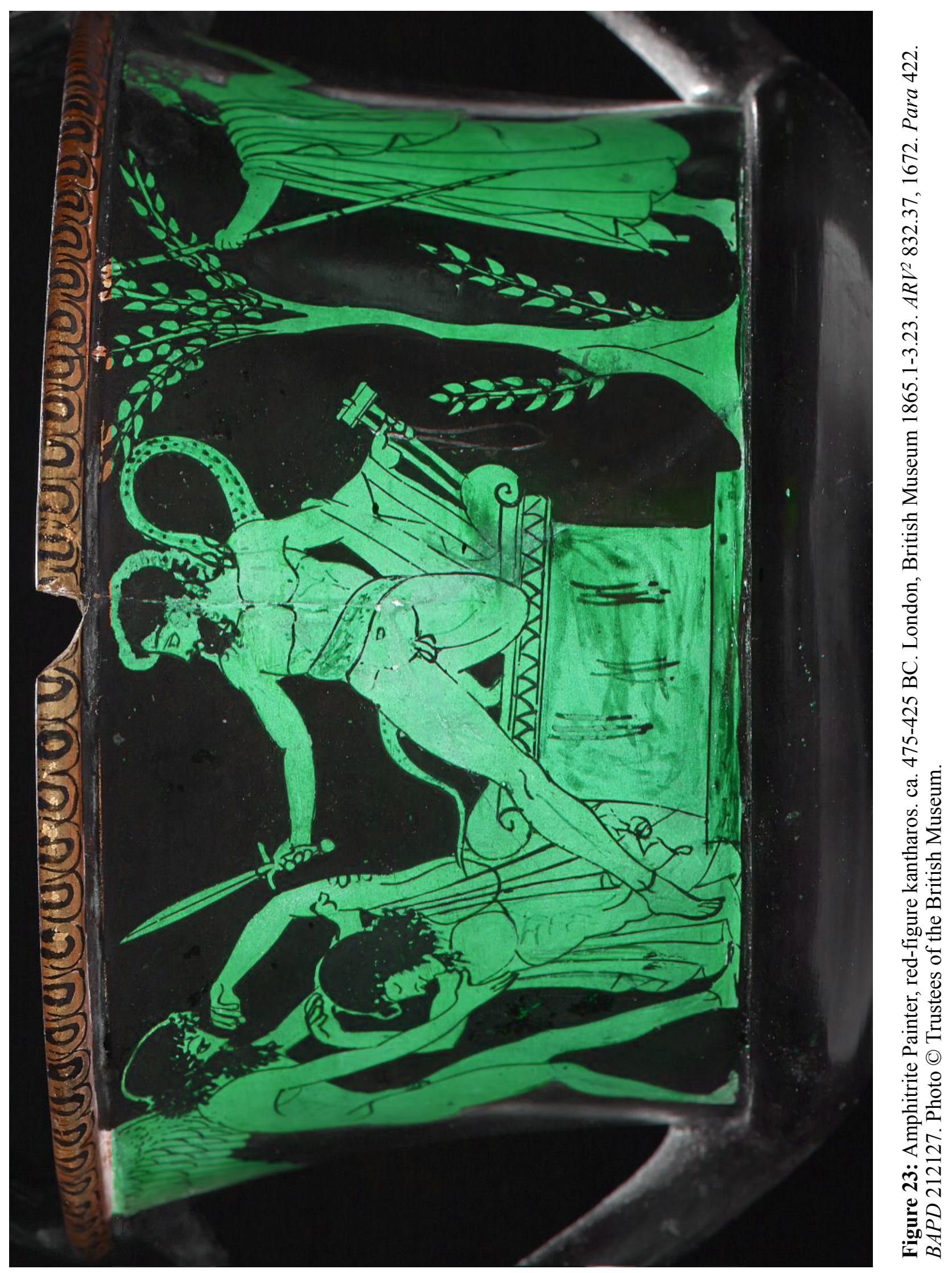




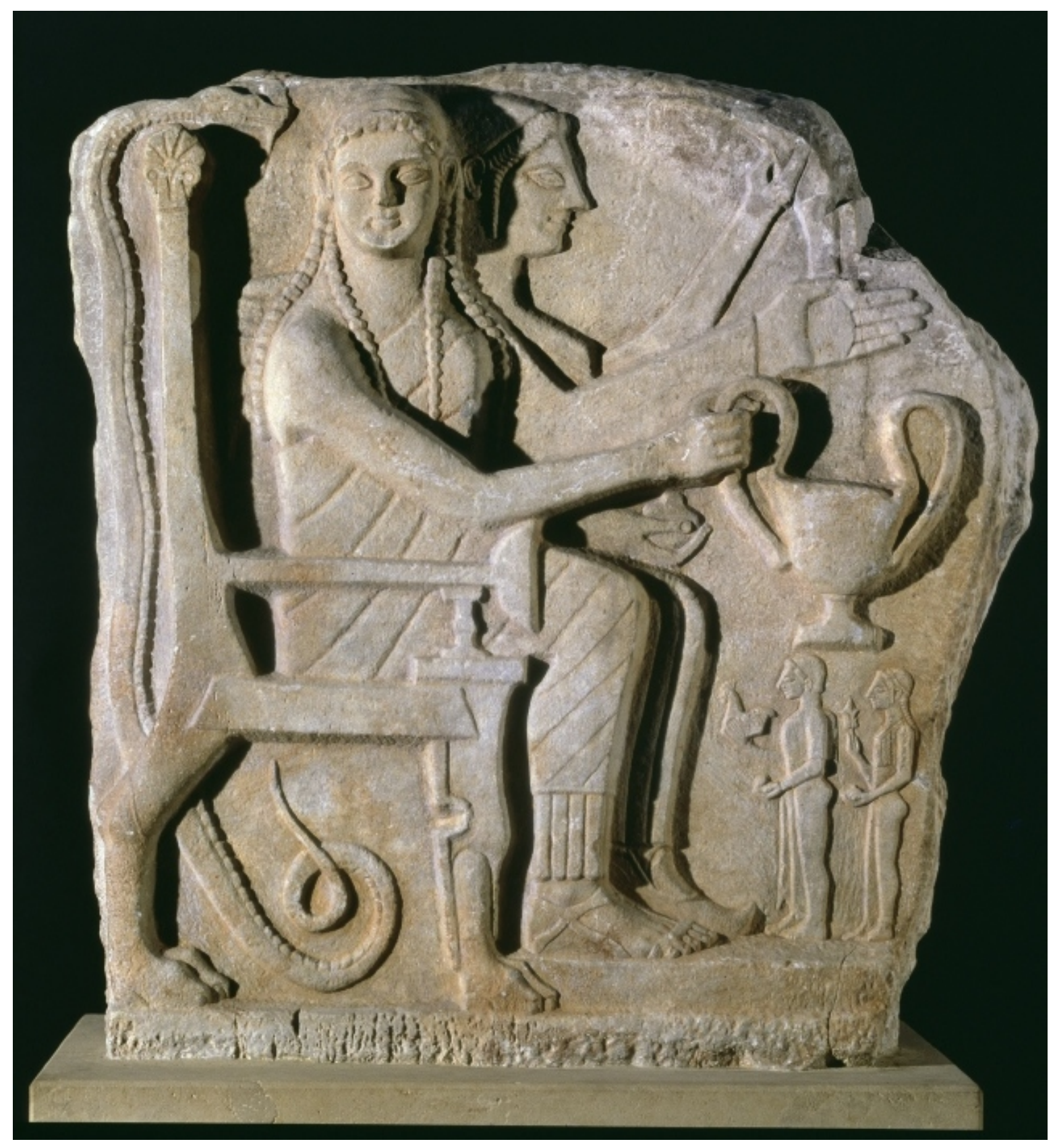

Figure 24: Lakonia, Chrysapha Relief. ca. 540 BC. Berlin, Pergamon Museum 731. Photo ( Antikensammlung der Staatliche Museen zu Berlin. 


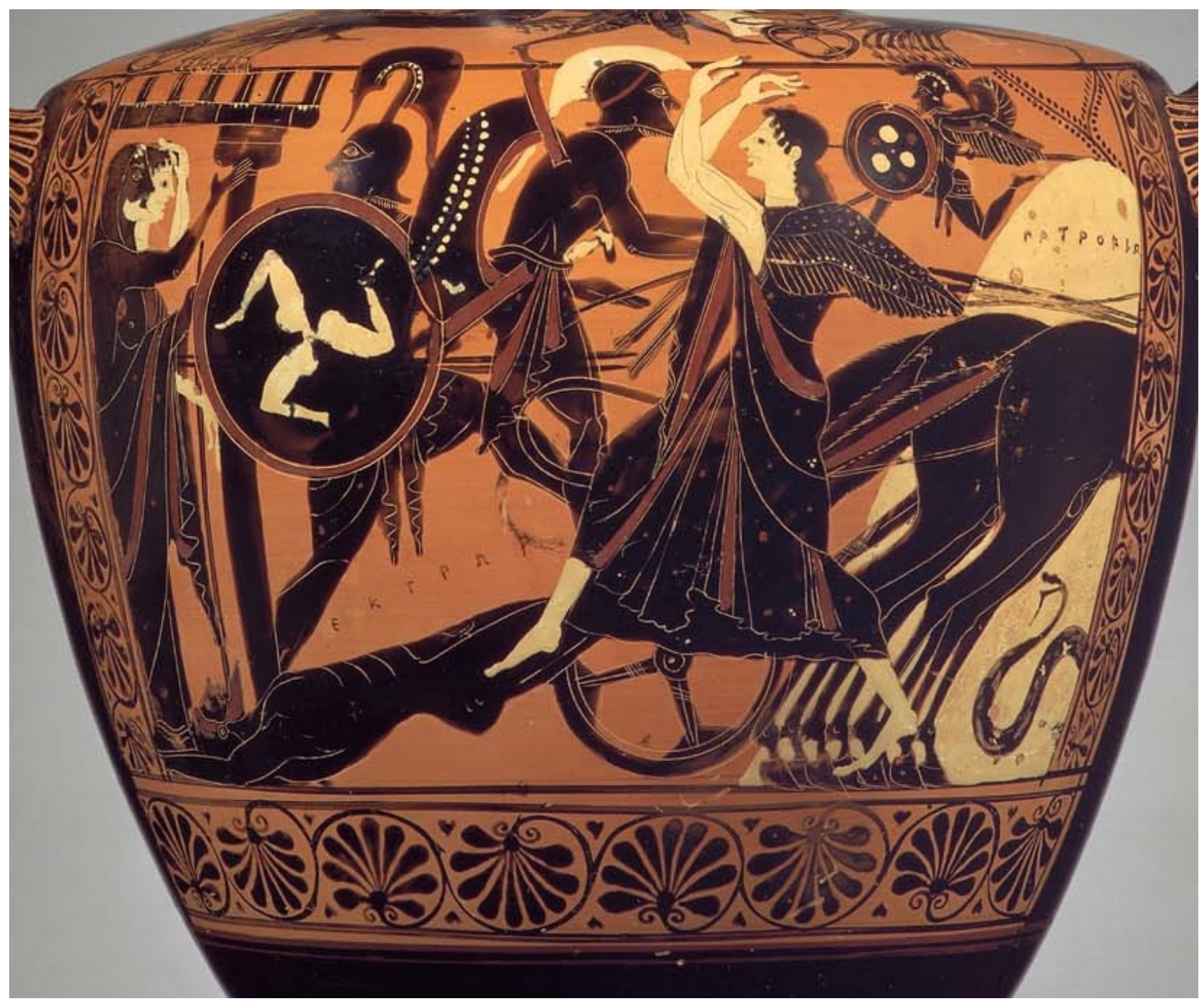

Figure 25: Leagros Group, black-figure hydria. ca. 520-510 BC. Boston, Museum of Fine Arts 63.473. Para 164.31 bis. BAPD 351200. Photo C Museum of Fine Arts. 


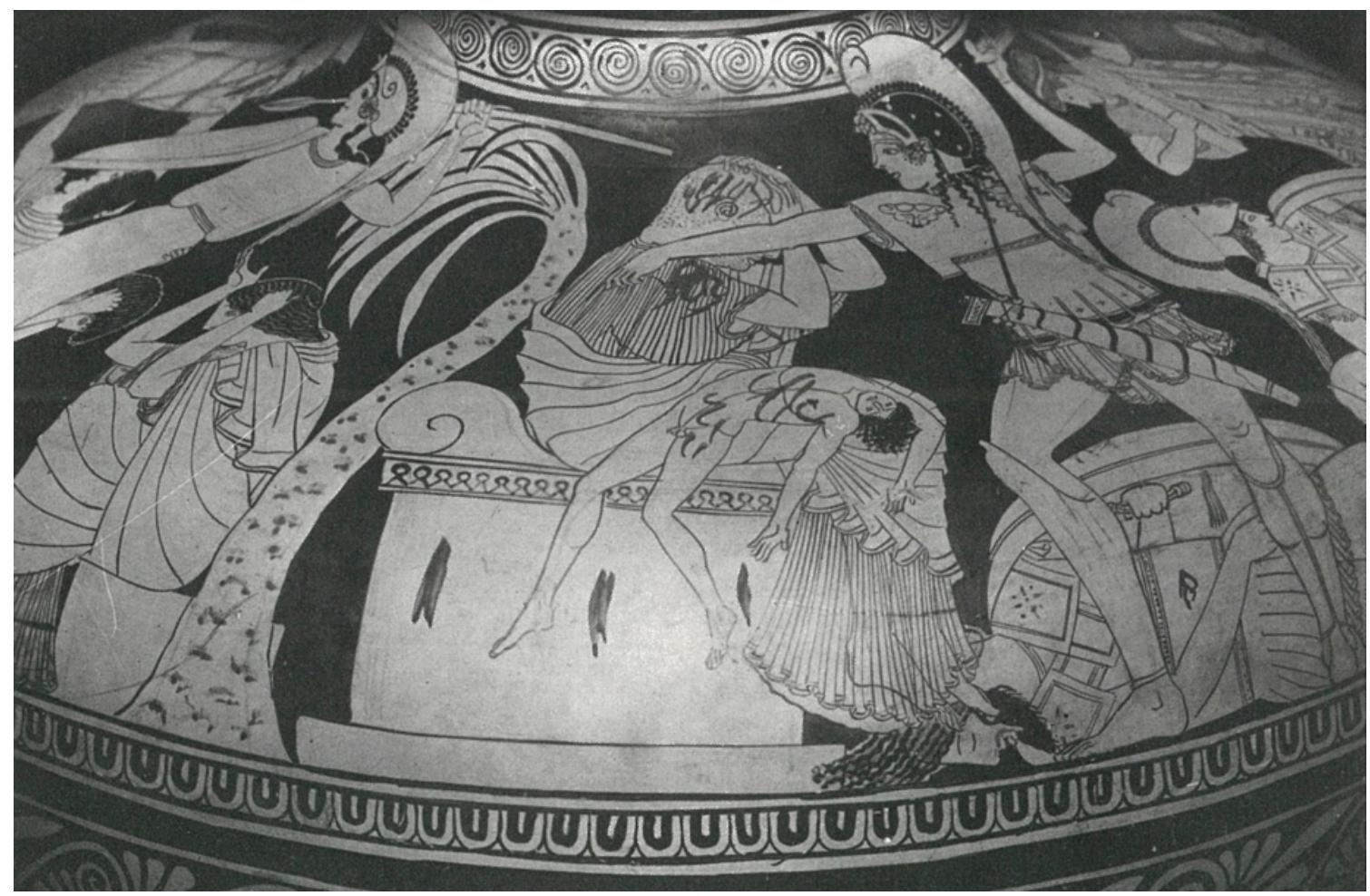

Figure 26a: Kleophrades Painter, red-figure hydria, detail of Priam, Neoptolemos, and unidentified Greek soldier. ca. 500-450 BC. Naples, Museo Archeologico Nazionale 81669. ARV 189.74. Para 341. BAPD 201724. Robertson (1981) 69 fig 102.

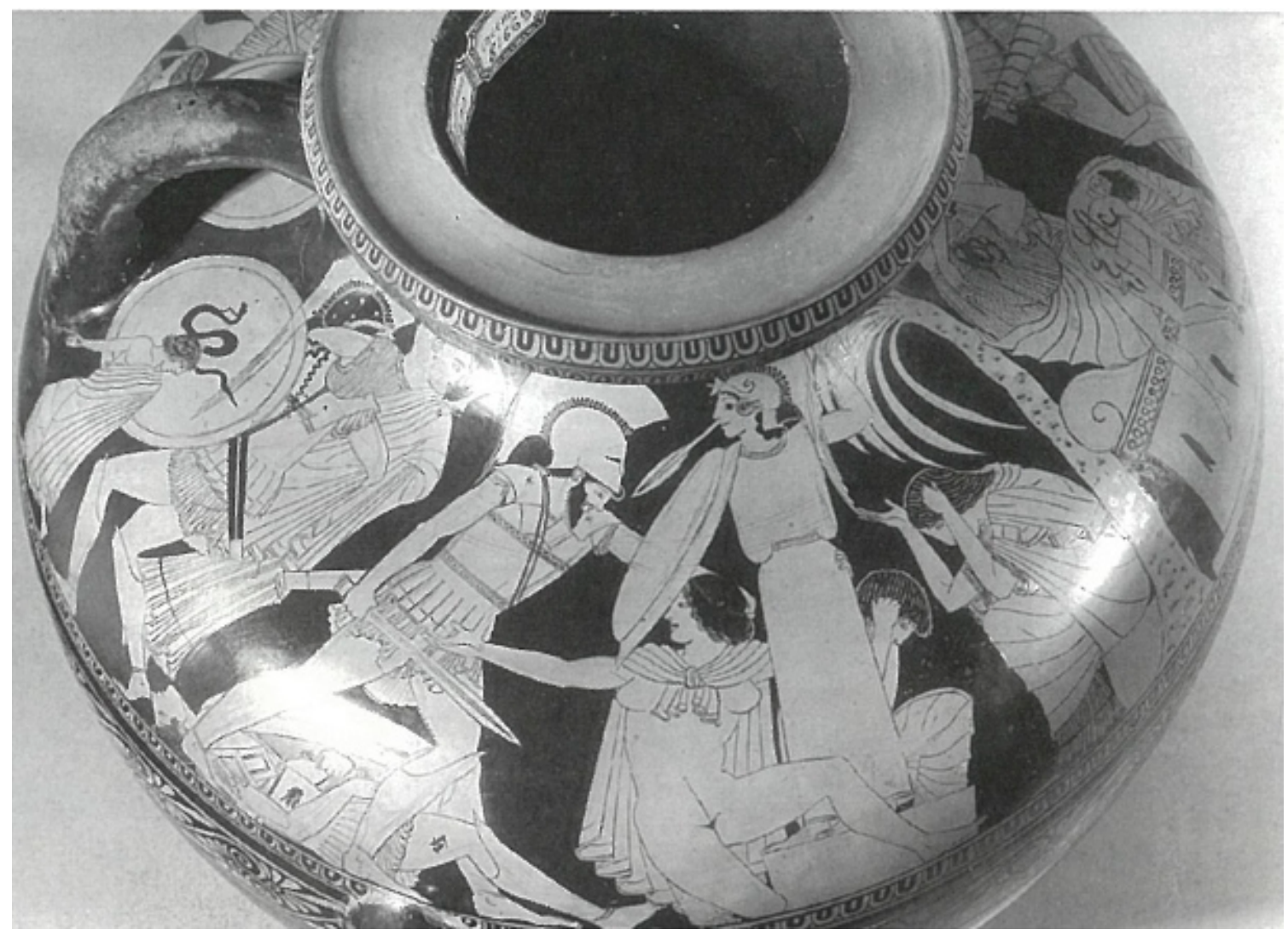

Figure 26b: Kleophrades Painter, red-figure hydria, detail of Anchises and Aias the Lesser. Osborne (1998) 144, fig. 76. 


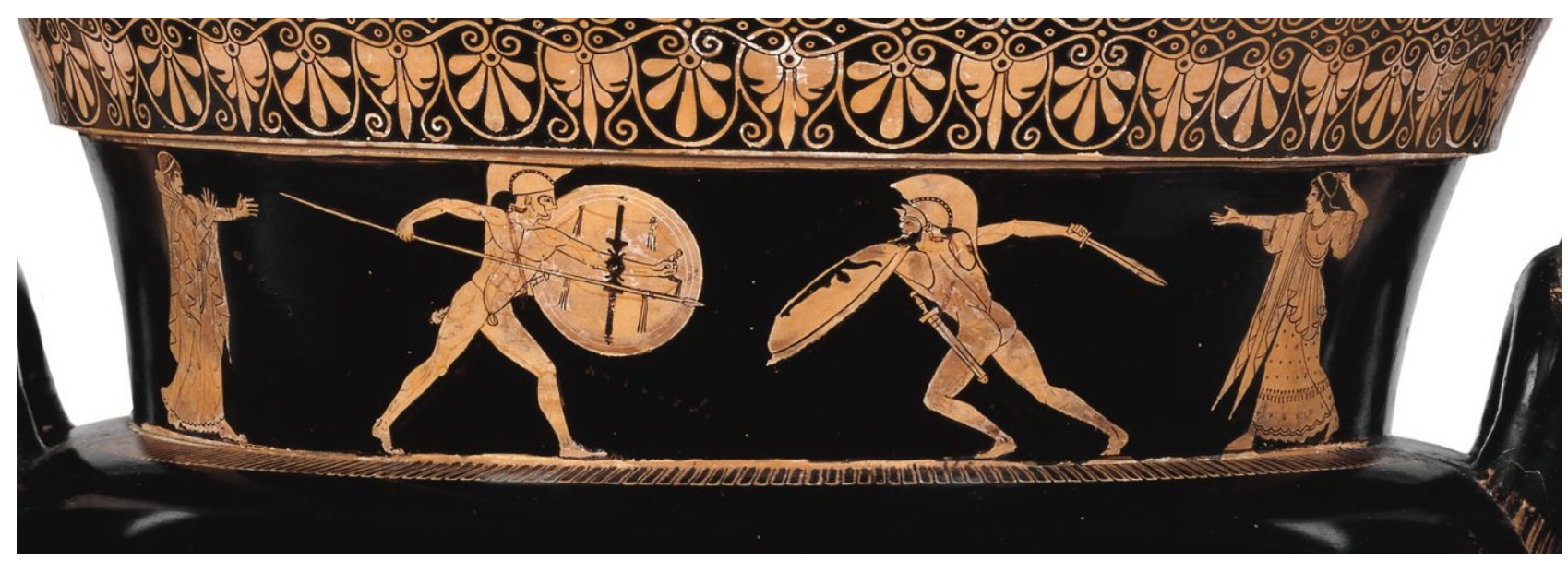

Figure 27a: Berlin Painter, red-figure volute-krater, Side A: Achilleus fighting Memnon. ca. 525-475 BC. London, British Museum E468. ARV 2206.122, 1633. Para 343. BAPD 201941. Photo $\mathbb{C}$ Trustees of the British Museum.

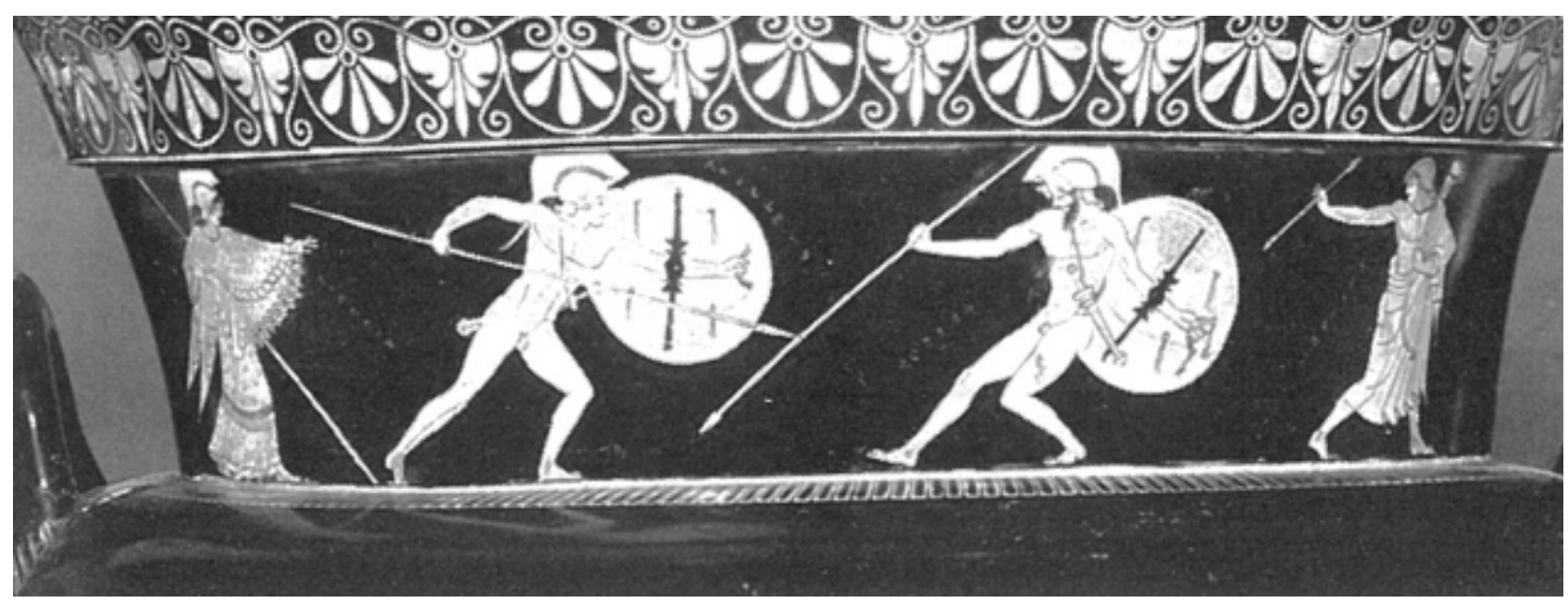

Figure 27b: Berlin Painter, red-figure volute-krater, Side B: Achilleus fighting Hektor, with Apollo looking on. Johnston (1993) fig. 75. 


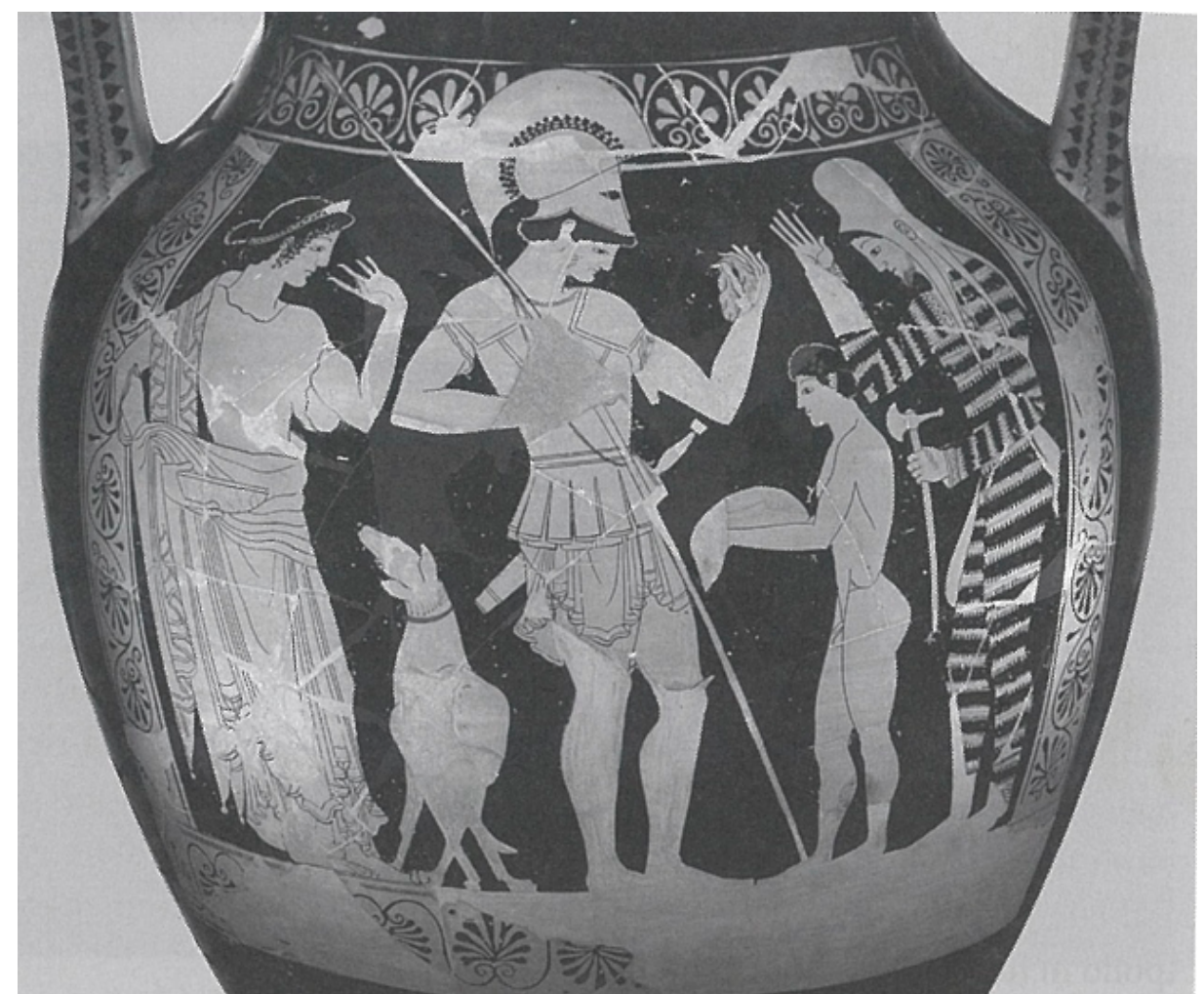

Figure 28a: Kleophrades Painter, red-figure amphora, Side A: departing warrior scene. ca. 525-475 BC. Würzburg, Universität, Martin von Wagner Mus. HA120. ARV 181.1. Para 340. BAPD 201654. Osborne (2011) 60, fig. 3.3.

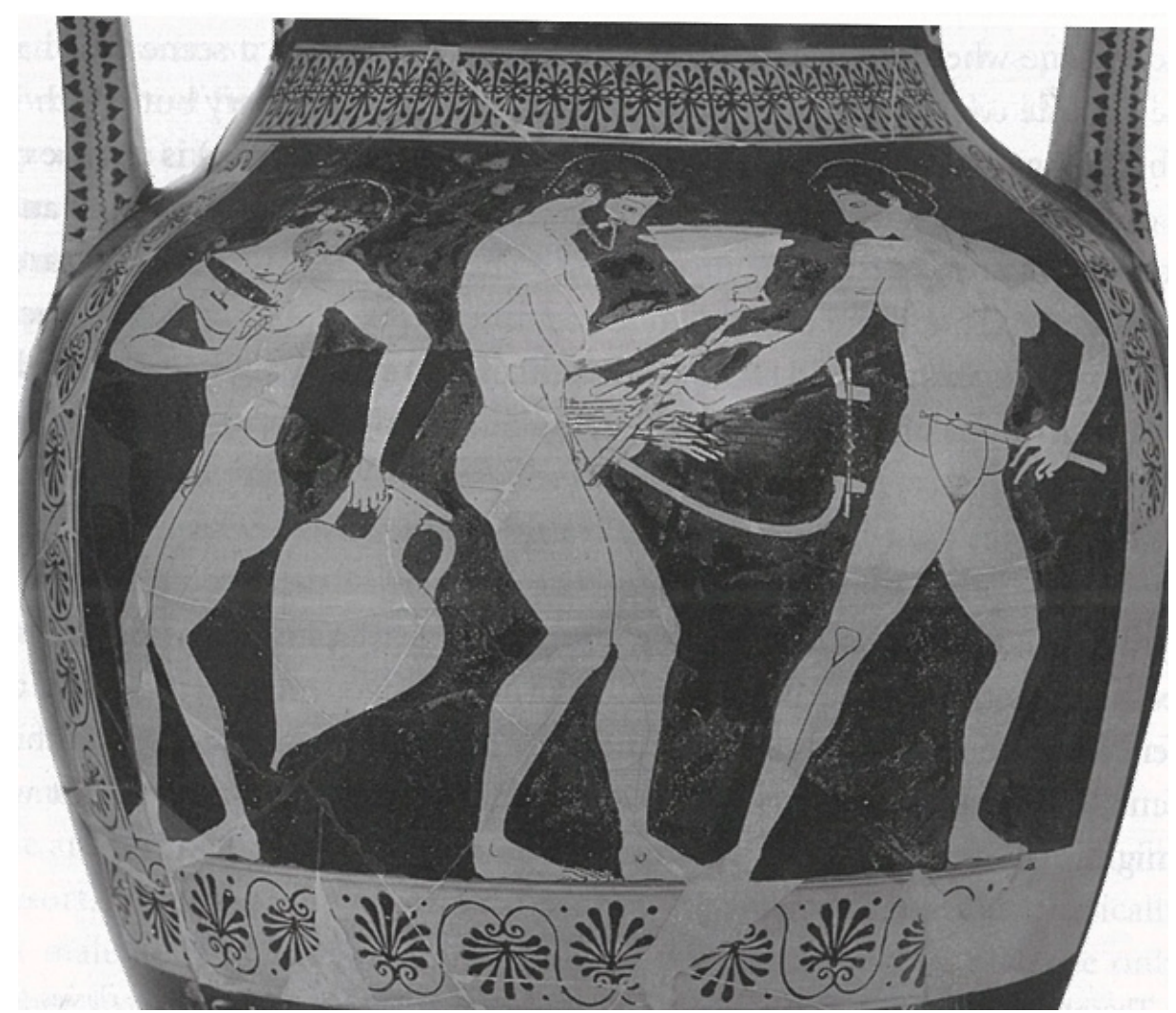

Figure 28b: Kleophrades Painter, red-figure amphora, Side B: Revellers. Osborne (2011) 60, fig. 3.4. 


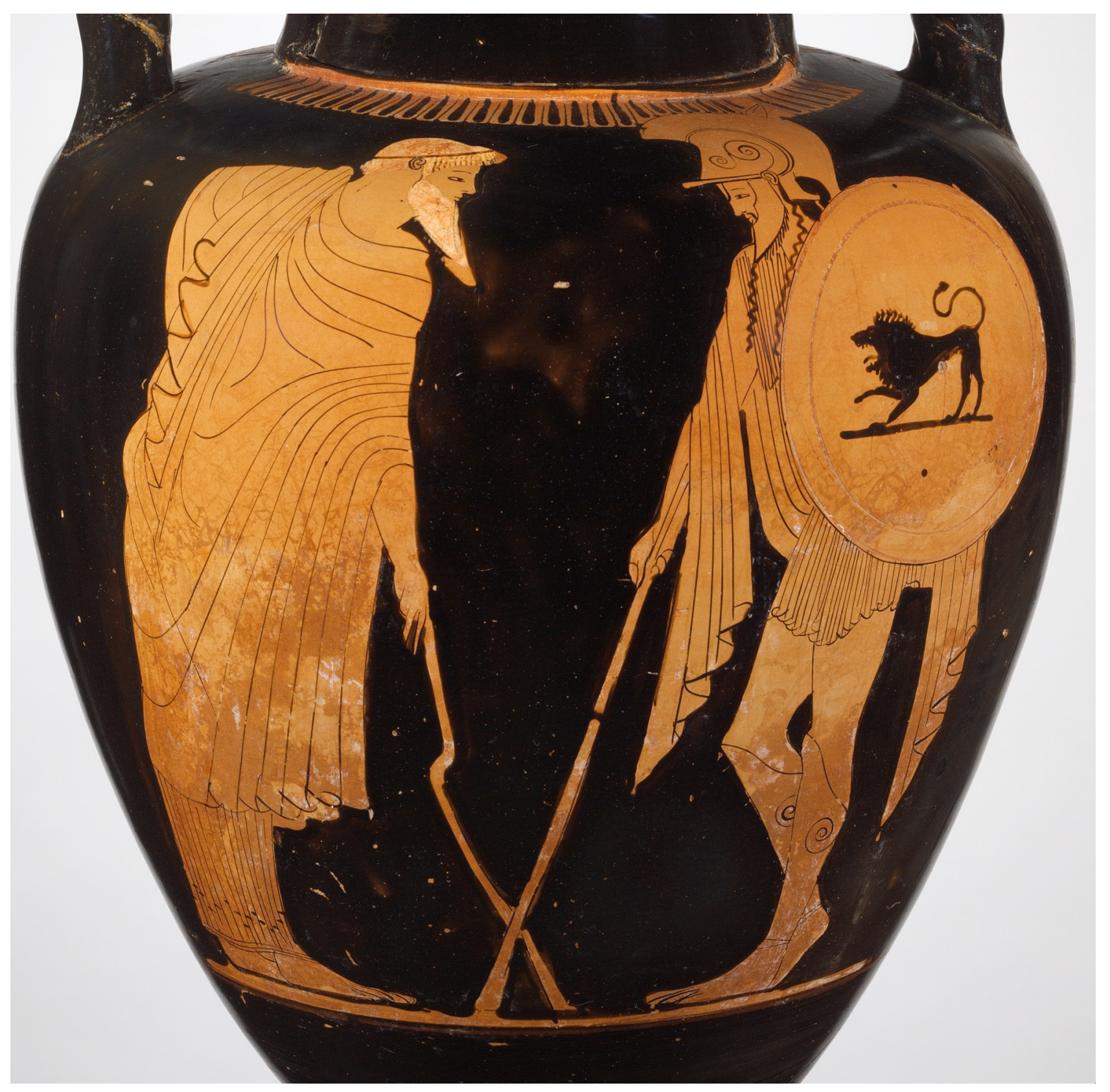

Figure 29: Matsch Painter, red-figure amphora. ca. 500-450 BC. New York, Metropolitan Museum 56.171.39. $A R V^{2}$ 284.4. BAPD 202570. The Metropolitan Museum of Art; Fletcher Fund, 1956. www.metmuseum.org. 


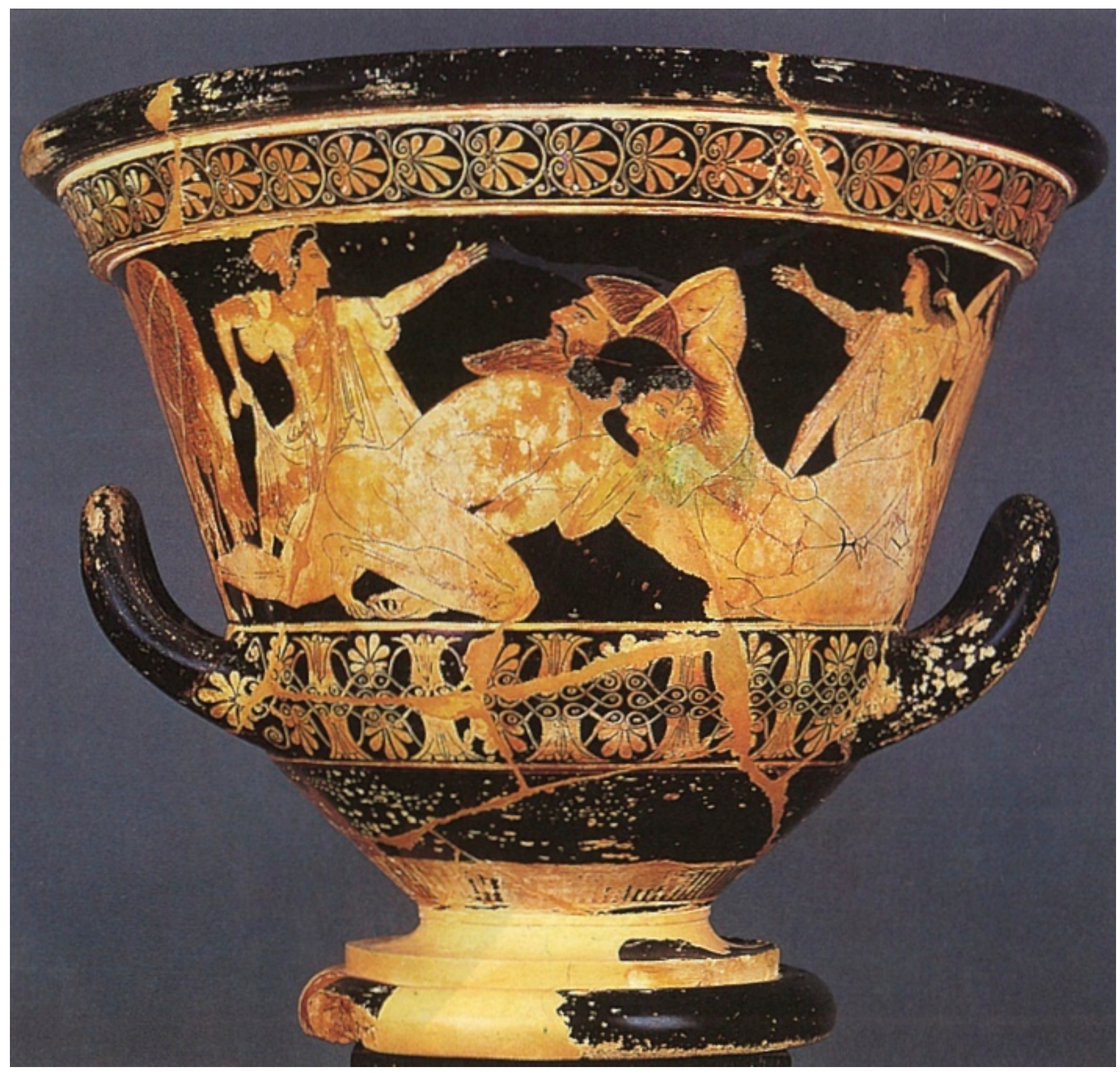

Figure 30: Euphronios, red-figure calyx-krater. ca. 550-500 BC. Paris, Musée du Louvre G103. $A R V^{2}$ 14.2. Para 322. BAPD 200064. Pedley (2007) 204, fig. 6.88. 


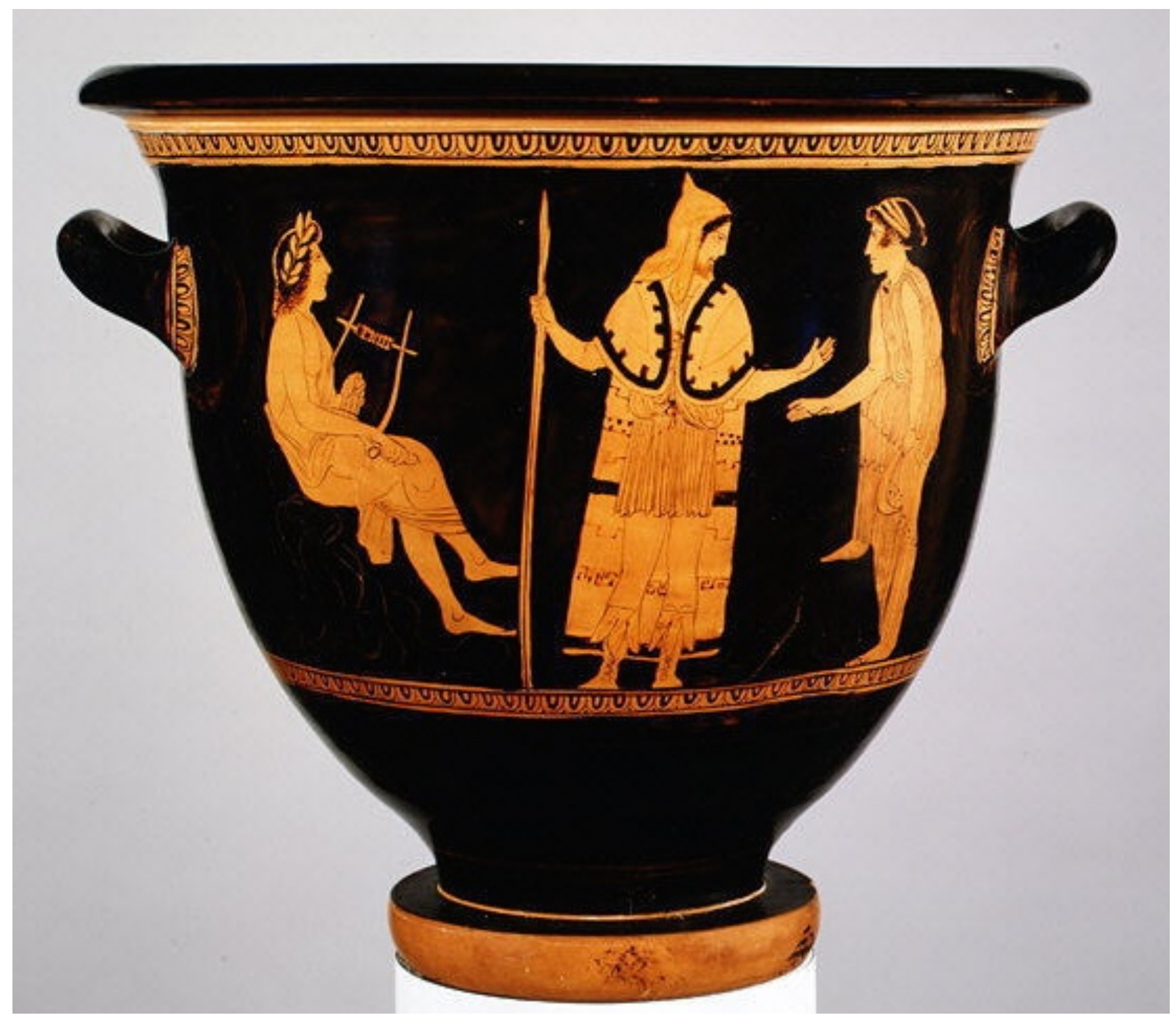

Figure 31a: Painter of London E 497, red-figure bell-krater. ca. 475-425 BC. New York, Metropolitan Museum 24.97.30. $A R V^{2}$ 1079.2. BAPD 214496. The Metropolitan Museum of Art; Fletcher Fund, 1924. www.metmuseum.org 


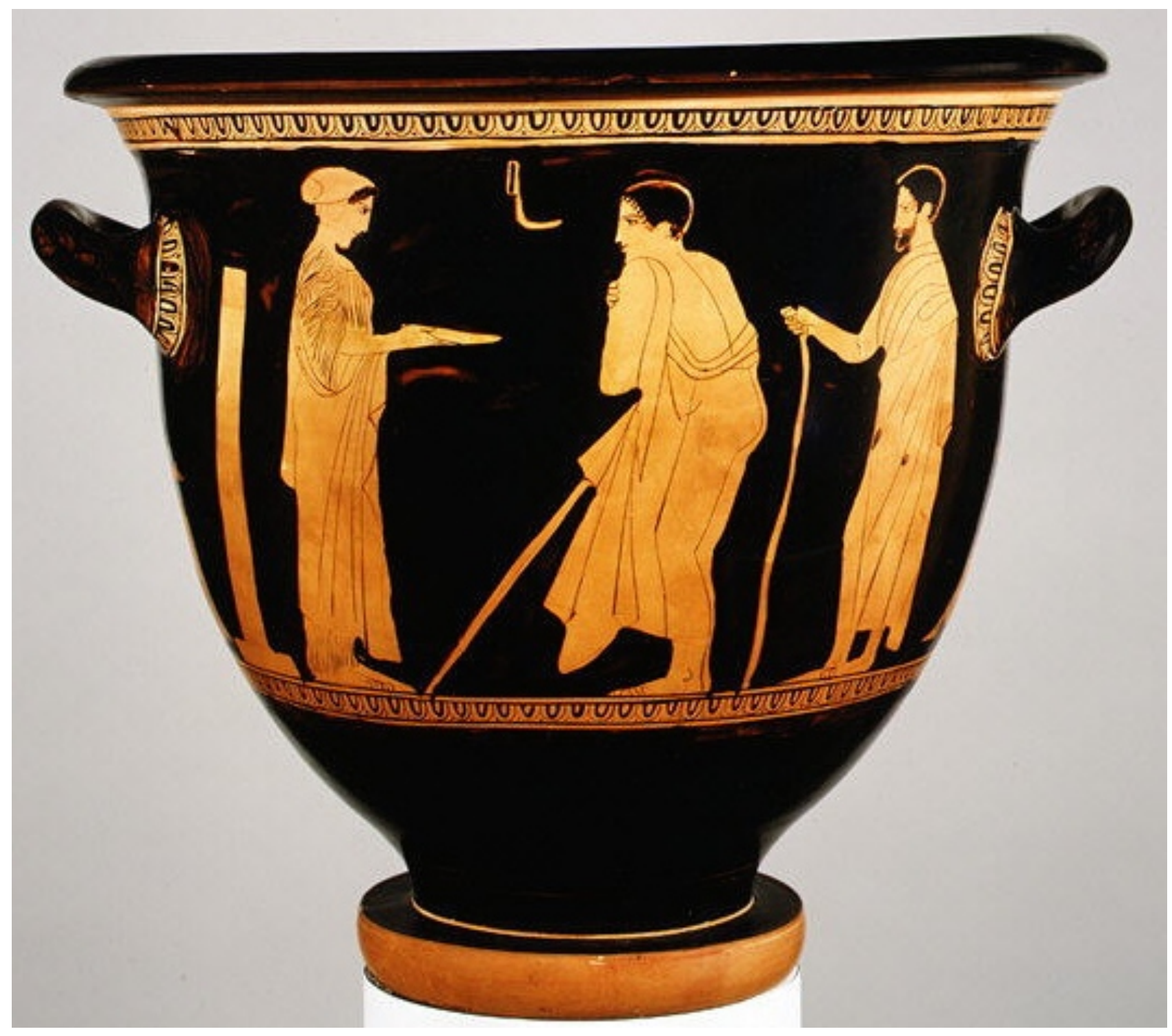

Figure 31b: Reverse of Painter of London E 497, red-figure bell-krater. The Metropolitan Museum of Art; Fletcher Fund, 1924. www.metmuseum.org 
Figure 32: Archer in Scythian dress with red beard.

Unattributed, Attic black-figure amphora. ca. 550-500 BC.

San Simeon (CA), Hearst Historical State Monument 5443.

LIMC Helene 353.
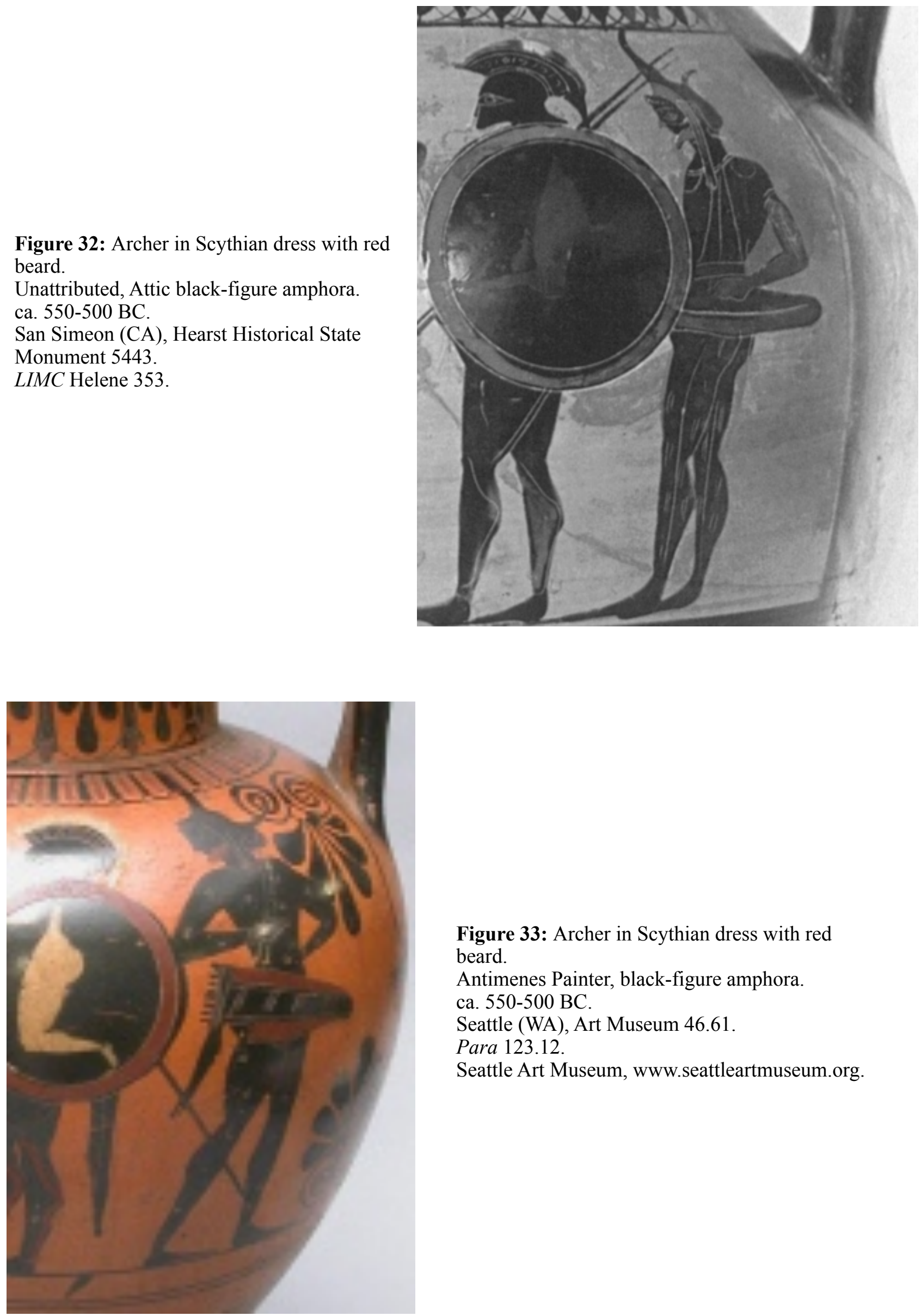

Figure 33: Archer in Scythian dress with red beard.

Antimenes Painter, black-figure amphora. ca. 550-500 BC.

Seattle (WA), Art Museum 46.61.

Para 123.12.

Seattle Art Museum, www.seattleartmuseum.org. 


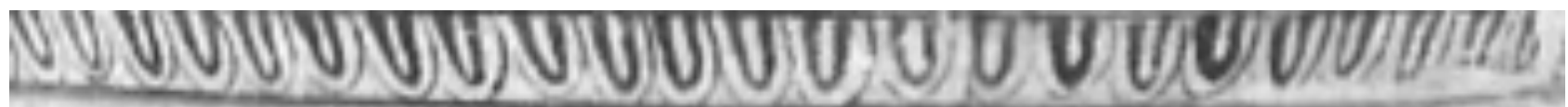

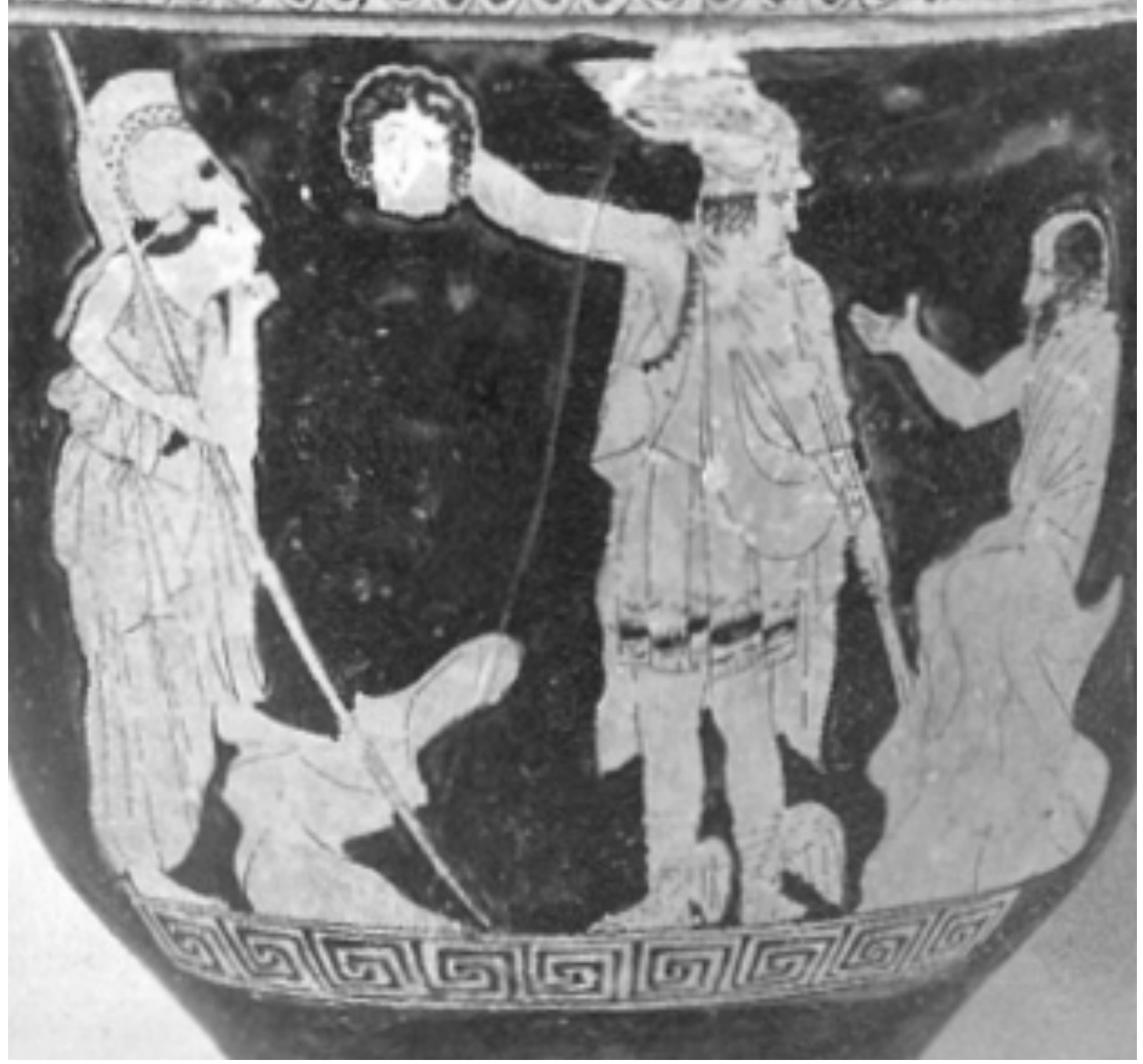

Figure 34: Polydektes Painter, red-figure bell-krater. ca.475-425 BC. Bologna, Museo Civico Archeologico 325. $A R V^{2}$ 1069.2, 1681. Para 447. BAPD 214401. Carpenter (1991) fig. 162. 


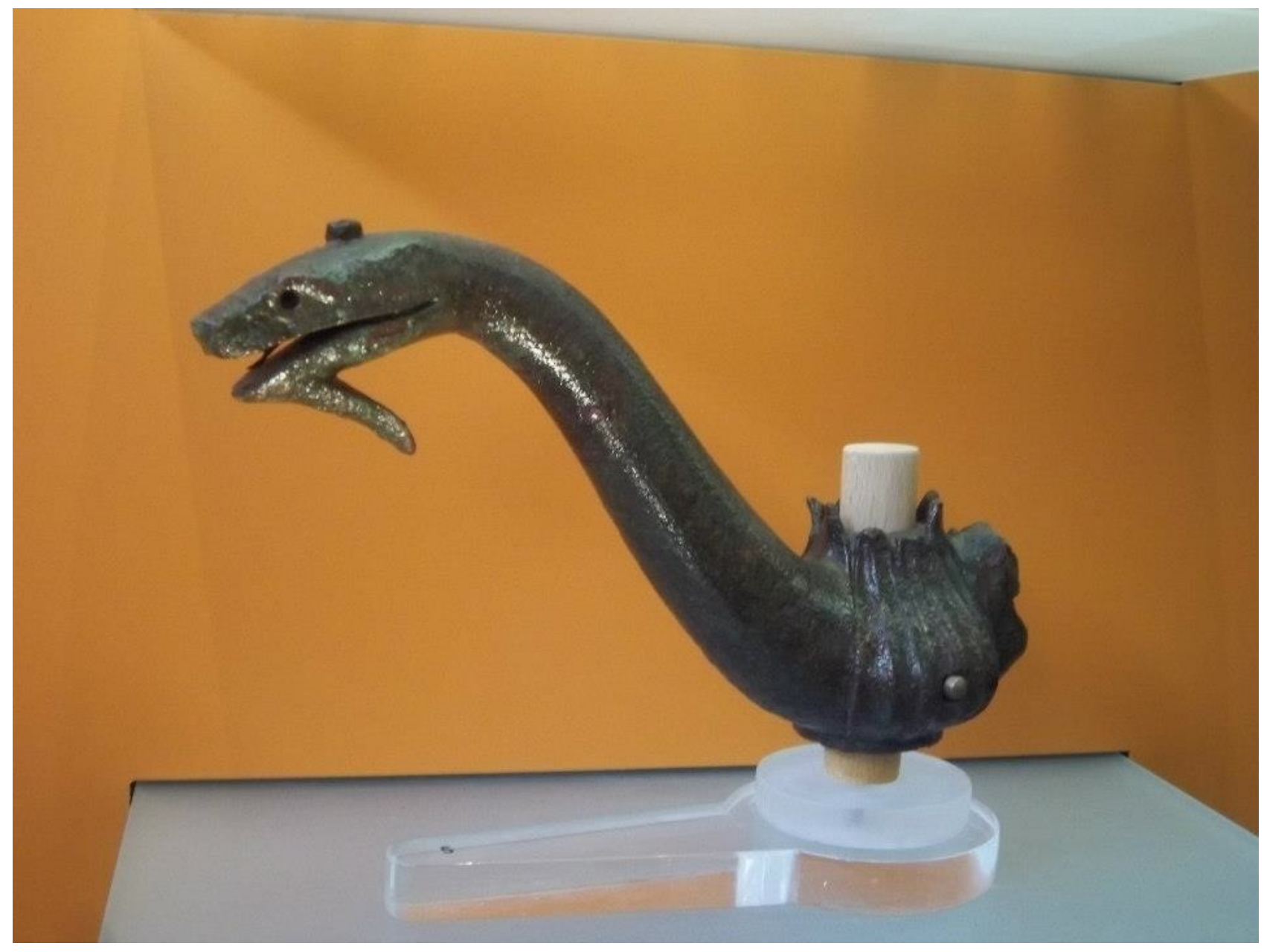

Figure 35: Bearded snake cauldron protome. Delphi, Archaeological Museum. Photo courtesy of P. Lindsay. 


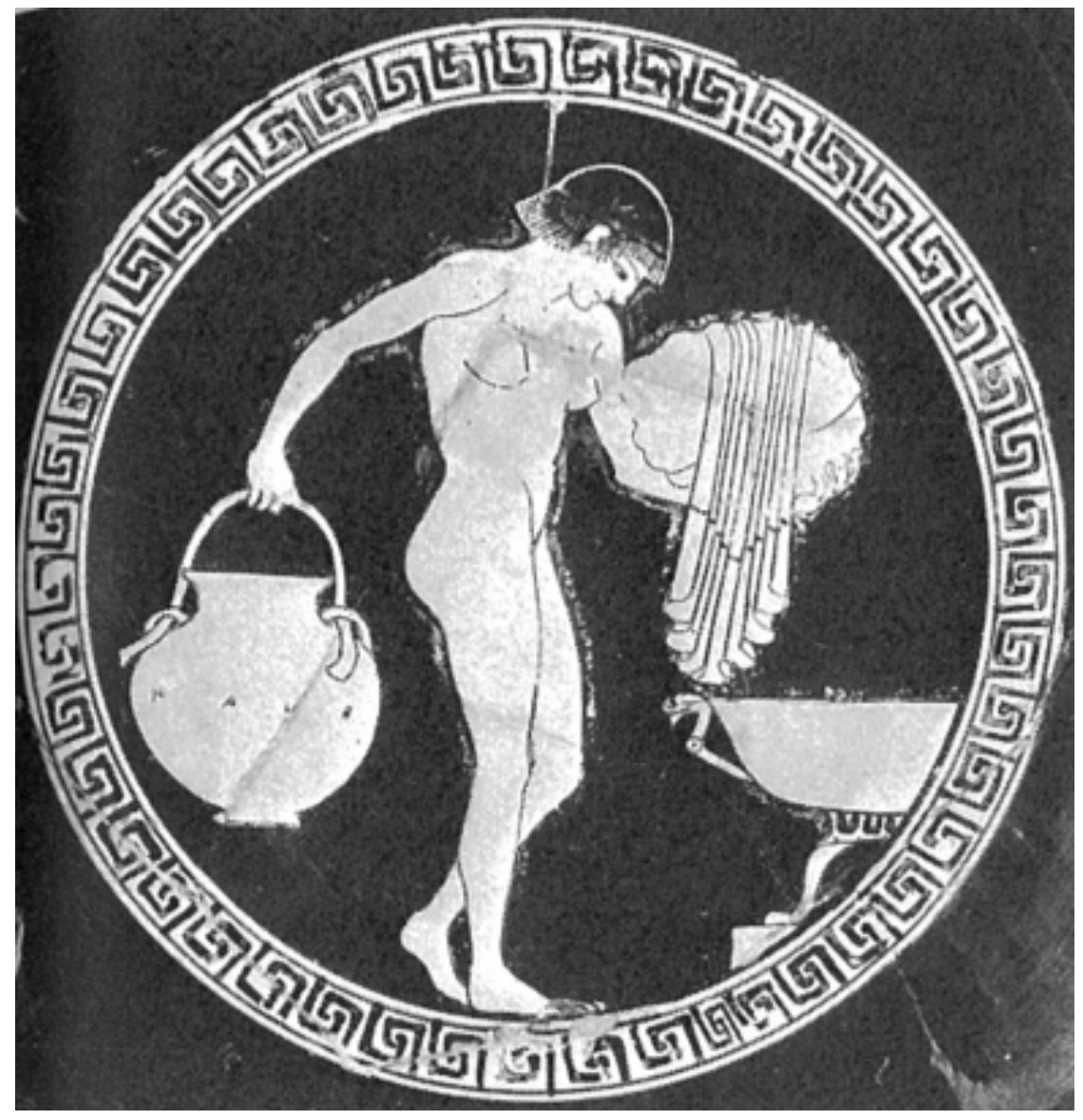

Figure 36a: Onesimos, red-figure kylix. ca. 500-450 BC. Brussels, Musées Royaux A889. $A R V^{2} 329.130$, 1645. Para 359. BAPD 203385. Boardman (1975) fig. 224.

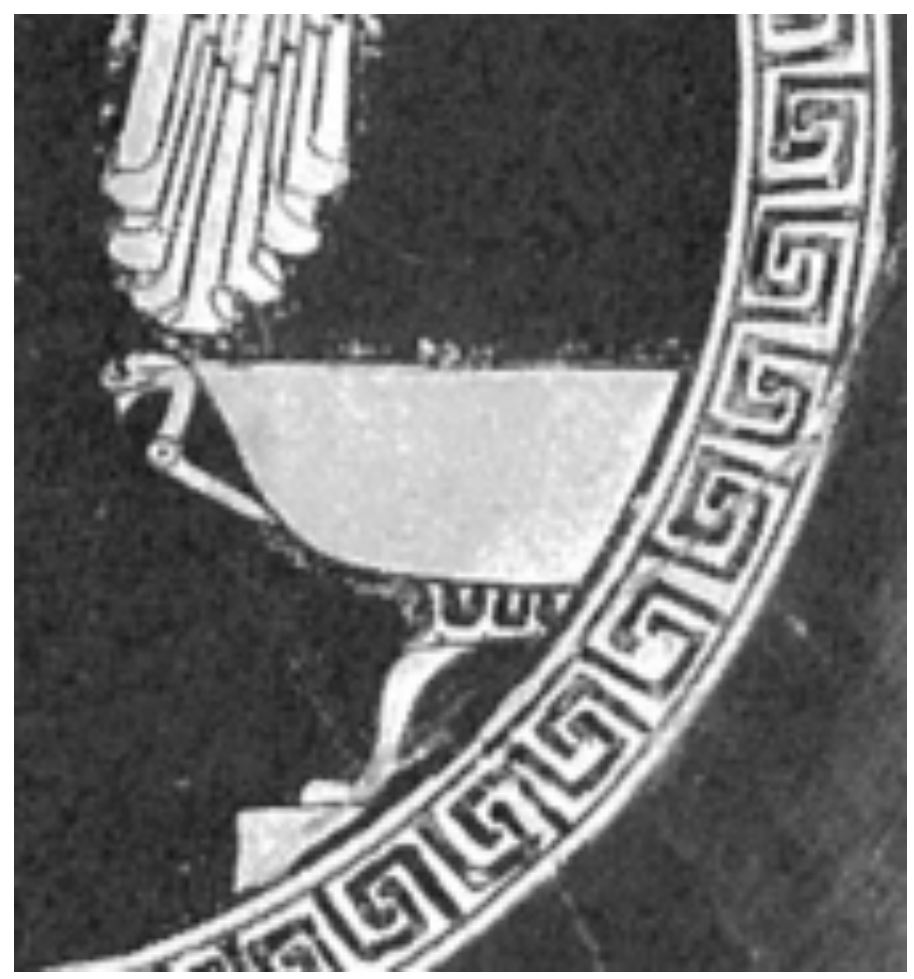

Figure 36b: Onesimos, red-figure kylix, detail of bearded snake handle. Boardman (1975) fig. 224. 


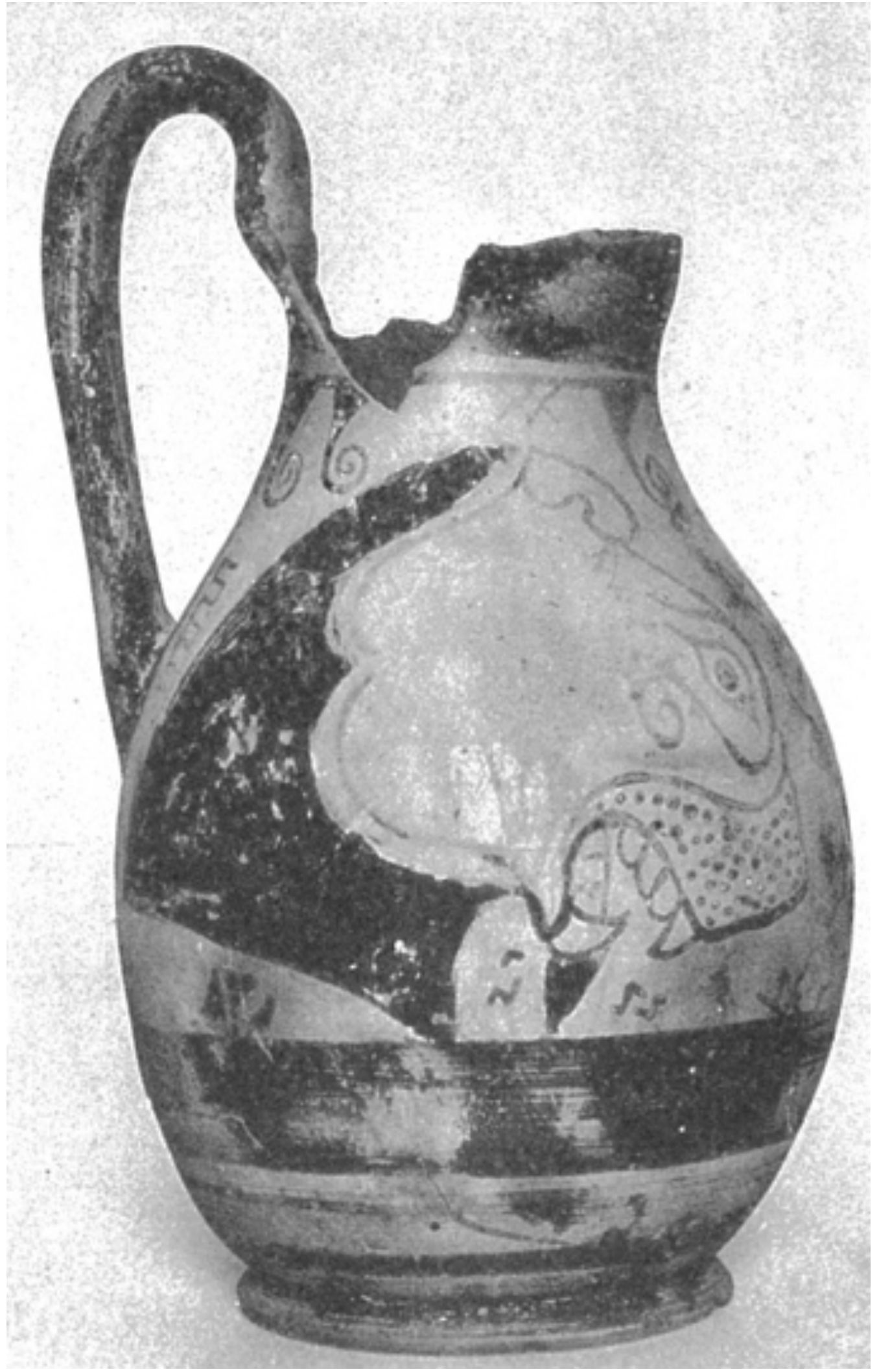

Figure 37: Ram Jug Painter, protoattic olpe. Late 7th century. Athens, Agora Museum P 22550. Brann (1962) 93, cat. 544. 


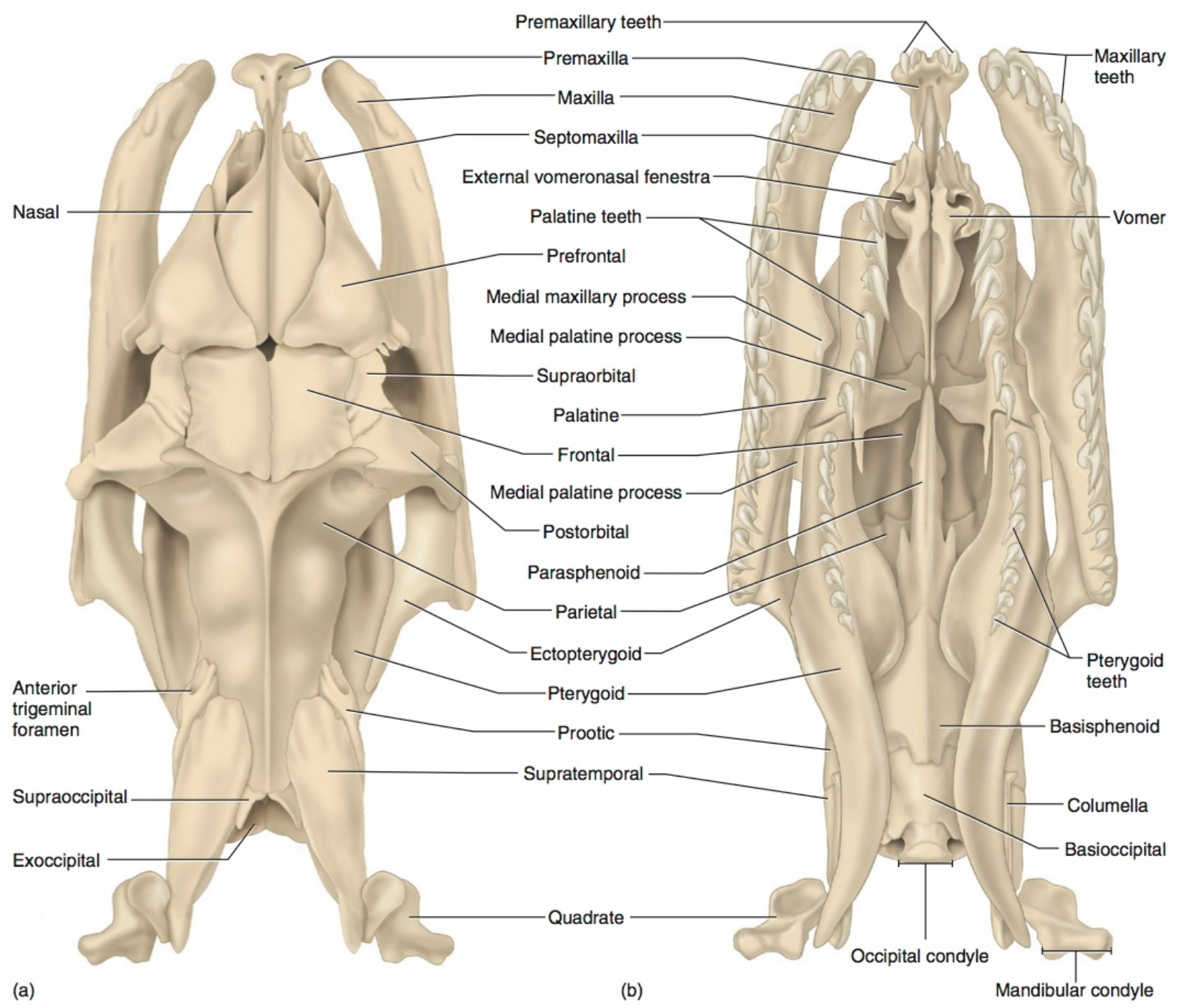

Figure 38: Python skull. Dorsal and ventral views. De Iuliis and Pulera (2011) 269, fig. 8.13. 


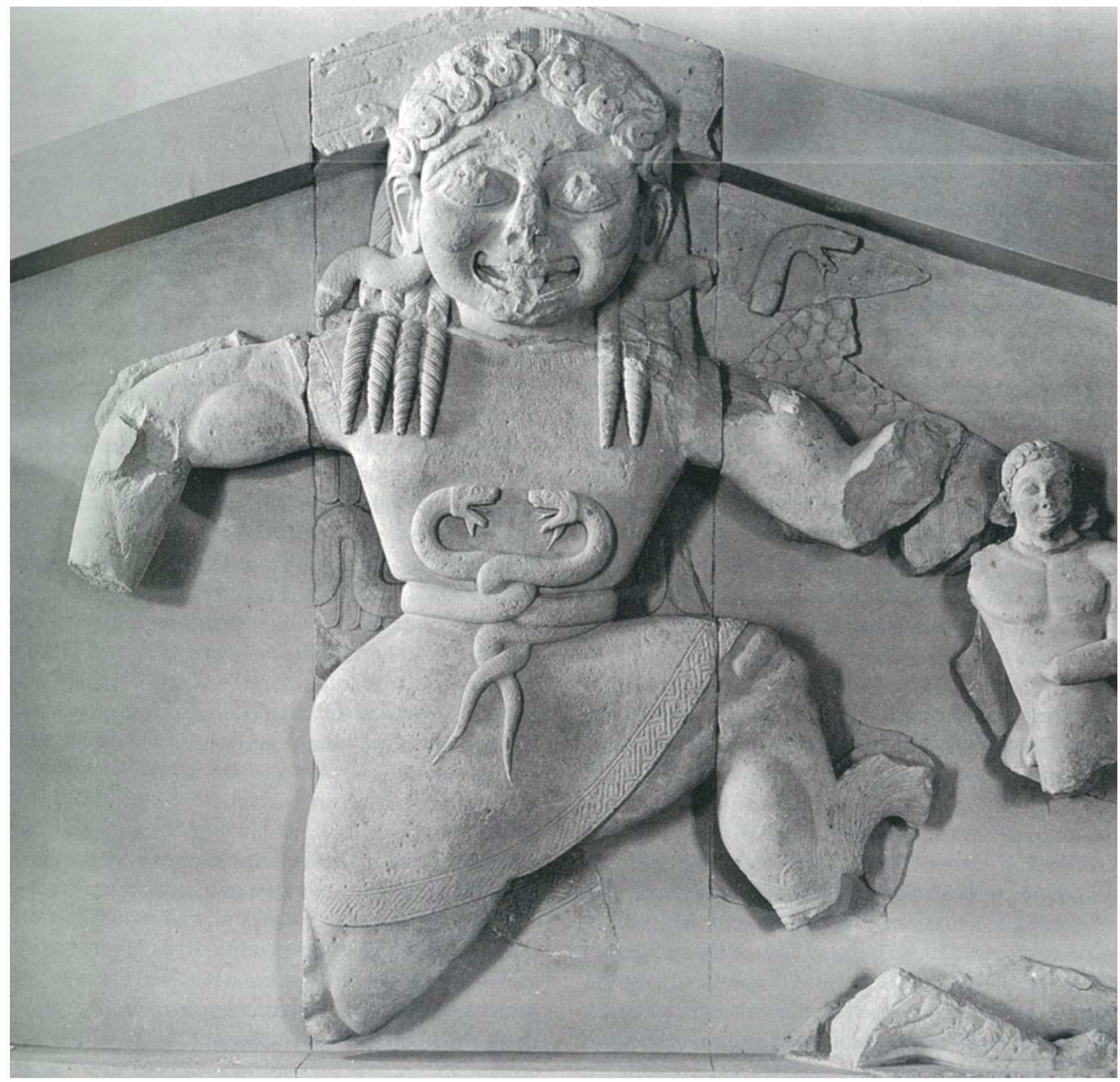

Figure 39a: Corcyra, Temple of Artemis, Medusa pediment. ca. 600-580 BC. Corfu, Archaeological Museum. Johnston (1993) 47, fig. 33. 


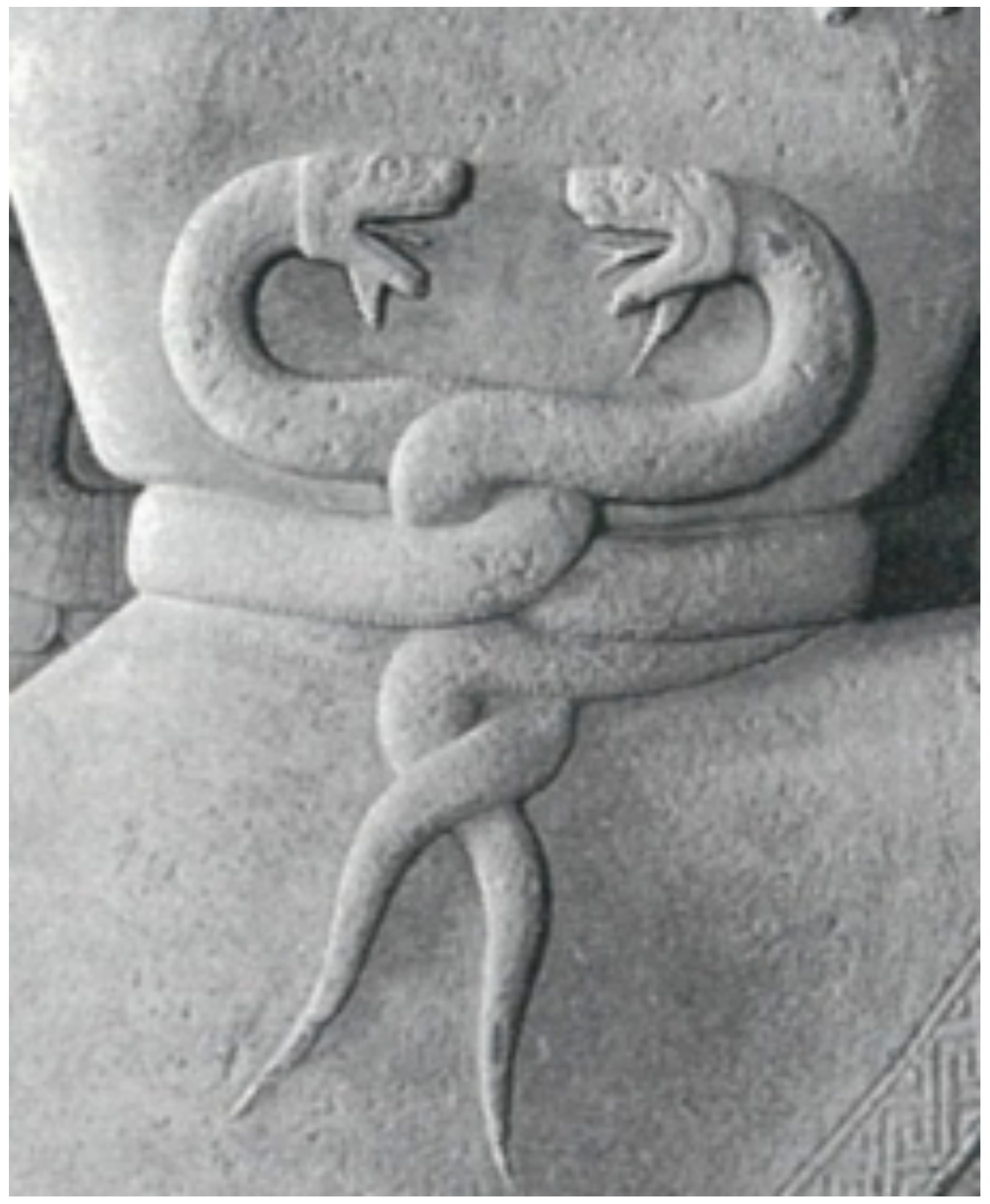

Figure 39b: Corcyra, Temple of Artemis, detail of Medusa pediment. Johnston (1993) 47, fig. 33 . 


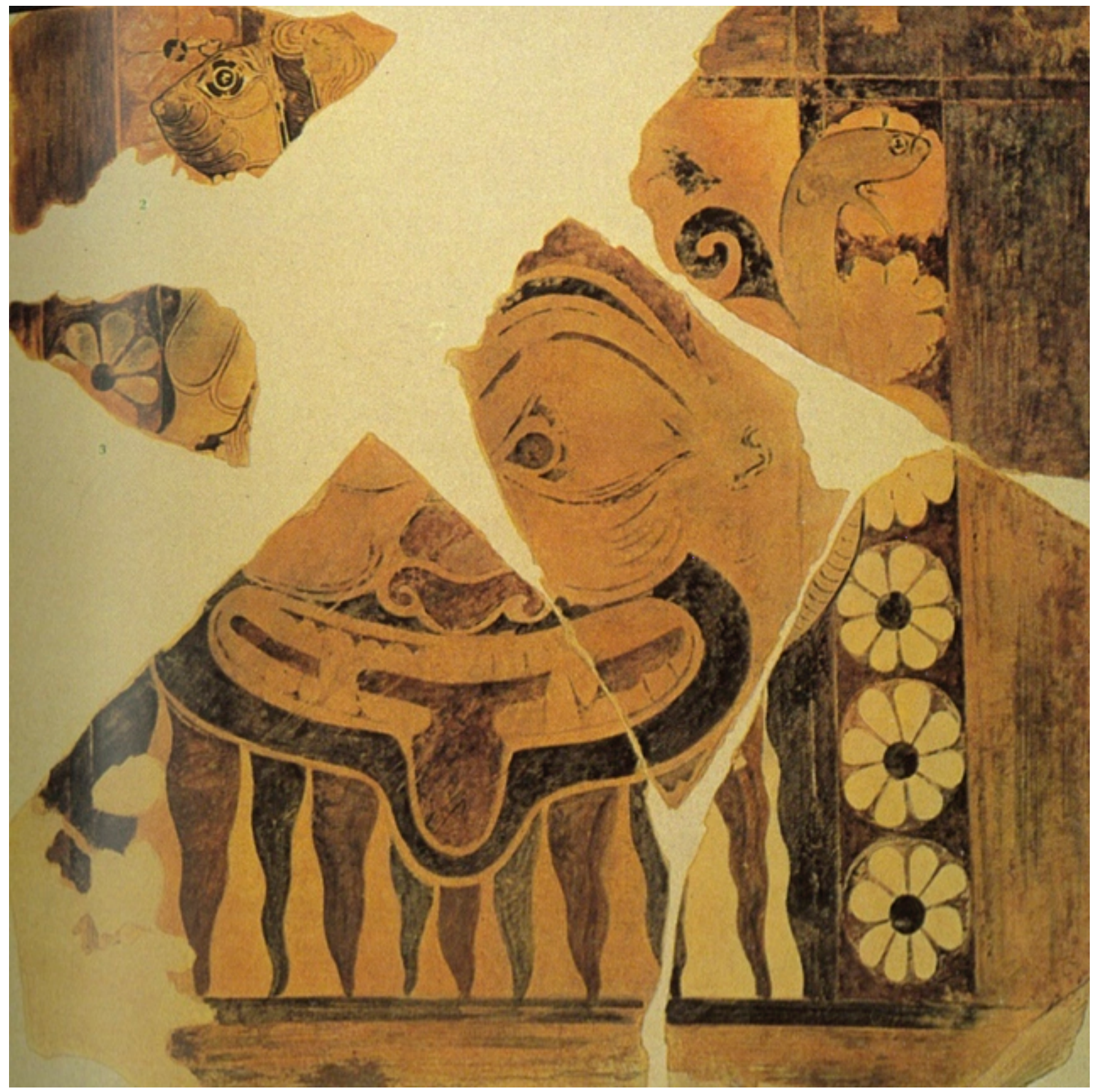

Figure 40: Thermon, Temple of Apollo, painted terracotta metope. ca. 620 BC. Athens, National Archaeological Museum. Hampe and Simon (1981) fig. 105. 


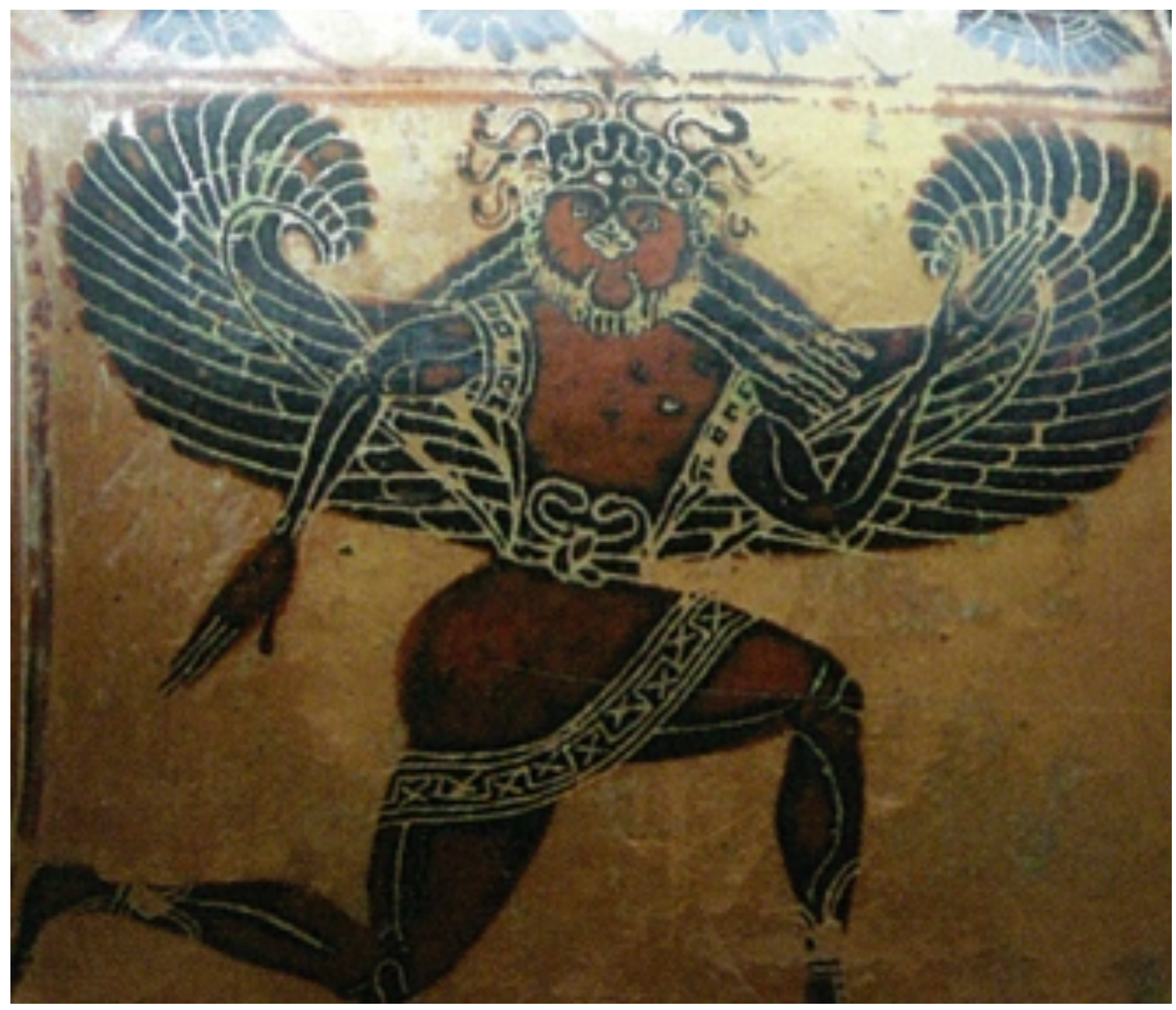

Figure 41: Kleitias, black-figure volute krater ("François Vase"), handle detail. ca. 570 BC. Florence, Museo Archeologico Etrusco 4209. ABV 76.1, 682. Para 29. BAPD 300000. Artus (2011) 12. 


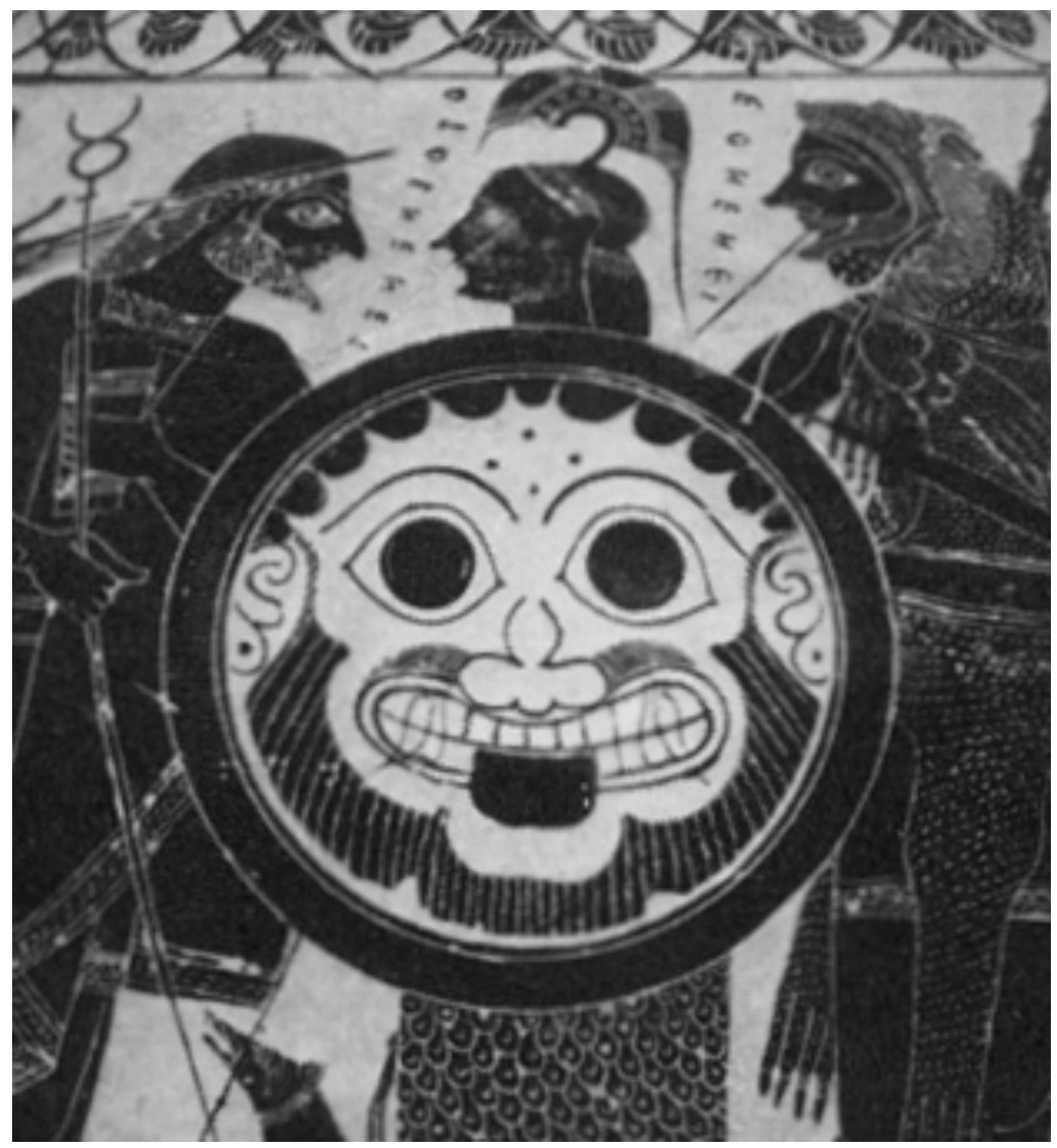

Figure 42: Phrynos Painter/Group E, black-figure amphora. ca. 575-525 BC. Basel, Antikenmuseum und Sammlung Ludwig BS1921.328. BAPD 213. Schefold (1992) 30, fig. 31. 


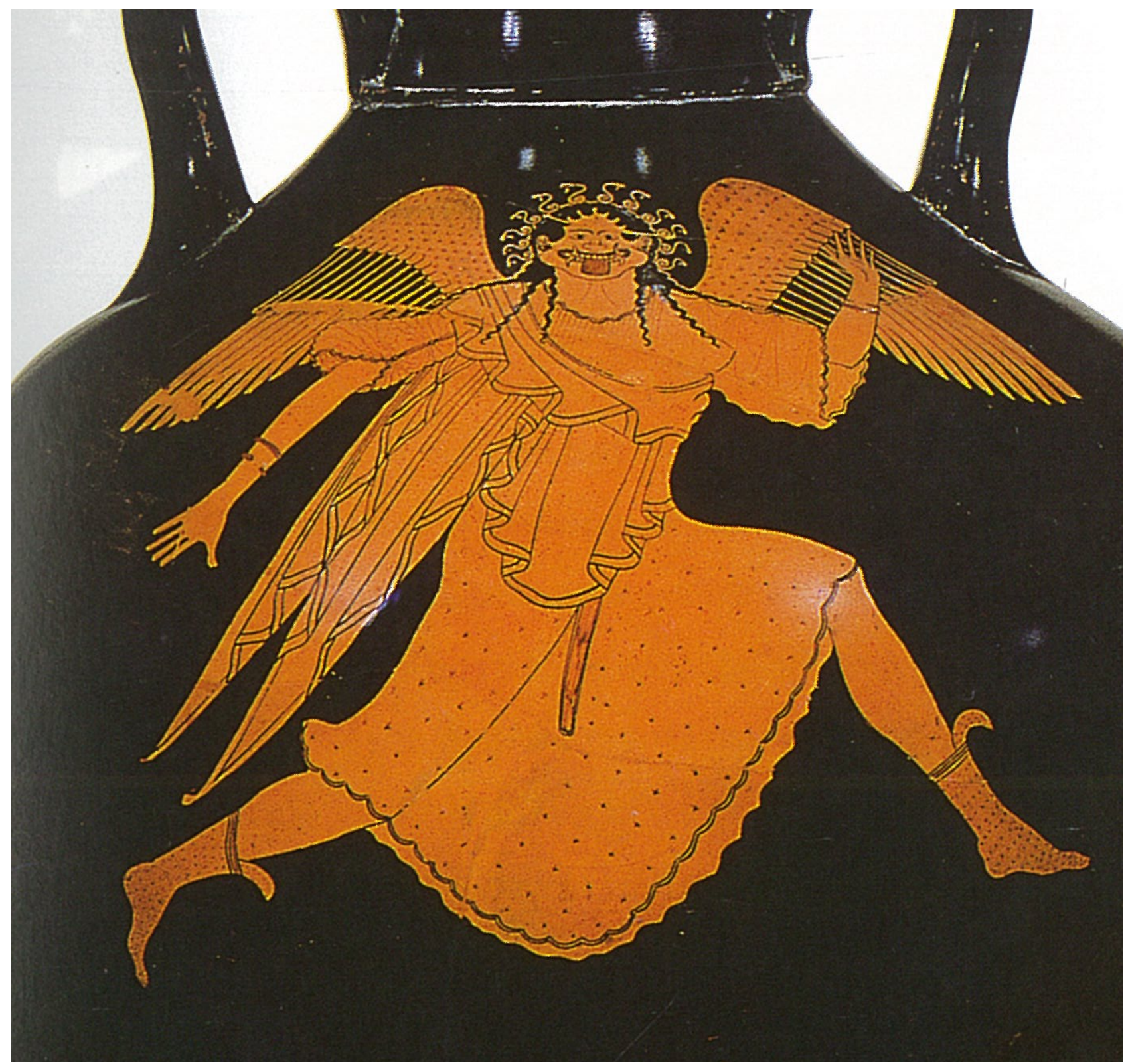

Figure 43: Berlin Painter, red-figure amphora. ca. 525-475 BC. Munich. Antikensammlungen 2312. $A R V^{2}$ 197.11, 1633. Para 342. BAPD 201820. Spivey (1997) 93, fig. 52. 


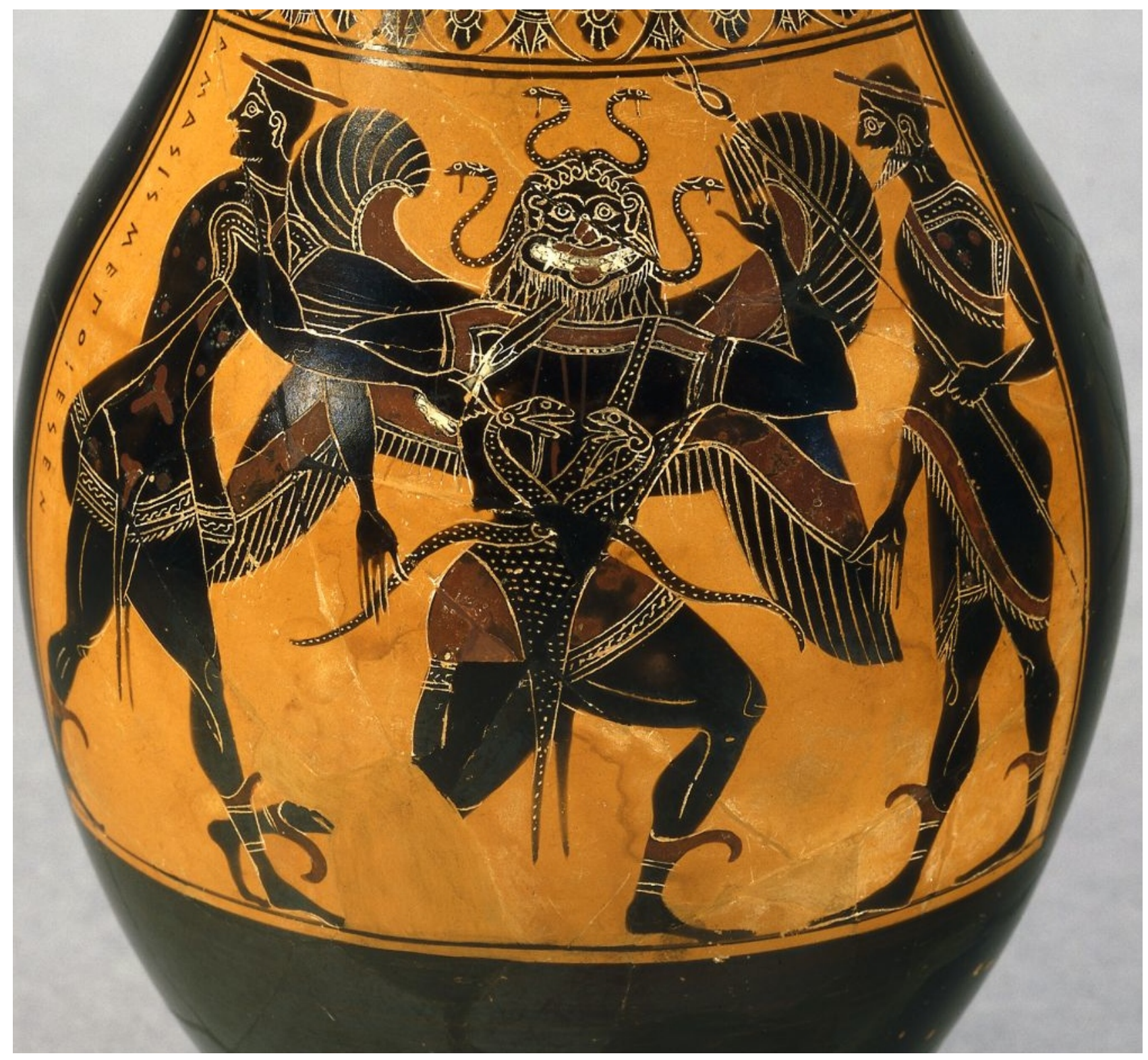

Figure 44a: Amasis Painter, black-figure oinochoe. ca. 575-525 BC. London, British Museum B471. ABV 153.32, 687. Para 64. BAPD 310459. Photo $@$ Trustees of the British Museum. 


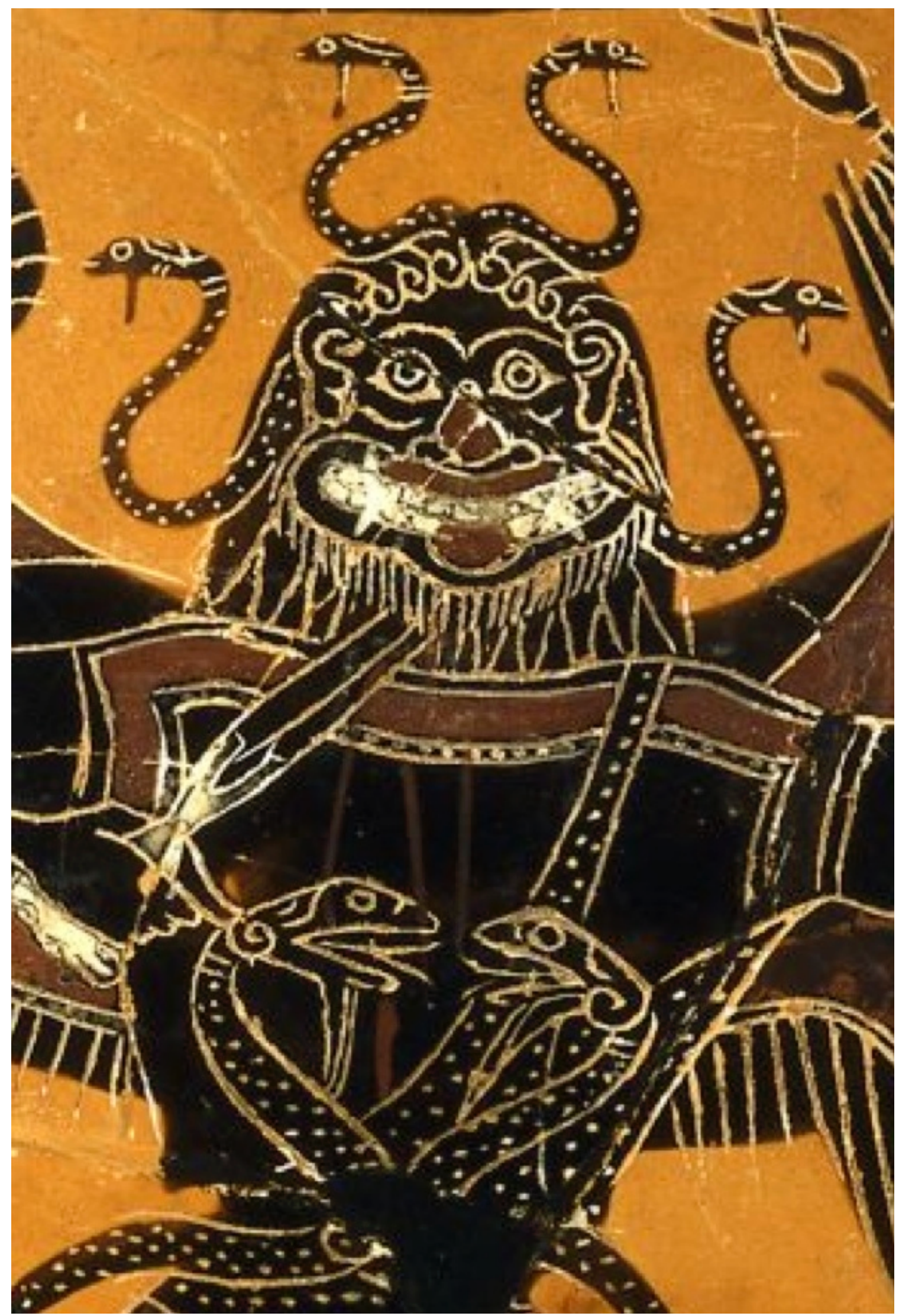

Figure 44b: Amasis Painter, black-figure oinochoe, detail of Medusa. Photo $\mathbb{C}$ Trustees of the British Museum. 


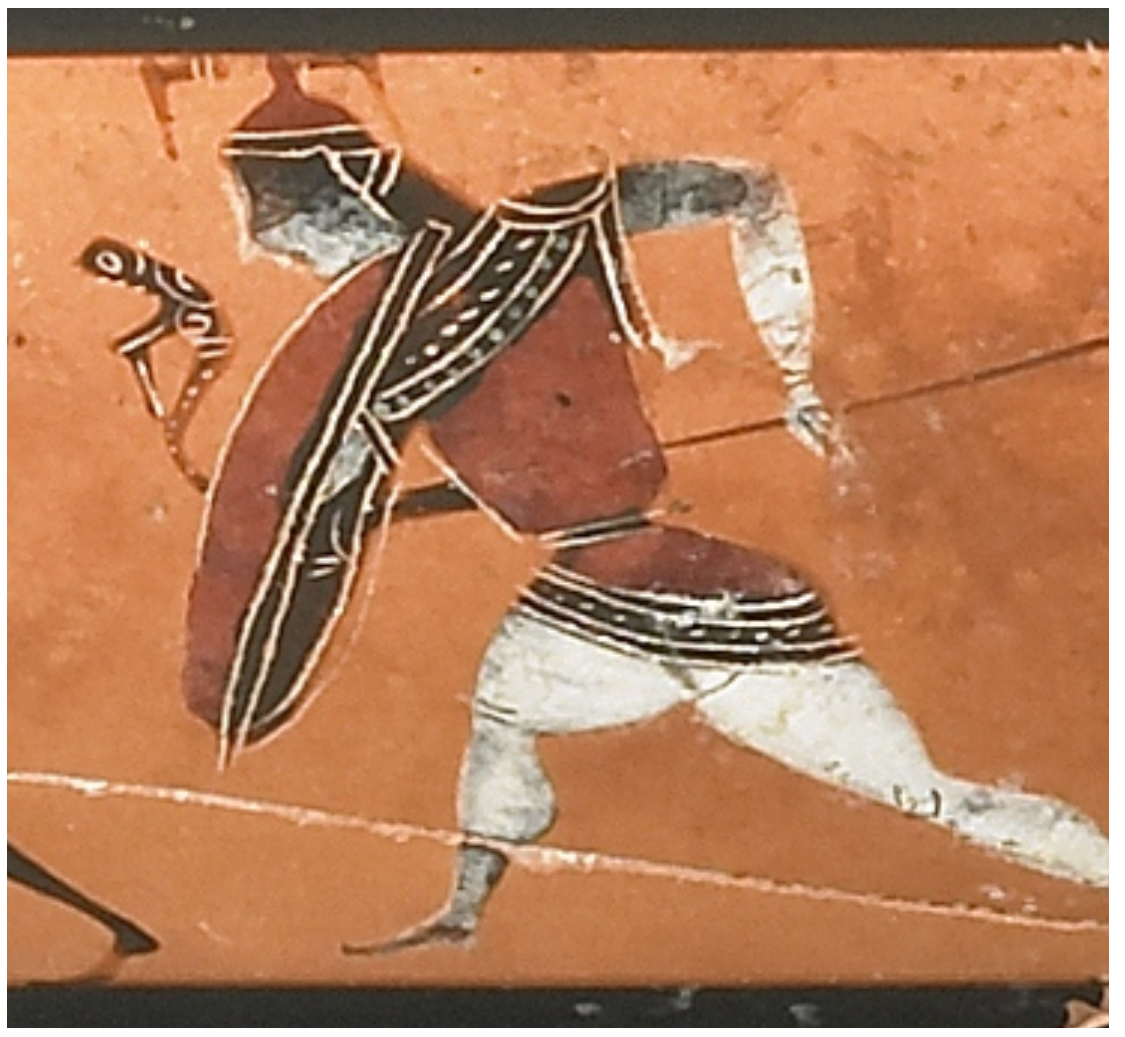

Figure 45: Amasis Painter, black-figure Little Master band cup. ca. 575-525. Malibu, The J. Paul Getty Museum 79.AE.197. BAPD 13712. Digital image courtesy of the Getty's Open Content Program.

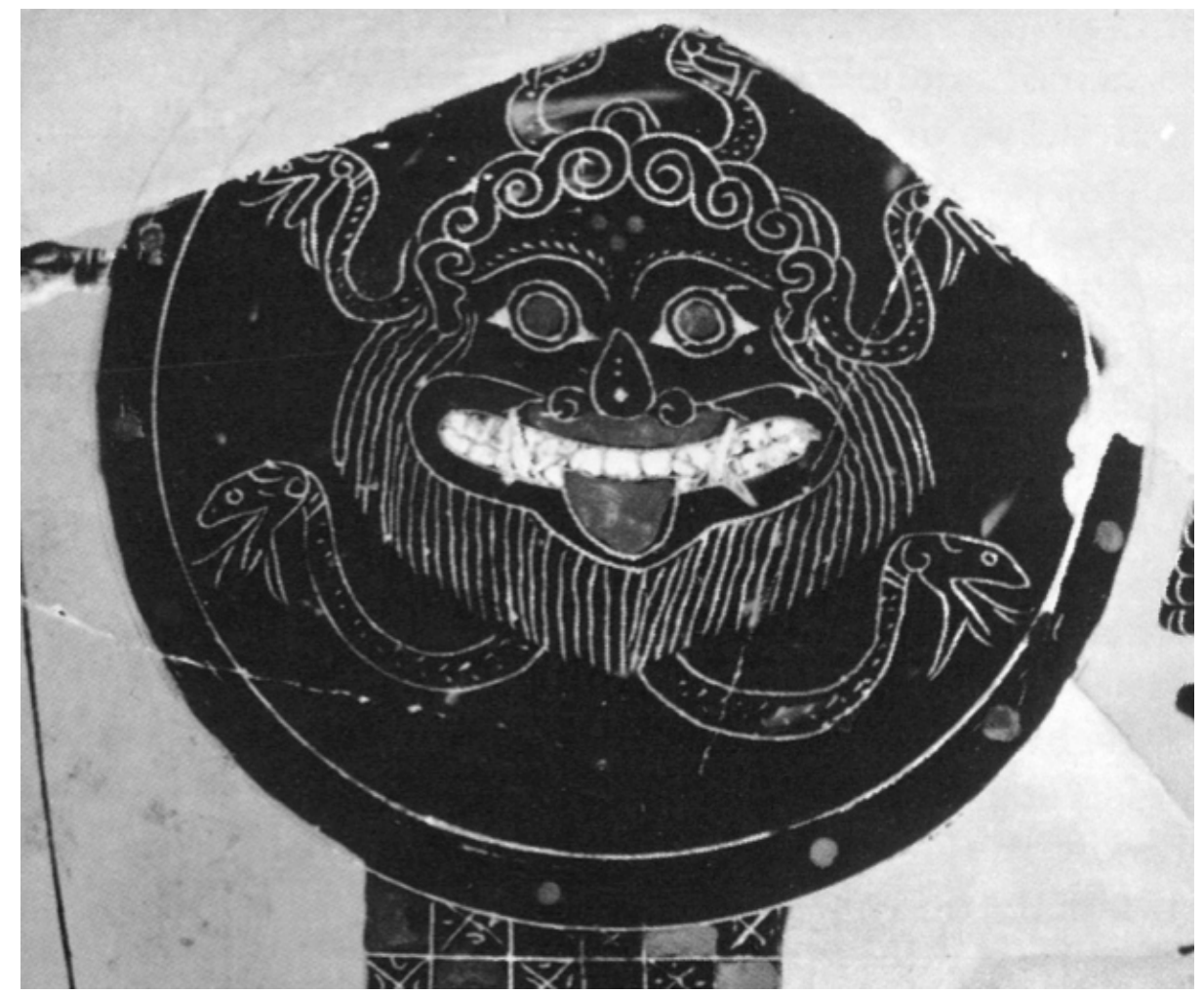

Figure 46: Amasis Painter, black-figure amphora. ca. 575-525 BC. Boston, Museum of Fine Arts 01.8026. $A B V$ 152.26, 687. Para 63. BAPD 310453. von Bothmer (1985) 130, fig. 24. 


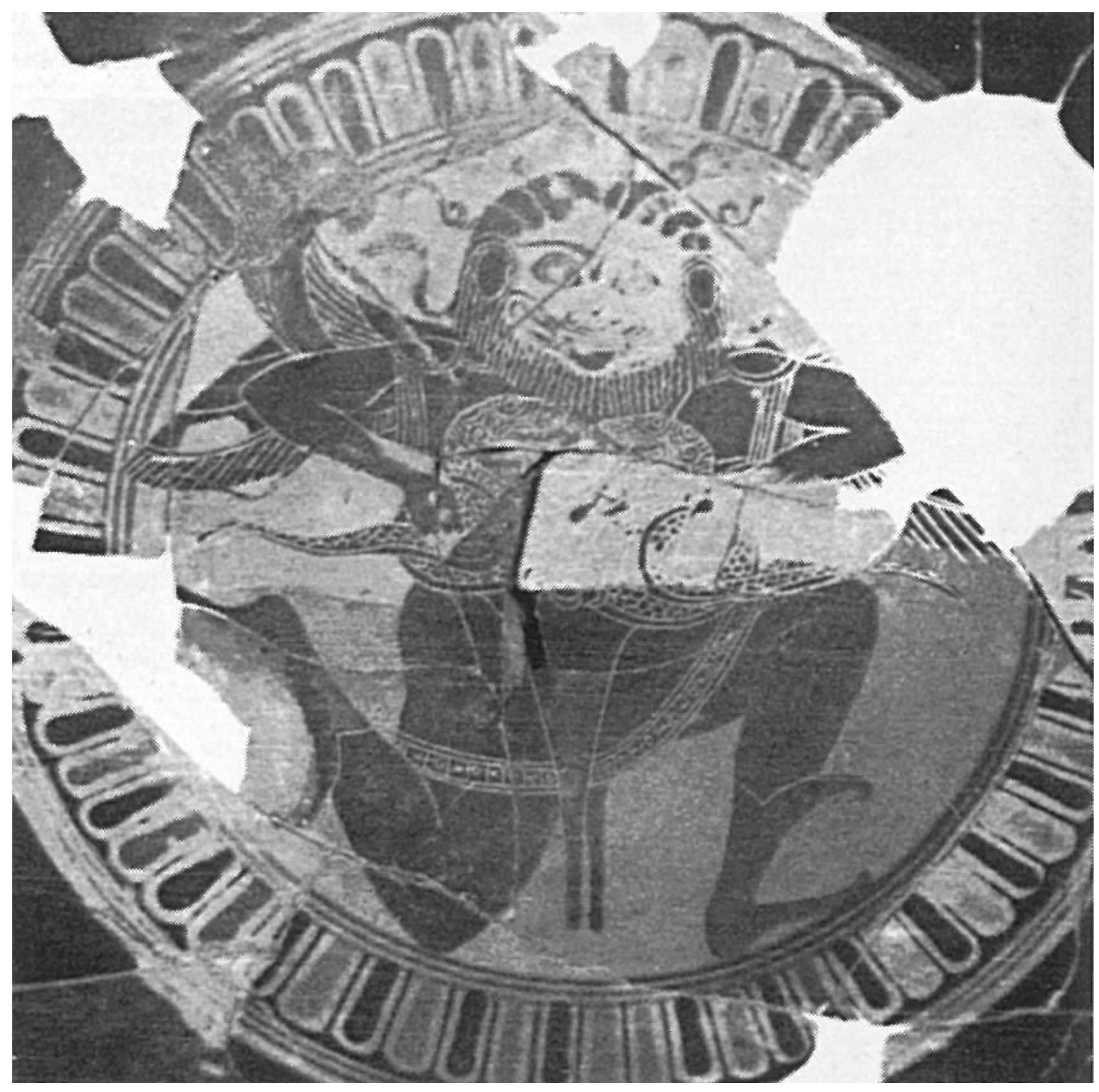

Figure 47: Heidelberg Painter, black-figure Siana cup. ca. 575-525 BC. Rhodes, Archaeological Museum 15370. ABV 64.14. BAPD 300558. LIMC Gorgo, Gorgones 235. 


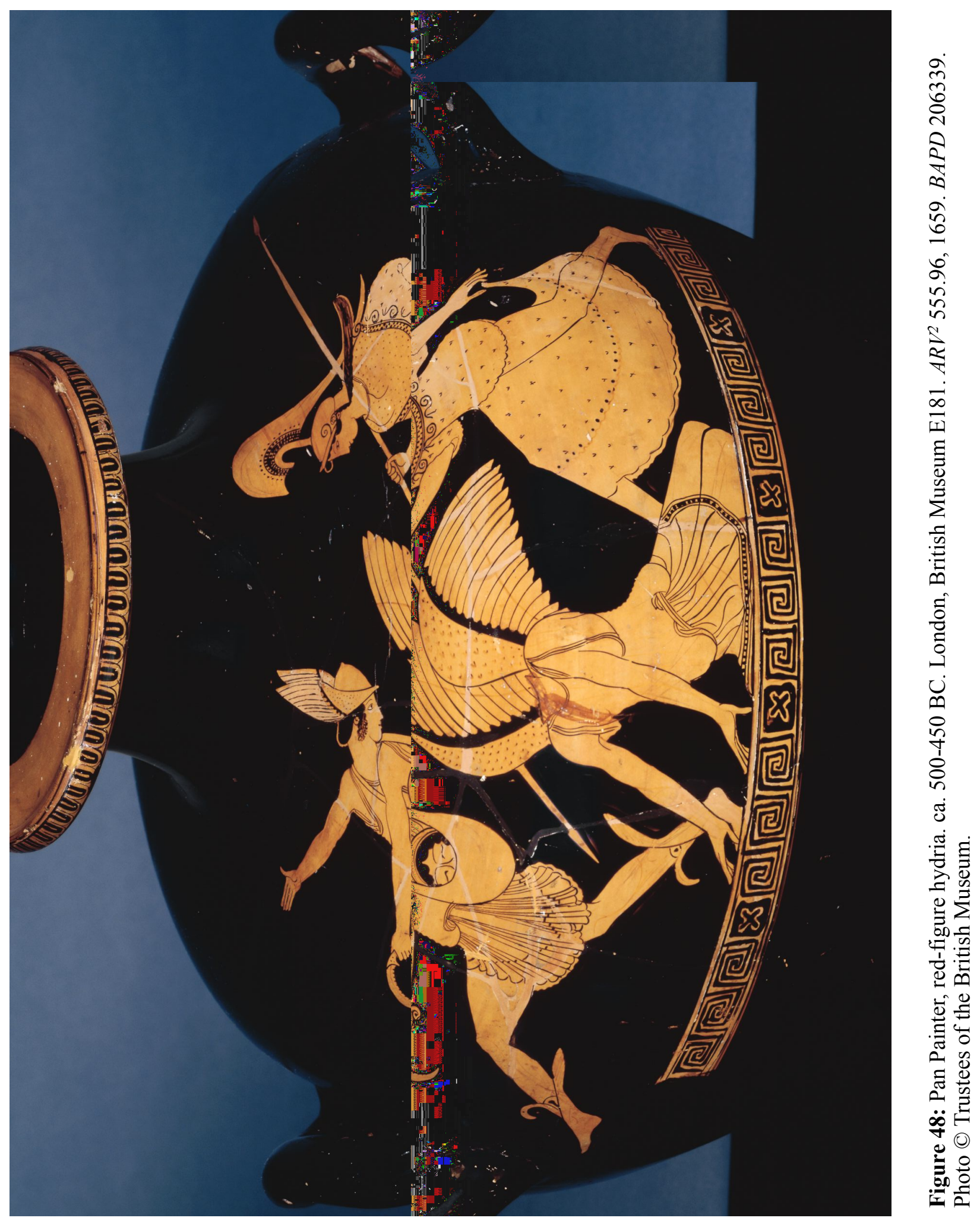




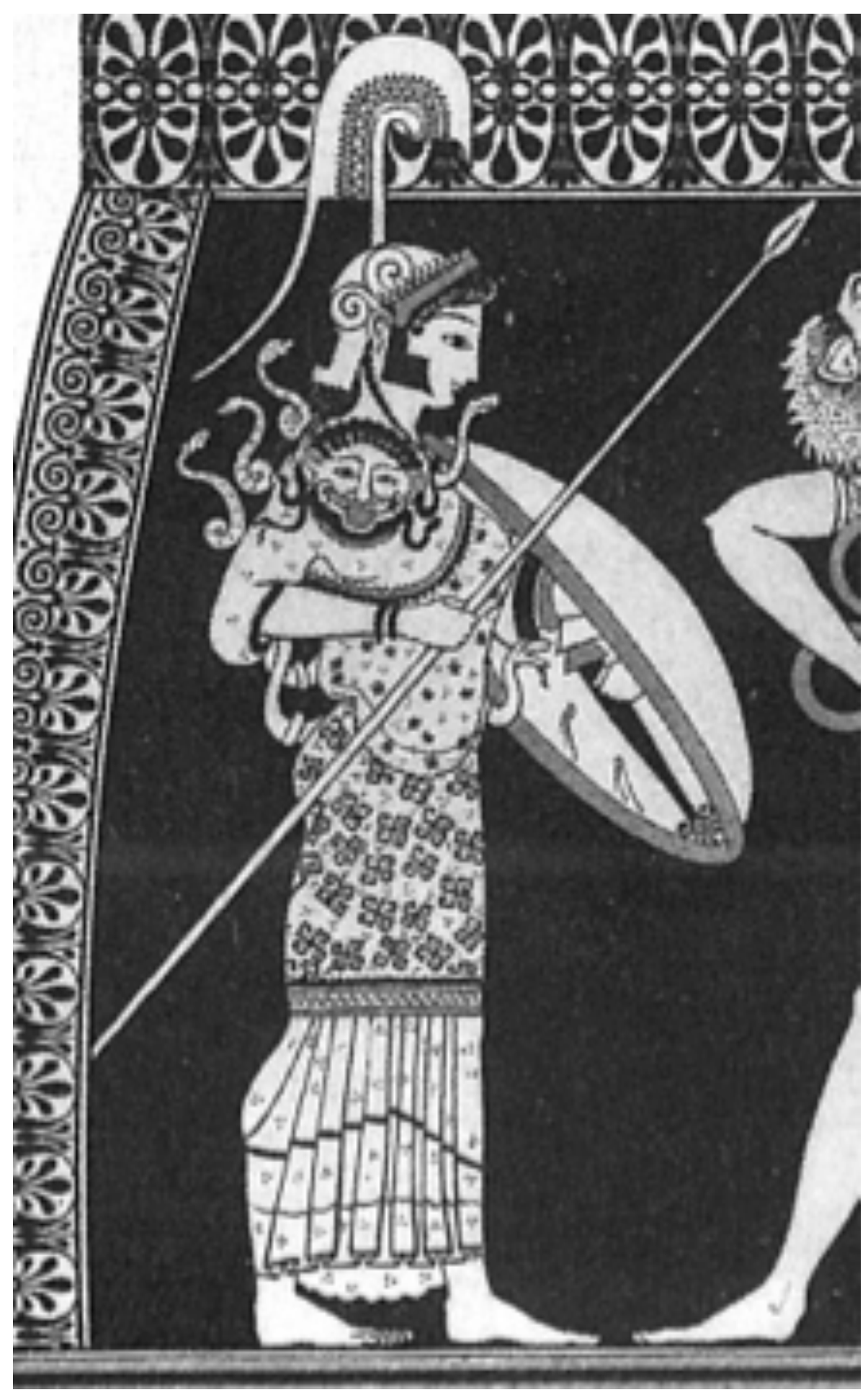

Figure 49: Andokides Painter, red-figure amphora (drawing). ca. 550-500 BC. Berlin, Antikensammlung F2159. $A R V^{2}$ 3.1, 1617. Para 320. BAPD 200001. Carpenter (1990) fig. 73 (drawing). 


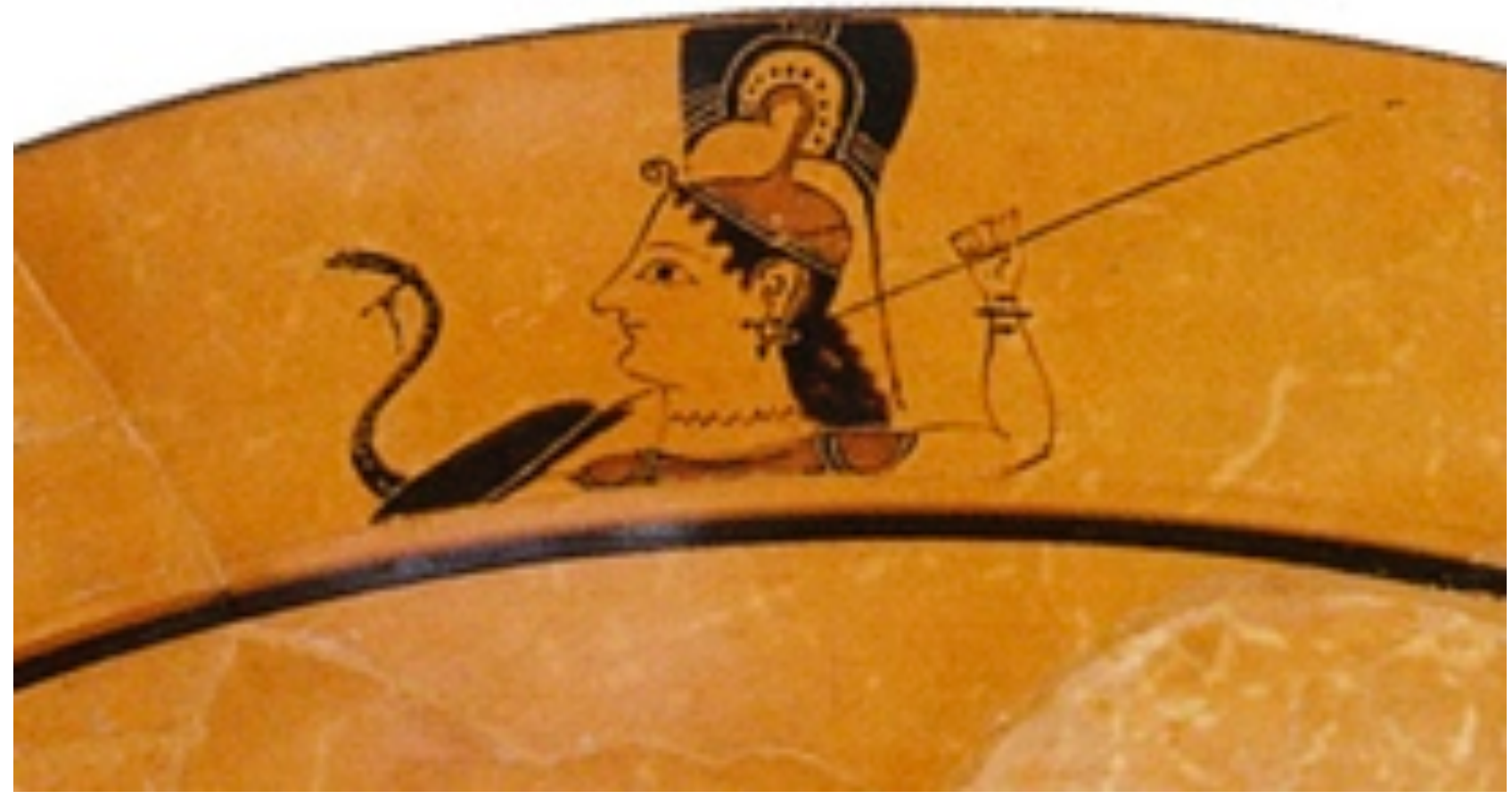

Figure 50a: Epitimos black-figure Little Master lip cup, Side A. ca. 575-525 BC. Copenhagen, National Museum 13966. Para 48. BAPD 350369. Cohen (2006) 164, fig. 41.1.

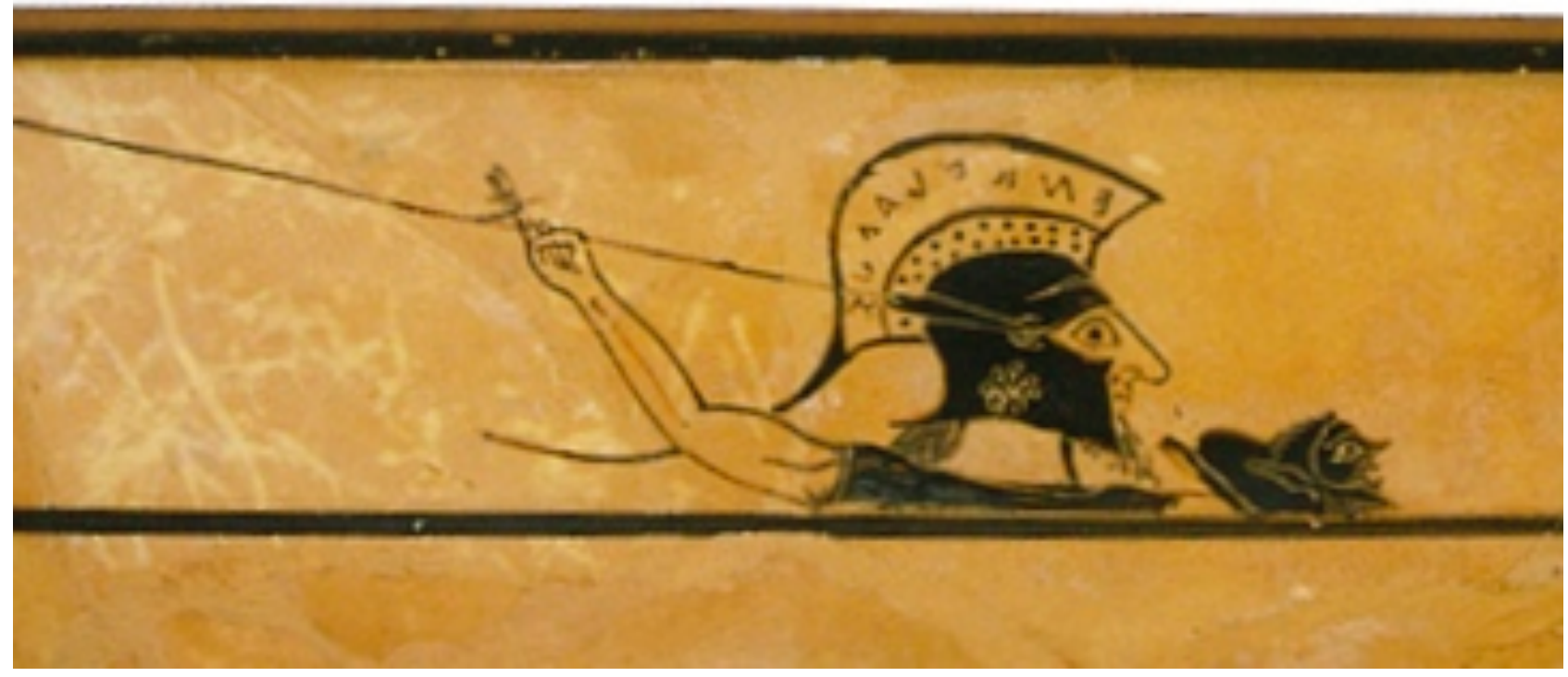

Figure 50b: Epitimos, black-figure Little Master lip cup, Side B. Cohen (2006) 165, fig. 41.2. 


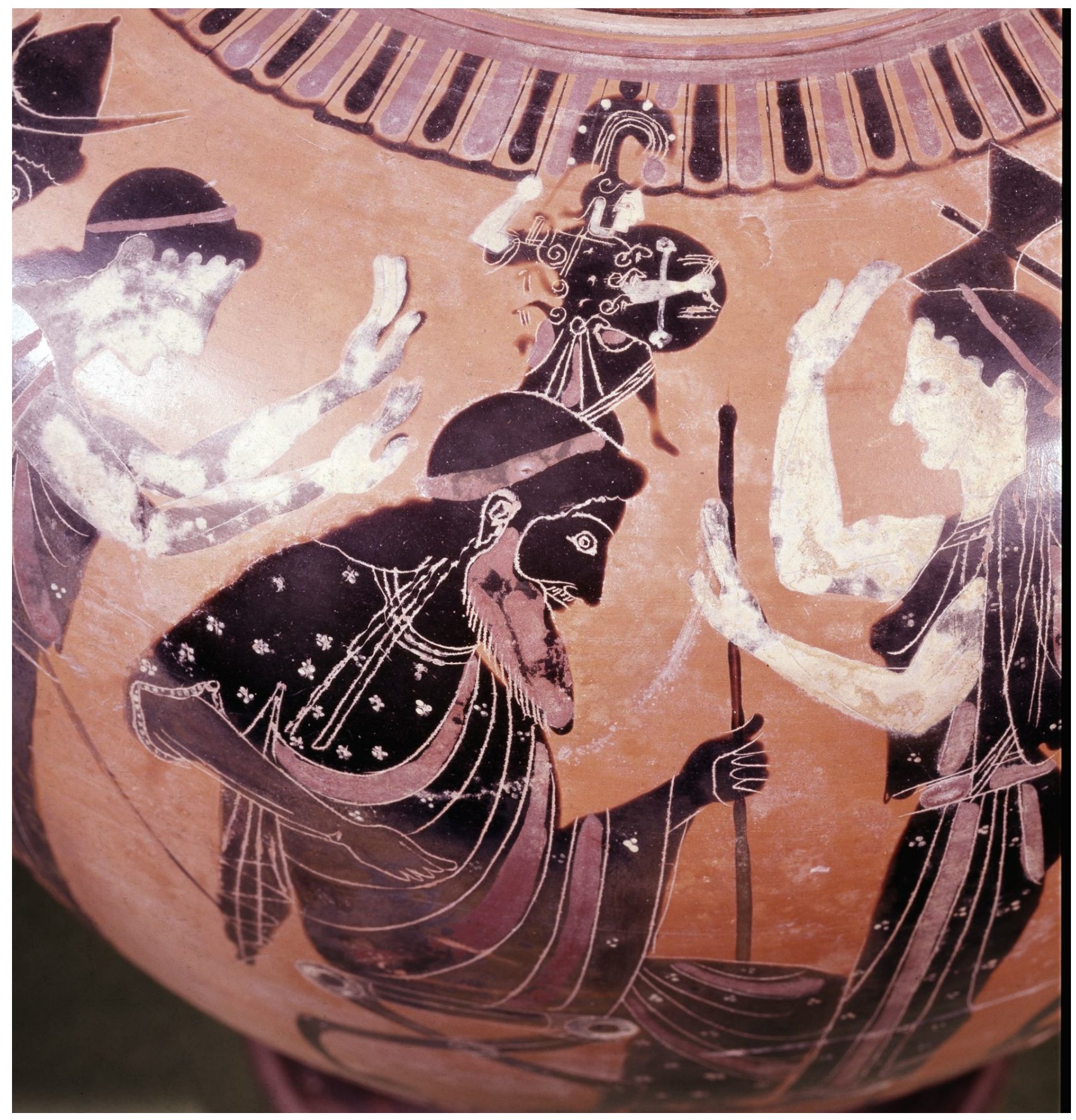

Figure 51: Antimenes Painter, black-figure neck amphora. ca. 550-500 BC. London, British Museum B244. $A B V$ 271.74. BAPD 320085. Photo (C) Trustees of the British Museum. 


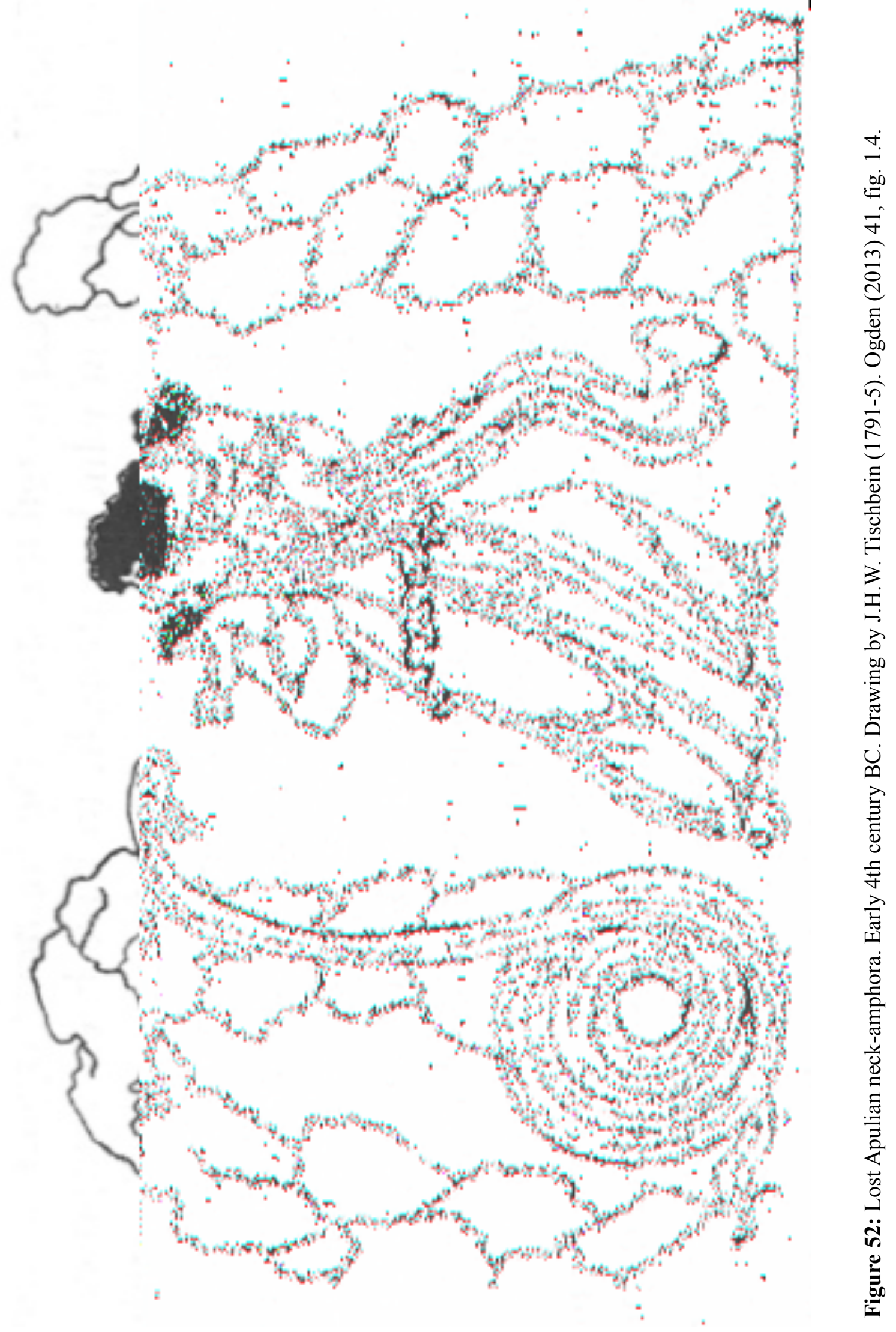




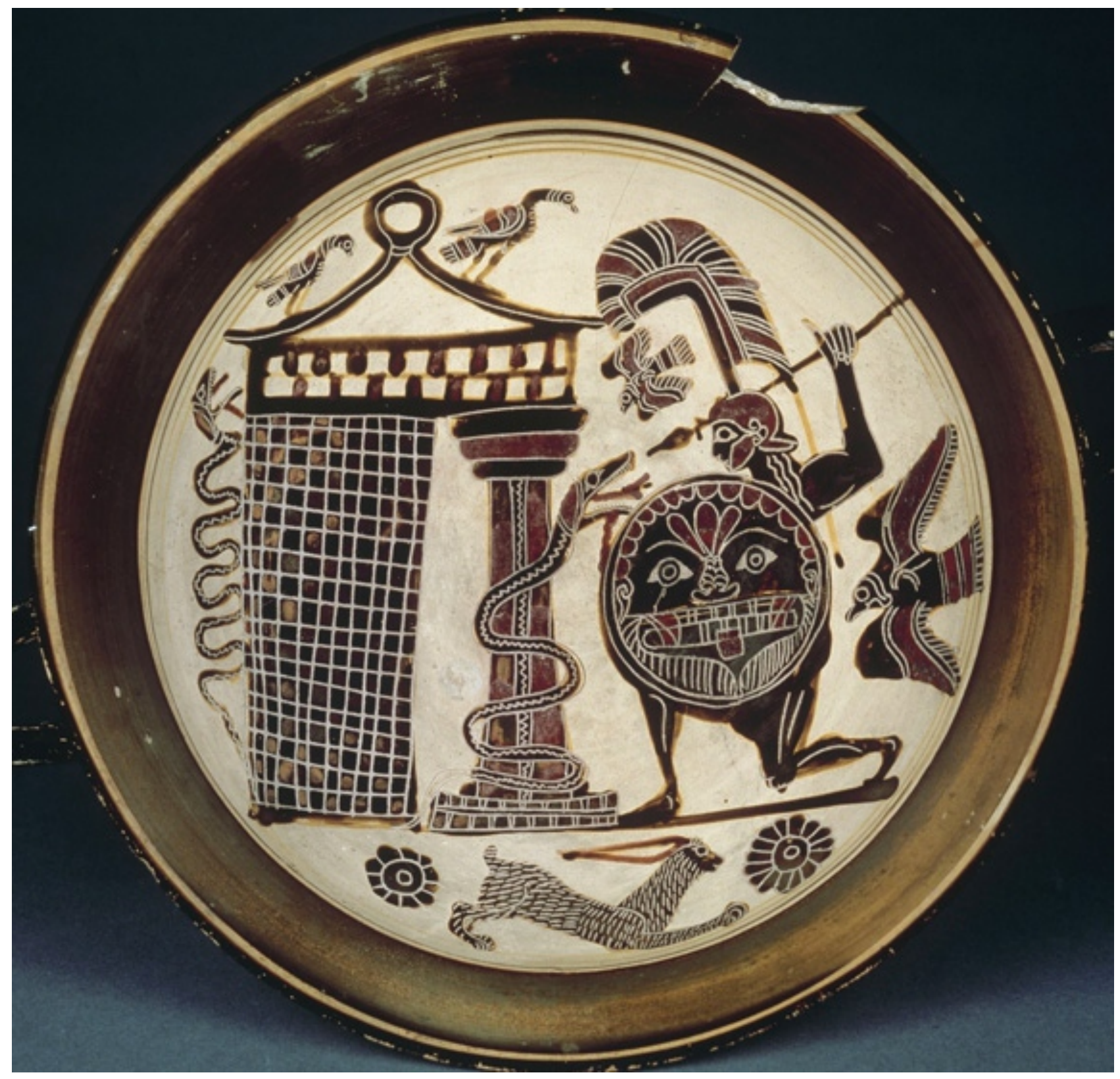

Figure 53: Rider Painter, Lakonian kylix. ca. 550 BC. Paris, Musée du Louvre: E 669. Photo (C 1993 RMN, Musée du Louvre/Hervé Lewandowski 


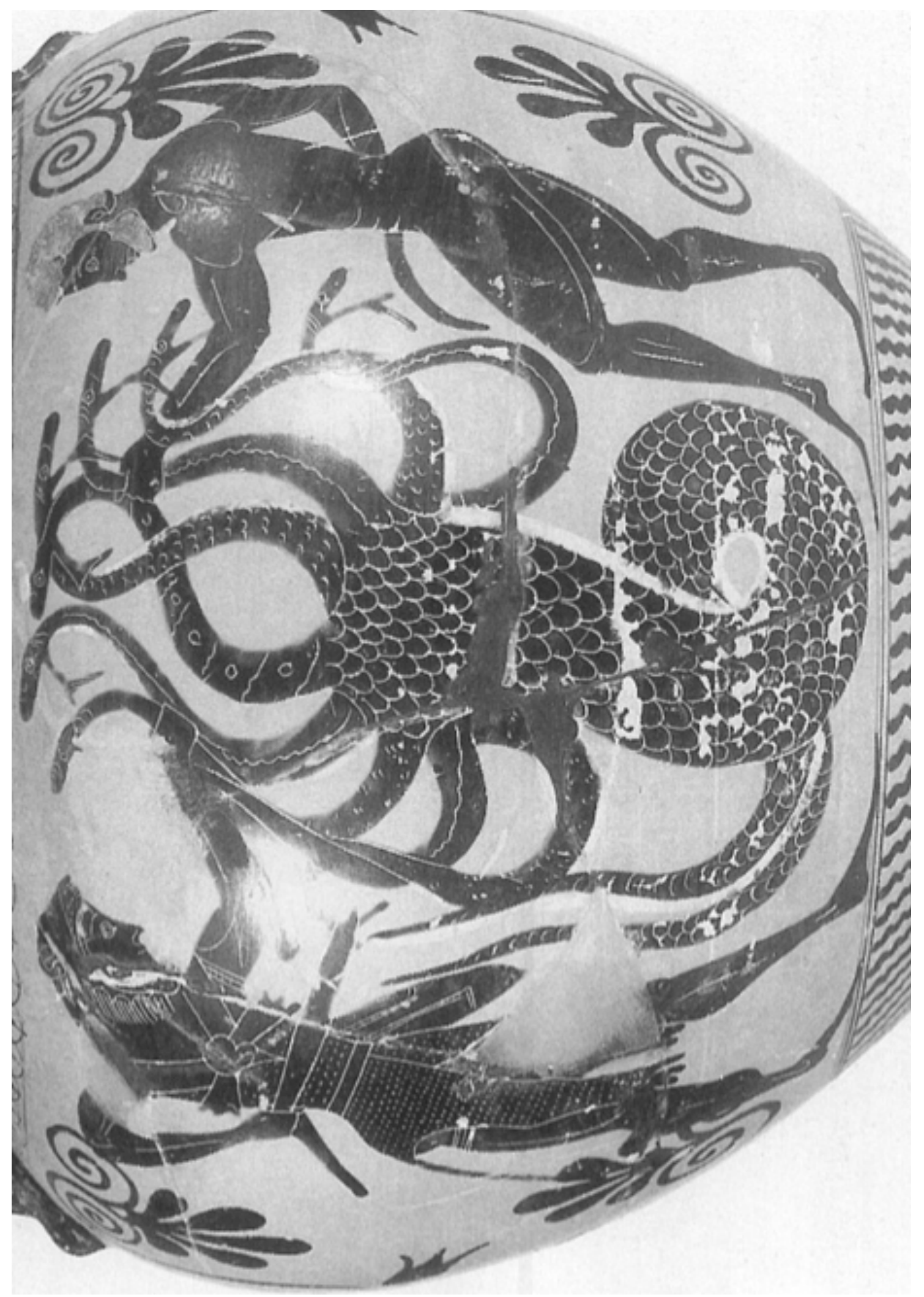

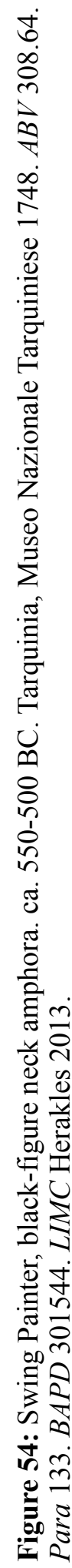




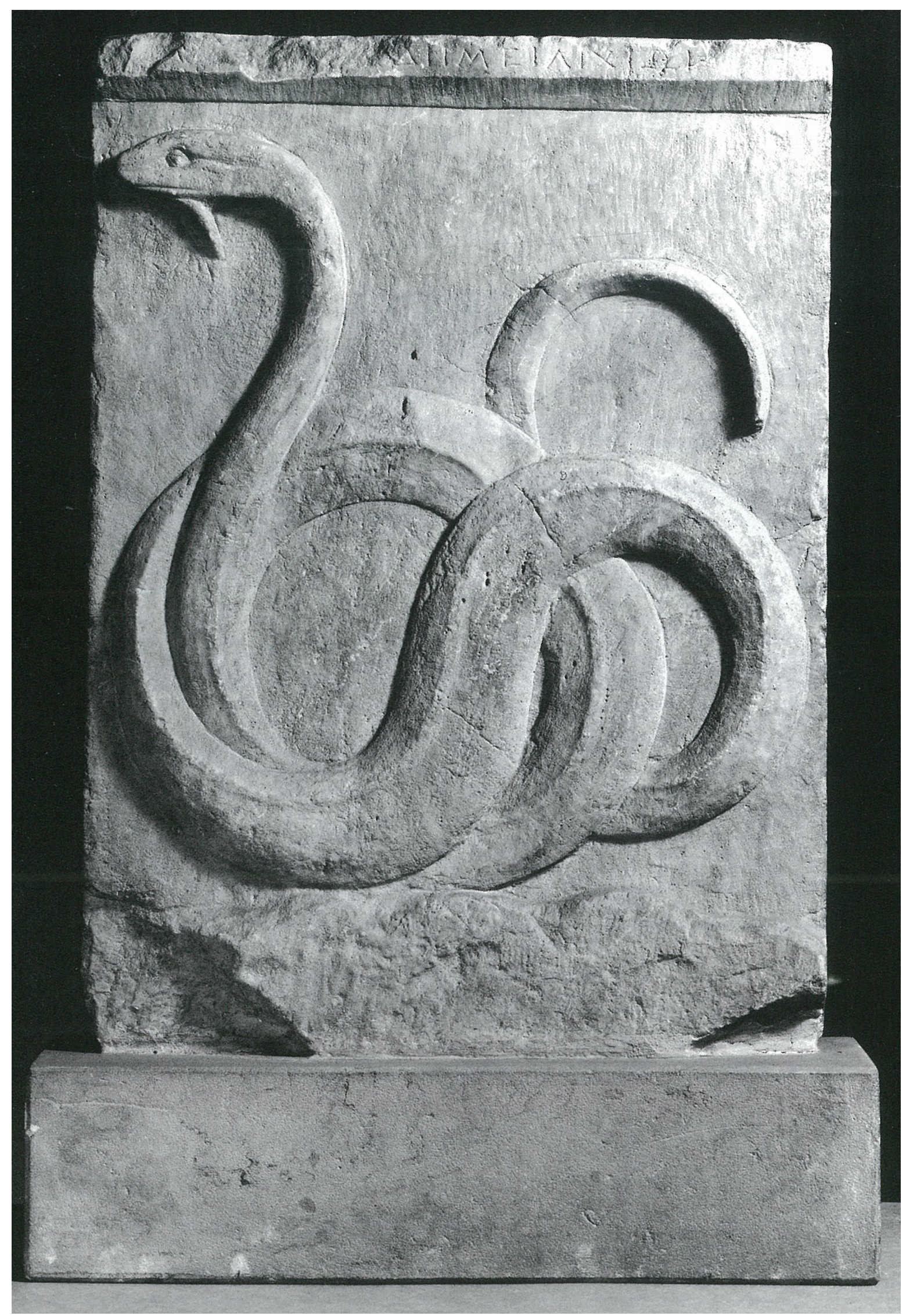

Figure 55: Votive relief of Zeus Meilichios. ca. 400 BC. Berlin, Staatliche Museum. Lalonde (2006) fig. 29. 


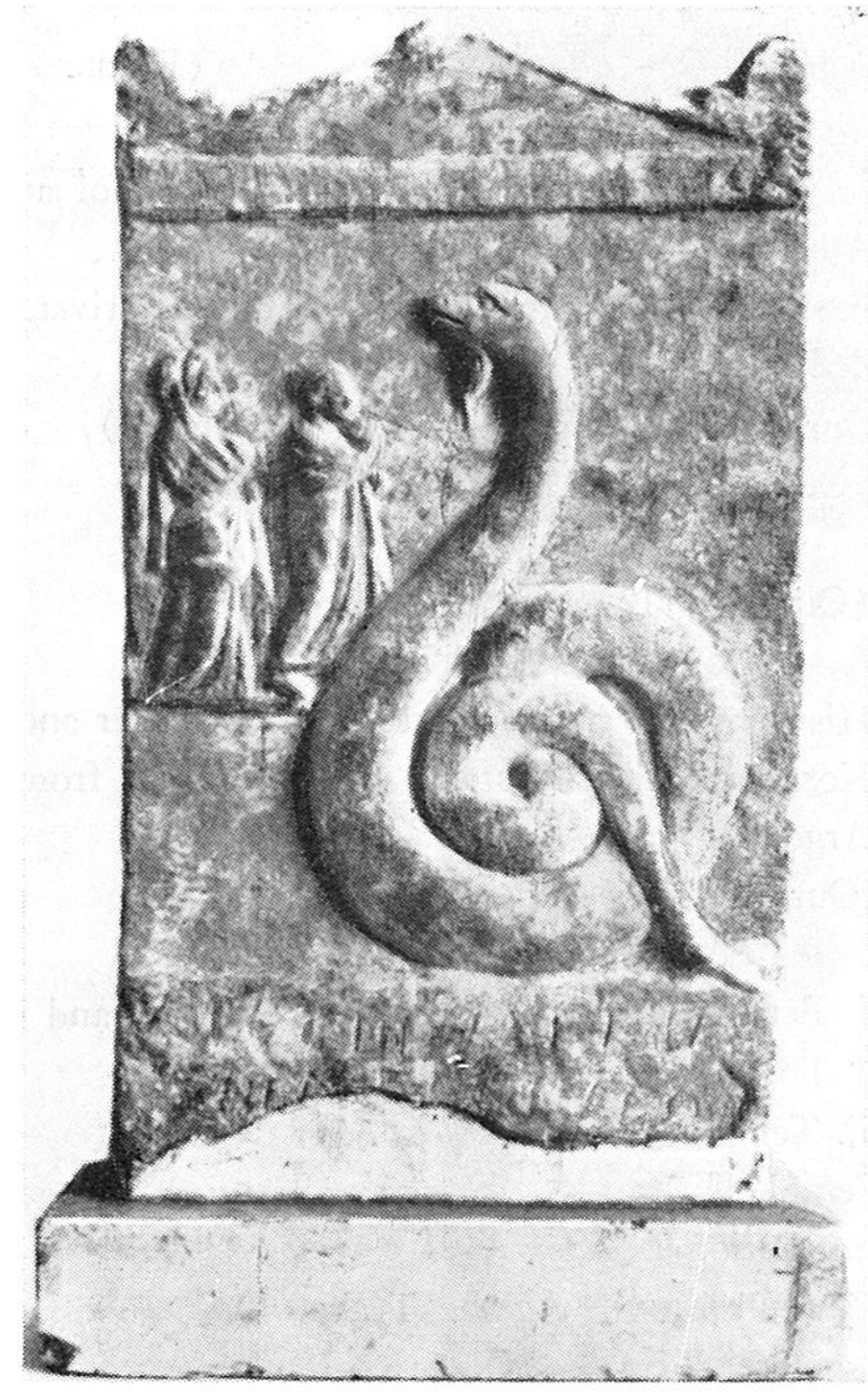

Figure 56: Votive relief of Zeus Meilichios. 4th century BC. Athens, National Archaeological Museum 3329. Mitropoulou (1977) 112, fig. 48a. 


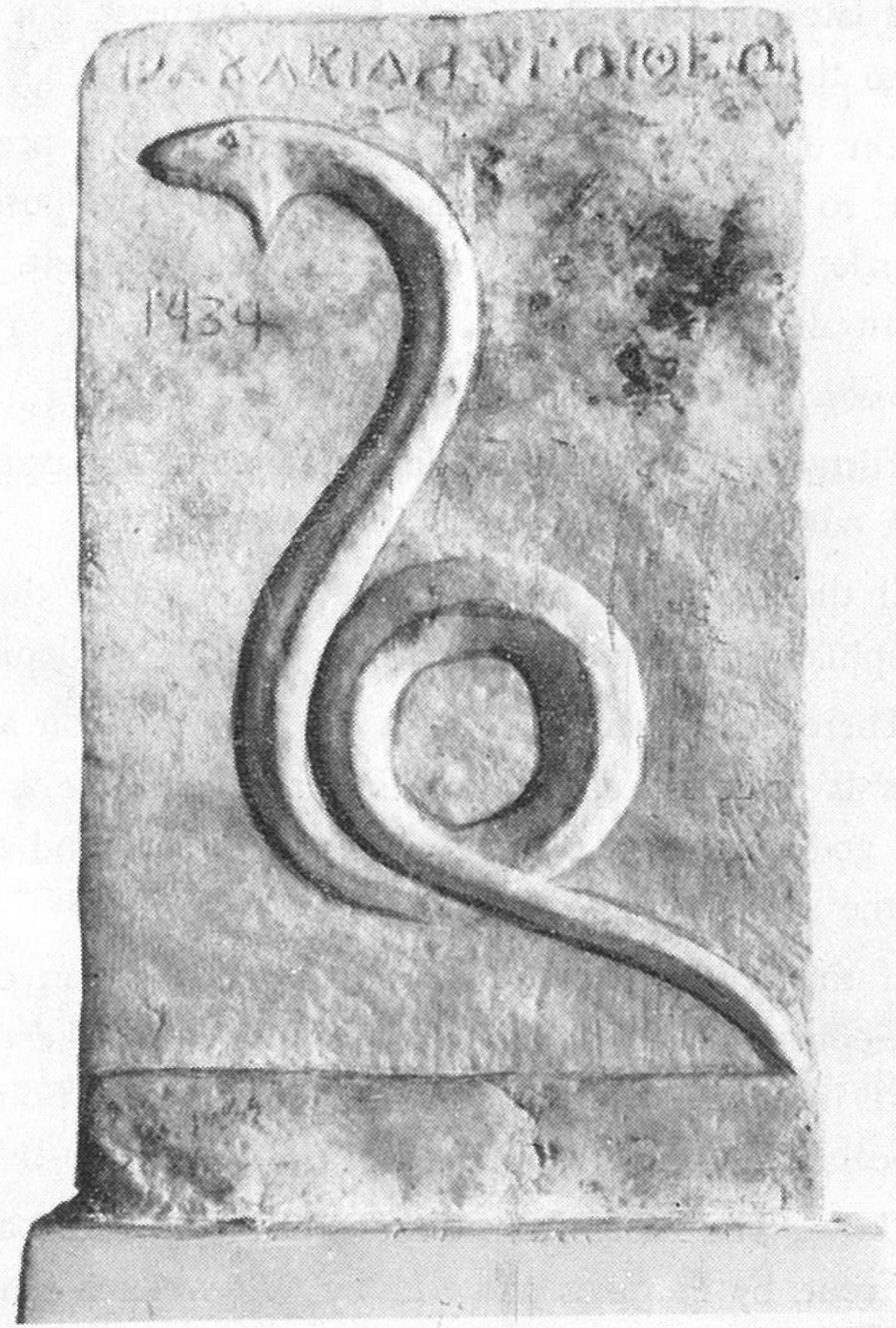

Figure 57: Votive relief of Zeus Meilichios. ca. 324/3 BC. Athens, National Archaeological Museum 1434. Mitropoulou (1977) 126, fig. 56. 


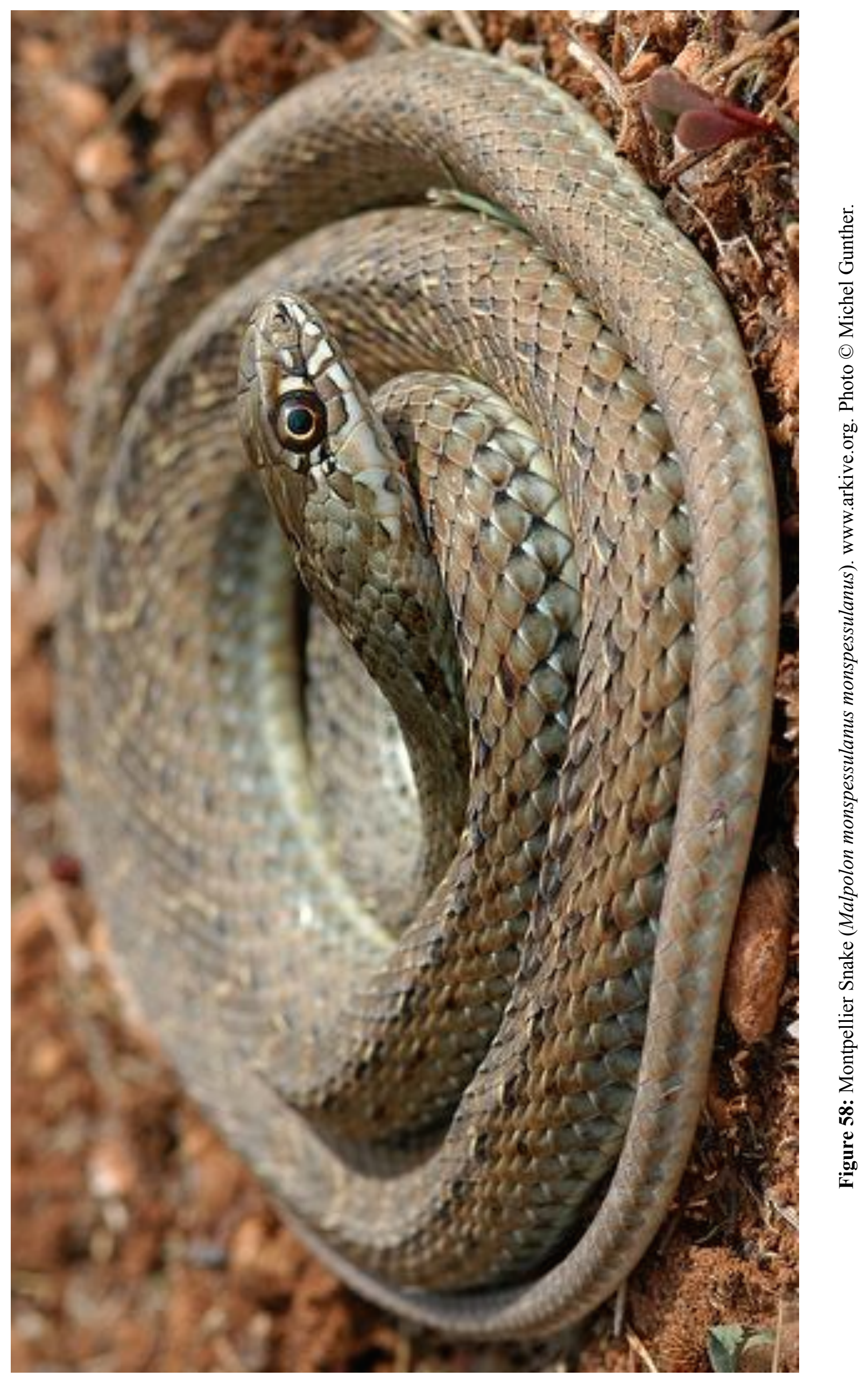




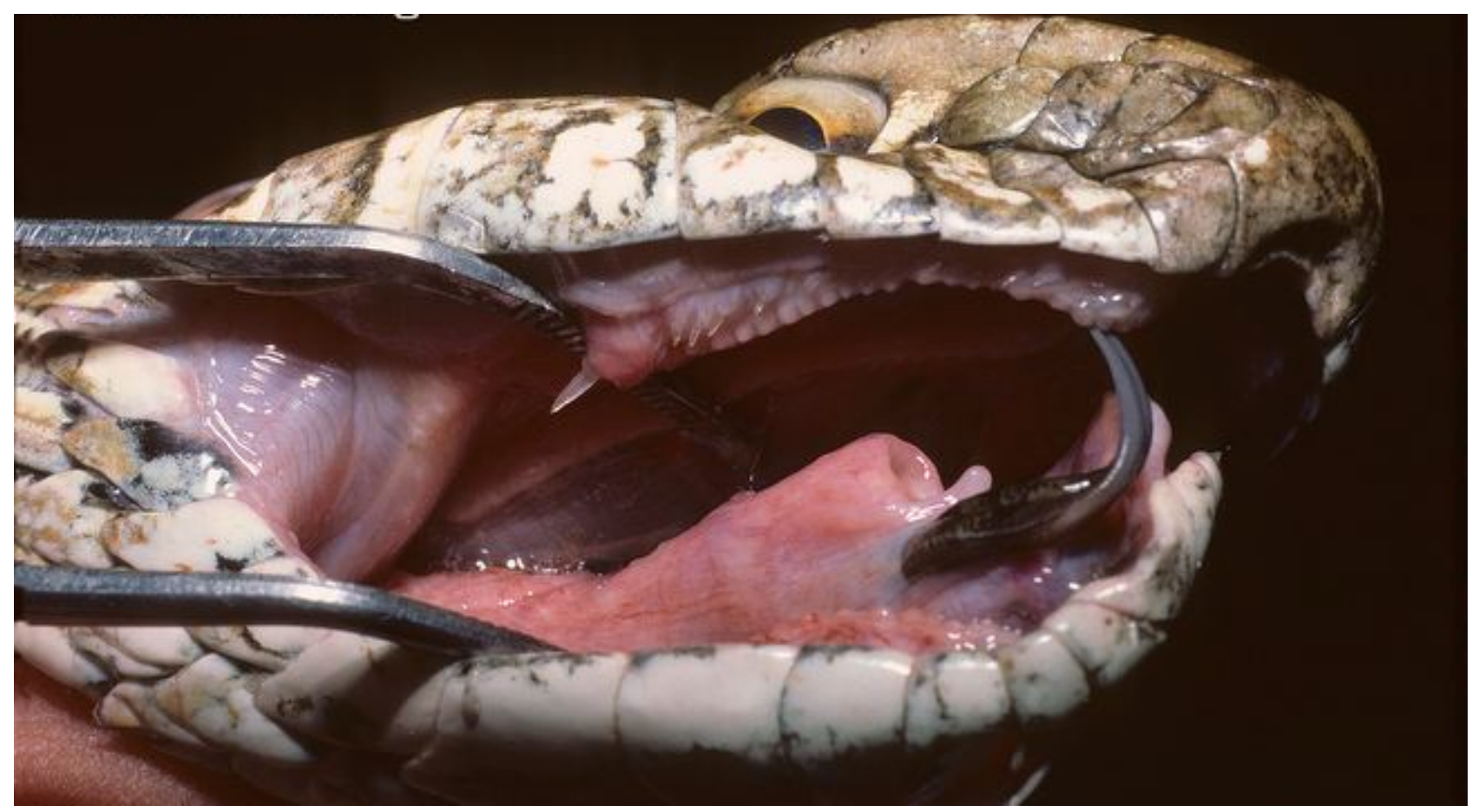

Figure 59: Fangs of Montpellier Snake (Malpolon monspessulanus monspessulanus). www.arkive.org. Photo (C) Daniel Heuclin.

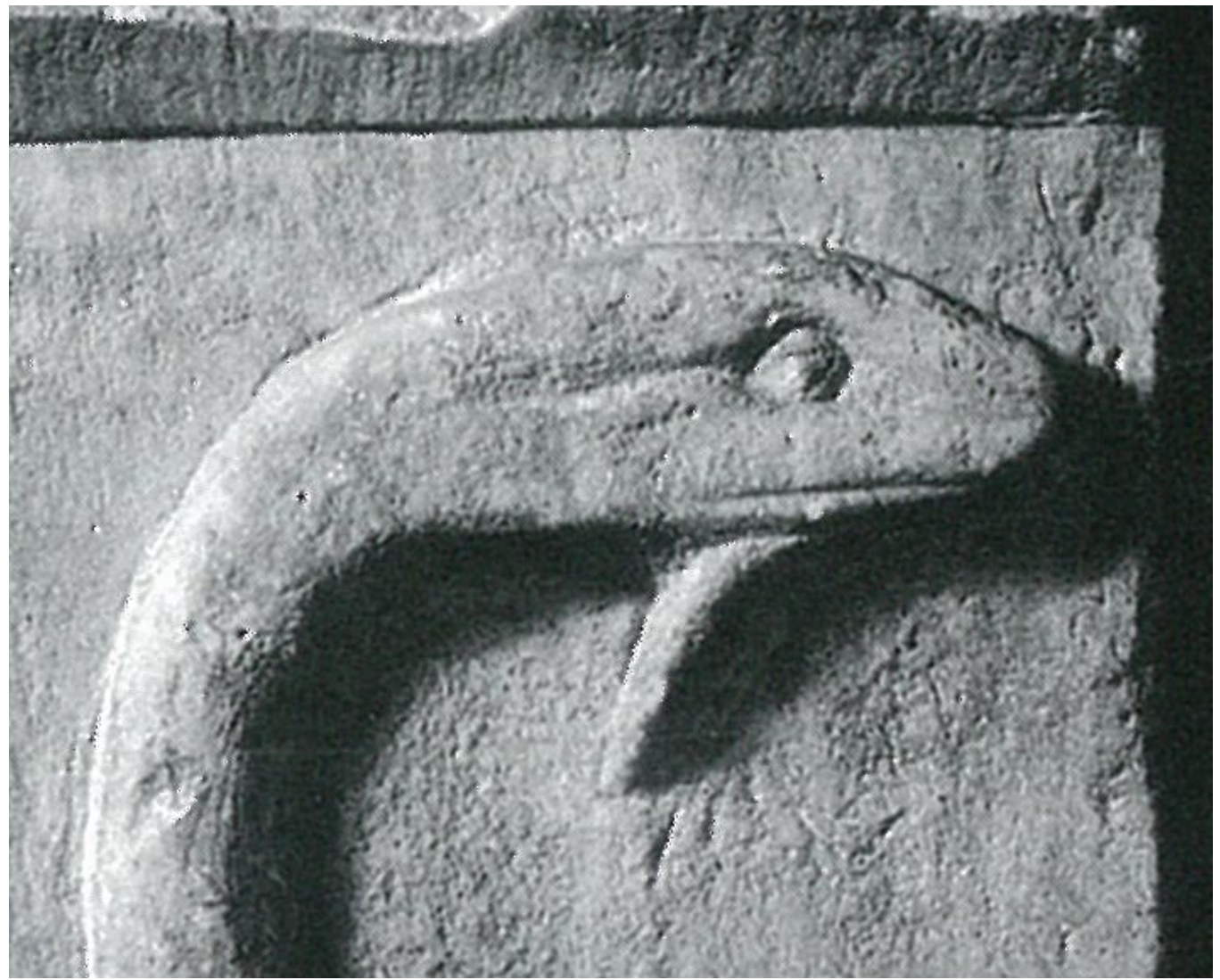

Figure 60: Detail of votive relief of Zeus Meilichios. ca. 400 BC. Berlin, Staatliche Museum. Lalonde (2006) fig. 29. 


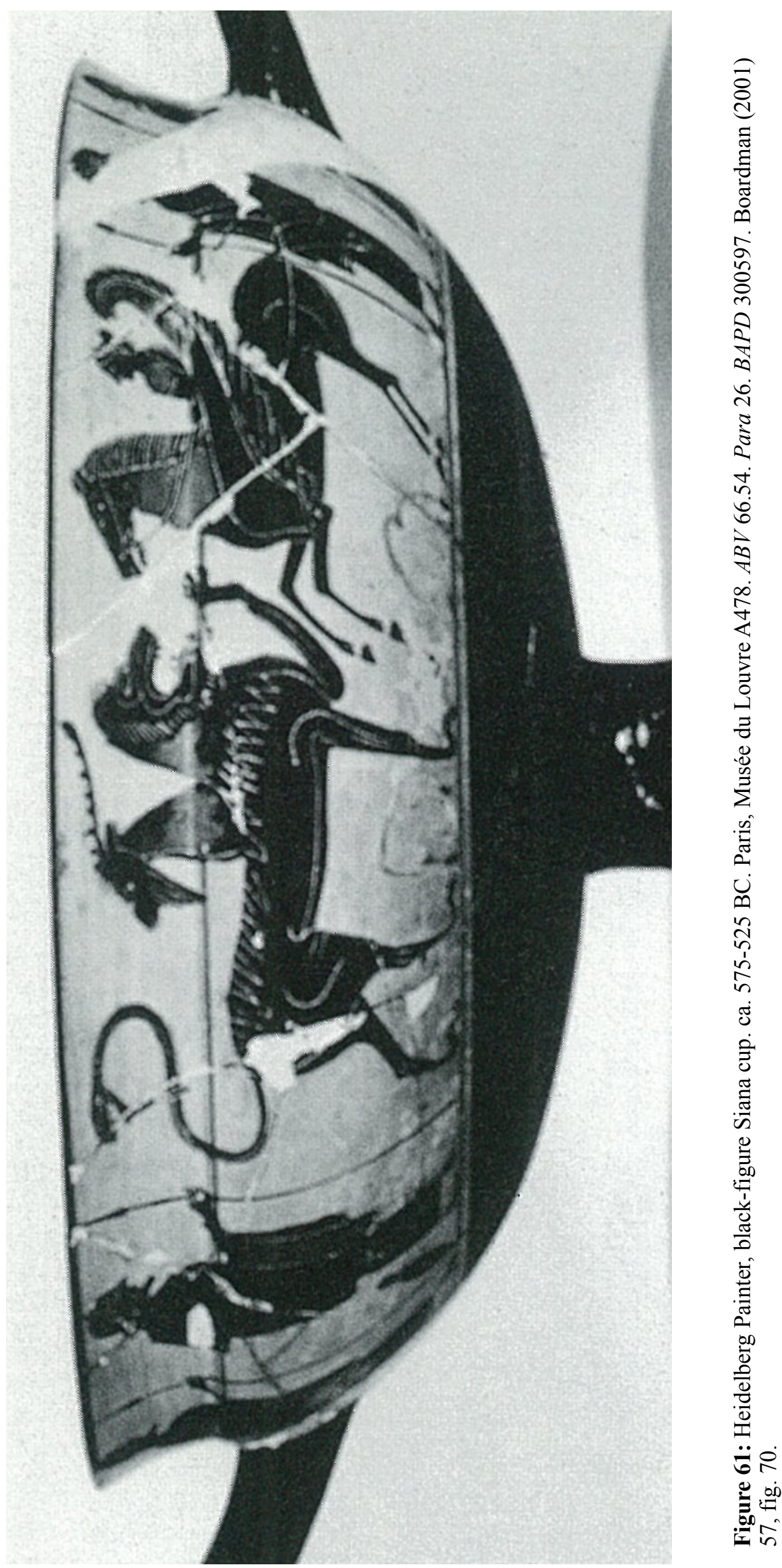




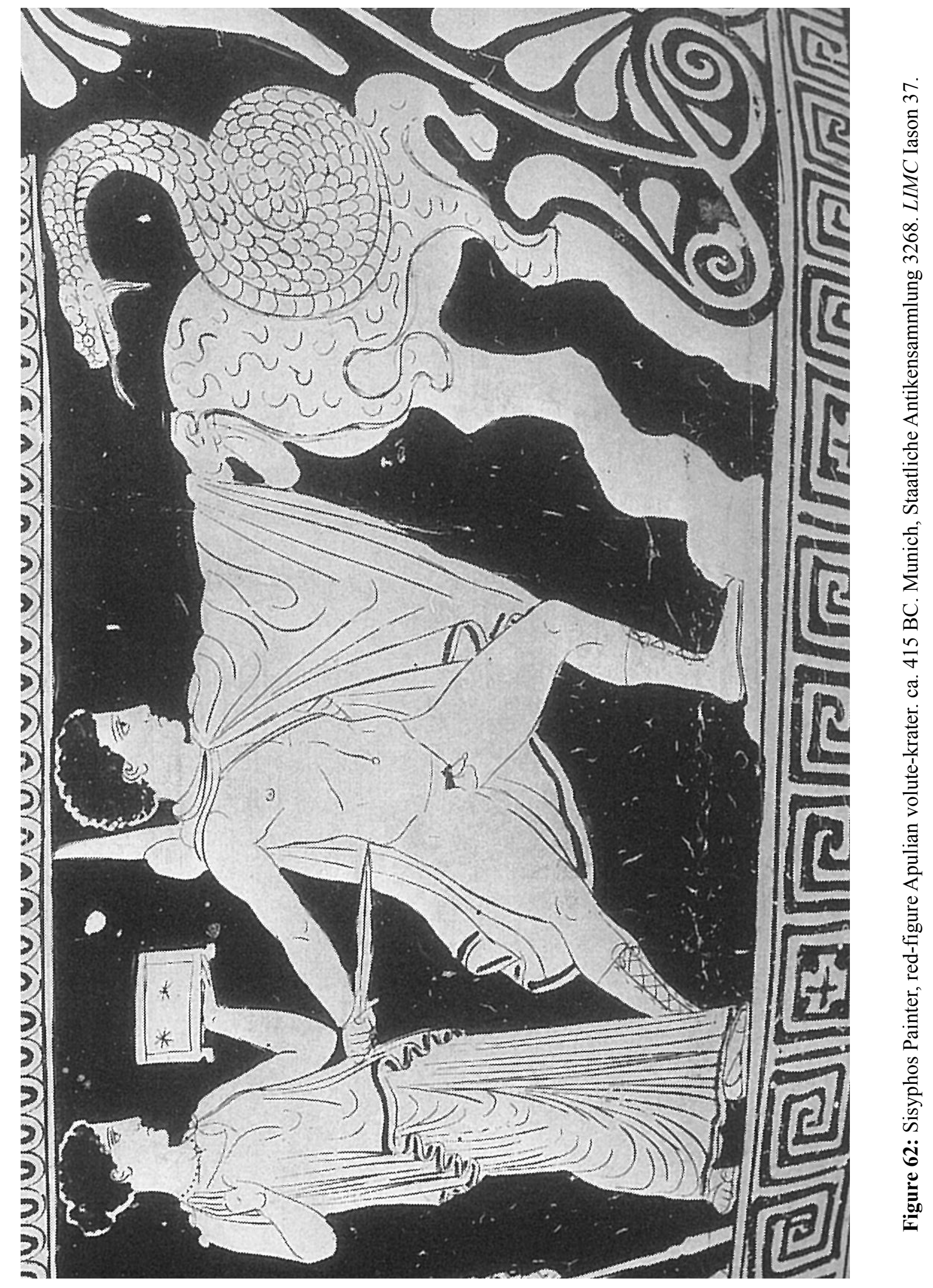




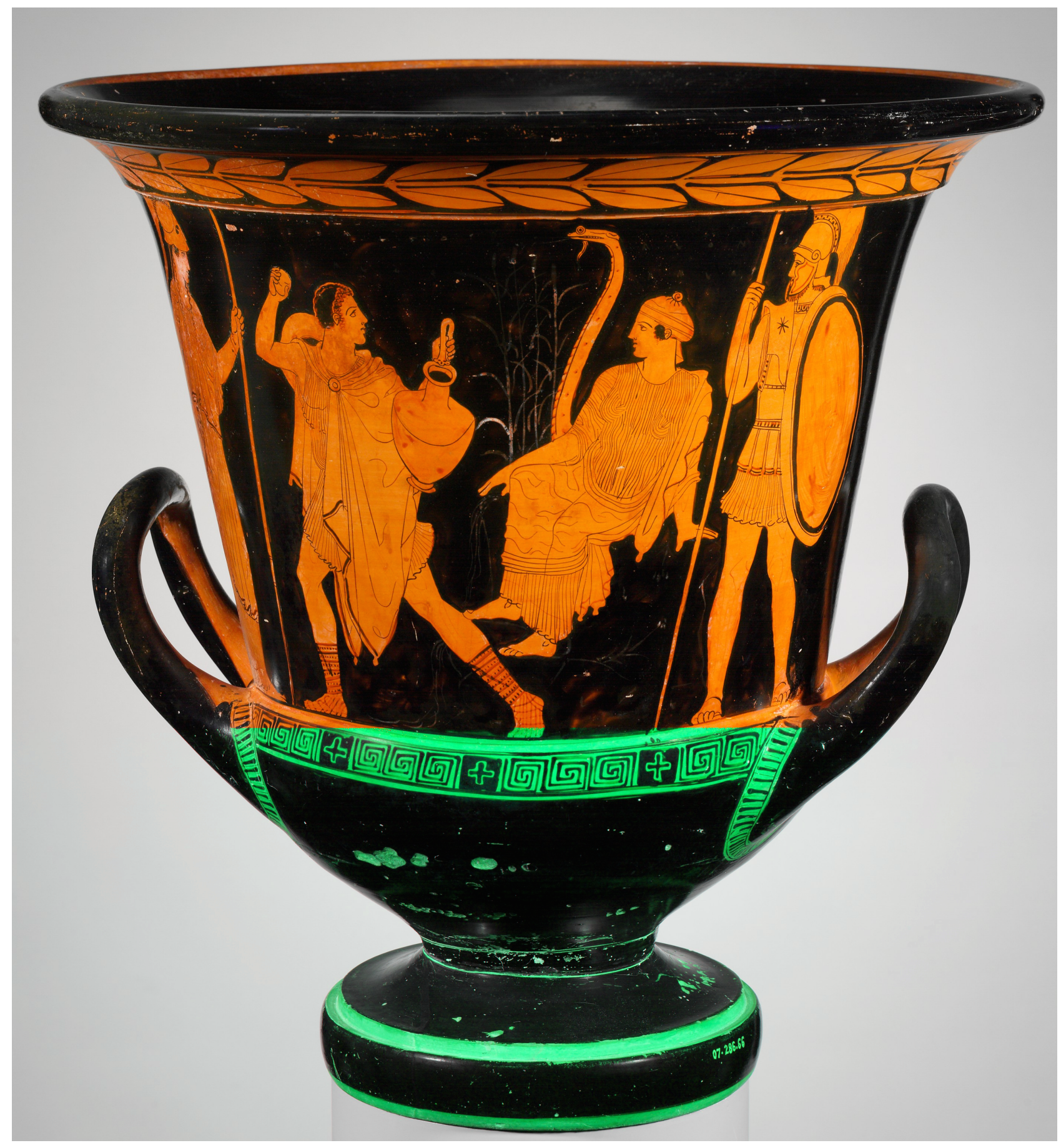

Figure 63: Spreckles Painter, red-figure volute krater. ca. 475-425 BC. New York, Metropolitan Museum of Art 07.286.66. $A R V^{2}$ 1580. Para 398. BAPD 207136. The Metropolitan Museum of Art; Rogers Fund, 1907. www.metmuseum.org. 


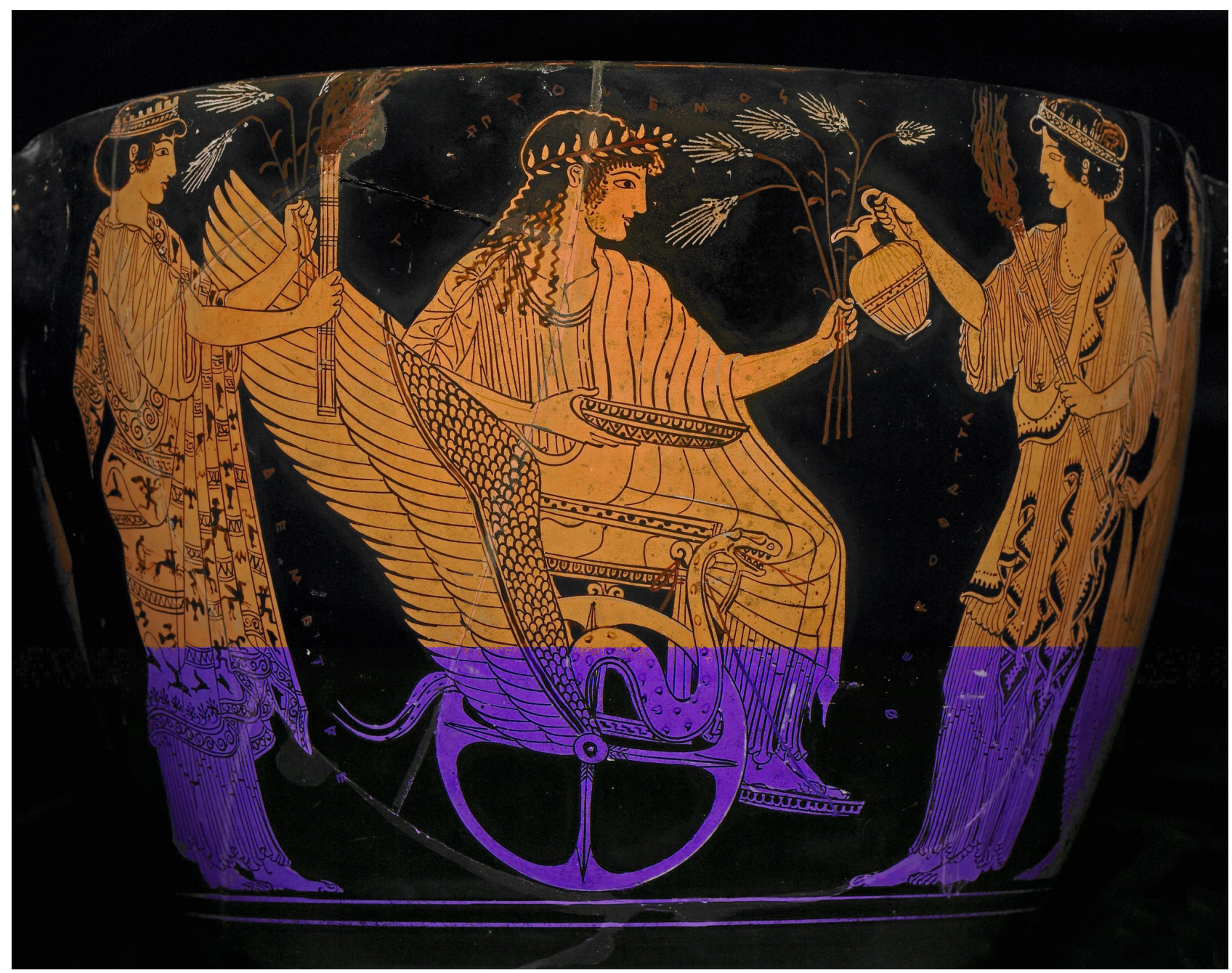

Figure 64: Makron, red-figure skyphos. ca. 500-450 BC. London, British Museum E140. $A R V^{2}$ 459.3, 481, 1654. Para 377. BAPD 204683. Photo (C) Trustees of the British Museum. 


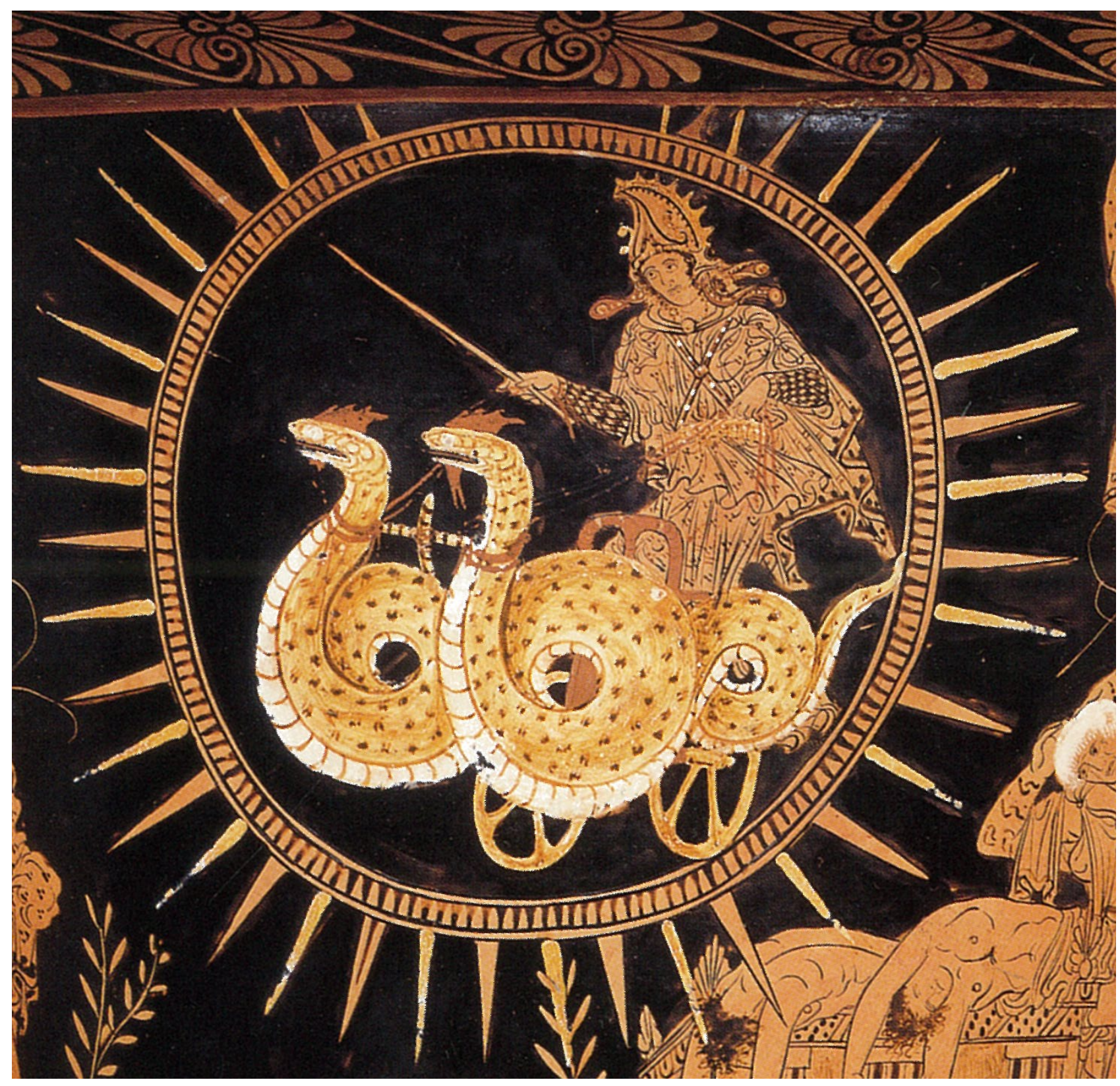

Figure 65: Unattributed (close to Policoro Painter by Taplin) red-figure Lucanian calyx-krater. ca. 400 BC. Cleveland, The Cleveland Museum of Art 1991.1. Taplin (2007) 122, fig. 35. 


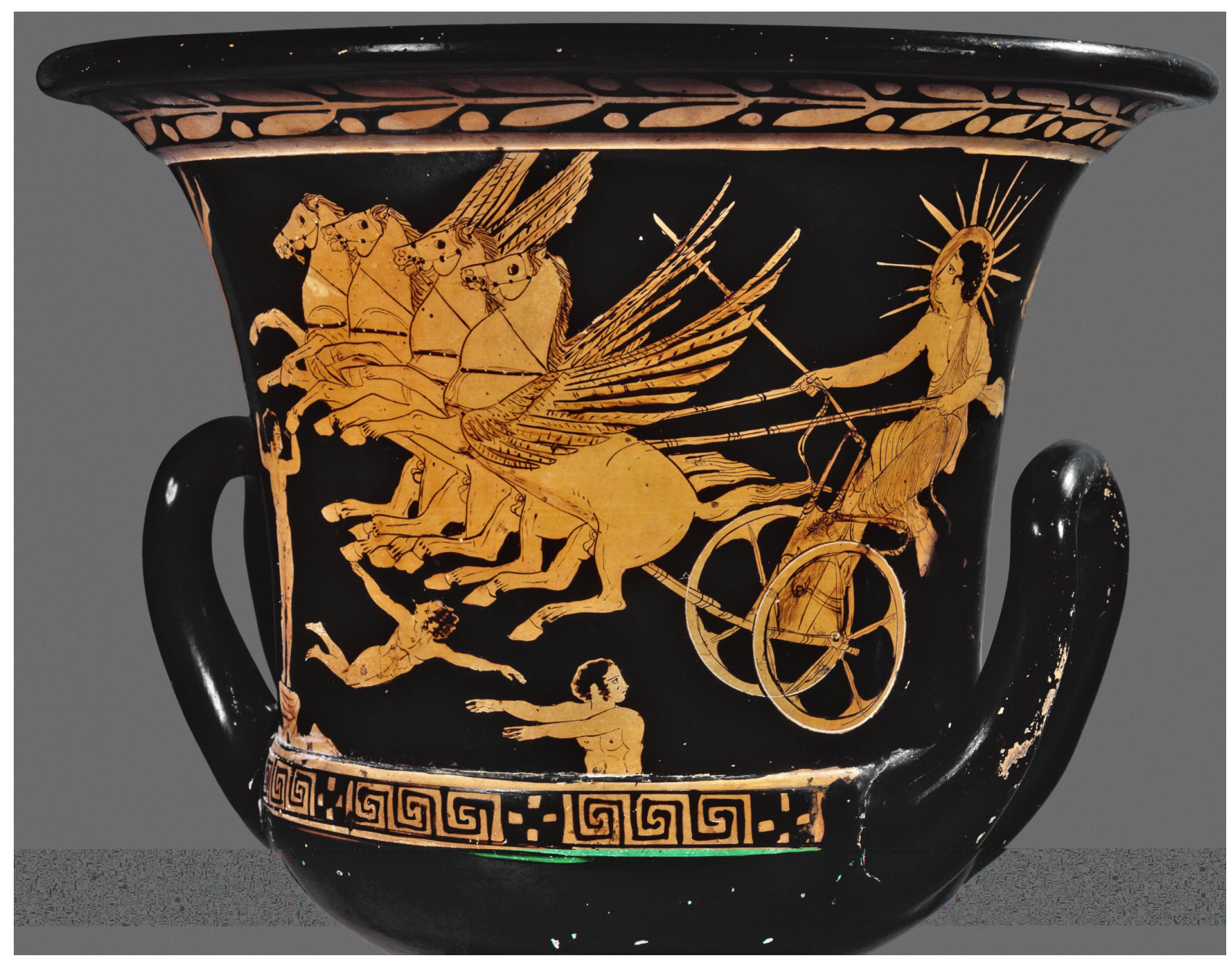

Figure 66: Unattributed red-figure Apulian calyx krater. ca. 450-400 BC. London, British Museum E466. BAPD 5967. Photo (C) Trustees of the British Museum. 


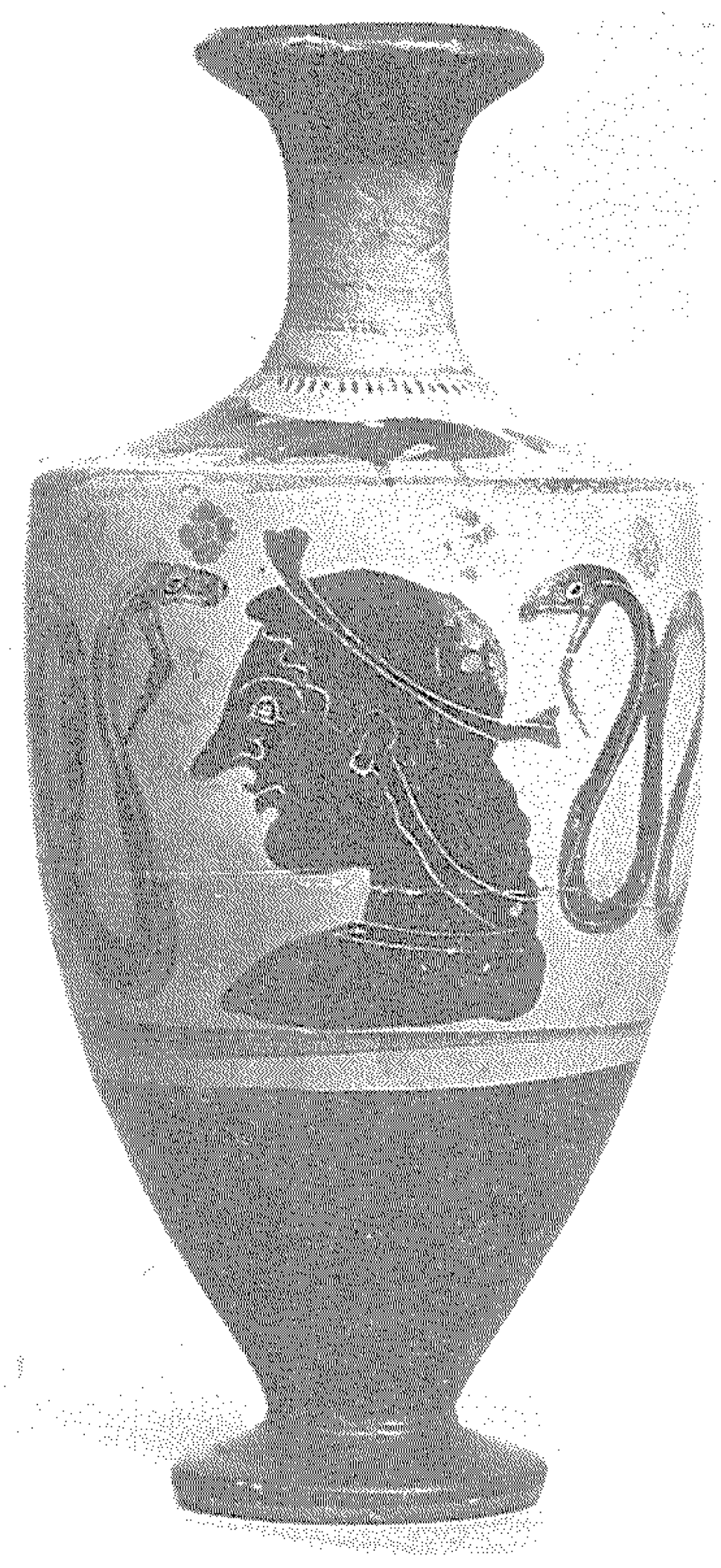

Figure 67: Cock Group, black-figure lekythos. ca. 550-500 BC. London, British Museum 1926.4-17.1. $B A P D$ 330526. Photo $\mathbb{C}$ Trustees of the British Museum. 
